\title{
Alcohol and Cardiovascular Disease: a longitudinal study on impact of intake measurement and health status
}

Ingrid Friesema 
Lay-out and printed by Ponsen \& Looijen bv, Wageningen Cover design by Peter van Leeuwen

ISBN 10: 90-6464-019-X

ISBN-13: 978-90-6464-019-3 


\title{
Alcohol and Cardiovascular Disease: a longitudinal study on impact of intake measurement and health status
}

\author{
Proefschrift
}

ter verkrijging van de graad van doctor aan de Universiteit

Maastricht, op gezag van de Rector Magnificus,

Prof. mr. G.P.M.F. Mols volgens het besluit van het College van Decanen, in het openbaar te verdedigen op

vrijdag 22 september 2006 om 16.00 uur

door

Ingrid Hendrika Mathea Friesema 
Promotores:

Prof.dr. J.A. Knottnerus

Prof.dr. M.J. Drop ${ }^{\dagger}$

Copromotores:

Dr. P.J. Zwietering

Dr. P.H.H.M. Lemmens

Beoordelingscommissie:

Prof. dr. G.J. Dinant (voorzitter)

Prof. dr. A.P.M. Gorgels

Prof. dr. R.A. Knibbe

Prof. dr. K. Poikolainen (Finnish Foundation for Alcohol Studies, Helsinki)

Prof. dr. F. Sturmans

The study presented in this thesis was performed at the Care and Public Health Research Institute (CAPHRI) of the Universiteit Maastricht, part of the Netherlands School of Primary Care Research (CaRe) re-acknowledged by the Royal Dutch Academy of Sciences (KNAW) in 2000.

The study described in this thesis was supported by a grant of the Netherlands Heart Foundation (NHF-48.001).

The study was also supported by the Foundation for the Moderate Use of Alcohol (STIVA).

Financial support by the Netherlands Heart Foundation for the publication of this thesis is gratefully acknowledged. 
Voor mijn ouders 



\section{Contents}

1. Introduction 9

1.1. Background 11

1.2. Outline of the thesis 11

2. Beneficial effects of moderate alcohol intake on cardiovascular disease: A review of 13 the major cohort studies

3. Leefstijl En Gezondheid Onderzoek (LEGO) 37

3.1. Aims, population, and design 39

3.2. Questionnaires and response 40

3.3. Alcohol intake measurement 41

3.4. Health problems and endpoints 42

3.5. Loss to follow-up 45

4. Lower prevalence of heart disease, but higher mortality risk during follow-up 47 among non-respondents to a cohort study

5. Measurement of lifetime alcohol intake: Utility of a self-administered questionnaire 61

6. Alcohol intake and cardiovascular disease and mortality: Current drinking status $\quad 75$ has more impact than lifetime and past intake

7. Effects of alcohol intake on cardiovascular disease and mortality in diabetic subjects

8. Alcohol intake and cardiovascular disease and mortality: The role of pre-existing disease

9. Discussion

Summary \& Samenvatting

Dankwoord

Curriculum Vitae

Appendix:

A. Baseline questionnaire 143

B. LDH-q (version follow-up 1997) 173 

CHAPTER

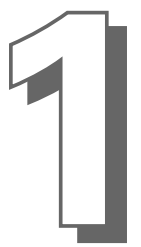

Introduction 



\subsection{Background}

In the past decades, many epidemiological studies have been conducted to investigate the relationship between alcohol consumption and cardiovascular disease. In most of these studies, a J- or Ushaped curve was found with an elevated risk for non-drinkers and heavy drinkers and a reduced risk for moderate drinkers. Most attention has been paid to biological mechanisms as a possible explanation for this curve. There is clinical evidence of decreased platelet aggregation, increased fibrinolysis, and increased HDL-cholesterol transport after intake of alcohol (1). Other proposed associations with light to moderate alcohol intake are reduction in blood pressure, decreased insulin resistance, and increased insulin sensitivity (2). However, besides biological mechanisms, other mechanisms and explanations could also be relevant.

An explanation could lay in methodological aspects which could have influenced the results. A possible important aspect is model specification. Adjustment for the main risk indicators of cardiovascular disease, and exclusion of former drinkers of the group of non-drinkers both have been reported to influence the relationship between alcohol intake and cardiovascular disease or mortality (3-5). Another methodological aspect could be measurement of alcohol intake. A gold standard for measurement of alcohol intake is lacking, which has led to the use of a variety of questions and questionnaires, ranging from one simple question to extensive questionnaires. Although these differences, all previous studies on the relationship between alcohol intake and cardiovascular disease are based upon current intake or intake in the recent past of adults, and not on lifetime intake $(6,7)$.

The use of current alcohol intake also implies another possible explanation. In 1988, Shaper et al (8) already proposed that the relationship between alcohol intake and cardiovascular mortality was produced by pre-existing disease. It was suggested that men with a disease reduce their drinking or even quit drinking, whereas the healthy men do not change their alcohol habits, causing a possible disbalance in alcohol intake between ill and healthy men. The shift in alcohol intake could even take place before deterioration in health is noticed.

Finally, psychological and behavioural mechanisms could also influence the relationship between alcohol intake and cardiovascular disease. It is known that stress is a risk factor for cardiovascular disease and reduction of stress is considered to be an important motivation for drinking alcohol $(9,10)$. Therefore, a possible explanation could be a stress-buffering effect of alcohol.

Thus, many epidemiological studies have reported the relationship between alcohol intake and cardiovascular disease, but the mechanism or mechanisms responsible for this relationship remain obscure. One could consider to advice people to drink one or two glasses of alcohol every day based upon the repeated finding of the relationship. However, especially in case of a methodological mechanism, the benefits of this advice will probably not counterbalance the risks. Therefore, the Leefwijze En Gezondheid Onderzoek (LEGO, Lifestyle and Health Study) was set up to investigate some of the possible explanations, other than biological, for the relationship between alcohol intake and cardiovascular disease reported in the literature. The cohort comprised 16,210 men and women aged 45-70 years, who were followed for a five-years period. A total of 679 men and 397 had a cardiovascular event, and 330 men and 204 women died during this follow-up period.

\subsection{Outline of the thesis}

Chapter 2 presents the results of the systematic review. This review focuses on methodological aspects of previous studies to the relationship between alcohol intake and cardiovascular disease. Spe- 
cial attention has been given to the way alcohol intake was measured, correction for covariates and pre-existing diseases, and length of follow-up. Chapter 3 outlines the design of the LEGO-study and the methods used in the study. The results of a non-response analysis are reported in chapter 4. Two research questions were addressed. First, does health status at baseline influence response behaviour? Second, is the chance of dying during the follow-up period equal for respondents and non-contacts? In the LEGO-study, a new alcohol questionnaire was used, called the Lifetime Drinking History questionnaire (LDH-q). The utility of this questionnaire was tested and the results are presented in chapter 5. The relationships between alcohol intake and cardiovascular disease, and between alcohol intake and all-cause mortality is described in chapter 6. First aim was to assess the impact of different periods of alcohol intake and type of questionnaire on both relationships. Second aim was to assess the impact of several model specifications on both relationships. In chapter 7, special attention is given to alcohol intake and cardiovascular disease in diabetics. First, differences in alcohol intake between diabetics and non-diabetics were analysed. Second, the relationships between alcohol intake and cardiovascular disease, and all-cause mortality were analysed for this subpopulation of diabetics. In chapter 8, differences in health between drinkers and non-drinkers are examined. Second, the influence of those health differences on the relationships between alcohol intake and cardiovascular disease, and between alcohol intake and all-cause mortality are analysed. Finally, the results are merged and discussed in chapter 9.

\section{References}

1. Booyse FM, Parks DA. Moderate wine and alcohol consumption: beneficial effects on cardiovascular disease. Thromb Haemost 2001;86:517-28.

2. Agarwal DP. Cardioprotective effects of light-moderate consumption of alcohol: A review of putative mechanisms. Alcohol Alcohol 2002;37:409-15.

3. Corrao G, Rubbiati L, Bagnardi V, Zambon A, Poikolainen K. Alcohol and coronary heart disease: a metaanalysis. Addiction 2000;95:1505-23.

4. Tsubono Y,Yamada S, Nishino Y, Tsuji I, Hisamichi S. Choice of comparison group in assessing the health effects of moderate alcohol consumption. JAMA 2001;286:1177-8.

5. Shaper AG. Alcohol and mortality: a review of prospective studies. Br J Addict 1990;85:837-47.

6. Lemmens PHHM, Drop MJ. Op zoek naar de gezonde drinker. Tijdschr Alcohol Drugs Andere Psychotr Stoffen 1995/96;21:226-34.

7. Gunzerath L, Faden V, Zakhari S, Warren K. National Institute on Alcohol Abuse and Alcoholism Report on Moderate Drinking. Alcohol Clin Exp Res 2004;28:829-47.

8. Shaper AG, Wannamethee G, Walker M. Alcohol and mortality in British men: explaining the U-shaped curve. Lancet 1988;2:1267-73.

9. Abbey A, Smith MJ, Scott RO. The relationship between reasons for drinking alcohol and alcohol consumption: an interactional approach. Addict Behav 1993;18:659-70.

10. Holahan CJ, Moos RH, Holahan CK, Cronkite RC, Randall PK. Drinking to cope, emotional distress and alcohol use and abuse: a ten-year model. J Stud Alcohol 2001;62:190-8. 
CHAPTER

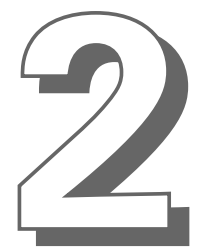

Beneficial effects of moderate alcohol intake on cardiovascular disease: A review of the major cohort studies 


\begin{abstract}
Moderate alcohol intake has been related to lower risks of coronary heart disease. This paper reviews previous studies on the relationship between alcohol intake and coronary heart diseases with special attention to alcohol measurement, covariates and pre-existing disease, and follow-up. Examining these factors could reveal methodological shortcomings and thus subjects for further research. In a systematic review of the epidemiological literature (1966-2002), cohort studies on the relationship between alcohol intake and cardiovascular disease, coronary heart disease, myocardial infarction, angina pectoris, sudden cardiac death, or non-sudden cardiac death were included. Shape of the association and risk ratios for moderate drinking were placed next to alcohol measurement, covariates and pre-existing disease, and length of follow-up. A total of 58 articles were included.All studies measured current alcohol intake, of which $71 \%$ did not even define the reference period of the alcohol intake. Of the studies, $74 \%$ did not distinguish different groups of non-drinkers. The studies reported, in general, a lower risk of all endpoints for moderate drinkers compared to nondrinkers, except for sudden cardiac death. Definition of reference period, definition of the nondrinkers group, length of follow-up, and pre-existing disease and covariates each seemed to affect some endpoints, but not all. This review showed several methodological shortcomings, especially in the domain of alcohol measurement. Overall, measurement of alcohol intake should receive more attention in epidemiological studies. Besides current drinking habits at baseline, effects of lifetime alcohol intake and drinking habits in the past on cardiovascular disease should be investigated.
\end{abstract}




\section{Introduction}

It is well known that heavy and chronic alcohol intake are risk factors for several diseases including cardiovascular disease (1). On the other hand, it is also a widely held view that moderate alcohol consumption is beneficial with respect to the occurrence of coronary heart disease (CHD) (2-5). Both non-drinkers and heavy drinkers seem to have an increased risk of developing or dying of CHD, resulting in a J-shaped or U-shaped curve.

This phenomenon has been examined extensively in original studies and reviews. The reviews concentrated mainly on the question whether there is a J-shaped or U-shaped curve between alcohol intake and CHD. Methodological aspects of the studies in the field of alcohol intake and CHD have received little attention. One meta-analysis about the relationship between alcohol intake and CHD concluded that proper adjustments for main risk indicators, exclusion of former drinkers from the group of non-drinkers, and exclusion of subjects with pre-existing disease led to a less marked Jshaped curve (6). Another important methodological aspect is the measurement of alcohol intake (7). Studies have been using different types of self-reports of alcohol intake, although all were related to current consumption at baseline (8). Alcohol intake is likely to change over time (9-12). Restriction to baseline measurement and to a short reference period over which alcohol intake is assessed can only give an indication of the alcohol intake. Generalizing such short measurement to the overall alcohol intake of a person could, therefore, lead to bias. Considering length of follow-up could provide insight into the duration of the relationship with the observed relationship fading with increasing years of follow-up.

The main aim of this paper is to reveal possible methodological shortcomings in the main cohort studies on the relationship between alcohol intake and CHD, in which often a J-shape has been reported. In this overview the impact of measurement of alcohol intake, incorporation of covariates and pre-existing disease, and length of follow-up on the observed relationship between alcohol intake and CHD will be discussed.

\section{Materials and methods}

The literature was searched using Medline (1966-July 2002) applying the thesaurus terms 'alcohol drinking' and 'myocardial ischaemia' and a methodological filter ('cohort studies' or 'risk' or ('odds' and 'ratio ${ }^{\star}$ ') or ('relative' and 'risk')). To reduce the possibility of missing studies a similar search was performed within Embase (1988-July 2002). A double check for missing studies was done by checking citations in reviews on this subject. Finally, a subsequent search was done for each identified cohort to search for other relevant publications based on the cohort. A cohort can be represented by more than one publication if the articles differ in duration of follow-up or definition of CHD. In case of duplicates, the article giving the best details on alcohol consumption or outcome variables was included. Articles were included if a risk ratio was given, or could be calculated from percentages or incidence rates, for associations between alcohol intake and cardiovascular disease, CHD, myocardial infarction, angina pectoris, sudden cardiac death, or non-sudden cardiac death. Each endpoint was further categorized into non-fatal events, fatal events, and all incident events of the endpoint, i.e. fatal and non-fatal in all. The different endpoints were presented and discussed separately.

A physician/researcher (PZ) and an epidemiologist/researcher (IF) independently read all articles in a systematic way. Attention was paid to the description of the study design, data collection methods of alcohol intake, and incorporation of covariates and pre-existing disease. Information about alco- 
hol intake collection methods extracted from the articles consisted of 1) reference time period over which alcohol intake was reported, 2) use of repeated measurement of alcohol intake, 3) distinction between never drinkers, former drinkers, and drinkers who drink less than the lowest category, 4) number of beverages considered, 5) type of questions (frequency, dose and/or duration), 6) type of questionnaire (no specific questionnaire, beverage or food questionnaire, or alcohol questionnaire), 7) number of categories in which the alcohol intake is divided. Data on covariates and pre-existing disease that have been taken into account in the analyses were extracted from the studies as well. All information was derived from each article irrespective of other included studies of the same cohort. The assessment of the alcohol intake collection methods, follow-up period, and covariates and preexisting disease was done to explore associations with the endpoints of the studies. The emphasis for the alcohol intake collection methods was laid on reference time period of alcohol intake, and distinction between never drinkers and former drinkers. For practical reasons, only covariates reported in more than ten studies were presented in the tables. Pre-existing disease was limited to cardiovascular disease, CHD, stroke, and diabetes mellitus, and were reported as exclusion of persons with pre-existing disease or adjustment for pre-existing disease in the analyses.

Two results were extracted from the reviewed studies: risk ratio for moderate consumption relative to that of non-drinkers or occasional drinkers, and shape of the curve. Moderate alcohol intake was defined as the category including two drinks per day, which was set equal to the following units pure alcohol per day: 20 grams, 25 millilitre, 0.8 ounces, or 0.9 Japanese go pure alcohol per day. In case no risk ratio was given, it was calculated from information given in the article, mostly numbers of cases and number of persons at risk, for the compared categories of exposure. If adjusted incidence rates were given, these were used. A 95\% confidence interval was also calculated. Risk ratios and confidence intervals were calculated using the formulas given by Morris and Gardner (13). Most studies used non-drinkers as reference group. In case moderate drinkers were used as reference group, it was converted relative to that of non-drinkers to be able to compare the results of the different studies. Shape of the association between alcohol intake and the endpoint was only extracted from a study when explicitly mentioned in the text or a table of the concerning article.

\section{Results}

\section{Overall results}

A total of 63 articles met the inclusion criteria. Four articles (14-17) were subsequently excluded, because they appeared to be duplicates. Yet another article (18) was excluded because in it three cohorts were being compared. Nevertheless, all three cohorts are present in the current review since they were also reported elsewhere. This left 58 articles (19-76) with results obtained from 37 cohorts. Most studies examined solely men (37 studies from 25 cohorts), 16 studies (11 cohorts) investigated both men and women, and five studies ( 3 cohorts) reported the results for women only. The majority were more or less general population studies (38 studies from 25 cohorts). The other studies obtained data from employees or specific professional groups (16 studies from 9 cohorts), and risk groups ( 3 studies from 2 cohorts). The number of participants in the analyses varied from 1,112 to 581,321 persons. The different periods of follow-up ranged from 2 years to a maximum of 31 years.

Table 1 gives an overview of the extracted data about measurement of alcohol intake in the studies. Most studies did not define a reference period over which the respondent had to summarize his intake or did not report it (71\%), and made no distinctions within the group of non-drinkers $(74 \%)$. The majority of the studies measured alcohol intake separately for three or more alcoholic beverages $(72 \%)$. Five studies used a structured alcohol questionnaire. 
Table 1. Summary of alcohol intake collection methods of the included studies

\begin{tabular}{|c|c|}
\hline & $\mathrm{N}$ of studies $(\%)$ \\
\hline \multicolumn{2}{|l|}{ Reference time period ${ }^{\star}$} \\
\hline Current or usual intake & $41(71)$ \\
\hline Actual intake (previous 1-7 days) & $3(5)$ \\
\hline Usual intake previous month & $2(3)$ \\
\hline Usual intake previous year & $12(21)$ \\
\hline Current intake \& duration of this intake & $1(2)$ \\
\hline \multicolumn{2}{|l|}{ Distinction within non-drinkers } \\
\hline Total group of non-drinkers & $43(74)$ \\
\hline Exclusion of former drinkers & $3(5)$ \\
\hline Never drinkers only & $12(21)$ \\
\hline \multicolumn{2}{|l|}{ Repetition of alcohol measurement } \\
\hline No (one measurement) & $37(64)$ \\
\hline Yes & $21(36)$ \\
\hline \multicolumn{2}{|l|}{ Number of beverages considered } \\
\hline Not specified & $14(24)$ \\
\hline Two & $2(3)$ \\
\hline Three or more & $42(72)$ \\
\hline \multicolumn{2}{|l|}{ Type of questions } \\
\hline Usual dose or frequency or not specified & $32(55)$ \\
\hline Dose and frequency or dose and duration & $22(38)$ \\
\hline Dose, frequency and duration & $4(7)$ \\
\hline \multicolumn{2}{|l|}{ Type of questionnaire } \\
\hline A couple of questions or not specified & $40(69)$ \\
\hline A beverage or food questionnaire 1 & $3(22)$ \\
\hline An alcohol questionnaire & $5(9)$ \\
\hline \multicolumn{2}{|l|}{ Number of categories of alcohol intake } \\
\hline$\leq 3$ & $4(7)$ \\
\hline $4-5$ & $23(40)$ \\
\hline$\geq 6$ & $31(53)$ \\
\hline
\end{tabular}

* One study measured actual intake and usual intake in previous year

\section{Cardiovascular events}

All events Table 2 presents the studies with reports of alcohol intake in relationship to cardiovascular events in order of increasing ratios. The association between alcohol intake and incident cardiovascular events was reported by three studies $(19,67,70)$. Female moderate drinkers seemed to have a lower risk $(67,70)$. For men, the ratios did not reach significance $(19,70)$. Effects of covariates and follow-up period could not be distinguished because of the small number of studies.

Fatal events The point estimates ranged from 0.59 to 1.45 with most ratios between 0.70 and 0.80 , as can be seen in the second part of table 2. Overall, the ratios were lower for women than for men. Length of follow-up or adjustments for covariates had no clear influence on the association between alcohol intake and fatal cardiovascular events. Point estimates below 0.8 were mainly based upon alcohol measurement with a defined reference period, and above 0.8 upon current intake. The shape of the relationship was described as negative linear as well as U-shaped, although not all significant. 


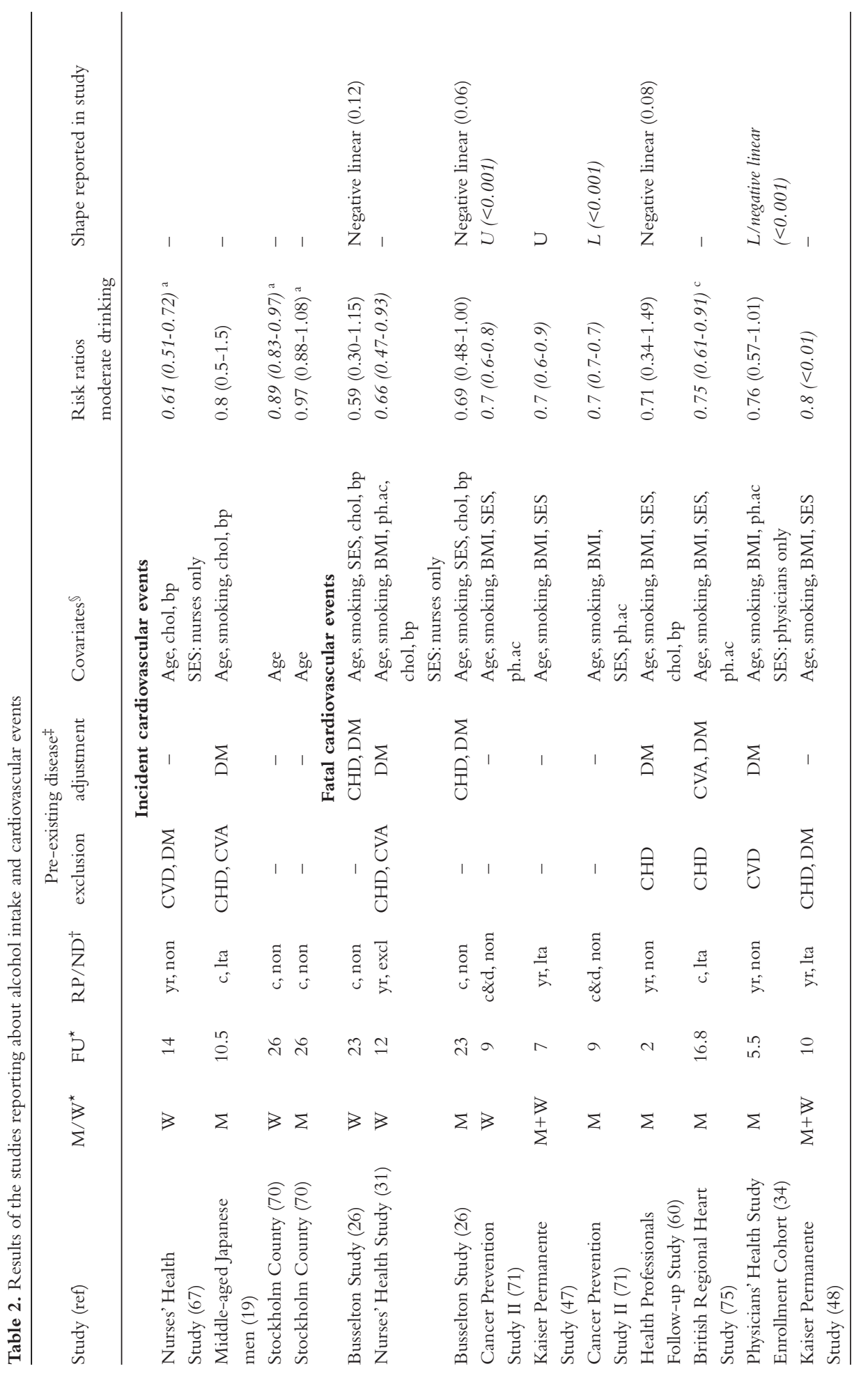




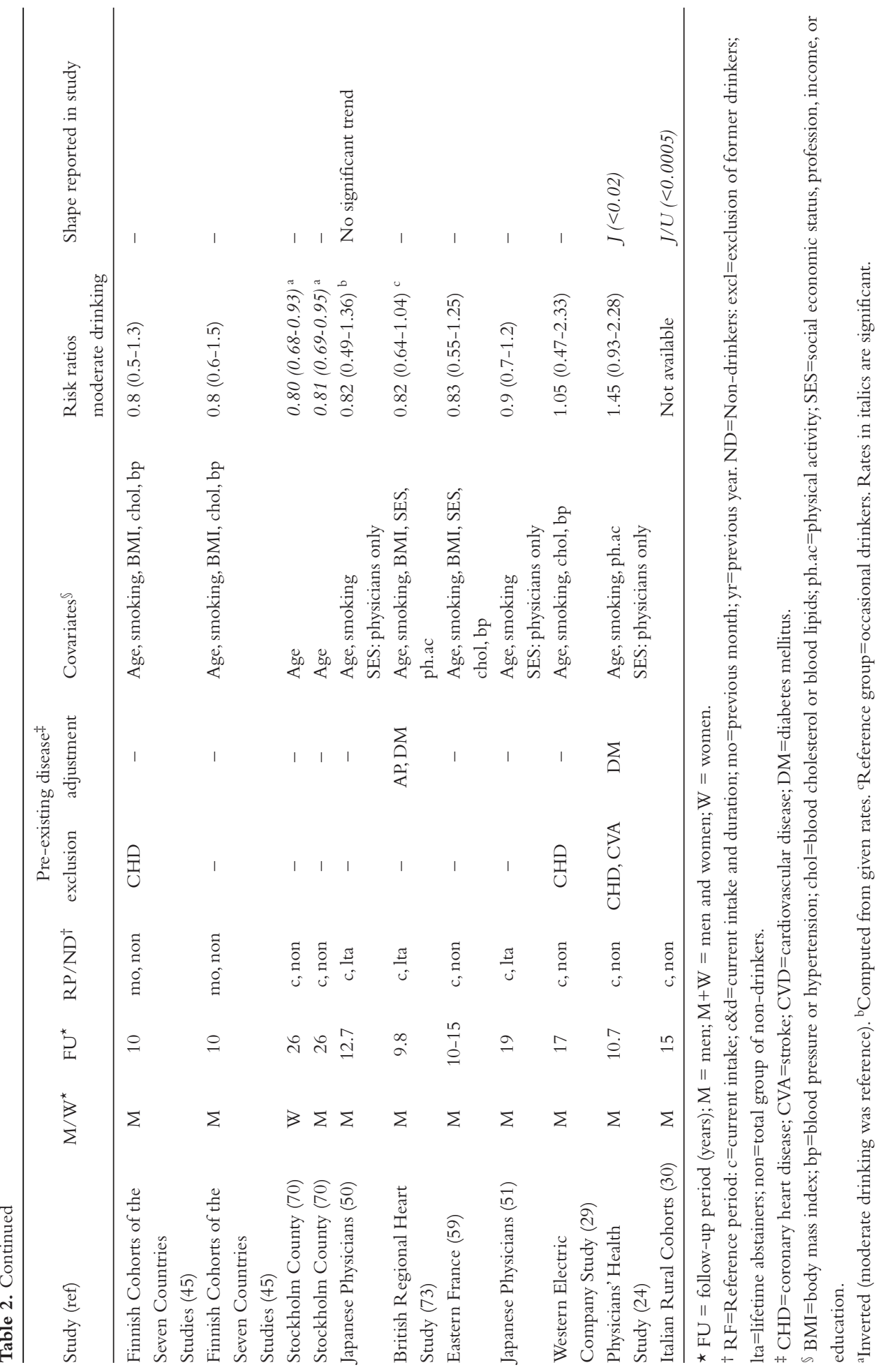




\section{Coronary heart events}

Incident CHD Table 3 presents the results found for alcohol intake related to coronary heart events. The risk ratios for female moderate drinkers compared to non-drinkers ranged from 0.41 to 0.78 $(33,36,41,56,58,66,70)$ and for men the estimates ranged from 0.28 to $1.01(19,23,35-37,41$ $43,49,52,54-56,58,60,63,70,73-76)$. No trends were seen in risks with reference to measurement of alcohol intake, length of follow-up, or pre-existing disease and covariates. In most studies, the shape of the relationship found for incident CHD was described as negative linear $(23,36,37,55$, $58,60,76)$, although some reported a $U$-shape $(35,58,66)$ or no significant shape $(37,42,49,63)$. Non-fatal CHD One study (49) reported about non-fatal CHD. Moderate drinking seemed to lead to a small lower risk compared to occasional drinkers $(\mathrm{RR}=0.75(0.56-1.01))$.

Fatal CHD Although the point estimates for moderate drinking ranged from 0.20 to 1.90 , only ratios between 0.50 and 0.80 reached significance. The point estimates below 0.50 and above 0.80 were almost all based upon total group of non-drinkers as reference group. Studies reporting estimates for persons with pre-existing disease and persons without pre-existing disease found, in general, lower risks for moderate drinkers with pre-existing disease than moderate drinkers without pre-existing disease $(62,71,72)$. Of the studies describing a shape, most reported a non-significant shape or no data on significance $(22,26,28,38-40,49,50,58,65,71,76)$, a few studies reported a L-shape or negative linear relationship $(38,49,71)$ or a U-shape relationship (66, $71)$.

\section{Myocardial infarctions, angina pectoris, sudden and non-sudden (cardiac) death}

Myocardial infarction The first part of table 4 gives the results of the studies on alcohol intake and myocardial infarction. Incident myocardial infarction was investigated by three studies $(43,46,61)$ of which one studied men and women together finding a significant lower risk of 0.54 compared to never drinkers (46).

Six studies about alcohol intake and non-fatal myocardial infarction reported estimates of the risk ratios for moderate drinkers from 0.46 to 0.73 (second part table 4). All ratios are based upon total group of non-drinkers as reference group. Five studies described the relationship as negative linear $(20,44,60,66,76)$. The studies with follow-up periods up to 6 years had point estimates around 0.70 and studies with longer follow-up periods reported estimates around 0.50 .

Fatal myocardial infarction was investigated in three studies $(34,47,51)$, of which two reported lower risks for moderate drinkers compared to non-drinkers (34) or never drinkers (47).

Angina pectoris The ratios for moderate drinking varied from 0.26 to $0.53(23,43,44,76)$. A surgery associated with angina pectoris, CABG/PTCA, showed a risk ratio of 0.84 for moderate drinkers (60). The relationship between alcohol intake and angina pectoris seemed to be negative linear.

Sudden (cardiac) death The point estimates adjusted for pre-existing disease and several covariates showed no significant relationship between alcohol intake and sudden cardiac death. The studies without exclusion of pre-existing disease and scarce adjustment for covariates found a higher risk of sudden cardiac death for moderate drinkers compared to non-drinkers $(52,69)$.

Non-sudden (cardiac) death The association between alcohol intake and non-sudden death was reported by four studies with ratios between 0.18 and 0.73 for moderate drinkers $(20,44,52,72)$. The study taking both pre-existing disease and covariates into account reported a non-significant point estimate closest to unity compared to the other studies. The relationship between alcohol intake and non-sudden cardiac death seemed to be best described as negative linear. 


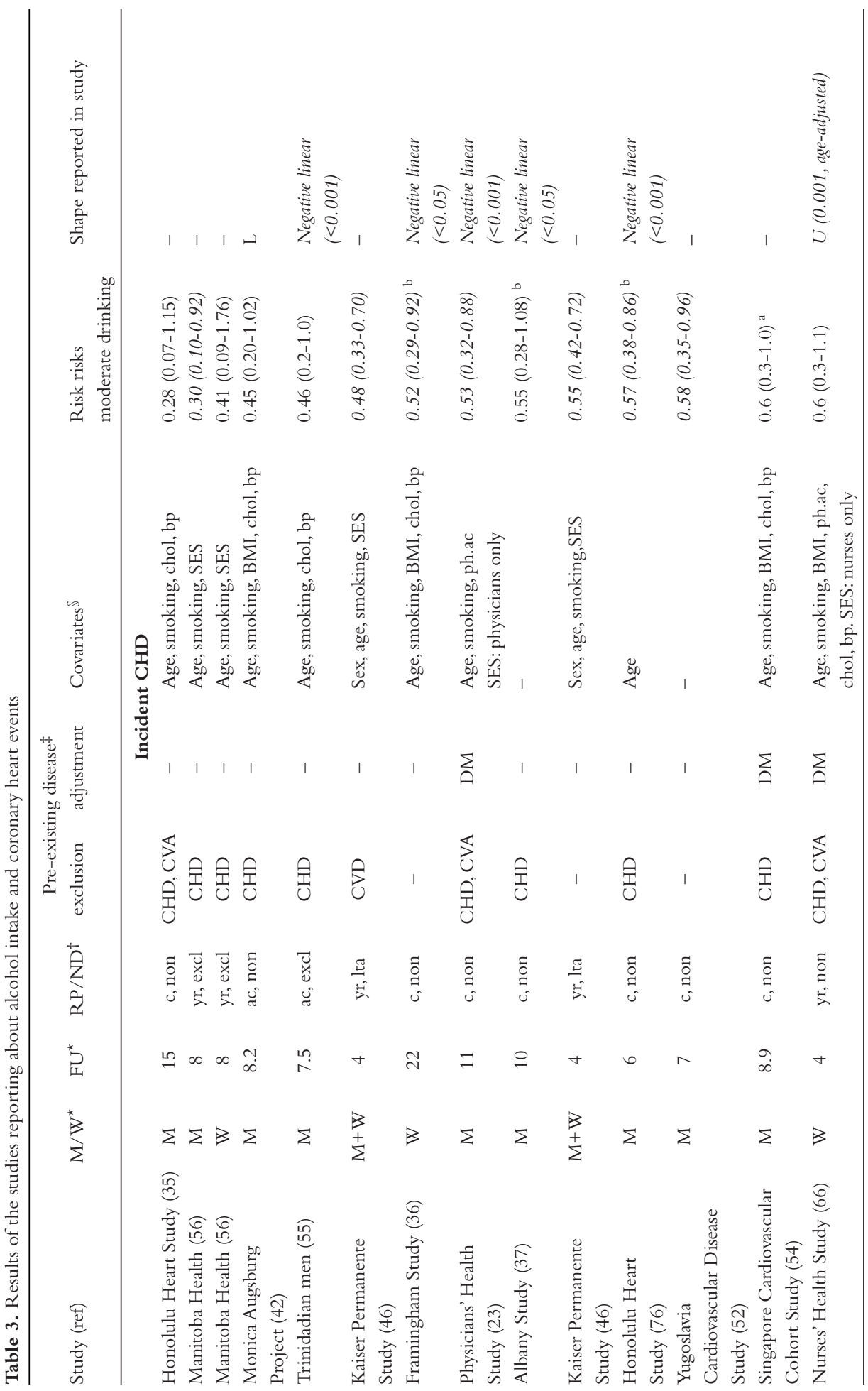




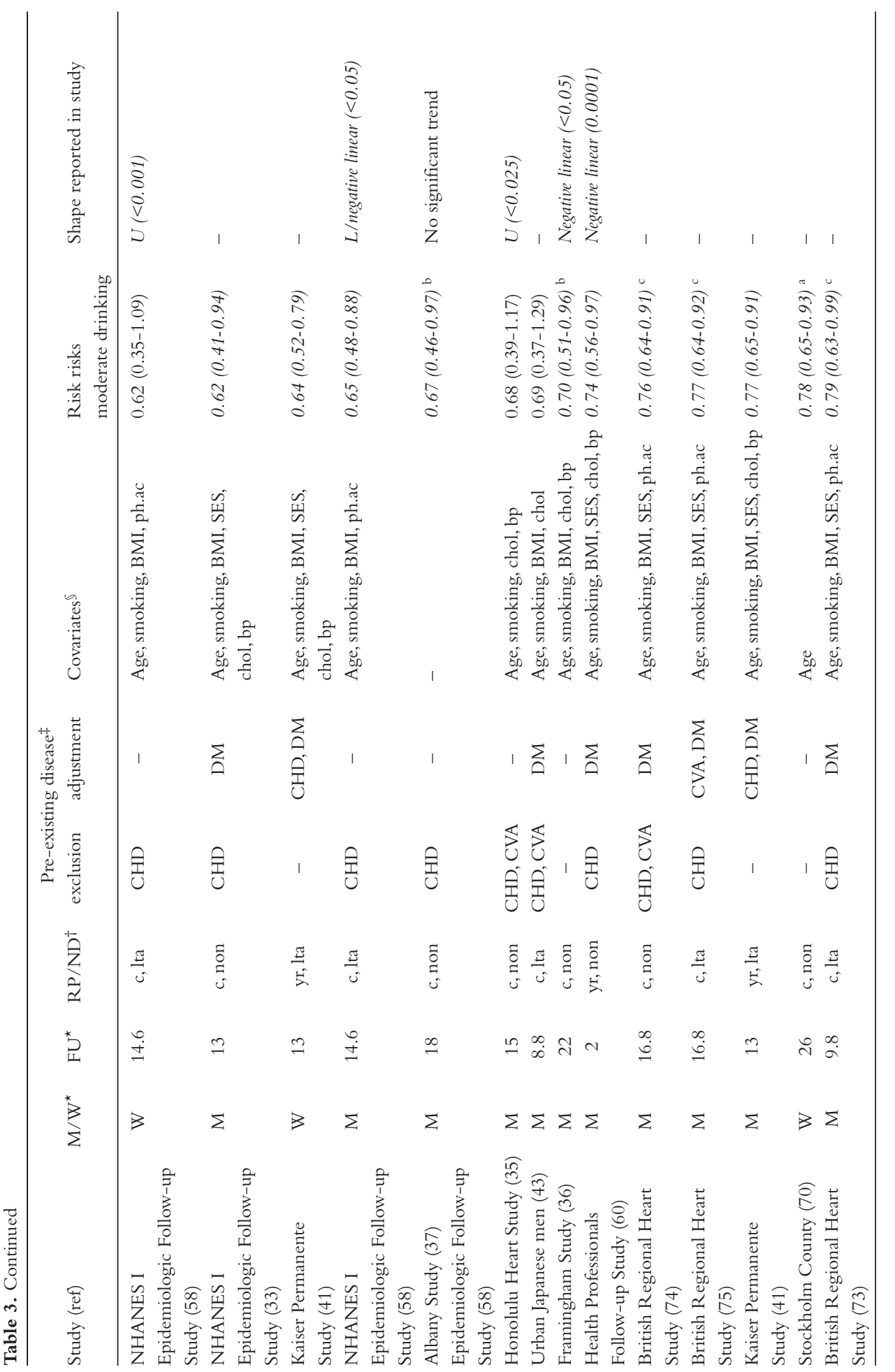




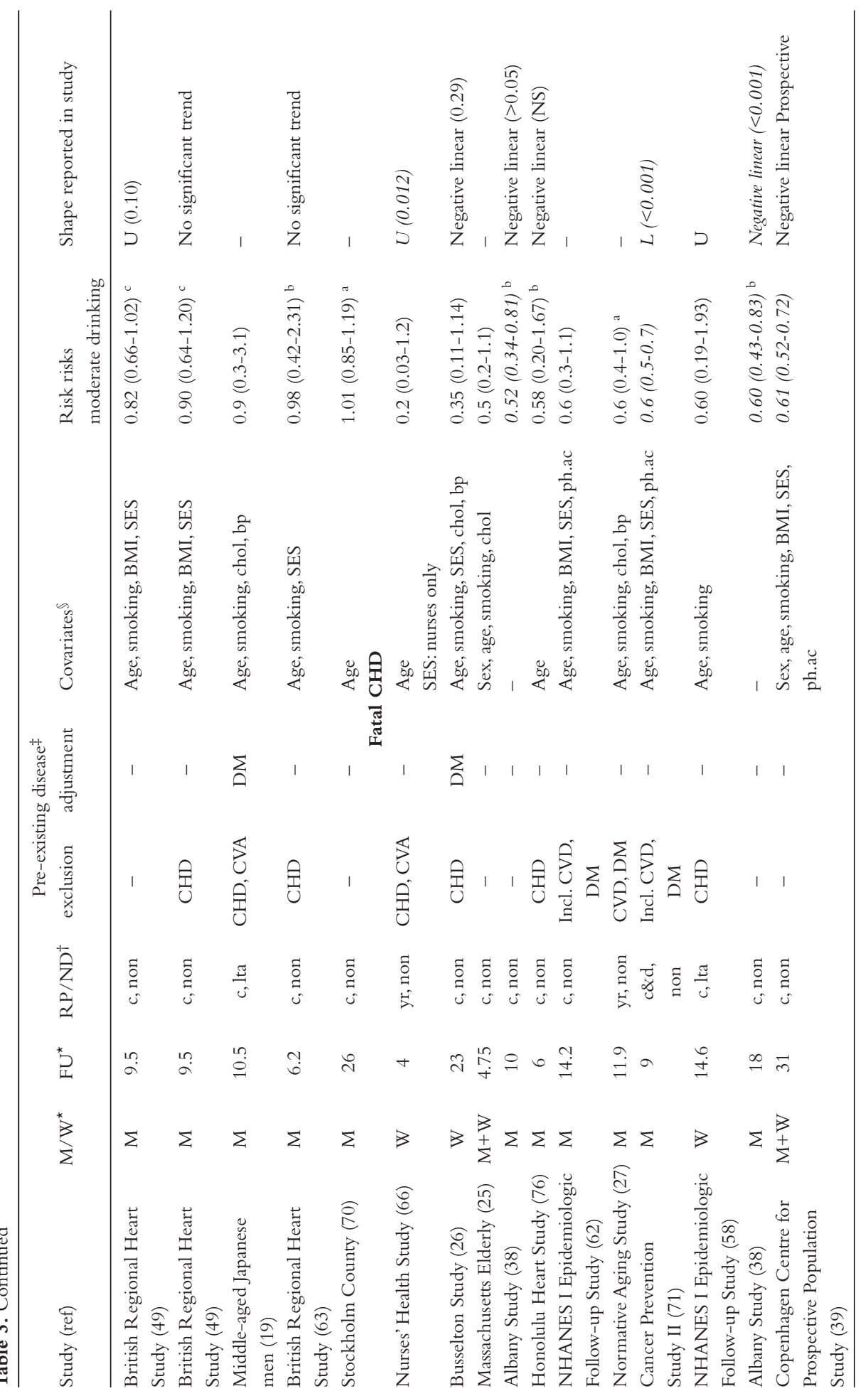




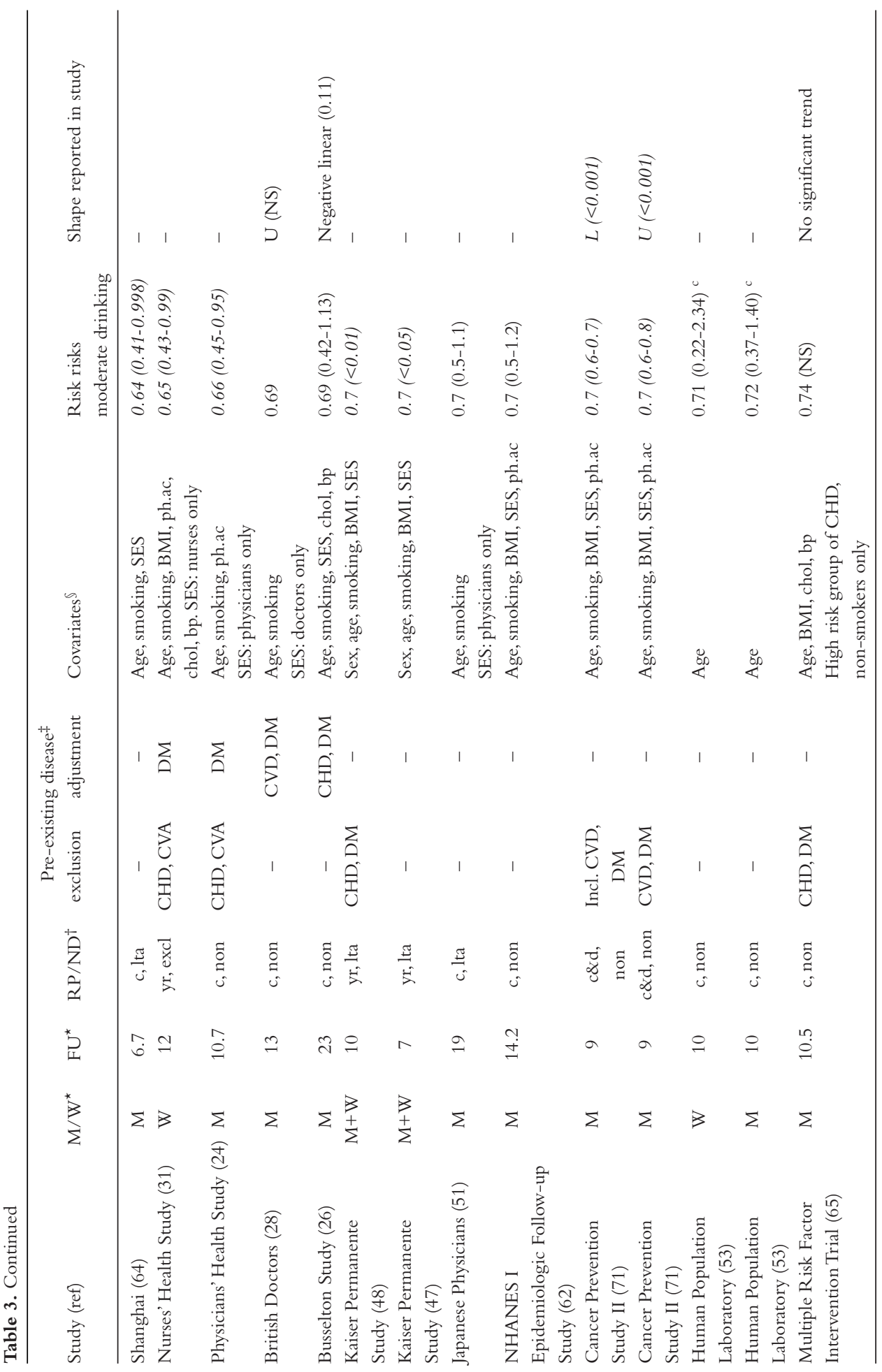




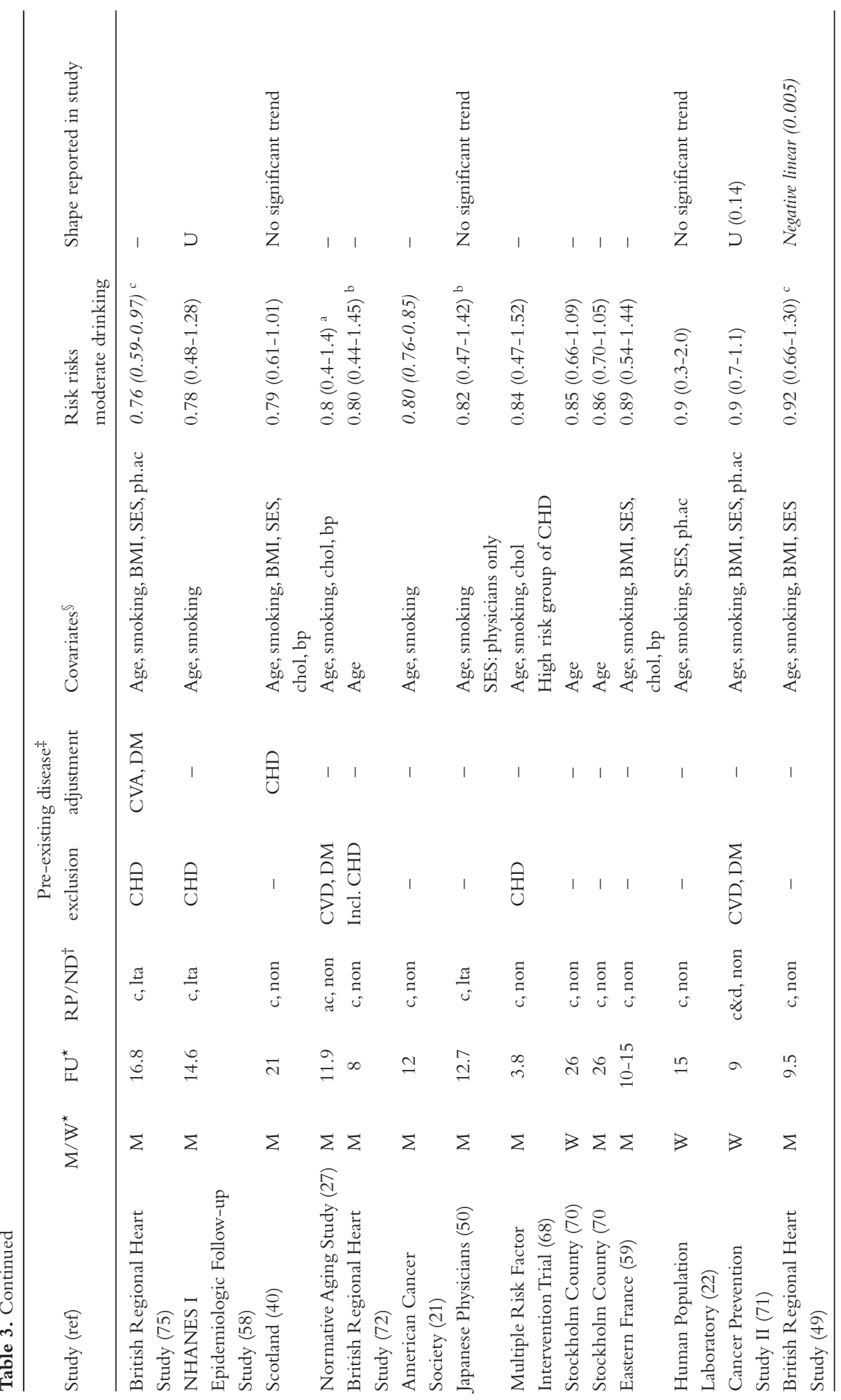




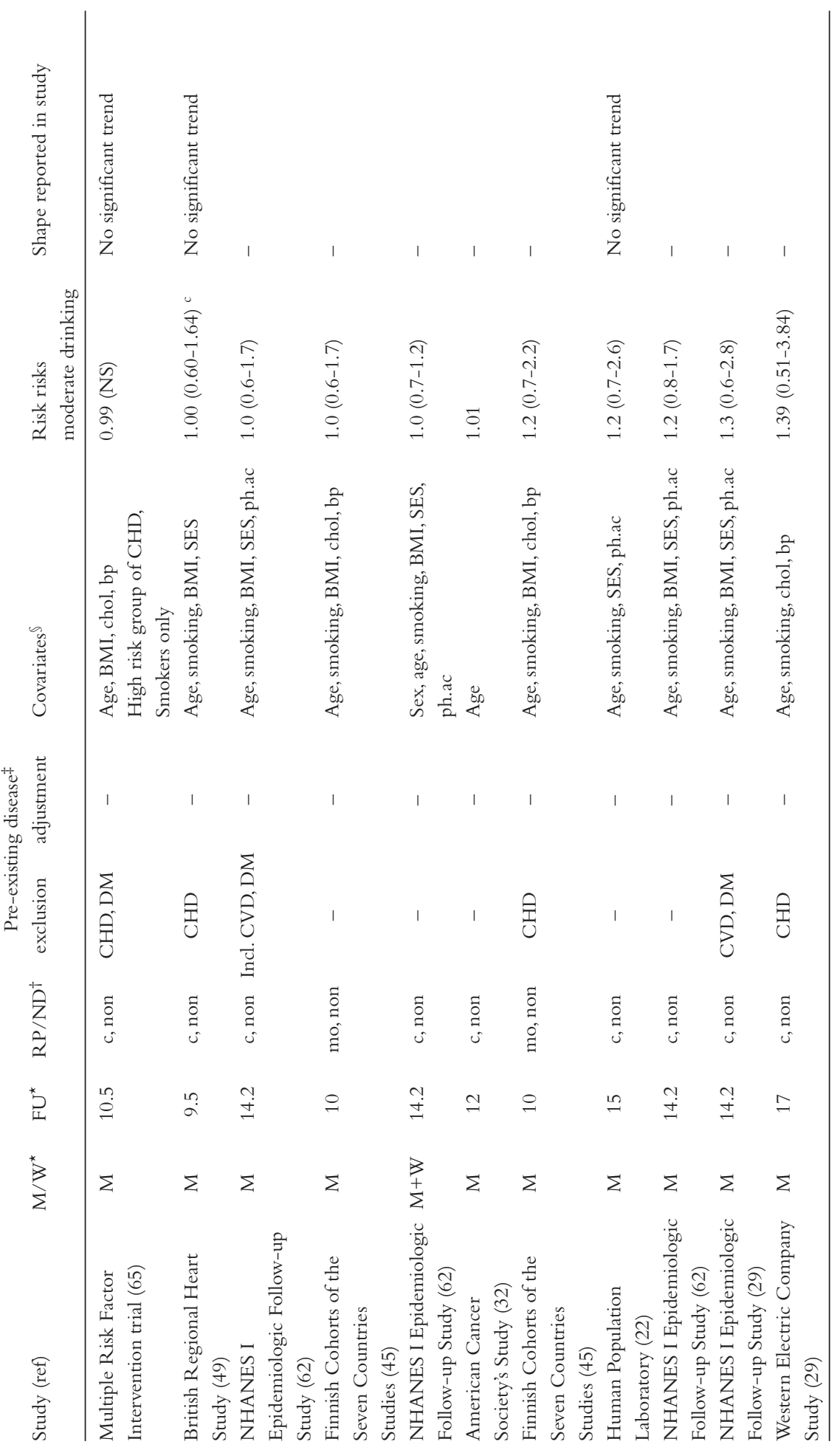




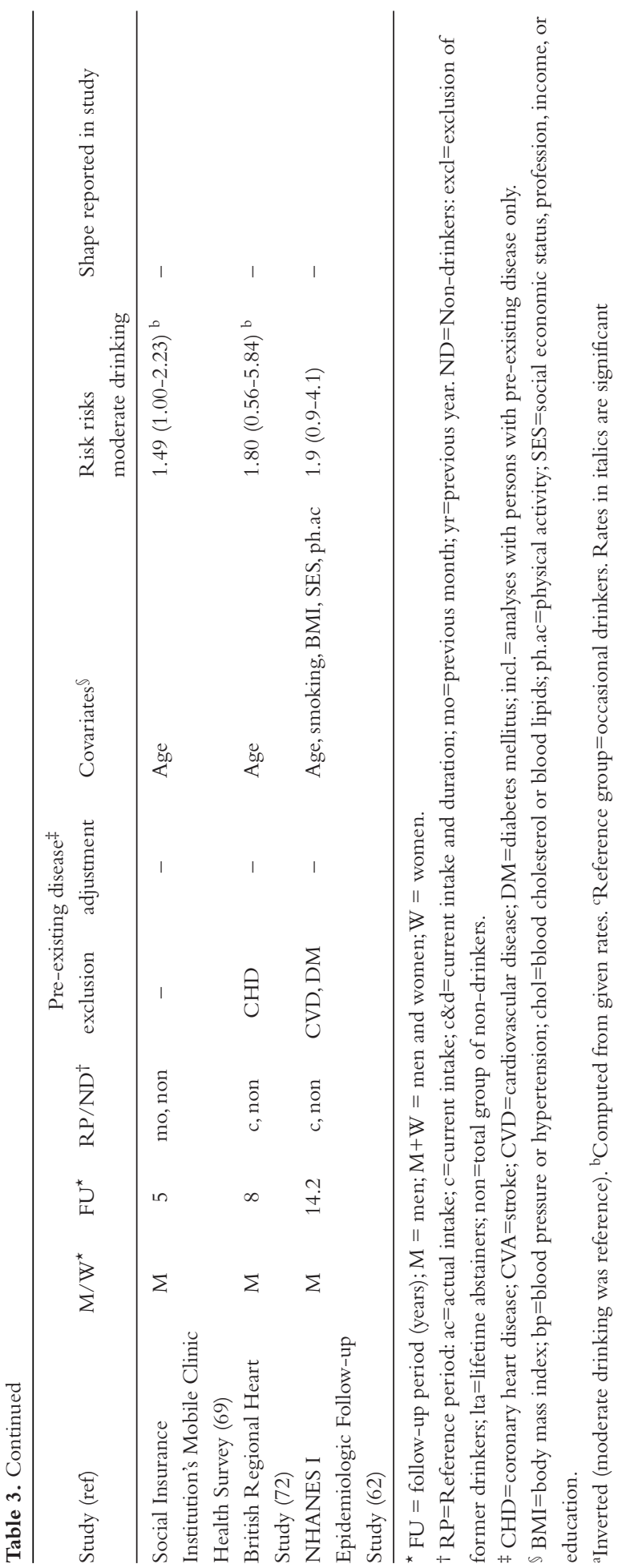




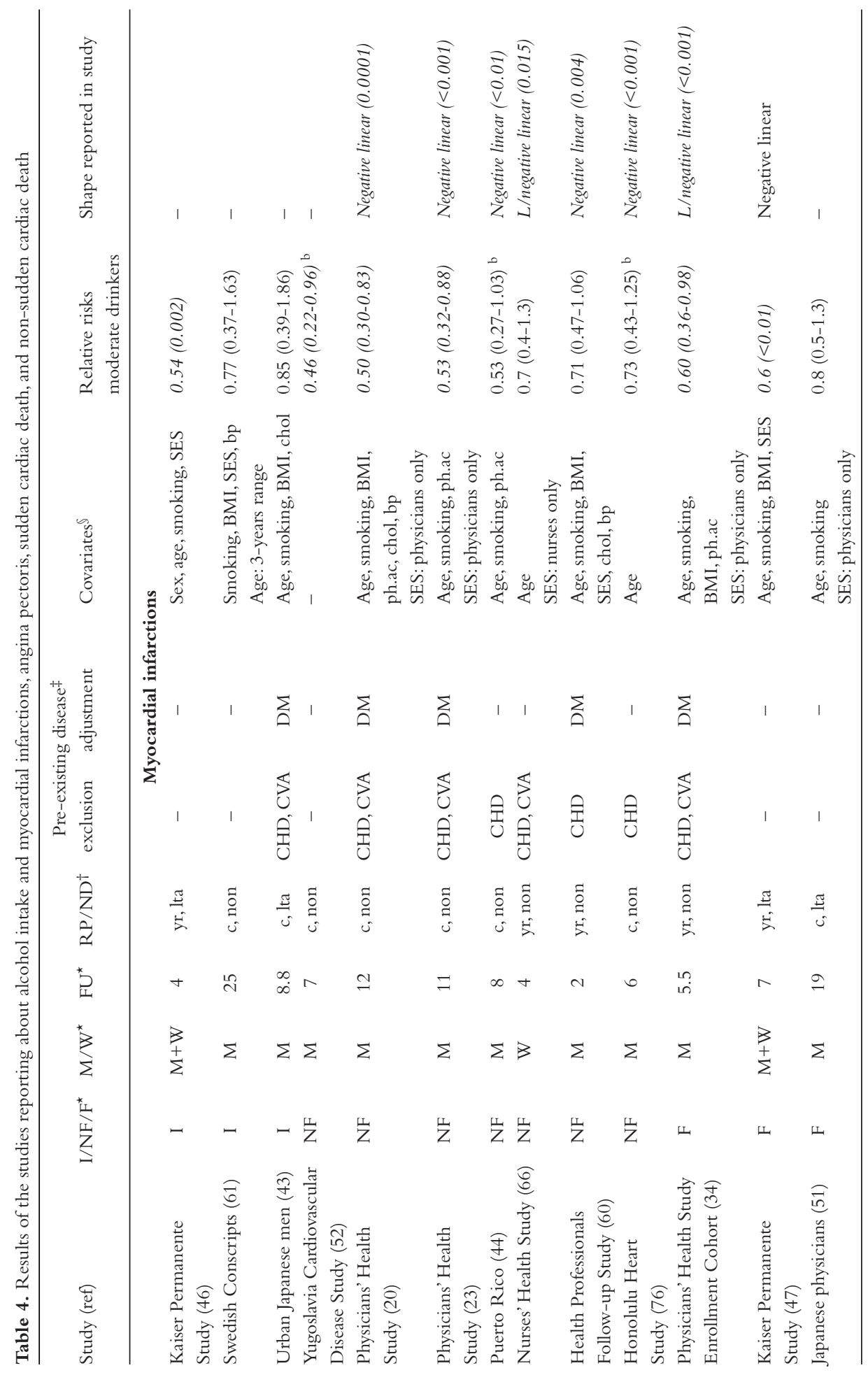




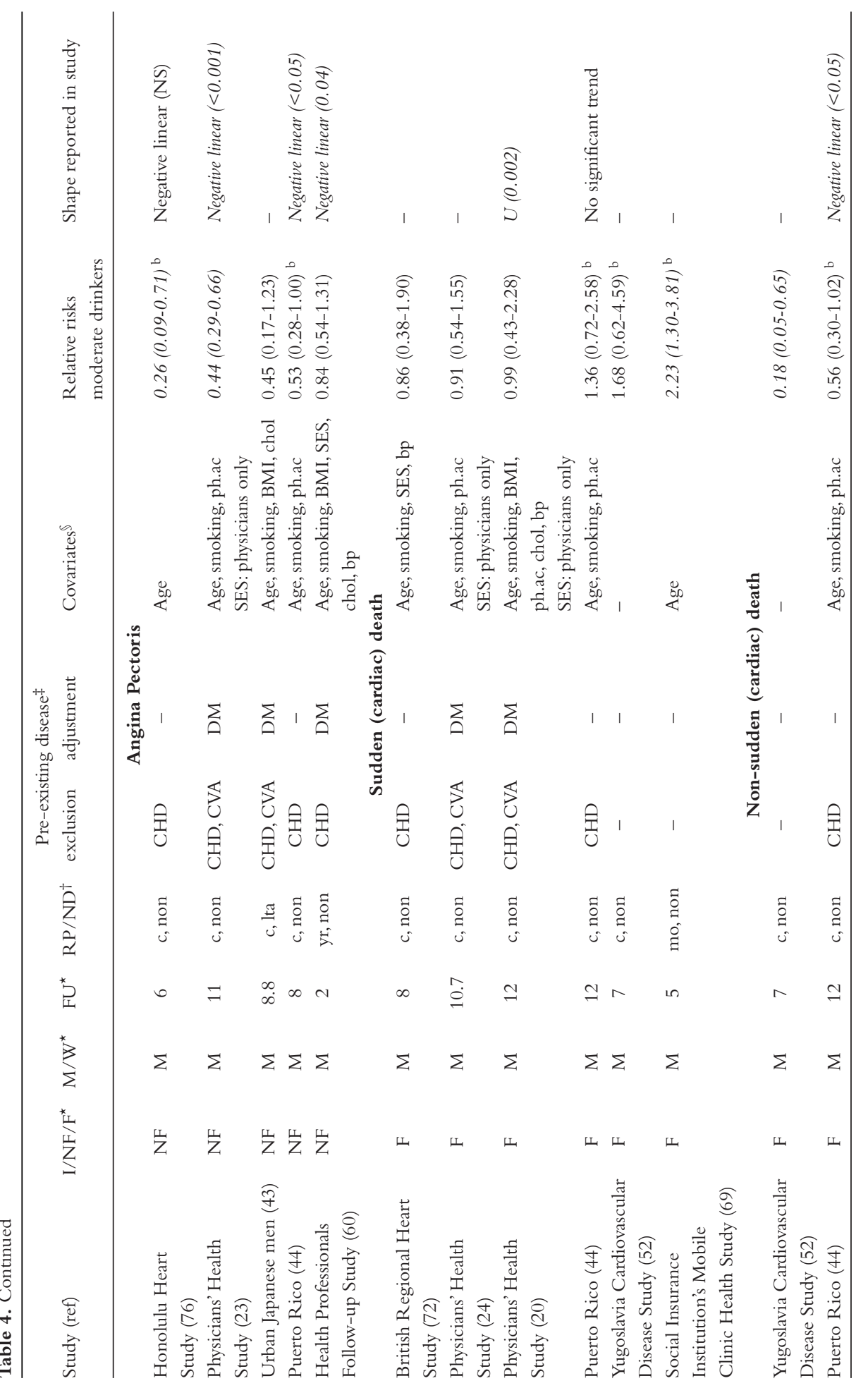




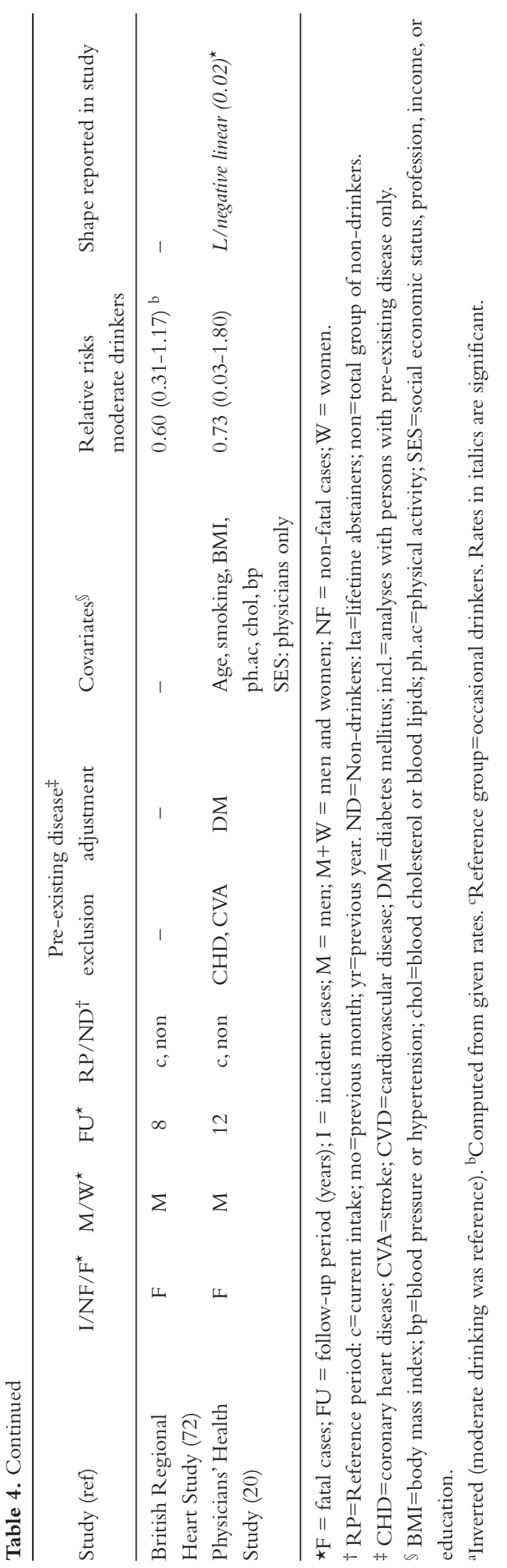




\section{Discussion}

The present review gives an overview of 58 studies on the relationship between alcohol intake and coronary heart diseases. All studies used current alcohol intake at baseline of which 41 studies did not define a reference period. Fifteen studies distinguished different groups of non-drinkers. The studies reported, in general, a lower risk for all endpoints for moderate drinkers compared to nondrinkers, except for sudden cardiac death. Moderate drinkers seemed to have a similar or higher risk at sudden cardiac death compared to non-drinkers. Effects of the way alcohol intake was measured, principally definition of reference period and of the non-drinkers group, length of follow-up, and pre-existing disease and covariates each seemed to affect some endpoints, but not all.

An overall problem of measurement of alcohol intake is the lack of a gold standard, which leads to difficulties in comparing results across studies. All studies measured current alcohol intake with short or undefined reference periods and the populations often consisted of adults aged 40 years or older. Coronary heart disease occur mainly in adults aged 45 years or older (77), but the preceding atherosclerotic process starts already early in life (78-82). Possible effects of past drinking or total lifetime consumption are ignored when only current intake of adults is used, especially since alcohol intake is prone to change over time (9-12). The follow-up periods of the included studies were between 2 and 31 years. A clear effect of duration of follow-up was not seen, which could imply a prolonged effect of alcohol intake. However, one measurement of current alcohol intake remains a random indication. A study measuring alcohol intake from the first glass drunk could give the possibility to investigate the impact of early drinking habits and lifetime accumulation on coronary heart disease risk in later life (83). However, measurement of lifetime alcohol intake requires even more caution than current drinking.

The use of former drinkers and never drinkers as combined reference group has already been questioned, as former drinkers could have quit drinking because of ill-health (84). A reference group consisting of never drinkers only was found to attenuate the association, but could not completely explain the observed relationship (6). In the present review, an effect of choice of reference group was seen in fatal coronary heart disease.Yet, what makes never drinkers to abstain? It has been found that former drinkers and never drinkers differ from drinkers on more than on alcohol intake, including health $(85,86)$. Furthermore, young people with poorer psychological as well as physical health may more likely refrain from starting a drinking career, and remain abstainer throughout their life than young adults within a normal health range (87). Abovementioned would imply that it is conceivable that alcohol consumption is an expression of feeling well. Another possibility is that drinkers feel better, because moderate alcohol intake lessens the effects of stress (88). Expanding this view, moderate drinkers appear to have less depressions in the presence of stress (89).

The relationship between alcohol intake and cardiovascular disease is influenced by a range of surrounding factors. Adjustment or exclusion of known influencing factors is not done in all studies, as could be seen in the present review. Some studies extensively take these factors into account, others only minimal. A previous meta-analysis concluded that adjustment for covariates attenuates the association between alcohol intake and CHD (6), which underlines the complexity of this association. Therefore, part of the relationship could be explained by the influences of covariates and should not be ignored when examining the relationship between alcohol intake and cardiovascular disease.

The present review has several limitations. A meta-analysis would have yielded an overall point estimate on the relationship between alcohol intake and coronary heart disease. However, this review was meant to give an overview of studies done so far to find possible gaps for future research. The heterogeneity of the studies is large, which has the advantage that it provides an insight in what has been done up to now in an overview, but often leads to exclusion of studies when performing a 
meta-analysis. Second, the number of studies investigating the association between alcohol intake and cardiovascular disease was smaller than the number of studies to coronary heart diseases. This could have been caused by the thesaurus search terms, which were mainly concentrated on coronary heart diseases. On the other hand, several previous reviews and meta-analyses were inspected for missed cohorts and articles. Finally, in the present review, studies were used without accounting for dependence between studies of the same cohort. However, the possible effects are expected to be low, as studies of the same cohort had to differ at least on endpoint and/or length of follow-up. The epidemiological evidence that current alcohol intake at baseline is related to a lower risk of coronary heart disease for moderate drinkers is abundant. Replication of these kind of studies does not seem necessary. What is needed instead are studies assessing risk estimates with more specific attention to measurement of alcohol intake and adjustment and/or exclusion of pre-existing disease and covariates. Furthermore, it would be interesting to investigate the effect of lifetime alcohol intake and drinking across the lifetime course on the risk of cardiovascular and coronary heart disease. In addition, exploration of explanations of the association between alcohol intake and coronary heart disease could yield more understanding of this association.

\section{References}

1. Klatsky AL. Alcohol and cardiovascular diseases: a historical overview. In: Chadwick DJ, Goode JA, eds. Alcohol and Cardiovascular Diseases. Novartis Foundation Symposium no.216. Chichester: John Wiley \& Sons, 1998:2-12.

2. Kannel WB, Ellison RC.Alcohol and coronary heart disease: the evidence for a protective effect. Clin Chim Acta 1996;246:59-76.

3. Klatsky AL. Alcohol, coronary disease, and hypertension. Annu Rev Med 1996;47:149-60.

4. Rimm EB, Klatsky A, Grobbee D, Stampfer MJ. Review of moderate alcohol consumption and reduced risk of coronary heart disease: is the effect due to beer, wine, or spirits. Brit Med J 1996;312:731-6.

5. Cleophas TJ.Wine, beer and spirits and the risk of myocardial infarction: a systematic review. Biomed Pharmacother 1999;53:417-23.

6. Corrao G, Rubbiati L, Bagnardi V, Zambon A, Poikolainen K. Alcohol and coronary heart disease: a metaanalysis. Addiction 2000;95:1505-23.

7. Fillmore KM. Is alcohol really good for the heart? Addiction 2000;95:173-4.

8. Lemmens PHHM, Drop MJ. Op zoek naar de gezonde drinker.Tijdschr Alcohol Drugs Andere Psychotr Stoffen 1995/96;21:226-34.

9. Friesema IHM,Veenstra MY, Zwietering PJ, Knottnerus JA, Garretsen HFL, Lemmens PHHM. Measurement of lifetime alcohol intake: Utility of a self-administered questionnaire. Am J Epidemiol 2004;159:809-17.

10. Kerr WC, Fillmore KM, Bostrom A. Stability of alcohol consumption over time: evidence from three longitudinal surveys from the United States. J Stud Alcohol 2002;63:325-33.

11. Neve RJ, Diederiks JP, Knibbe RA, Drop MJ. Developments in drinking behavior in The Netherlands from 1958 to 1989, a cohort analysis. Addiction 1993;88:611-21.

12. Fillmore KM, Hartka E, Johnstone BM, Leino EV, Motoyoshi M,Temple MT.A meta-analysis of life course variation in drinking. Br J Addict 1991;86:1221-67.

13. Morris JA, Gardner MJ. Calculating confidence intervals for relative risks, odds ratios, and standardised ratios and rates. In: Gardner MJ, Altman DG, eds. Statistics with confidence. -Confidence intervals and statistical guidelines. London: British Medical Journal, 1989:50-63.

14. Kagan A, Yano K, Rhoads GG, McGee DL. Alcohol and cardiovascular disease: the Hawaiian experience. Circulation 1981;64:III 27-31.

15. Dyer AR, Stamler J, Paul O, Berkson DM, Lepper MH, McKean H, et al. Alcohol consumption, cardiovascular risk factors, and mortality in two Chicago epidemiologic studies. Circulation 1977;56:1067-74.

16. Dyer AR, Stamler J, Paul O, Berkson DM, Shekelle RB, Lepper MH, et al. Alcohol, cardiovascular risk factors and mortality: the Chicago experience. Circulation 1981;64:Iii 20-7. 
17. Kozarevic D,Vojvodic N, Gordon T, Kaelber CT, McGee D, Zukel WJ. Drinking habits and death. The Yugoslavia cardiovascular disease study. Int J Epidemiol 1983;12:145-50.

18. Gordon T, Kagan A, Garcia Palmieri M, Kannel WB, Zukel WJ, Tillotson J, et al. Diet and its relation to coronary heart disease and death in three populations. Circulation 1981;63:500-15.

19. Iso H, Kitamura A, Shimamoto T, Sankai T, Naito Y, Sato S, et al. Alcohol intake and the risk of cardiovascular disease in middle-aged Japanese men. Stroke 1995;26:767-73.

20. Albert CM, Manson JE, Cook NR, Ajani UA, Gaziano JM, Hennekens CH. Moderate alcohol consumption and the risk of sudden cardiac death among US male physicians. Circulation 1999;100:944-50.

21. Boffetta P, Garfinkel L. Alcohol drinking and mortality among men enrolled in an American Cancer Society prospective study. Epidemiology 1990;1:342-8.

22. Camacho TC, Kaplan GA, Cohen RD. Alcohol consumption and mortality in Alameda County. J Chronic Dis 1987;40:229-36.

23. Camargo CA, Jr., Stampfer MJ, Glynn RJ, Grodstein F, Gaziano JM, Manson JE, et al. Moderate alcohol consumption and risk for angina pectoris or myocardial infarction in U.S. male physicians. Ann Intern Med 1997; 126:372-5.

24. Camargo CA, Jr., Hennekens CH, Gaziano JM, Glynn RJ, Manson JE, Stampfer MJ. Prospective study of moderate alcohol consumption and mortality in US male physicians. Arch Intern Med 1997;157:79-85.

25. Colditz GA, Branch LG, Lipnick RJ, Willett WC, Rosner B, Posner B, et al. Moderate alcohol and decreased cardiovascular mortality in an elderly cohort. Am Heart J 1985;109:886-9.

26. Cullen KJ, Knuiman MW, Ward NJ. Alcohol and mortality in Busselton, Western Australia. Am J Epidemiol 1993;137:242-8.

27. de Labry LO, Glynn RJ, Levenson MR, Hermos JA, LoCastro JS, Vokonas PS. Alcohol consumption and mortality in an American male population: recovering the U-shaped curve-findings from the normative Aging Study. J Stud Alcohol 1992;53:25-32.

28. Doll R, Peto R, Hall E, Wheatley K, Gray R. Mortality in relation to consumption of alcohol: 13 years' observations on male British doctors. Brit Med J 1994;309:911-8.

29. Dyer AR, Stamler J, Paul O, Lepper M, Shekelle RB, McKean H, et al. Alcohol consumption and 17-year mortality in the Chicago Western Electric Company study. Prev Med 1980;9:78-90.

30. Farchi G, Fidanza F, Mariotti S, Menotti A. Alcohol and mortality in the Italian rural cohorts of the Seven Countries Study. Int J Epidemiol 1992;21:74-81.

31. Fuchs CS, Stampfer MJ, Colditz GA, Giovannucci EL, Manson JE, Kawachi I, et al. Alcohol consumption and mortality among women. New Engl J Med 1995;332:1245-50.

32. Garfinkel L, Boffetta P, Stellman SD. Alcohol and breast cancer: a cohort study. Prev Med 1988;17:686-93.

33. Garg R, Wagener DK, Madans JH. Alcohol consumption and risk of ischemic heart disease in women. Arch Intern Med 1993;153:1211-6.

34. Gaziano JM, Gaziano TA, Glynn RJ, Sesso HD, Ajani UA, Stampfer MJ, et al. Light-to-moderate alcohol consumption and mortality in the Physicians' Health Study enrollment cohort. J Am Coll Cardiol 2000;35:96-105.

35. Goldberg RJ, Burchfiel CM, Reed DM, Wergowske G, Chiu D. A prospective study of the health effects of alcohol consumption in middle-aged and elderly men: The Honolulu Heart Program. Circulation 1994;89:651-9.

36. Gordon T, Kannel WB. Drinking habits and cardiovascular disease: the Framingham Study. Am Heart J 1983;105:667-73.

37. Gordon T, Doyle JT. Drinking and coronary heart disease: the Albany Study. Am Heart J 1985;110:331-4.

38. Gordon T, Doyle JT. Drinking and mortality. The Albany Study. Am J Epidemiol 1987;125:263-70.

39. Gronbaek M, Becker U, Johansen D, Gottschau A, Schnohr P, Hein HO, et al. Type of alcohol consumed and mortality from all causes, coronary heart disease, and cancer. Ann Intern Med 2000;133:411-9.

40. Hart CL, Smith GD, Hole DJ, Hawthorne VM. Alcohol consumption and mortality from all causes, coronary heart disease, and stroke: results from a prospective cohort study of scottish men with 21 years of follow up. Brit Med J 1999;318:1725-9.

41. Klatsky AL, Armstrong MA, Friedman GD. Red wine, white wine, liquor, beer, and risk for coronary artery disease hospitalization. Am J Cardiol 1997;80:416-20.

42. Keil U, Chambless LE, Doring A, Filipiak B, Stieber J.The relation of alcohol intake to coronary heart disease and all-cause mortality in a beer-drinking population. Epidemiology 1997;8:150-6. 
43. Kitamura A, Iso H, Sankai T, Naito Y, Sato S, Kiyama M, et al. Alcohol intake and premature coronary heart disease in urban Japanese men. Am J Epidemiol 1998;147:59-65.

44. Kittner SJ, Garcia Palmieri MR, Costas R, Jr., CruzVidal M, Abbott RD, Havlik RJ. Alcohol and coronary heart disease in Puerto Rico. Am J Epidemiol 1983;117:538-50.

45. Kivela SL, Nissinen A, Ketola A, Punsar S, Puska P, Karvonen M. Alcohol consumption and mortality in aging or aged Finnish men. J Clin Epidemiol 1989;42:61-8.

46. Klatsky AL, Armstrong MA, Friedman GD. Relations of alcoholic beverage use to subsequent coronary artery disease hospitalization. Am J Cardiol 1986;58:710-4.

47. Klatsky AL, Armstrong MA, Friedman GD. Risk of cardiovascular mortality in alcohol drinkers, exdrinkers and nondrinkers. Am J Cardiol 1990;66:1237-42.

48. Klatsky AL, Armstrong MA, Friedman GD. Alcohol and mortality. Ann Intern Med 1992;117:646-54.

49. Shaper AG, Wannamethee G, Walker M. Alcohol and coronary heart disease: a perspective from the British Regional Heart Study. Int J Epidemiol 1994;23:482-94.

50. Kono S, Ikeda M, Ogata M,Tokudome S, Nishizumi M, Kuratsune M.The relationship between alcohol and mortality among Japanese physicians. Int J Epidemiol 1983;12:437-41.

51. Kono S, Ikeda M, Tokudome S, Nishizumi M, Kuratsune M. Alcohol and mortality: a cohort study of male Japanese physicians. Int J Epidemiol 1986;15:527-32.

52. Kozarevic D, Demirovic J, Gordon T, Kaelber CT, McGee D, Zukel WJ. Drinking habits and coronary heart disease: the Yugoslavia cardiovascular disease study. Am J Epidemiol 1982;116:748-58.

53. Lazarus NB, Kaplan GA, Cohen RD, Leu DJ. Change in alcohol consumption and risk of death from all causes and from ischaemic heart disease. Brit Med J 1991;303:553-6.

54. Lee J, Heng D, Chia KS, Chew SK, Tan BY, Hughes K. Risk factors and incident coronary heart disease in Chinese, Malay and Asian Indian males: The Singapore cardiovascular cohort study. Int J Epidemiol 2001;30:983-8.

55. Miller GJ, Beckles GL, Maude GH, Carson DC. Alcohol consumption: protection against coronary heart disease and risks to health. Int J Epidemiol 1990;19:923-30.

56. Murray RP, Connett JE, Tyas SL, Bond R, Ekuma O, Silversides CK, et al. Alcohol volume, drinking pattern, and cardiovascular disease morbidity and mortality: is there a U-shaped function? Am J Epidemiol 2002;155:242-8.

57. Paunio M, Heinonen OP,Virtamo J, Klag MJ, Manninen V, Albanes D, et al. HDL cholesterol and mortality in Finnish men with special reference to alcohol intake. Circulation 1994;90:2909-18.

58. Rehm JT, Bondy SJ, Sempos CT, Vuong CV. Alcohol consumption and coronary heart disease morbidity and mortality. Am J Epidemiol 1997;146:495-501.

59. Renaud SC, Gueguen R, Schenker J, d'Houtaud A. Alcohol and mortality in middle-aged men from eastern France. Epidemiology 1998;9:184-8.

60. Rimm EB, Giovannucci EL, Willett WC, Colditz GA, Ascherio A, Rosner B, et al. Prospective study of alcohol consumption and risk of coronary disease in men. Lancet 1991;338:464-8.

61. Romelsjo A, Leifman A. Association between alcohol consumption and mortality, myocardial infarction, and stroke in 25 year follow up of 49618 young Swedish men. Brit Med J 1999;319:821-2.

62. Serdula MK, Koong SL, Williamson DF, Anda RF, Madans JH, Kleinman JC, et al. Alcohol intake and subsequent mortality: Findings from the NHANES I follow-up study. J Stud Alcohol 1995;56:233-9.

63. Shaper AG, Phillips AN, Pocock SJ, Walker M. Alcohol and ischaemic heart disease in middle aged British men. Br Med J 1987;294:733-7.

64. Yuan JM, Ross RK, Gao YT, Henderson BE,Yu MC. Follow up study of moderate alcohol intake and mortality among middle aged men in Shanghai, China. Brit Med J 1997;314:18-23.

65. Shaten BJ, Kuller LH, Neaton JD. Association between baseline risk factors, cigarette smoking, and CHD mortality after 10.5 years. MRFIT Research Group. Prev Med 1991;20:655-9.

66. Stampfer MJ, Colditz GA, Willett WC, Speizer FE, Hennekens CH. A prospective study of moderate alcohol consumption and the risk of coronary disease and stroke in women. New Engl J Med 1988;319:267-73.

67. Stampfer MJ, Hu FB, Manson JE, Rimm EB, Willett WC. Primary prevention of coronary heart disease in women through diet and lifestyle. New Engl J Med 2000;343:16-22.

68. Suh I, Shaten BJ, Cutler JA, Kuller LH. Alcohol use and mortality from coronary heart disease: the role of high-density lipoprotein cholesterol. The Multiple Risk Factor Intervention Trial Research Group. Ann Intern Med 1992;116:881-7. 
69. Suhonen O, Aromaa A, Reunanen A, Knekt P. Alcohol consumption and sudden coronary death in middle-aged Finnish men. Acta Med Scand 1987;221:335-41.

70. Theobald H, Johansson SE, Bygren LO, Engfeldt P. The effects of alcohol consumption on mortality and morbidity: a 26-year follow-up study. J Stud Alcohol 2001;62:783-9.

71. Thun MJ, Peto R, Lopez AD, Monaco JH, Henley SJ, Heath CW, et al. Alcohol consumption and mortality among middle-aged and elderly U.S. adults. New Engl J Med 1997;337:1705-14.

72. Wannamethee G, Shaper AG. Alcohol and sudden cardiac death. Br Heart J 1992;68:443-8.

73. Wannamethee SG, Shaper AG. Lifelong teetotallers, ex-drinkers and drinkers: mortality and the incidence of major coronary heart disease events in middle-aged British men. Int J Epidemiol 1997;26:523-31.

74. Wannamethee SG, Shaper AG. Type of alcoholic drink and risk of major coronary heart disease events and all-cause mortality. Am J Public Health 1999;89:685-90.

75. Wannamethee SG, Shaper AG. Taking up regular drinking in middle age: effect on major coronary heart disease events and mortality. Heart 2002;87:32-6.

76. Yano K, Rhoads GG, Kagan A. Coffee, alcohol and risk of coronary heart disease among Japanese men living in Hawaii. New Engl J Med 1977;297:405-9.

77. Van der Linden MW,Westert GP, De Bakker DH, Schellevis FG. Tweede Nationale Studie naar ziekten en verrichtingen in de huisartspraktijk. Klachten en aandoeningen in de bevolking en in de huisartspraktijk. Utrecht/Bilthoven: NIVEL/RIVM, 2004.

78. Berenson GS, Srinivasan SR, Bao W, Newman WP, 3rd,Tracy RE, Wattigney WA. Association between multiple cardiovascular risk factors and atherosclerosis in children and young adults. The Bogalusa Heart Study. New Engl J Med 1998;338:1650-6.

79. Holman RL, McGill HC, Strong JP, Geer JC. The natural history of atherosclerosis. The early aortic lesions as seen in New Orleans in the middle of the 20th century. Am J Pathol 1958;34:209-35.

80. Stary HC, Chandler AB, Glagov S, Guyton JR, Insull W, Jr., Rosenfeld ME, et al. A definition of initial, fatty streak, and intermediate lesions of atherosclerosis. A report from the Committee on Vascular Lesions of the Council on Arteriosclerosis, American Heart Association. Circulation 1994;89:2462-78.

81. Strong JP, McGill HC. The natural history of coronary atherosclerosis. Am J Pathol 1962;40:37-49.

82. Tuzcu EM, Kapadia SR, Tutar E, Ziada KM, Hobbs RE, McCarthy PM, et al. High prevalence of coronary atherosclerosis in asymptomatic teenagers and young adults: evidence from intravascular ultrasound. Circulation 2001;103:2705-10.

83. Gunzerath L, Faden V, Zakhari S, Warren K. National Institute on Alcohol Abuse and Alcoholism Report on Moderate Drinking. Alcohol Clin Exp Res 2004;28:829-47.

84. Shaper AG, Wannamethee G, Walker M. Alcohol and mortality in British men: explaining the U-shaped curve. Lancet 1988;2:1267-73.

85. Shaper AG, Wannamethee SG. The J-shaped curve and changes in drinking habit. In: Chadwick DJ, Goode JA, eds. Alcohol and Cardiovascular Diseases. Novartis Foundation Symposium. Chichester, UK: John Wiley \& Sons, 1998:173-88.

86. Fillmore KM, Golding JM, Graves KL, Kniep S, Leino EV, Romelsjö A, et al. Alcohol consumption and mortality. I. Characteristics of drinking groups. Addiction 1998;93:183-203.

87. Vaillant GE. Natural history of male psychological health, XIV: Relationship of mood disorder vulnerability to physical health. Am J Psychiatry 1998;155:184-91.

88. Neff JA, Husaini BA. Life events, drinking patterns and depressive symptomatology; the stress-buffering role of alcohol consumption. J Stud Alcohol 1982;43:301-18.

89. Lipton RI.The effect of moderate alcohol use on the relationship between stress and depression. Am J Public Health 1994;84:1913-7. 



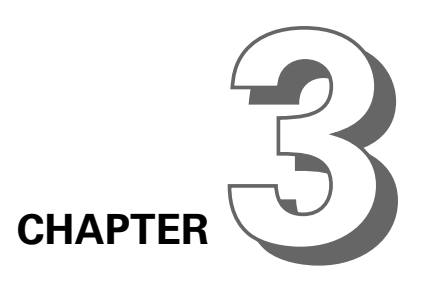

Leefstijl En Gezondheid Onderzoek

(LEGO) 



\title{
3.1 Aims, population, and design
}

\begin{abstract}
Aims
The review showed an abundance of studies on the relationship between alcohol intake and cardiovascular events. The overall outcome of these studies is a lower risk of cardiovascular events for moderate drinkers. A clear explanation for this relationship has not been found as yet. Biologically, alcohol appears to have positive effects on several mechanisms. Nevertheless, other explanations, such as methodological and psychological mechanisms, can not be ruled out.

The aim of the Leefwijze En Gezondheid Onderzoek (LEGO, Lifestyle and Health Study) was to investigate explanations, other than biological, for the observed relationship between alcohol consumption and cardiovascular morbidity and mortality, and between alcohol consumption and allcause mortality. Previous studies almost all measured current alcohol intake at baseline in a mostly adult or elderly population. First explanation to be discussed in this thesis is the effect of alcohol intake measurement. Alcohol intake was divided into current, past and lifetime drinking. Methodological factors could also be an explanation for the observed U-shaped relationship. Therefore, different methods for measuring current alcohol intake were compared, and the impact of model specification on the relationship evaluated. Another explanation could be that pre-existing diseases produce the J- or U-shaped relationship. Alcohol intake would then be more like an intermediate factor between health, and mortality and morbidity. Finally, several psychological and behavioural mechanisms could play a part in the relationship, and thus produce the typical shape. This explanation, especially impact of stress, will be discussed in the thesis of Marja Veenstra.
\end{abstract}

\section{Study population and general practitioners}

The study population consisted of men and women born between 1926 and 1951. Enrolment of the study population was done using registration systems of general practitioners (GPs). As a result of health insurance regulations, nearly all inhabitants of the Netherlands are insured and registered with a GP. Furthermore, the GP has a function as gatekeeper for admissions to hospital or specialist $(1,2)$. In the period $1995-1997,78.1 \%$ of adults aged 45 to 64 years visited their GP in a one-year period with a mean total of 4.0 visits. For people 65 years or older, this was $86.0 \%$ and 6.2 visits (3). An additional advantage of the registration system is the presence of background information as gender, age, and address. Finally, GPs register, in general, all relevant health problems of their patients.

General practitioners were sought through regional health institutes in the province of Limburg and the city of Rotterdam including surrounding area. These regions were chosen for historical reasons, namely men as well as women differ in alcohol abstinence and drinking patterns between these regions (4). GPs could only participate if health problems were or would be registered in a computerized database. This database was necessary to identify participants and extract health problems of patients. In 1994 about 37\% of the Dutch GPs used a computerized medical module, which increased considerably to $80 \%$ in 1997 (5).

Terminally ill patients with life expectancies of less than three months, patients with severe dementia, mentally handicapped persons and institutionalised persons were excluded from the cohort. Persons not having a command of the Dutch language were not directly excluded, but will probably not have been able to fill in the questionnaire. The intention was to also exclude persons with cardiovascular disease and related health problems. However, we did not have the health status for every participant at the start of the study. Therefore, it was decided to correct for it in the analyses. In some analyses, these persons were left out. 


\section{Cohort size}

The cohort size was estimated on the basis of calculations for the minimal number of cases with myocardial infarction. Simulated multivariate power analyses were done, calculating that 300 cases with incident MI would be necessary. Initially a cohort size of $\pm 16,600$ persons was calculated when assuming a response rate of $75 \%$ per year. The incidence of MI used was, however, overestimated. New calculations produced a cohort size of $\pm 25,000$ persons. As an average general practice in the Netherlands includes 2,350 patients of whom 32,9\% in the age of 45-74 ( $\mathrm{n}=773$ patients), 32 practices were needed. Finally, 31,556 persons were selected scattered among 33 practices and one health centre. Three of the 33 practices laid outside the two chosen areas, but were still included.

\section{Study design}

The prospective cohort study started July $1^{\text {st }}, 1996$ with a baseline questionnaire. One year later the baseline questionnaire was sent to all non-contacts to heighten the response. The follow-up period ended on June $30^{\text {th }}, 2001$. A case-cohort approach was applied, involving the selection of a random sample at baseline (6), further referred as subcohort. The sample size was $20 \%$ of all respondents at both baseline measurements, with a proportional equal sample of both baseline responses and stratified to practice. The data of the subcohort and of all incident cases in the total cohort were processed for analyses. Advantages of this approach are the ease of selection of the sample, the possibility of using one single sample for multiple outcomes and substantial reductions in time and costs of data collection and/or analyses with a minimal loss of efficiency compared to a full cohort study (7-9). A disadvantage is the need for a more complex analysis $(6,9)$. Data collection consisted of selfadministered questionnaires and health problems registered by GPs.

\subsection{Questionnaires and response}

\section{Baseline and follow-up questionnaires}

Respondents filled in the baseline questionnaire and a maximum of four follow-up questionnaires. The baseline questionnaire was about twice as long as the follow-up questionnaires. Main issues of the baseline questionnaire were demographic variables (e.g. age, sex, education, job, religion), behavioural factors (e.g. diet, alcohol consumption, smoking habits, physical activity), health and attitude towards health (e.g. subjective health, obesity, vital exhaustion, attitude towards health related aspects of alcohol intake) and social environment (e.g. working status, civil status, social support). The follow-up questionnaires were less extensive and contained two types of issues, namely factors playing a crucial part in the study, like alcohol consumption, and factors with a (potential) high intra-individual variance, for example subjective health and stress. Four follow-up questionnaires, which were not completely identical, were sent with an interval of one year.

\section{Questionnaires: course and response}

The study started by sending all selected individuals $(n=31,556)$ a baseline questionnaire in spring 1996 (figure 1). A total of 207 persons proved to be incorrectly included, leaving a cohort size of 31,349 persons. Individuals who sent back a blank questionnaire or who applied to the GP with a request of removal from the study, where registered as refusals $(18.8 \%)$. The non-respondents of 1996 received the baseline questionnaire again in spring 1997, whereas the respondents received the follow-up questionnaire 1997. Further, all baseline respondents (51.7\%) received in spring 1998, 1999 , and 2000, independently of their response to the preceding follow-up questionnaires. Table 1 


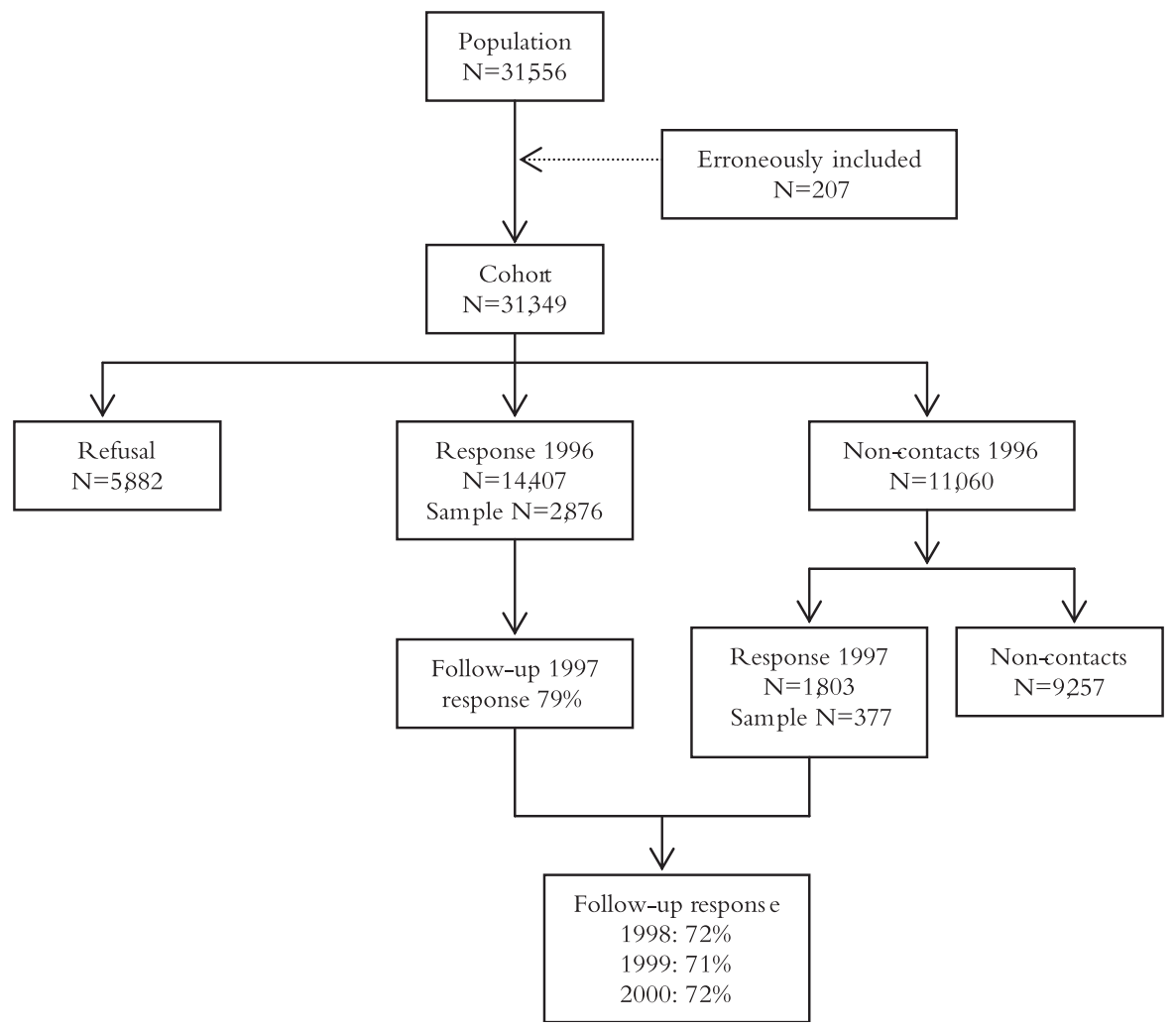

Figure 1. Flow chart of the response

shows the distribution of gender of the response for the total cohort and the subcohort. In chapter 4 the results of the non-response analyses are reported.

\subsection{Alcohol intake measurement}

Alcohol intake was measured in detail in the baseline as well as in the follow-up questionnaires. Three types of self-reports of alcohol intake were used, namely a 7-day recall or Weekly Recall (WR), a Quantity-Frequency questionnaire about alcohol intake in the last year (QF-last-year), and the Lifetime Drinking History questionnaire (LDH-q).

Table 1. Response divided to gender for the total cohort and the subcohort

\begin{tabular}{|c|c|c|c|c|c|c|}
\hline & \multicolumn{3}{|c|}{ Total cohort } & \multicolumn{3}{|c|}{ Subcohort } \\
\hline & Men & Women & Total & Men & Women & Total \\
\hline Baseline 1996 & 7,052 & 7,355 & 14,407 & 1,428 & 1,448 & 2,876 \\
\hline Baseline 1997 & 884 & 919 & 1,803 & 180 & 197 & 377 \\
\hline Non-contacts & 4,907 & 4,350 & 9,257 & & & \\
\hline Refusal & 2,973 & 2,909 & 5,882 & & & \\
\hline Total & 15,816 & 15,533 & 31,349 & 1,608 & 1,645 & 3,253 \\
\hline
\end{tabular}


Alcohol consumption was asked separately for beer, wine, and spirits in both the WR and the QFlast-year. The WR asks for actual drinking per day of the last week, as the QF-last-year is a summary of drinking about last year. The respondent had to generalize his consumption and abstract it into a usual frequency and quantity. The WR and the QF-last-year were entered in the baseline as well as in all follow-up questionnaires.

The LDH-q was developed for use in LEGO (10), because only interview-formats existed for asking for lifetime alcohol intake (11-13), and the LEGO-cohort was too large to interview all individuals. As the LDH-q had never been used before, except for the pilot study, it was administered twice: once in the baseline questionnaire and a shortened version in the follow-up questionnaire 1997. This enabled the examination of the utility of the LDH-q. The LDH-q is composed of five life periods (youth: age 12-18, young adulthood: age 19-27, adulthood: age 28-44, middle age: age 45-60, and elderly: age 61 or older) for which usual frequency and quantity of alcohol intake was asked. Other items were variability of drinking, type of beverage, context of drinking, and attempts to quit. These items were included in the baseline questionnaire, but left out the shortened version of the follow-up questionnaire of 1997.

\subsection{Health problems and endpoints}

\section{Medical databases}

Information on health problems of the cohort members was derived from the computerized registration systems of the GPs. Although all GPs register the same items of their patients, there are different software packages in use. Within LEGO three different packages were used: MicroHis, Elias, and Medicom. Besides changes within the three packages during the follow-up period, some GPs also altered their package. Before each extraction of health problems, a survey was made of the packages and upgrades in use among the GPs, as each package and upgrade required a separate programme for extraction. Cohort members could be identified within the databases by a specific flag. The health problems of patients with that particular flag were extracted.

In LEGO, only coded and non-directly identifiable data were used. All individuals had an unique number composed of the number of the general practice given at the start of the study and the patient number as given by the GP. Communication between the GPs and the research group was done using these unique codes, sometimes completed with gender and date of birth. This design was approved by the review committee of the Registration Network Family Practices of the University of Maastricht.

\section{Health information and refusal or non-contact}

If a GP starts a registration system the patients can declare that he/she does not want his/her data to be used for scientific research. The cohort is thus composed of persons who accepted registration of health problems until the start of the study. Persons who actively refused to participate at either baseline in 1996 or 1997 were defined as refusals. Persons who did not return a baseline questionnaire in 1996 or 1997, but did not actively refuse participation were defined as non-contacts. Refusals of participation were passed on to the GP, who then made a retrospective problem list. The retrospective problem list consisted of nine specified diagnoses (cardiovascular disease (7 diagnoses), diabetes mellitus, and hypercholesterolaemia), which were retrieved for incorporation in the nonresponse analysis. Health problems presented after baseline were not extracted for the refusals. As the GPs only knew who refused participation, non-contacts and respondents were handled the same by the GP and problem lists were extracted for both groups. 


\section{Problem lists}

A medical database consists of a large scale of health problems. As short-term, minor health problems are of less interest in the present study, it was chosen to use only health problems registered in the so-called 'problem list'. A problem list with accurately entered medical problems gives a fast and complete overview of all relevant past and present health problems of a patient. A health problem should be placed on the problem list if it is 'anything that has required, does or may require health care management and has affected or could significantly affect a person's physical or emotional wellbeing' (14). Several types of problems can be distinguished: risk factors, patterns of complaints, abnormal findings, diagnoses, and other problems $(14,15)$. Every health problem was given an ICPC-code (International Classification of Primary Care (16)), which enables categorization of health problems.

The following data were extracted from the problem list for each participant:

- problem number (normally in order of time of diagnosis);

- ICPC-code;

- description of the health problem;

- starting and, when applicable, final date of the health problem;

- active or blind problem (still of interest or a problem of the past);

- data stop of the problem list with the reason (deceased, moved, switched to an other GP, etc).

\section{Quality of problem lists}

Quality of the problem lists has been surveyed in several ways. First, the problem lists have been extracted several times with a maximum of six times. Only the last extraction was used for analyses. The other extractions were done for insight in the number of patients with a problem list as well as the mean number of problems per patient. Furthermore, the succession of extractions gave insight in the improvement of input of the problem lists, which was used as feedback to the GPs.

Basically, all relevant problems during the whole life of a patient had to be entered on the problem list. GPs, however, started recording health problems systematically on the so called "green card" since the sixties, where as the cohort members are born between 1926 and 1951. If relevant health problems were missing on the problem list, in most cases it will have been health problems diagnosed during youth or young adulthood.

Inspection of the last extraction revealed that irrelevant items were entered on the problem lists. These items, such as flu vaccination and blood type, were separated from the relevant health problems. In addition, about $10 \%$ of the health problems did not have an ICPC-code. Both adjustments were done by the research group.

A quality check was done for some specific diagnoses, i.e. coronary heart disease (ICPC-codes K74, K75 and K76), heart failure (K77), hypertension (K86 and K87), transient ischemic attack and cerebrovascular accident (K89 and K90), and diabetes mellitus (T90). The prevalences of these diagnoses were calculated per practice and compared to the prevalence reported in the Registration Network of Family Practices (Registratienet Huisartspraktijken, RNH). The RNH was established in 1988, and is an initiative of the department of General Practice of the University Maastricht (2). The RNH consists of 56 GPs in 23 practices who register the health problems of their patients. Staff members from the university monitor the quality and give feedback to the GPs. The RNH, therefore, seems an appropriate database for comparison. If a prevalence in a LEGO practice was more than one standard deviation below the mean prevalence of the RNH, a quality control was done. This control consisted of a procedure in which specific medicine use, on the basis of the ATC-code (Anatomical Therapeutic Chemical-code, (17)), was applied to identify patients with the disease, but without the concerning ICPC-code. 
Table 2. Number of individuals registered in the excluded practice

\begin{tabular}{|c|c|c|c|c|c|c|}
\hline & \multicolumn{3}{|c|}{ Total cohort } & \multicolumn{3}{|c|}{ Subcohort } \\
\hline & Men & Women & Total & Men & Women & Total \\
\hline Baseline 1996 & 110 & 134 & 244 & 27 & 26 & 53 \\
\hline Baseline 1997 & 27 & 36 & 63 & 55 & 10 & \\
\hline Non-contacts & 187 & 174 & 361 & & & \\
\hline Refusal & 25 & 27 & 52 & & & \\
\hline Total & 349 & 371 & 720 & 32 & 31 & 63 \\
\hline
\end{tabular}

\section{Problem lists: course}

In 1996, all GPs were enabled to follow a course about the making of problem lists in an attempt to align the way it is done. Floppy disks for extraction of problem lists were sent in winter 1997-1998, last trimester 1998, spring 2000, spring 2001, autumn 2001, and finally the definitive extraction was done in 2002 or 2003, depending on the last necessary input of problem lists and the quality control. One GP failed to report the health status of his patients. So, these individuals had to be excluded. Table 2 presents the involved numbers. Table 3 shows the number of problem lists available after exclusion of the individuals of the excluded practice.

\section{Reports}

The GPs were asked to report all incident cases of non-fatal myocardial infarctions (MI) and all deaths occurring between July $1^{\text {st }}, 1996$, and July $1^{\text {st }}, 2001$, as soon as possible after presentation. The report consisted of a form which was send by fax to the research group. Most GPs also phoned as double-check. Reports of incident cases of sudden imminent MI were later added, as the number of persons developing a non-fatal MI was lower than expected. This was partly caused by an increase of preventive operations in cases with imminent MI. Therefore, patients with imminent MI who underwent surgery in four weeks after first presentation of the symptoms to the GP, were also included. For both sudden imminent and non-fatal myocardial infarction the GP had to report whether it was the first presentation or a recurrent event. Reports of deaths were categorized into nine clusters: fatal myocardial infarction, other cardiac disease, CVA, vascular (non-cardiac and noncerebral) disease, cancer, infections or autoimmune disease, violence or accidents, suicide, and unknown or other causes.

\section{Verification and quality of reports}

Verification of the reports was done in two ways. First, the reports were compared to the problem lists. In case of discrepancy the GP was contacted for clarification of the ambiguity. A second verification was performed for the cases with a first myocardial infarction who agreed to be interviewed. Their medical records were searched for diagnostic ECGs and lab results at the time of the

Table 3. Number of problem lists by response ${ }^{\star}$

\begin{tabular}{lccc}
\hline & Problem list & No problem list & Total \\
\hline Respondents & $13,856(87.1 \%)$ & $2,047(12.9 \%)$ & 15,903 \\
subcohort & $3,125(96.1 \%)$ & $128(3.9 \%)$ & 3,253 \\
Non-contacts & $6,518(73.3 \%)$ & $2,378(26.7 \%)$ & 8,896 \\
Total & $20,374(82.2 \%)$ & $4,425(17.8 \%)$ & $\mathbf{2 4 , 7 9 9}$ \\
\hline
\end{tabular}

* excluding refusals and individuals of the excluded practice 
event, all done with informed consent of the patient. A cardiologist evaluated these data. Medical records of those 81 patients were evaluated of which 79 (97.5\%) had had definite myocardial infarction and 2 patients had had a possible myocardial infarction. Finally, the total number of myocardial infarctions in the cohort were compared to the nationwide admissions into hospitals (18), which did not reveal large differences in incidence.

\subsection{Loss to follow-up}

Loss to follow-up arose if a participant left a participating practice and his new GP was not one of the participating GPs. These moves were not kept up to date systematically. Every year, the addresses of all respondents were verified, in order to prevent sending the annual follow-up questionnaire to addresses of persons who had died, or had moved. Secondly, problem lists are stored in the archive of the database, mentioning the reason, for example death or move, and mostly date of filing. Finally, in the last years of the study GPs were asked to report moves of patients. However, not all GPs reported accurately. If someone had moved, the follow-up period was stopped on the date given by the GP. If this date was not available, the filing date of the medical record was used, and in case this was also missing date of most recent health problem was used.

\section{References}

1. Van der Linden MW, Westert GP, De Bakker DH, Schellevis FG. Tweede Nationale Studie naar ziekten en verrichtingen in de huisartspraktijk. Klachten en aandoeningen in de bevolking en in de huisartspraktijk. Utrecht/Bilthoven: NIVEL/RIVM, 2004.

2. Metsemakers JF, Hoppener P, Knottnerus JA, Kocken RJ, Limonard CB. Computerized health information in The Netherlands: a registration network of family practices. Br J Gen Pract 1992;42:102-6.

3. Statistisch Jaarboek 1999.Voorburg/Heerlen: Centraal Bureau voor de Statistiek, 1999.

4. Garretsen HFL, Knibbe RA. Alkohol prevalentie onderzoek Rotterdam/Limburg. Landelijk eindrapport. Rotterdam/Maastricht: Ministerie van Welzijn,Volksgezondheid en Cultuur, 1983.

5. Van Althuis T. Nut 3 rapport. Verslag van enquête onder huisartsen naar praktijkautomatisering. Utrecht: NHG, 1999.

6. Prentice RL. A case-cohort design for epidemiologic cohort studies and disease prevention trials. Biometrika 1986;73:1-11.

7. ErnsterVL. Nested case-control studies. Prev Med 1994;23:587-90.

8. Wacholder S, Silverman DT, McLaughlin JK, Mandel JS. Selection of controls in case-control studies. III. Design options. Am J Epidemiol 1992;135:1042-50.

9. Langholz B, Thomas DC. Nested case-control and case-cohort methods of sampling from a cohort: a critical comparison. Am J Epidemiol 1990;131:169-76.

10. Lemmens PH, Volovics L, Haan Yd. Measurement of lifetime exposure to alcohol: data quality of a self-administered questionnaire and impact on risk assessment. Contemp Drug Probl 1997;24:581600 .

11. Skinner HA. Development and validation of a lifetime alcohol consumption assessment procedure. Toronto, 1982.

12. Chaikelson JS, Arbuckle TY, Lapidus S, Gold DP. Measurement of lifetime alcohol consumption. J Stud Alcohol 1994;55:133-40.

13. Russell M, Marshall JR, Trevisan M, Freudenheim JL, Chan AW, Markovic N, et al. Test-retest reliability of the cognitive lifetime drinking history. Am J Epidemiol 1997;146:975-81.

14. Sandlow LJ, Bashook PG. Problem oriented medical records. Self instruction for practitioners. Chicago: Michael Reese Hospital and Medical Center, 1978. 
15. Metsemakers JFM. Unlocking patients' records in general practices for research, medical education and quality assurance: the Registration Network Family Practices. Department of General Practice. Maastricht: Universiteit Maastricht, 1994.

16. Lamberts H, Wood M. ICPC : International Classification of Primary Care. In: Party IW, ed. Oxford: Oxford University Press, 1987:201.

17. WHO Collaborating Centre for drug Statistics Methodology. About the ATC/DDD system. http://www. whocc.no/atcddd/ (2002).

18. Landelijk aantal opnamen, kliniek en dagverpleging, verpleegdagen en gemiddelde verpleegduur per diagnose onderverdeeld naar leeftijd en geslacht. Prismant: http://www.prismant.nl (2004). 


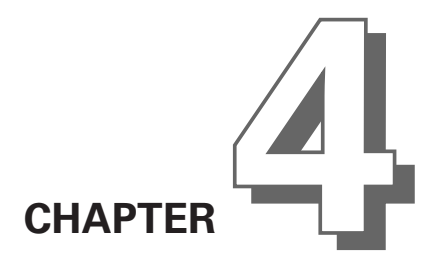

\section{Lower prevalence of heart disease, but higher mortality risk during follow-up among non-respondents to a cohort study}




\begin{abstract}
Primary aim of this study was to assess the association between response behaviour and health status at baseline, and survival in a 5 years follow-up period. A secondary aim was to assess whether reasons for non-response were associated with health status at baseline. Data come from a prospective cohort study, consisting of 31,349 men and women aged 45-70 years. Objective retrospective and prospective health information, derived from general practitioner registries, was available in this study for both respondents and non-respondents. Results show that among respondents coronary heart disease was more prevalent. Compared with respondents, non-contacts had a higher mortality risk during follow-up. Refusals had more often hypercholesterolaemia, and less often coronary heart disease, or diabetes mellitus, compared to non-contacts. The paradoxical results that respondents are less healthy at baseline, but prospectively have a lower mortality risk may point at a selection effect indicating that the 'worried ill' are more inclined to participate. This effect could imply that observed relationships between risk factors or behaviours and outcomes in cohort studies may be attenuated.
\end{abstract}




\section{Introduction}

A decreasing trend in response rates in epidemiological studies and health surveys in the Netherlands is observed. Response rates as low as $30 \%$ and $50 \%$ are not uncommon $(1,2)$. If non-response is random, threat to the generalizability of the results of the study is limited $(1,3)$. However, if nonresponse is not random, it may lead to bias in study outcomes $(1,4)$. The likelihood of non-response bias increases when non-respondents differ from respondents on the exposure or target variable of the study (4). One approach to deal with non-response bias is to increase the response rates. However this is not a general rule, as was shown in a methodological paper by Stang and Jockel (5), who showed that under certain conditions studies with low response rates may be less biased than studies with high response rates. In addition, Austin et al. (6) demonstrated in their paper that the odds ratio was not biased when subjects participation was related only to either the exposure or to the outcome of the study. To determine whether non-response is random it is necessary to compare respondents with non-respondents on both exposure and outcome (4). Information is often limited to a few background characteristics available from population registries, which often serve as a sampling frame (7).

Previous studies found differences between respondents and non-respondents concerning background and/or demographic characteristics $(1,8-14)$, for example non-response was higher among men (8,9-10), and the less educated (1,10-13).

If non-respondents differ from respondents on the target variable the likelihood of non-response bias will increase. Information regarding the target variable in health surveys is often not available for non-respondents. Respondents have been found to be healthier than the general population, referred to as a "healthy volunteer effect" (4). A similar effect was found by Paganini-Hill et al. (15) who found that users of medical services and health screening procedures tended to be early respondents to a health survey. These early respondents were typified as "worried well", a term originally introduced by Criqui et al (16), people who are healthy, yet worry more about their health, and for that reason visit their physician more regularly, receive more disease detection screening, and follow healthy lifestyle practices more often (15).

This healthy volunteer effect has been found in several studies. Respondents were found to have a better general health $(13,17)$, non-respondents were found to have more often hypertension $(10,13$, $18)$, a history of diabetes $(13,16)$, a history of hospitalisation for heart failure (16), myocardial infarction 913,19), stroke $(13,17,18)$ and macrovascular disease (11). Exceptions are lipid disorders $(13,16)$ and a family history of cardiovascular problems $(14,16)$, which seem to be more prevalent among respondents.

Few studies have looked into response behaviour and survival rates. Mortality rates were found to be higher in non-respondents, which indicates again that non-respondents are less healthy than respondents $(9,19-24)$.

Reasons for participation and non-participation may be related to the topic or design of the study. For example, if the topic of a survey is important to a person (saliency), response was found to be higher (25). The phenomenon of the 'worried well' is an example of the effect of saliency. Others, however, may refuse cooperation because of privacy reasons, or because of the perceived burden. Apart from a distinction between participants and active refusals, research has also documented differences in health related variables between categories of non-response, such as refusals or untraceable subjects. Etter et al. (26) found that persons who explicitly refused to participate had higher health care expenditures compared with persons who moved or failed to return the questionnaire. Pope et al. (27) found that "refusers" consulted their general practitioner more often than "ghosts" (incorrect addresses, moved, and so on.) 
Contrary to most studies, in this study objective retrospective and prospective health information was available for both respondents and non-respondents. Primary aim of this study was to assess the association between response behaviour and health status at baseline, and survival in a 5 years follow-up period. A secondary aim was to assess whether reasons for non-response were associated with health status at baseline. Data come from the Lifestyle and Health Study (Leefwijze en Gezondheid Onderzoek, LEGO), a prospective cohort study on cardiovascular disease in the general Dutch population of men and women, aged 45 to 70 years. Main research questions are: 1) Do respondents and non-respondents differ regarding cardiovascular health problems and risk factors at the start of this cohort study? 2) Among non-respondents, do refusals and non-contacts differ regarding cardiovascular health problems and risk factors at the start of this cohort study? 3) Is the allcause mortality rate higher in non-contacts compared with respondents?

\section{Materials and methods}

\section{Design and population}

The LEGO-study started in 1996 with a baseline questionnaire. The target population consists of men and women aged 45 to 70 from the Dutch general population. The registries of general practitioners (GPs) were used as the sampling frame. Coverage of the target population is high since, the GP is considered to be the gatekeeper in the Dutch health care system. Nearly all patients are registered with a GP (28). Over $80 \%$ of the general population has visited their GP at least once a year (29). GPs have detailed information regarding health status of their patients (28).

The sample consisted of 34 participating general practices in the western and south-eastern part of the Netherlands. The western part of the Netherlands is more urbanized compared with the southeastern part. For practical reasons, choice of practice was restricted to these two parts. GPs were sought through regional health institutes, until a sufficient sample size of about 32,000 subjects was reached. GPs excluded terminal patients, patients with severe dementia, mentally disabled patients and institutionalised patients. All other patients aged 45 to 70 registered with the participating GPs were included in the LEGO-study, and received a baseline questionnaire. In 1996, the baseline questionnaire was send to 31,556 subjects. The questionnaire contained questions about health, lifestyle, for example alcohol consumption, life-events, coping styles, mood, and so on. Some subjects ( $\mathrm{n}=$ 207) were excluded by the GP, but received mistakenly a baseline questionnaire and were excluded afterwards, which leaves a cohort of 31,349 subjects. Persons who refused to participate at baseline could indicate this by returning an empty questionnaire to the researchers, and were excluded for follow-up. To all respondents of baseline 1996, a follow-up questionnaire was send a year later. A second baseline questionnaire was sent to the non-respondents of baseline 1996 excluding the persons who refused participation at baseline 1996 in the same period in 1997 as the follow-up questionnaire was send to the respondents. The number of persons responding to baseline 1997 was to small to create separate response groups, for example early, and late respondents.

In this study respondents are defined as persons who responded to either the baseline questionnaire in 1996 or in 1997. Non-respondents consisted of refusals and non-contacts. Refusals are defined as persons who actively refused to participate at either the baseline in 1996 or in 1997. Non-contacts are defined as persons who did not return a baseline questionnaire in 1996 or in 1997, and who did not actively refuse cooperation.

The study design using only coded and non-directly identifiable data was approved by the review committee of the Registration Network Family Practice of the University of Maastricht. The initial cohort consisted of patients not objecting to the use of medical information. Before the GPs 
started their data collection, they informed their patients about the participation of the practice in scientific medical research. Patients could personally object to such participation. According to the GPs no patient initially objected to such participation. Information on the patients not objecting to the use of medical information is used up to the start of this particular study. Each subject had the costless opportunity to object to this particular study. Of these refusals, no further prospective medical information was obtained. Of the respondents and non-contacts, prospective information on mortality was used. This is in accordance with the current Code for Adequate Secondary Use of Data in the Netherlands (Gedragscode Gezondheidsonderzoek, 2004) (30).

\section{Data}

Medical information of patients was obtained through their GP who file all relevant health problems of the past and during the follow-up period on a so called problem list, which is an essential part of the medical record. A relevant health problem is defined as "anything that has, does, or may require health care management, and has or could significantly affect a person's physical or emotional well being" (31). Health problems were categorized according to ICPC-codes (International Classification of Primary Care) (32). GPs received a file which contained information about the study, and instructions about the registration of the cardiovascular health problems and risk factors. Besides this file, all GPs also received a training aiming to improve consensus regarding the registration of the diagnoses according to the ICPC.

Because one GP failed to report the health status of his patients, 307 respondents, 52 refusals, and 361 non-contacts had to be excluded, leaving 30,629 subjects for the analysis regarding background variables.

Cardiovascular health problems and risk factors are of specific interest in the LEGO-study. For $12.9 \%(\mathrm{n}=2,047)$ of respondents and $26.7 \%(\mathrm{n}=2,378)$ of non-contacts no complete problem list was available, they were excluded from the analyses. No problem list was available for the refusals. To compare the different response groups, GPs were asked to write down on a list, for refusals, whether one of the cardiovascular health problems or risk factors was present before July 1996. No list was available for $1.4 \%(\mathrm{n}=79)$ of refusals, they were also excluded. Leaving a total of effectively 26,125 subjects for the analysis regarding cardiovascular health problems and risk factors.

The following cardiovascular health problems were extracted from the problem list of respondents and non-contacts, and from the list of refusals: coronary heart disease(CHD) (angina pectoris, acute myocardial infarction, or chronic ischemic heart disease); heart failure; non-fatal stroke; and other arterial obstructive / peripheral vascular disease. The following risk factors were extracted: hypertension with involvement of target organs; diabetes mellitus; and hypercholesterolaemia. A quality check of the data from the GPs was performed. Frequencies of myocardial infarction in this study were found to be comparable to those of nationwide admissions into hospitals (33). Prevalence and incidence of cardiovascular health problems and risk factors in this study were comparable to the number of cardiovascular health problems and risk factors in an established registration network, the Registration Network of Family Practices (28). Data on the problem list were checked by the researchers, and, if necessary corrected in accordance with the ICPC.

A GP had to report to the researchers when one of the patients of the cohort died during the follow-up period (1996-2001). Because of privacy reasons, a GP was not informed of the status of a patient as a respondent or non-contact. Survival status is known for respondents and non-contacts, but not for refusals. Death rates in this study were found to be somewhat lower compared with death rates in the total Dutch population. The distribution over the different causes of death was comparable, between this study and the total Dutch population, although a small overrepresentation of cardiovascular deaths was found in this study (34). 
For all GPs and most subjects, a zip code of either neighbourhood or district was available. This provided a link to demographic and social economic characteristics of neighbourhood or district collected by Statistics Netherlands which are included in the analyses: degree of urbanization, ethnic diversity (percentage of non-western), percentage of persons living alone, and mean income per resident (35). Correlation between characteristics of neighbourhood and district was high, between 0.65 and 0.90 (from now on if neighbourhood, read neighbourhood or district). When for a subject no zip code was available, the zip code of the practice of the GP was used to link the information to the patient.

\section{Data analysis}

First, a comparison between respondents and non-respondents is made in the way most studies classify non-respondents. Second, a comparison between refusals and non-contacts is made, providing insight into the effect of different reasons of non-response in this study. A third comparison between respondents and non-contacts, yields information on mortality during follow-up.

Respondents and non-respondents, refusals and non-contacts, and respondents and non-contacts are compared bivariately on age, gender, cardiovascular health and risk factors, and demographic variables. Statistical significance is assessed by chi-square tests for categorical variables and t-tests for continuous variables. Next, probability of response is modelled by age, gender, demographic variables, and cardiovascular health and risk factors. Among non-respondents, probability of refusal is modelled by age, gender, demographic variables, and cardiovascular health and risk factors. Multiple logistic regression analyses are conducted to model response probability, taking all independent variables simultaneously into account. First, interaction of gender with cardiovascular health and risk factors were tested. The alpha level was set at 0.05 , the least significant interaction was manually excluded from the model (i.e. the backward method). Second, when all not significant interaction effects were excluded from the model, the least significant variable was manually excluded from the model until a model with statistical significant variables remains. After that, respondents and noncontacts are compared bivariately on number of deaths. Finally, probability of death is modelled by response behaviour, age, gender, and cardiovascular health problems and risk factors. Subjects who moved during the follow-up period were excluded from the last two analyses, because no information was available regarding death. Because no information was available regarding death rates for refusals, respondents could not be compared with non-respondents for mortality.

Since sampling followed a two-stage procedure, subjects are considered 'nested' in 33 general practices. To take this group structure into account, an analysis of covariance approach was used to correct for potential bias due to correlated data, with patients registered with one of the 33 participating GPs entered as 32 dummy variables in the logistic analysis. Essentially, this procedure is similar to a random coefficient approach (see Snijders \& Bosker, 1999) (36). The study did not have a priori hypotheses concerning the impact of general practice characteristics on the response variable. The dummy variable for the GPs is entered only to secure a correct estimation of our principal parameters and its effect is not interpreted substantively (36).

\section{Results}

Gross response rate was $51.7 \%(\mathrm{n}=16,210), 18.8 \%(\mathrm{n}=5,882)$ actively refused, and $29.5 \%(\mathrm{n}=$ $9,257)$ did not respond. The numbers in the following tables of subject characteristics and demographic variables are based on 30,629 cohort members from the 33 remaining GPs. Cardiovascular health and risk factors are based on 26,125 cohort members of which health information is avail- 
Table 1. Comparison of respondents and non-respondents, refusals and non-contacts, and respondents and noncontacts by subject characteristics, demographic characteristics, and history of cardiovascular health problems and risk factors

\begin{tabular}{|c|c|c|c|c|c|}
\hline \multirow{2}{*}{ Variables } & & \multirow[b]{2}{*}{$\begin{array}{l}\text { Respondents } \\
(51.9 \%)\end{array}$} & \multirow[b]{2}{*}{$\begin{array}{c}\text { Non-respondents } \\
(48.1 \%)\end{array}$} & \multicolumn{2}{|c|}{ Non-respondents } \\
\hline & & & & $\begin{array}{c}\text { Refusals } \\
(39.6 \%)\end{array}$ & $\begin{array}{c}\text { Non-contacts } \\
(60.4 \%)\end{array}$ \\
\hline \multicolumn{6}{|l|}{ Subject characteristics $(N=30,629)$} \\
\hline \multicolumn{6}{|l|}{ Gender } \\
\hline Men & 15,467 & $49.0^{\mathrm{a}}$, & 52.1 & $50.6^{\mathrm{b}, \star \star}$ & $53.1^{\mathrm{c}, \star \star}$ \\
\hline Women & 15,162 & 51.0 & 47.9 & 49.4 & 46.9 \\
\hline \multicolumn{6}{|l|}{ Age, years } \\
\hline $44-49$ & 8,692 & $28.4^{\mathrm{a}, \star}$ & 28.4 & $23.4^{\mathrm{b}, \star \star}$ & $31.7^{c, \star \star}$ \\
\hline $50-54$ & 6,652 & 20.8 & 22.8 & 20.2 & 24.4 \\
\hline $55-59$ & 5,639 & 18.4 & 18.5 & 19.0 & 18.1 \\
\hline $60-64$ & 4,697 & 15.6 & 15.0 & 17.6 & 13.3 \\
\hline $65-73$ & 4,943 & 16.9 & 15.4 & 19.7 & 12.5 \\
\hline \multicolumn{6}{|c|}{ Demographic characteristics $(N=30,629)$} \\
\hline \multicolumn{6}{|l|}{ Degree of urbanization } \\
\hline very high & 4,500 & $13.9^{\mathrm{a}, \star}$ & 15.6 & $11.0^{\mathrm{b}, \star \star}$ & $18.6^{\mathrm{c}, \star \star}$ \\
\hline high & 4,329 & 15.1 & 13.1 & 14.6 & 12.1 \\
\hline intermediate & 7,951 & 26.0 & 25.9 & 28.3 & 24.3 \\
\hline low & 8,262 & 26.7 & 27.3 & 29.1 & 26.1 \\
\hline very low & 5,587 & 18.4 & 18.1 & 16.9 & 18.9 \\
\hline $\begin{array}{l}\text { Non-Western } \\
\text { ethnicity, \% (SD) }\end{array}$ & & $7.53(8.6)^{\mathrm{a}, \star}$ & $7.94(9.9)$ & $7.21(8.3)^{\mathrm{b}, \star \star}$ & $8.42(10.9)^{\mathrm{c}, \star \star}$ \\
\hline Living alone, \% (SD) & & $19.17(8.2)^{\mathrm{a},{ }^{\star}}$ & $19.62(8.4)$ & $19.60(7.2)^{\mathrm{b}, \star \star}$ & $19.64(9.2)^{\mathrm{c}, \star \star}$ \\
\hline Mean income, euros (SD) & & $14,980(1208)^{\mathrm{a}, \star}$ & $14,915(1144)$ & $15,004(1055)^{\mathrm{b}, \star \star}$ & $14,857(1,195)^{\mathrm{c}, \star \star}$ \\
\hline \multicolumn{6}{|c|}{ Positive history of cardiovascular health problems and risk factors $(N=26,125)^{d}$} \\
\hline Coronary heart disease & 1,824 & $7.5^{\mathrm{a}, \star}$ & 6.4 & 6.4 & $6.3^{\mathrm{c}, \star \star}$ \\
\hline Heart failure & 136 & 0.5 & 0.5 & 0.6 & 0.5 \\
\hline $\begin{array}{l}\text { Hypertension with } \\
\text { involvement } \\
\text { of target organs }\end{array}$ & 928 & 3.5 & 3.5 & $4.1^{\mathrm{b}, \star \star}$ & 3.1 \\
\hline Non-fatal stroke & 480 & 1.7 & 1.9 & 2.1 & 1.8 \\
\hline $\begin{array}{l}\text { Other arterial obstructive or } \\
\text { peripheral vascular disease }\end{array}$ & 381 & 1.4 & 1.5 & 1.6 & 1.5 \\
\hline Diabetes mellitus & 1,091 & 4.0 & 4.3 & 4.0 & 4.6 \\
\hline Hypercholesterolaemia & 1,635 & $6.6^{\mathrm{a}, \star}$ & 5.9 & $7.2^{\mathrm{b}, \star \star}$ & $4.7^{\mathrm{c}, \star \star}$ \\
\hline
\end{tabular}

Abbreviation: $\mathrm{SD}$, standard deviation. ${ }^{\star} \mathrm{P}<0.05 ;{ }^{\star \star} \mathrm{P}<0.01$.

a Significant differences between respondents and non-respondents. ${ }^{b}$ Significant differences between refusals and non-contacts. ${ }^{c}$ Significant differences between respondents and non-contacts. ${ }^{\mathrm{d}}$ Sample excludes 4,504 patients for whom no problem list was available: 2,074 respondents, 2,378 non-contacts, and 79 refusals.

able. Mortality rates are based on 22,362 cohort members, including respondents and non-contacts, and excluding persons who moved during follow-up.

\section{Respondents versus non-respondents}

Bivariate analyses in table 1 shows that respondents had a higher percentage of CHD, and a higher percentage of hypercholesterolaemia. From the subjects with hypercholesterolaemia $24.3 \%$ had also CHD (data not shown). The multiple logistic regression analysis in table 2 presents that there was an 
interaction between CHD and gender (OR $=1.35,95 \%$ CI: 1.08-1.68) and between heart failure and gender $(\mathrm{OR}=0.32,95 \% \mathrm{CI}: 0.16-0.66)$. Analyses were performed separately for male and female (data not shown). The separate analyses showed that male respondents were more likely to have $\mathrm{CHD}(\mathrm{OR}=1.36,95 \% \mathrm{CI}: 1.21-1.53)$ and were less likely to have heart failure $(\mathrm{OR}=0.53,95 \%$ CI: $0.33-0.84)$. Where female respondents were more likely to have heart failure $(\mathrm{OR}=1.62,95 \%$ CI: $0.94-2.80)$, but this was not to be found statistically significant. Hypercholesterolaemia was no

Table 2. Adjusted odds ratios and 95\% confidence intervals from multiple logistic regression for subject characteristics, demographic variables, and history of cardiovascular health problems and risk factors

\begin{tabular}{|c|c|c|c|}
\hline & \multicolumn{3}{|c|}{ Adjusted OR (95\% CI) } \\
\hline & $\begin{array}{l}\text { Respondents vs. } \\
\text { non-respondents }^{\mathrm{a}}\end{array}$ & $\begin{array}{l}\text { Refusals vs. } \\
\text { non-contacts }\end{array}$ & $\begin{array}{l}\text { Respondents vs. } \\
\text { non-contacts }^{c}\end{array}$ \\
\hline Male gender & $0.89(0.84-0.94)$ & - & $0.89(0.83-0.94)$ \\
\hline \multicolumn{4}{|l|}{ Age, years } \\
\hline $44-49$ & $1.02(0.94-1.10)$ & $0.59(0.52-0.66)$ & $0.75(0.68-0.83)$ \\
\hline $50-54$ & $0.90(0.83-0.97)$ & $0.63(0.56-0.71)$ & $0.69(0.62-0.76)$ \\
\hline $55-59$ & $0.98(0.90-1.06)$ & $0.78(0.69-0.89)$ & $0.84(0.75-0.93)$ \\
\hline $60-64$ & $0.97(0.89-1.06)$ & $0.91(0.79-1.03)$ & $0.91(0.81-1.01)$ \\
\hline $65-73^{\mathrm{d}}$ & 1.00 & 1.00 & 1.00 \\
\hline \multicolumn{4}{|l|}{ Degree of urbanization } \\
\hline Very high & $1.44(1.12-1.85)$ & $0.09(0.04-0.19)$ & - \\
\hline High & $0.65(0.53-0.79)$ & $2.30(1.54-3.44)$ & - \\
\hline Intermediate & $0.58(0.48-0.71)$ & $6.46(4.36-9.58)$ & - \\
\hline Low & $0.74(0.65-0.85)$ & $3.54(2.71-4.63)$ & - \\
\hline Very low ${ }^{\mathrm{d}}$ & 1.00 & 1.00 & - \\
\hline Percentage non-Western & - & $0.97(0.96-0.98)$ & - \\
\hline Percentage persons living alone & - & $1.02(1.01-1.04)$ & - \\
\hline \multicolumn{4}{|c|}{ Positive history of cardiovascular health problems and risk factors } \\
\hline Coronary heart disease & $1.01(0.84-1.22)$ & $0.85(0.72-0.99)$ & $1.15(1.01-1.31)$ \\
\hline Heart failure & $1.60(0.93-2.77)$ & - & $2.13(0.94-4.84)$ \\
\hline $\begin{array}{l}\text { Hypertension with involvement of } \\
\text { target organs---Non-fatal stroke }\end{array}$ & - & - & - \\
\hline $\begin{array}{l}\text { Other arterial obstructive or peripheral } \\
\text { vascular disease }\end{array}$ & - & - & - \\
\hline Diabetes mellitus & - & $0.77(0.64-0.93)$ & $0.81(0.70-0.94)$ \\
\hline Hypercholesterolaemia & - & $1.40(1.19-1.66)$ & $1.33(1.16-1.53)$ \\
\hline \multicolumn{4}{|l|}{ Interaction with gender } \\
\hline Coronary heart disease X Gender & $1.35(1.08-1.68)$ & - & - \\
\hline Heart failure X Gender & $0.32(0.16-0.66)$ & - & $0.23(0.09-0.62)$ \\
\hline
\end{tabular}

Abbreviations: $\mathrm{CI}$, confidence interval; $\mathrm{OR}$, odds ratio

${ }^{a}$ Adjusted for general practice, gender, age, history of coronary heart disease, history of heart failure, degree of urbanization, interaction between history of coronary heart disease and gender, and interaction between history of heart failure and gender. Odds of responding was modeled.

${ }^{b}$ Adjusted for general practice, age, history of coronary heart disease, history of diabetes mellitus, history of hypercholesterolaemia, degree of urbanization, and persons living alone. Odds of refusal was modeled

${ }^{c}$ Adjusted for general practice, gender, age, history of coronary heart disease, history of heart failure, history of diabetes mellitus, history of hypercholesterolaemia, and interaction between history of heart failure and gender. Odds of responding was modeled

${ }^{d}$ Reference category 
longer a predictor of response in the multivariate analysis. Non-respondents were more likely to be male, and more likely to live in urban neighbourhoods (table 1). The multivariate analysis in table 2 shows also that non-respondents were more likely to be male (OR $=0.89,95 \% \mathrm{CI}$ : $0.84-0.94)$.

\section{Refusals versus non-contacts}

Among refusals and non-contacts, refusals had a higher percentage of hypercholesterolaemia, and of hypertension with involvement of target organs (table 1). The multivariate analysis, among non-respondents illustrates that, compared with non-contacts, refusals were more likely to have hypercholesterolaemia $(\mathrm{OR}=1.40,95 \% \mathrm{CI}: 1.19-1.66)$, and were less likely to have $\mathrm{CHD}(\mathrm{OR}=0.85,95 \%$ CI: 0.72-0.99) and diabetes mellitus (OR $=0.77,95 \%$ CI: 0.64-0.93) (table 2). No interaction effect was found for gender. Refusals were found to be older, and non-contacts were more likely to live in urban neighbourhoods or districts (table 1).

Table 3. Deaths by gender and age group in respondents and non-contacts at 5 year follow-up

\begin{tabular}{|c|c|c|c|c|}
\hline & \multicolumn{4}{|c|}{ Deaths, no. (\%) } \\
\hline & $\begin{array}{l}\text { Respondents } \\
(\mathrm{n}=14,467)\end{array}$ & $\begin{array}{l}\text { Non-contacts } \\
(\mathrm{n}=7,895)\end{array}$ & $\begin{array}{c}\text { Combined } \\
(\mathrm{n}=22,362)\end{array}$ & $\begin{array}{c}\text { Total in } \\
\text { sample, no. }\end{array}$ \\
\hline \multicolumn{5}{|l|}{ Men } \\
\hline $44-49$ & $25(1.2)$ & $23(1.8)$ & $48(1.4)$ & 3,337 \\
\hline $50-54$ & $38(2.5)$ & $34(3.3)$ & $72(2.8)$ & 2,538 \\
\hline $55-59$ & $54(4.1)$ & $30(3.7)$ & $84(4.0)$ & 2,118 \\
\hline $60-64$ & $72(6.6)$ & 41 (7.6) & $113(6.9)$ & 1,635 \\
\hline $65-73$ & $144(12.5)$ & $75(15.2)$ & $219(13.3)$ & 1,642 \\
\hline Total & $333(4.7)$ & $203(4.9)$ & $536(4.8)$ & 11,270 \\
\hline \multicolumn{5}{|l|}{ Women } \\
\hline $44-49$ & $27(1.3)$ & $15(1.3)$ & $42(1.3)$ & 3,203 \\
\hline $50-54$ & $31(2.0)$ & $17(1.9)$ & $48(2.0)$ & 2,431 \\
\hline $55-59$ & $24(1.8)$ & $21(3.3)$ & $45(2.3)$ & 1,982 \\
\hline $60-64$ & $50(4.2)$ & $20(3.9)$ & $70(4.1)$ & 1,693 \\
\hline $65-73$ & $80(6.3)$ & $43(8.5)$ & $123(6.9)$ & 1,783 \\
\hline Total & $212(2.9)$ & $116(3.1)$ & $328(3.0)$ & 11,092 \\
\hline
\end{tabular}

\section{Respondents versus non-contacts}

Concerning all-cause mortality rates in non-contacts and respondents, table 3 illustrates that death rates by age groups rises with increasing age, death rates were also higher for men. The bivariate analysis shows that no significant differences in death rates between respondents and non-contacts were seen. However, the multiple logistic regression analysis in table 4 presents that response behaviour was a significant predictor of mortality (OR $=0.78,95 \% \mathrm{CI}: 0.67-0.90)$, non-contacts had a higher risk of dying during follow-up, even if corrected for age, gender, and cardiovascular health and risk factors. No interaction effect was found for gender. The bivariate analysis (table 1, middle 2 columns) between respondents and non-contacts, shows that respondents had a higher percentage of CHD, and had a higher percentage of hypercholesterolaemia. The multivariate analysis in table 2 (last columns) also illustrates that compared with non-contacts, respondents were found to have more often CHD (OR $=1.15,95 \%$ CI: 1.01-1.31), and hypercholesterolaemia $(\mathrm{OR}=1.33,95 \%$ CI: 1.16-1.53), but on the other hand were found to have less often diabetes mellitus $(\mathrm{OR}=0.81$, 95\% CI: 0.70-0.94). Subjects who moved during the follow-up period were excluded from the analyses concerning all-cause mortality. In a separate analysis, a comparison was made between per- 
Table 4. Adjusted odds ratios and 95\% confidence intervals from multiple logistic regression analysis for mortality vs. survival for response behaviour, subject characteristics, and history of cardiovascular health problems and risk factors

Mortality $^{\mathrm{a}}$ vs. survival, OR $(95 \% \mathrm{CI})$

$\begin{array}{lc}\text { Response behaviour: } & \\ \text { Respondents (vs. non-contacts) } & 0.78(0.67-0.90) \\ \text { Male gender } & 1.60(1.38-1.85) \\ \text { Age, years } & \\ 44-49 & 0.18(0.14-0.24) \\ 50-54 & 0.30(0.24-0.37) \\ 55-59 & 0.36(0.29-0.45) \\ 60-64 & 0.59(0.48-0.71) \\ 65-73^{b} & 1.00 \\ \text { Positive history of cardiovascular health problems and risk factors } & \\ \text { Coronary heart disease } & 1.54(1.25-1.91) \\ \text { Heart failure } & 3.36(2.02-6.00) \\ \text { Hypertension with involvement of target organs } & 1.38(1.04-1.83) \\ \text { Non-fatal stroke } & 2.34(1.69-3.23) \\ \text { Other arterial obstructive or peripheral vascular disease } & 2.62(1.86-3.70) \\ \text { Diabetes mellitus } & 1.54(1.18-1.99) \\ \text { Hypercholesterolaemia } & 1.29(1.00-1.66)\end{array}$

Abbreviations: CI, confidence interval; OR, odds ratio.

People who moved during follow-up were excluded from the analyses.

${ }^{a}$ Adjusted for general practice, and the other variables.

b Reference category

sons who moved and persons who did not move during follow-up (data not shown). Of the noncontacts 11.2 percent moved compared with 9.0 percent of the respondents. People who moved during follow-up were found to have a higher percentage of heart failure at the start of the study $(0.9 \%$ versus $0.5 \%)$, but it concerns less than 15 cases. Therefore, it is not to be expected that these findings influence the results concerning all-cause mortality.

\section{Discussion}

The present study investigated differences between respondents and non-respondents regarding health, and found non-respondents to be healthier with regard to CHD. Mortality rate during follow-up, was found to be higher for non-contacts compared with respondents. And finally, refusals were found to be healthier than non-contacts regarding cardiovascular health, but have more risk factors regarding CHD.

Contrary to expectation, non-respondents were found to be healthier with regard to CHD than respondents, especially among male non-respondents. The odds of responding is 1.36 times higher for males with CHD. This result differs from the general findings in the literature that respondents are healthy volunteers $(11,13,19)$. As discussed in the introduction, saliency could be a trigger for people to respond to a survey, for example the phenomenon "worried well". In this study the respondents were found to be less healthy, and cannot be considered as "worried well". Probably, this saliency is most linked with the worries, people have regarding a topic. People with CHD are ill, 
and are advised to change their lifestyle into a healthy one, which might increase their worries regarding their health, and these worries may motivate a subject to respond to a questionnaire on health. So perhaps these respondents have to be regarded as the "worried ill".

Regarding cardiovascular risk factors no differences in hypertension were found between respondents and non-respondents. This results differs from previous studies in which non-respondents had more often hypertension $(10,13,18)$. There might be a difference in definition of hypertension. In this study, hypertension was defined as hypertension with involvement of target organs, no statement can be made regarding hypertension without involvement of target organs.

The difference in prevalence of another cardiovascular risk factor, hypercholesterolaemia was small, about $1 \%$. In accordance with previous studies hypercholesterolaemia was found more prevalent among respondents $(13,16)$. But, as seen from the multiple logistic regression model, hypercholesterolaemia was not associated with response behaviour. A word of caution has to be made, the probability of under-recording of hypercholesterolaemia is high in the Dutch situation, compared with other countries. A positive cardiovascular risk profile is an indication for cholesterol measurement in the Netherlands national guidelines on cholesterol for screening and management of hypercholesterolaemia (37). A patient has a positive risk profile, if at least one of the six cardiovascular risk factors (CHD in patients history; signs of familial hypercholesterolaemia; familial hyperlipidaemia in a relative; CHD in sibling or parent $<60$ years; hypertension; or diabetes mellitus) mentioned in the Dutch guidelines is present (37). In contrast with the Dutch situation, where only people at risk are tested, are the United States guidelines which recommend that all adults aged 20-70 should be screened. For example, in a Dutch study it was found that of those with a positive risk profile only one third had had their cholesterol measured (37). They also found that of all the patients in the Dutch study, only $12 \%$ (37) were tested, compared with 67\% (38) of adults in a study from the United States.

Paradoxically, respondents seem less healthy at baseline than non-respondents, but prospectively have a lower mortality risk. After correction for age, gender, cardiovascular health, and risk factors, mortality risk remains higher for non-contacts compared with respondents, which is in line with results from previous studies $(9,19-23)$. Excess mortality among the non-contacts could ensue when respondents are more health conscious and see their doctor more often (better surveillance) and get better care, parallel to the idea of the worried ill. Secondly, excess mortality could be caused not by CHD, but by some other disease (e.g. cancer). Thirdly, the higher prevalence of diabetes among non-contacts could have led to the excess mortality observed. A separate analysis was performed to compare causes of death between respondents and non-contacts (data not shown). This comparison revealed no differences between respondents and non-contacts regarding causes of death, there might be other factors not measured in this study which could explain the differences in mortality risk.

As described in the introduction the likelihood of non-response bias increases when non-respondents differ from respondents on both the outcome and the exposure. For the non-respondents, no information was available regarding health behavioural risk factors, such as alcohol consumption, smoking, or depression. People with CHD are advised to change their lifestyle into a healthy one. It could be speculated that the respondents also differ from the non-respondents with regard to health behavioural risk factors. Which might partly explain the differences in mortality risk. To answer this question information regarding the exposure variable is necessary.

Results showed differences regarding cardiovascular health within reasons of non-response in this study. The odds of refusal was lower, about 0.85 in subjects with CHD, and also lower in subjects with diabetes mellitus, about 0.77 . However, the odds of refusal was 1.40 times higher in subjects with hypercholesterolaemia. CHD and diabetes mellitus are considered to be health problems or diseases, whereas hypercholesterolaemia is considered to be a risk factor. This difference in health and risk factor indicates that refusals are healthier compared with non-contacts, but have more risk 
factors regarding CHD. There is no clear explanation why refusals differ in health from non-contacts. It can be speculated that because refusals are healthier, they are not inclined to respond to a questionnaire about health. Possibly other factors explain why some subjects explicitly refuse participation. One factor, also investigated in this study, could be degree of urbanization. Non-contacts are for example living in urban neighbourhoods, who are more anonymous, which increases the probability of not responding.

The response rate in this study of about $52 \%$ is considered to be slightly higher, compared with response rates in the Netherlands between $30 \%$ and 50\% (1,2). A large cohort study on diet and cancer in the Netherlands, using a postal questionnaire had a response rate of about $35 \%$ (39). A possible explanation, of the higher response rate in the LEGO-study, is the role of the GP.The invitation letter which accompanied the questionnaire was signed by the GP, who is considered to be an authority. People are inclined to respond to a questionnaire if the request is supported by an authority $(1,40)$. Persons with CHD have a history of treatment, a GP plays an important role in the treatment and for that reason could be an authority to his patient.

The finding of overrepresentation of subjects with CHD at baseline among respondents seems to pose less of a threat to validity of substantive analyses concerning the association between a determinant and CHD. The finding that during the follow-up period non-respondents are less well off as regards all-cause mortality may indicate that respondents may be better monitored and receive more or better care, which would mitigate the negative effects of certain risk factors or health related behaviours. This could imply that observed relationships between such factors or behaviours and outcomes in respondents may be attenuated compared to non-respondents.

\section{References}

1. de Leeuw ED, Hox JJ. Nonrespons in surveys: een overzicht. Kwantitatieve Methoden 1998;19:31-53.

2. Kalfs N, Kool E. Ervaringen met non-respons. Amsterdam: NIMMO Nederlands Instituut voor Maatschappij en Marktonderzoek, 1994.

3. Bethlehem JG, Kersten HMP. Werken met non-respons. Amsterdam: Universiteit van Amsterdam, 1986.

4. Sackett DL. Bias in analytic research. J Chronic Dis 1979;32:51-63.

5. Stang A, Jockel KH. Studies with low response proportions may be less biased than studies with high response proportions. Am J Epidemiol 2004;159:204-10.

6. Austin MA, Criqui MH, Barrett Connor E, Holdbrook MJ. The effect of response bias on the odds ratio. Am J Epidemiol 1981;114:137-43.

7. Stang A. Nonresponse research-an underdeveloped field in epidemiology. Eur J Epidemiol 2003;18:929-31.

8. Van Loon AJ, Tijhuis M, Picavet HS, Surtees PG, Ormel J. Survey non-response in the Netherlands: effects on prevalence estimates and associations. Ann Epidemiol 2003;13:105-10.

9. Chou P, Kuo HS, Chen CH, Lin HC. Characteristics of non-participants and reasons for non-participation in a population survey in Kin-Hu, Kinmen. Eur J Epidemiol 1997;13:195-200.

10. Korkeila K, Suominen S, Ahvenainen J, Ojanlatva A, Rautava P, Helenius H, et al. Non-response and related factors in a nation-wide health survey. Eur J Epidemiol 2001;17:991-9.

11. Melton LJ, 3rd, Dyck PJ, Karnes JL, O'Brien PC, Service FJ. Non-response bias in studies of diabetic complications: the Rochester Diabetic Neuropathy Study. J Clin Epidemiol 1993;46:341-8.

12. Burhenne W, van de Leest J. Respons en non-respons in het Aanvullend Voorzieningengebruik Onderzoek. Dongen: Sociaal en Cultureel Planbureau, 1997.

13. Jackson R, Chambless LE, Yang K, Byrne T, Watson R, Folsom A, et al. Differences between respondents and nonrespondents in a multicenter community-based study vary by gender ethnicity. The Atherosclerosis Risk in Communities (ARIC) Study Investigators. J Clin Epidemiol 1996;49:1441-46.

14. Macera CA, Jackson KL, Davis DR, Kronenfeld JJ, Blair SN. Patterns of non-response to a mail survey. J Clin Epidemiol 1990;43:1427-30. 
15. Paganini Hill A, Hsu G, Chao A, Ross RK. Comparison of early and late respondents to a postal health survey questionnaire. Epidemiology 1993;4:375-9.

16. Criqui MH, Barrett Connor E, Austin M. Differences between respondents and non-respondents in a population-based cardiovascular disease study. Am J Epidemiol 1978;108:367-72.

17. Hoeymans N, Feskens EJ, Van Den Bos GA, Kromhout D. Non-response bias in a study of cardiovascular diseases, functional status and self-rated health among elderly men. Age Ageing 1998;27:35-40.

18. Heilbrun LK, Ross PD, Wasnich RD, Yano K,Vogel JM. Characteristics of respondents and nonrespondents in a prospective study of osteoporosis. J Clin Epidemiol 1991;44:233-9.

19. Bisgard KM, Folsom AR, Hong CP, Sellers TA. Mortality and cancer rates in nonrespondents to a prospective study of older women: 5-year follow-up. Am J Epidemiol 1994;139:990-1000.

20. Heilbrun LK, Nomura A, Stemmermann GN. The effects of nonresponse in a prospective study of cancer. Am J Epidemiol 1982;116:353-63.

21. Walker M, Shaper AG, Cook DG. Non-participation and mortality in a prospective study of cardiovascular disease. J Epidemiol Community Health 1987;41:295-9.

22. Barchielli A, Balzi D. Nine-year follow-up of a survey on smoking habits in Florence (Italy): higher mortality among non-responders. Int J Epidemiol 2002;31:1038-42.

23. Hara M, Sasaki S, Sobue T, Yamamoto S, Tsugane S. Comparison of cause-specific mortality between respondents and nonrespondents in a population-based prospective study: ten-year follow-up of JPHC Study Cohort I. Japan Public Health Center. J Clin Epidemiol 2002;55:150-6.

24. Richiardi L, Boffetta P, Merletti F. Analysis of nonresponse bias in a population-based case-control study on lung cancer. J Clin Epidemiol 2002;55:1033-40.

25. Hox JJ, de Leeuw ED. Non-respons bij schriftelijke vragenlijsten, telefonische interviews en face-to-face interviews; een vergelijkende meta-analyse. Kwantitatieve Methoden 1993;43:59-78.

26. Etter JF, Perneger TV. Analysis of non-response bias in a mailed health survey. J Clin Epidemiol 1997;50: 1123-8.

27. Pope D, Croft P. Surveys using general practice registers: who are the non-responders? J Public Health Med 1996;18:6-12.

28. Metsemakers JF, Hoppener P, Knottnerus JA, Kocken RJ, Limonard CB. Computerized health information in The Netherlands: a registration network of family practices. Br J Gen Pract 1992;42:102-6.

29. Van der Linden MW, Westert GP, De Bakker DH, Schellevis FG. Tweede Nationale Studie naar ziekten en verrichtingen in de huisartspraktijk. Klachten en aandoeningen in de bevolking en in de huisartspraktijk. Utrecht/Bilthoven: NIVEL/RIVM, 2004.

30. Code Goed Gedrag: http://www.fmwv.nl/gedragscodes/goedgedrag/CodeGoedGedrag.pdf (2005)

31. Sandlow LJ, Bashook PG. Problem oriented medical records. Self instruction for practitioners. 3rd ed. Chicago: Michael Reese Hospital and Medical Center, 1978.

32. Lamberts H, Wood M, editors. ICPC : International Classification of Primary Care. Oxford: Oxford University Press, 1987.

33. Landelijk aantal opnamen, kliniek en dagverpleging, verpleegdagen en gemiddelde verpleegduur per diagnose onderverdeeld naar leeftijd en geslacht. Prismant: http://www.prismant.nl (2004).

34. Sterfte naar leeftijd, geslacht en burgerlijk staat. Centraal Bureau voor de Statistiek: http://statline.cbs.nl/ StatWeb/ (2002).

35. Statistiek Nederland. Kerncijfers Wijken en Buurten 1999. Centraal Bureau voor de Statistiek: http://statline.cbs.nl/StatWeb/ (2000).

36. Snijders AB, Bosker RJ. Multilevel Analysis. An introduction to basic and advanced multilevel modeling. London: SAGE, 1999.

37. van der Weijden T, Dansen A, Schouten BJ, Knottnerus JA, Grol RP. Comparison of appropriateness of cholesterol testing in general practice with the recommendations of national guidelines: an audit of patient records in 20 general practices. Qual Health Care 1996;5:218-22.

38. Hudson JW, Keefe CW, Hogan AJ. Cholesterol measurement and treatment in community practices. J Fam Pract 1990;31:139-44.

39. van den Brandt PA, Goldbohm RA, van 'tVeer P,Volovics A, Hermus RJ, Sturmans F. A large-scale prospective cohort study on diet and cancer in The Netherlands. J Clin Epidemiol 1990;43:285-95.

40. Edwards P, Roberts I, Clarke M, DiGuiseppi C, Pratap S, Wentz R, et al. Increasing response rates to postal questionnaires: systematic review. BMJ 2002;324:1183. 



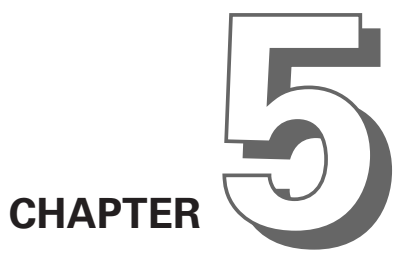

\section{Measurement of lifetime alcohol intake: Utility of a self-administered questionnaire}




\begin{abstract}
Prior epidemiologic research revealing cardio protective effects of alcohol intake has systematically neglected lifetime exposure to alcohol, which may cause serious bias in conclusions regarding drinking and heart disease risk. Departing from use of an earlier interview schedule, the authors of the present 1996-2001 cohort study developed a self-administered Lifetime Drinking History questionnaire (LDH-q). A total of 16,211 Dutch men and women older than age 45 years participated by completing the baseline questionnaire. A random sample of 3,255 men and women was used to determine the reliability and validity of the LDH-q. Test-retest reliability was assessed by means of the intraclass correlation coefficient and kappa scores. Correlations between lifetime and current intake scores were used to assess discriminant and convergent validity. Both reliability and validity appeared to be reasonably high compared with results obtained by using interview formats to measure lifetime alcohol intake. Reliability of the LDH-q was higher for men than for women, probably because of the more frequent and regular drinking of men. Indices of validity were similar for men (0.75) and women (0.70). Results show that the LDH-q can be a useful instrument in large-scale cohort studies.
\end{abstract}




\section{Introduction}

Epidemiologic research on the relationship between alcohol intake and coronary heart disease has led to the generally accepted idea that moderate intake of alcohol is beneficial to health (1-6). Coronary heart disease does not occur suddenly but is a preliminary outcome of an atherosclerotic process. This process may start early in life:Visible lipid deposits have been found in adolescents and even in children (7-11). Clinical studies suggest that the cardio protective effects of alcohol may be generated by certain lipoproteins, decreased platelet function, and increased fibrinolysis (12). Of these effects of alcohol, some seem to be immediate or short-term, such as blood platelet aggregation. In such instances, there is no need to consider lifetime exposure because it would explain little of the variation in risk. Because most population studies measure alcohol intake by means of self-reports with short reference periods (13), it should not come as a surprise that results from these studies often confirm these immediate, short-term beneficial effects. However, for other outcomes, such as arterial lipid formation or high blood pressure, exposure to alcohol throughout life may affect risk. When, for example, the natural course of atherosclerosis is considered, an additive or cumulative effect of lifetime alcohol exposure is conceivable, necessitating measurement of lifetime intake. Unfortunately, measuring alcohol intake, especially earlier in life, is not straightforward.

A general problem in measuring alcohol intake is the absence of a "gold standard." Self-reports are the simplest method but are prone to response bias. However, other, more objective techniques such as use of biomarkers of alcohol intake do not seem more valid than self-reports when the reference period is stretched over some time (14-16). Since accuracy of recall of an autobiographic event is affected by the elapsed time since the event occurred (next to saliency of the event and its frequency of occurrence), extending the reference period to a lifetime probably will affect the accuracy of such self-reports (17). Research into the quality of self-reports for lifetime intake is scarce, however. To our knowledge, only one study is available in which self-reported drinking (actual intake in the last week) was directly compared with recall of intake during that period 18 years later (18). Paradoxically, intake recalled 18 years later was, on average, found to be higher than when intake was assessed immediately after the drinking occurred. However, current intake was not related to the size of the discrepancy in reports, suggesting absence of differential bias in the self-reports after 18 years.

Results on the stability of self-reports of lifetime drinking from three studies in which an interview schedule was used showed moderate-to-high correlations ranging from 0.73 to 0.94 for total lifetime intake (19-21). However, in large cohort studies, interviewing all participants is often not feasible, and one has to resort to a self-administered questionnaire format. Despite the potential cost of an increased number of missing values and inconsistencies often attributed to a lower perception of threat when self-administered questionnaires are used (22), self-administered questionnaire formats yield similar or even better results than personal interviews when alcohol intake is measured (22-24).

In the present 1996-2001 study, the quality of the self-administered format of the Lifetime Drinking History questionnaire (LDH-q) was tested in a large cohort study, the Lifestyle and Health Study (in Dutch, abbreviated as the LEGO study). The LDH-q was developed in an earlier pilot study (25) on the basis of an interview schedule (26), since no self-administered questionnaire about lifetime drinking was available. In the present study, test-retest reliability of the LDH-q was estimated. The construct validity of the LDH-q was tested by comparing it with two measures of current drinking, assuming that scores for corresponding drinking periods should show a high correlation. It was further presumed that the further back in time the intake for which the subject was reporting occurred, the lower its correlation with current intake. 


\section{Materials and methods}

\section{Population}

The LDH-q was developed primarily for measuring lifetime exposure to alcohol in a large prospective cohort study. The data in this article were derived from the Dutch Lifestyle and Health Study, which started in 1996. The study cohort was composed of men and women born between 1925 and 1951 and registered at 34 participating general practices. Coverage of the general population by patient registration in primary practices is high in the Netherlands. In the period 1995-1997, an estimated 78-86 percent of all men and women aged 45 years or older visited their general practitioner at least once in a 1-year period (27). The primary practices were drawn from two regions of the Netherlands, south-eastern and western, because of differences in past drinking patterns. Historically, the south-eastern region, compared with the western region, is characterized by a low alcohol abstinence rate among men but a relatively high abstinence rate among women and by a higher intake among men versus a relatively lower intake among women $(28,29)$. Participation of practices was sought with the help of municipal health authorities and through the network of practices of the Department of General Practice of the University of Maastricht (30). No particular criteria were used in selection other than number of patients and availability of medical information. The study design, in which only anonymous data were used, was approved by the review committee of the Registration Network Family Practices. Informed consent was obtained by using a letter explaining the questionnaire.

After patients with terminal disease, patients with severe dementia, mentally disabled patients, and institutionalised patients were excluded, 31,348 persons were presented with a baseline questionnaire. Those who refused to participate (18.7 percent) could indicate so by returning a blank questionnaire. These persons were then removed from the cohort. To all other non-respondents $(35.3$ percent), a second baseline questionnaire was sent out in 1997. From these respondents $(n=1,803)$, no retest data were available. Of the 14,408 baseline-1996 respondents, 77.2 percent responded to the follow-up questionnaire with the retest. Preliminary data did not reveal differences in age or sex between respondents and non-respondents.

From the 16,211 persons constituting the cohort, a random sample of 3,255 was drawn. For this sample, questionnaires were processed and data were made available for analysis.

\section{Alcohol intake}

Alcohol intake was measured by using three methods: the LDH-q; a quantity-frequency index of intake in the last year, measured at baseline (QF-last-year); and the weekly recall. For the latter, actual intake in the past week was reported.

The self-administration format of the LDH-q is based on the interview schedule of the Lifetime Drinking History (19), which was in turn an adaptation of a format suggested by Rohan (31). The interview schedule of the Lifetime Drinking History provides quantitative data on patterns of alcohol intake starting from onset of regular drinking and was intended primarily to assess the drinking history of heavy drinkers. The major alteration made to the LDH-q was in the format of the drinking periods. In the interview schedule of the Lifetime Drinking History, drinking periods are not fixed but "floating"; the respondent defines the different drinking periods in his or her life. These periods are demarcated by changes in drinking behaviour, which the respondent qualifies as large. However, such a free format is too complicated to use in a self-administered questionnaire context, so the drinking periods in the $\mathrm{LDH}-\mathrm{q}$ were presented as fixed. Nevertheless, comparison of a free format and the floating format of the Cognitive Lifetime Drinking History interview did not lead to differences in results (21). In the pilot study, the LDH-q was compared with the interview sched- 
ule of the Lifetime Drinking History in a sample of 45 male social drinkers (25). The test-retest correlation was about 0.70 , a figure easily affected by a few outliers caused by routing errors. The conclusion was that, after some major (routing) adjustments, the LDH-q could yield a reliability profile similar to the one for the interview schedule of the Lifetime Drinking History.

For the present study, the LDH-q was conducted twice in the spring, 1 year apart. The LDH-q was part of the baseline questionnaire. The 1997 follow-up questionnaire was slightly shorter; the main indices of drinking were retained but questions about reasons for discontinuing drinking were omitted. The LDH-q starts off with a question about age (in years) at onset of drinking, defined as consuming the "first, full glass" of alcohol. Then, respondents are asked about their usual frequency of drinking (eight options ranging from "every day" to "never") and their usual quantity per occasion (in glasses) during each age period. Five drinking periods were defined: youth (aged 12-18 years), young adult (aged 19-27 years), adult (aged 28-45 years), middle age (aged 46-60 years), and elderly (aged $\geq 61$ years) (25). Usual quantity and usual frequency, converted to fit a weekly frequency, were multiplied to form an index of usual intake for each drinking period. Cumulated index scores for the drinking periods were added to produce an estimate of total lifetime intake. Additional questions in the original version inquiring about variability, that is, the frequency of binge drinking, type of beverage (beer, wine, spirits), drinking context, and attempts to quit, were omitted from the retest version.

Additional drinking indicators in both the test and retest versions of the LDH-q were QF-last-year and a measure of actual drinking during the last week (weekly recall). Both indices measured alcohol intake separately for beer, wine, and spirits.

\section{Analysis}

Test-retest reliability was assessed by calculating the kappa measure for a binary variable or the single-score intraclass correlation coefficient (ICC) for one-way models (32) The ICC is closely related to the kappa measure and, under some conditions, is a special case of weighted kappa (33). An advantage of the ICC is correction for possible systematic variation between two measurements or methods in addition to application of only the variation between subjects and the random variation in the Pearson's correlation coefficient (34). ICCs were calculated for frequency, quantity, and total weekly intake for each drinking period and for lifetime intake. The indices were examined for influential cases by using Cook's distance. ICC changes of more than 0.10 for one or two cases were considered influential, and those cases were excluded temporarily.

Construct validity was determined by comparing the LDH-q with the QF-last-year and the weekly recall, all measured in the baseline questionnaire. The five drinking periods were also compared with each other.The rationale behind these tests is that the association between intake scores for different drinking periods should be weaker the further apart in time they are. If reporting bias is large, it would be reflected in equally high correlations between reported intake over periods even far apart in time. Construct validity was determined for alcohol intake per week by using Spearman's correlation coefficient because the variables used probably do not follow a normal distribution. Furthermore, if there is a normal distribution, Spearman's $\rho$ will be equal to Pearson's correlation coefficient (35).

Finally, an aspect of face validity was investigated by comparing trends in the cohort with those in the Dutch population at large over the period 1950-1995. Mean alcohol intake in the cohort (in litres of pure alcohol per year) for the years 1950, 1955, and so on up to 1995 was calculated for comparison with per-capita intake for these years in the Netherlands. Drinks were converted to litres of pure alcohol, assuming that one glass contains $12.5 \mathrm{ml}$ of pure alcohol. Data for all cohort members were used in the calculation, with those for members not (yet) drinking set to zero. When 
per-capita intake was calculated (based on sales data), data for Dutch inhabitants of all ages were included in the denominator (36).

\section{Results}

Baseline data were available for 1,608 men and 1,647 women, of whom 1,427 men and 1,450 women had responded in 1996. About half of the respondents were aged 44-54 years. The distribution over the five 5 -year age categories was equal to the distribution of these groups in the Netherlands (37).

\section{Drinking behaviour}

Table 1 shows that, compared with older men, younger men started drinking earlier in life $(p<$ 0.01 ) and tended to report consuming more drinks per week during each life period, which was significant for reports of drinking by young adults, adults, and elderly men. A similar pattern was found for women (table 2), with significant trends in reports about age at onset for young adults, adults, and middle-aged women.

When tables 1 and 2 are compared, it becomes obvious that, for each life period, men reported consuming at least twice as many drinks per week as women did, and they started drinking about 2 years earlier. Both men and women reported consuming more drinks per week according to the weekly recall than to the QF-last-year, except for men aged 60-64 years. However, this finding was statistically significant for men aged 44-59 years only. The gender differences were consistent across the age range in the sample. The expected differences between the two regions were found for men only. For women, no significant differences or inverse differences in drinking pattern were found.

\section{Test-retest reliability}

Baseline and follow-up data were available for 1,074 men and 1,085 women. However, 31 men and 87 women were excluded from the study because of incomplete alcohol intake data for either year; six men and seven women did not complete the alcohol questions for both years. The LDH-q

Table 1. Age of onset of alcohol intake and mean number of glasses consumed per week per drinking period in relation to age at baseline for male drinkers

\begin{tabular}{|c|c|c|c|c|c|c|c|c|c|c|c|}
\hline \multirow[b]{3}{*}{ Alcohol intake } & \multirow[b]{3}{*}{ No. } & \multicolumn{10}{|c|}{ Age at baseline (years) } \\
\hline & & \multicolumn{2}{|c|}{$44-49$} & \multicolumn{2}{|c|}{$50-54$} & \multicolumn{2}{|c|}{$55-59$} & \multicolumn{2}{|c|}{$60-64$} & \multicolumn{2}{|c|}{$65-71$} \\
\hline & & Mean & $\mathrm{SD}^{\star}$ & Mean & $\mathrm{SD}$ & Mean & $\mathrm{SD}$ & Mean & $\mathrm{SD}$ & Mean & $\mathrm{SD}$ \\
\hline Age of onset (years) & 1,496 & 16.4 & 2.71 & 6.7 & 2.8 & 17.1 & 3.0 & 17.6 & 3.4 & 18.6 & 4.5 \\
\hline \multicolumn{12}{|l|}{ Drinking period } \\
\hline Youth & 1,010 & 6.9 & 10.1 & 6.7 & 15.4 & 5.5 & 7.5 & 4.8 & 6.8 & 6.3 & 17.7 \\
\hline Young adult & 1,334 & 14.6 & 15.4 & 13.0 & 15.9 & 10.1 & 12.6 & 7.7 & 9.1 & 7.2 & 14.5 \\
\hline Adult & 1,354 & 14.8 & 16.4 & 12.5 & 14.6 & 12.3 & 18.3 & 7.9 & 10.0 & 8.2 & 14.1 \\
\hline Middle age & 1,355 & 13.1 & 12.9 & 12.5 & 14.0 & 12.6 & 12.9 & 11.0 & 16.6 & 11.3 & 17.1 \\
\hline Elderly & 347 & 0 & - & 0 & - & 0 & - & 11.6 & 17.6 & 10.2 & 15.5 \\
\hline Mean lifetime intake & 1,503 & 13.2 & 13.6 & 11.8 & 12.3 & 10.8 & 12.0 & 8.0 & 10.0 & 8.1 & 13.5 \\
\hline QF last year ${ }^{\star}$ & 1,110 & 14.9 & 15.7 & 14.1 & 14.1 & 12.8 & 13.1 & 14.5 & 20.5 & 11.7 & 10.6 \\
\hline Weekly recall & 1,032 & 16.7 & 13.5 & 16.8 & 13.8 & 14.4 & 11.8 & 14.1 & 12.9 & 13.7 & 11.2 \\
\hline
\end{tabular}

* SD, standard deviation; QF-last-year, quantity-frequency index of alcohol intake in the last year, measured at baseline 
Table 2. Age of onset of alcohol intake and mean number of glasses consumed per week per drinking period in relation to age at baseline for female drinkers

\begin{tabular}{|c|c|c|c|c|c|c|c|c|c|c|c|}
\hline \multirow[b]{3}{*}{ Alcohol intake } & \multirow[b]{3}{*}{ No. } & \multicolumn{10}{|c|}{ Age at baseline (years) } \\
\hline & & \multicolumn{2}{|c|}{$44-49$} & \multicolumn{2}{|c|}{$50-54$} & \multicolumn{2}{|c|}{$55-59$} & \multicolumn{2}{|c|}{$60-64$} & \multicolumn{2}{|c|}{$65-71$} \\
\hline & & Mean & $\mathrm{SD}^{\star}$ & Mean & SD & Mean & SD & Mean & $\mathrm{SD}$ & Mean & SD \\
\hline Age of onset (years) & 1,275 & 18.2 & 3.6 & 18.8 & 3.9 & 20.4 & 4.9 & 21.3 & 5.1 & 21.1 & 5.8 \\
\hline \multicolumn{12}{|l|}{ Drinking period } \\
\hline Youth & 501 & 2.0 & 6.1 & 1.3 & 1.8 & 1.6 & 3.1 & 0.9 & 1.2 & 1.7 & 2.2 \\
\hline Young adult & 1,020 & 3.3 & 4.2 & 3.0 & 3.8 & 1.8 & 2.2 & 1.4 & 2.6 & 1.9 & 2.9 \\
\hline Adult & 1,087 & 5.6 & 7.5 & 5.1 & 7.8 & 4.1 & 6.5 & 2.9 & 5.1 & 2.8 & 4.2 \\
\hline Middle age & 1,076 & 6.0 & 6.0 & 5.6 & 7.1 & 5.7 & 7.6 & 4.1 & 6.3 & 5.0 & 6.8 \\
\hline Elderly & 270 & 0 & - & 0 & - & 0 & - & 4.8 & 7.2 & 5.8 & 7.6 \\
\hline Mean lifetime intake & 1,297 & 4.5 & 5.7 & 4.2 & 5.6 & 3.9 & 5.9 & 2.6 & 4.4 & 3.0 & 4.3 \\
\hline QF last year ${ }^{\star}$ & 925 & 8.3 & 13.7 & 6.7 & 8.0 & 7.1 & 9.2 & 5.8 & 7.8 & 7.7 & 9.3 \\
\hline Weekly recall & 765 & 9.0 & 8.1 & 8.9 & 8.7 & 8.3 & 7.2 & 6.5 & 6.7 & 8.3 & 8.1 \\
\hline
\end{tabular}

* SD, standard deviation; QF-last-year, quantity-frequency index of alcohol intake in the last year, measured at baseline

Table 3. Test-retest reliability of the $\mathrm{LDH}-\mathrm{q}^{\star}$, excluding lifelong abstainers of alcohol

\begin{tabular}{|c|c|c|c|c|c|c|}
\hline \multirow[b]{2}{*}{ Alcohol intake } & \multicolumn{3}{|c|}{ Men } & \multicolumn{3}{|c|}{ Women } \\
\hline & No. & $\mathrm{ICC}^{\star}$ & $95 \% \mathrm{CI}^{\star}$ & No. & $\mathrm{ICC}^{\star}$ & $95 \% \mathrm{CI}^{\star}$ \\
\hline Age at onset & 984 & 0.21 & $0.15,0.27$ & 779 & 0.52 & $0.46,0.57$ \\
\hline First drinking period & 1,014 & 0.60 & $0.56,0.64$ & 850 & 0.61 & $0.57,0.65$ \\
\hline \multicolumn{7}{|l|}{ Frequency: } \\
\hline Youth & 913 & 0.48 & $0.43,0.53$ & 703 & 0.42 & $0.36,0.48$ \\
\hline Young adults & 986 & 0.64 & $0.61,0.68$ & 793 & 0.53 & $0.48,0.58$ \\
\hline Adults & 995 & 0.72 & $0.69,0.75$ & 870 & 0.75 & $0.72,0.78$ \\
\hline Middle age & 994 & 0.78 & $0.75,0.80$ & 865 & 0.79 & $0.76,0.81$ \\
\hline Elderly & 284 & 0.80 & $0.75,0.84$ & 230 & 0.77 & $0.72,0.82$ \\
\hline \multicolumn{7}{|l|}{ Quantity: } \\
\hline Youth & 863 & 0.68 & $0.64,0.71$ & 663 & 0.56 & $0.50,0.61$ \\
\hline Young adults & 929 & 0.75 & $0.72,0.78$ & 734 & 0.62 & $0.57,0.66$ \\
\hline Adults & 949 & 0.72 & $0.69,0.75$ & 803 & 0.57 & $0.52,0.61$ \\
\hline Middle age & 961 & 0.72 & $0.69,0.75$ & 821 & 0.54 & $0.49,0.58$ \\
\hline Elderly & 277 & 0.77 & $0.72,0.82$ & 223 & 0.50 & $0.40,0.59$ \\
\hline \multicolumn{7}{|l|}{ Quantity ${ }^{\star}$ Frequency } \\
\hline Youth & 855 & 0.44 & $0.39,0.50$ & 655 & $0.50^{\dagger}$ & $0.45,0.56$ \\
\hline Young adults & 922 & 0.74 & $0.71,0.77$ & 727 & $0.66^{\ddagger}$ & $0.61,0.70$ \\
\hline Adults & 938 & 0.74 & $0.71,0.77$ & 796 & $0.83^{\ddagger}$ & $0.81,0.85$ \\
\hline Middle age & 955 & 0.73 & $0.70,0.76$ & 814 & 0.79 & $0.76,0.81$ \\
\hline Elderly & 267 & 0.88 & $0.85,0.90$ & 217 & 0.88 & $0.84,0.91$ \\
\hline Total lifetime intake & 1,007 & 0.75 & $0.72,0.77$ & 891 & 0.70 & $0.66,0.73$ \\
\hline
\end{tabular}

* LDH-q, Lifetime Drinking History questionnaire; ICC, intraclass correlation coefficient; CI, confidence interval.

† After exclusion of one case whose data influenced the correlation coefficient by more than 0.10 .

$\ddagger$ After exclusion of two cases whose data influenced the correlation coefficient by more than 0.10 . 
specifically asks the respondent if he or she has been a lifelong abstainer. Of the women, 6.0 percent, compared with 1.2 percent of the men, indicated on both questionnaires that they had never drunk any alcohol. Answers about lifelong abstention were inconsistent more often among women (8.1 percent) than among men (1.5 percent). The kappa measure of agreement for this question was 0.61 for men and 0.55 for women. Combining this specific question with information from subsequent questions on alcohol intake revealed a conflict for another six men and 37 women who seemed to be "ever" drinkers. In all, when information from both questionnaires was used, 15 men (1.4 percent) and 74 women (7.4 percent) could be considered lifelong abstainers on both occasions. These 89 persons were excluded from the remaining test-retest analyses, leaving 1,028 men and 924 women.

Table 3 shows the ICCs for the LDH-q. The ICC for age at onset was low, especially for men (0.21). In some instances, current age instead of age at onset was given. Correction was made by combining age at onset with information on drinking during the first drinking period, increasing the ICCs to 0.60 for men and 0.61 for women. The ICCs for the drinking indices during different drinking periods ranged from 0.44 to 0.88 for men but were somewhat lower for women (range, 0.42-0.88). This finding especially concerned the ICCs for quantity per occasion; they ranged from 0.68 to 0.77 for men and from 0.50 to 0.62 for women. The ICCs for reports about the "youth" period were, in general, the lowest. Finally, the ICCs for mean lifetime intake were 0.75 for men and 0.70 for women. ICC values were calculated separately for the different 5-year age categories. There did not seem to be a trend with age, although the ICCs seemed the lowest for the oldest men. In another analysis (results not shown), beer preference among men and wine preference among women did not lead to any relevant differences in reliability outcomes for either category.

\section{Construct validity}

The Spearman's correlation coefficient between both measurements of current intake was 0.83 for men and 0.81 for women. Table 4 shows the correlations between both indices of current intake and the intake estimates for the different drinking periods. The correlations between QF-last-year and quantity-frequency index of alcohol intake per week (QF) indices for different drinking periods were somewhat higher than those between the weekly recall and period-specific QF measures. The greater the interval between current intake and the LDH-q drinking period, the lower the correla-

Table 4. Spearman's correlation coefficients between current and past alcohol intake

\begin{tabular}{|c|c|c|c|c|c|c|c|c|}
\hline \multirow[b]{4}{*}{ Past alcohol intake } & \multicolumn{8}{|c|}{ Current alcohol intake } \\
\hline & \multicolumn{4}{|c|}{ Men } & \multicolumn{4}{|c|}{ Women } \\
\hline & \multicolumn{2}{|c|}{ QF-last-year ${ }^{\star}$} & \multicolumn{2}{|c|}{ Weekly recall } & \multicolumn{2}{|c|}{ QF-last-year } & \multicolumn{2}{|c|}{ Weekly recall } \\
\hline & No. & $r$ & No. & $r$ & No. & $r$ & No. & $r$ \\
\hline$\overline{\mathrm{QF}^{\star} \text { Youth }}$ & 743 & 0.20 & 696 & 0.20 & 351 & 0.23 & 303 & 0.17 \\
\hline $\mathrm{QF}^{\dagger}$ Young adults & 990 & 0.37 & 922 & 0.35 & 724 & 0.45 & 606 & 0.35 \\
\hline $\mathrm{QF}^{\dagger}$ Adults & 1,012 & 0.67 & 940 & 0.62 & 791 & 0.68 & 667 & 0.56 \\
\hline $\mathrm{QF}^{\dagger}$ Middle age $\leq 60 \mathrm{yr}^{\dagger}$ & 748 & 0.87 & 700 & 0.78 & 616 & 0.89 & 509 & 0.79 \\
\hline $61 \mathrm{yr} \geq^{\dagger}$ & 299 & 0.72 & 274 & 0.70 & 216 & 0.81 & 181 & 0.62 \\
\hline $\mathrm{QF}^{\dagger}$ Elderly & 321 & 0.87 & 292 & 0.81 & 240 & 0.93 & 199 & 0.76 \\
\hline Mean lifetime intake & 1,102 & 0.66 & 1024 & 0.63 & 902 & 0.78 & 749 & 0.68 \\
\hline
\end{tabular}

* QF-last-year, quantity-frequency index of alcohol intake in the last year, measured art baseline; QF, quantityfrequency index of alcohol intake per week.

† Age at baseline. 
Table 5. Spearman's correlation coefficients between average weekly alcohol intake estimates for five different drinking periods

\begin{tabular}{|c|c|c|c|c|c|c|c|c|}
\hline \multirow{3}{*}{ Drinking period } & \multicolumn{8}{|c|}{ Drinking period } \\
\hline & \multicolumn{2}{|c|}{ Youth } & \multicolumn{2}{|c|}{ Young adults } & \multicolumn{2}{|c|}{ Adults } & \multicolumn{2}{|c|}{ Middle age } \\
\hline & Men & Women & Men & Women & Men & Women & Men & Women \\
\hline Young adults & 0.60 & 0.54 & & & & & & \\
\hline Adults & 0.40 & 0.37 & 0.66 & 0.71 & & & & \\
\hline Middle age & 0.24 & 0.28 & 0.43 & 0.49 & 0.78 & 0.78 & & \\
\hline Elderly & 0.07 & 0.23 & 0.25 & 0.33 & 0.56 & 0.62 & 0.80 & 0.88 \\
\hline
\end{tabular}

tion. In particular, intake estimates for youth and young adulthood were poorly correlated with selfreports of current drinking. From adulthood on, correlations with current intake indices increased. Self-reports over periods overlapping with current intake, that is, "middle age" for persons no older than age 60 years and "elderly" for persons aged 61 years or older, showed the highest correlations. The correlations between current intake and mean lifetime intake were between 0.63 and 0.78 .

In table 5 , the results of the comparison of the five drinking periods are shown. Two trends became apparent. First, correlations were lower between reports of drinking the further apart in time the reports were made. For example, the correlation between reports over the last period (elderly) and drinking during youth was as low as 0.07 for men. The correlations increased to $0.25,0.56$, and 0.80 for periods approaching current age (last row of table 5). Second, as age increased, the correlation between two adjacent, contiguous life periods increased. For example, the correlations on the diagonal in table 5 increased from 0.60 to 0.80 for men and from 0.54 to 0.88 for women.

\section{Per-capita intake}

Figure 1 compares per-capita intake in the Netherlands (36) with mean intake in the cohort dur-

Figure 1. Per-capita consumption in the Netherlands (PCC) and mean alcohol intake of the study cohort $(\mathrm{n}=$ 3,255 ) (in litres pure alcohol per year) between 1950 and 1995.

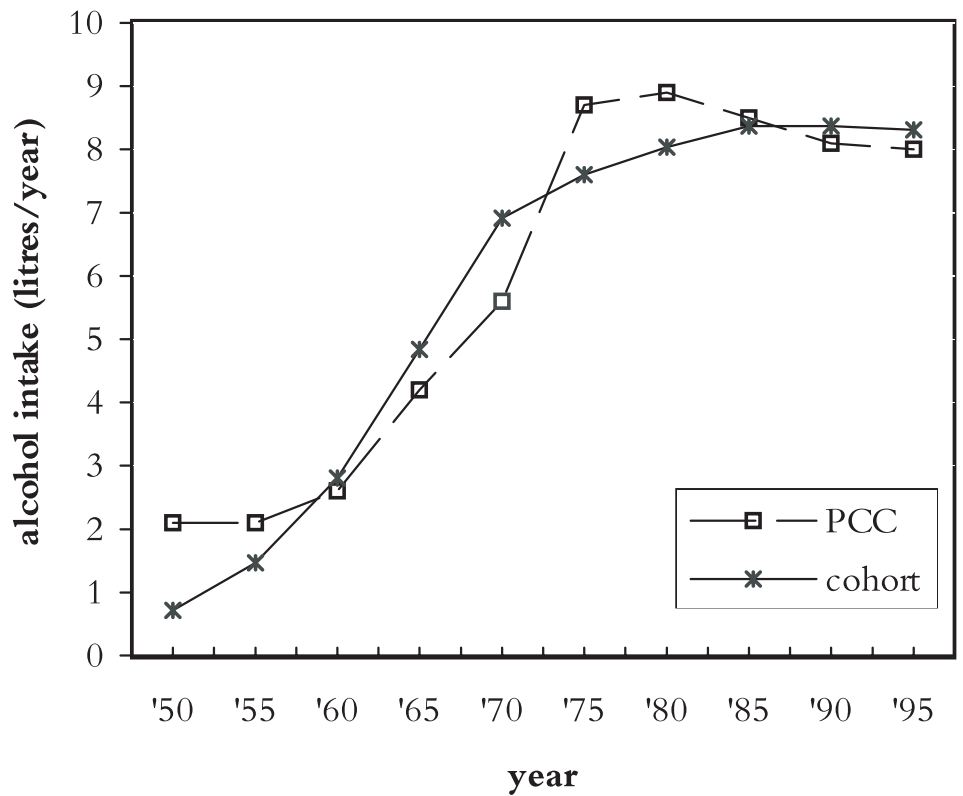


ing the same years. The averages, in litres of alcohol consumed per capita, in the Dutch population and the cohort were similar, and they increased equally through the years. The same trends were found for age-specific intakes plotted against per-capita intake (data not shown).

\section{Disscussion}

The present study investigated the stability and validity of self-reports of lifetime drinking behaviour in a self-administered questionnaire (the LDH-q). Correlation coefficients were used as indicators for test-retest reliability of self-reports of intake collected 1 year apart. Stability of self-reported lifetime intake was found to be reasonable: 0.75 for men and 0.70 for women. As expected, reliability of self-reported intake decreased as the reference period became further back in time, with the lowest ICCs of about 0.50 for intake during youth (12-18 years of age).

In the present study, men on average claimed to have started drinking about 2 years before women did and drank about twice as much as women. Both younger men and women tended to report a greater alcohol intake than the elderly during the same drinking period. This finding is consistent with the trend in per-capita intake in the Netherlands, which increased substantially from 2.1 litres of pure alcohol in 1955 to 9.4 litres in 1979 (36). Although comparable trends were found for mean alcohol intake and per capita intake, the composition of the populations differs. The cohort was a fixed population aging as time passed, whereas the age of the Dutch population was reasonably stable. On the other hand, differences in alcohol intake between age categories were small relative to the period effects, and all age categories showed a similar trend in intake between the 1950s and the 1990s (29). Such an increase in overall intake over the years could affect self-reports of alcohol intake, as was found by Simpura and Poikolainen (18). They reported a tendency by respondents to overestimate their intake of 18 years ago, suggesting a period effect caused by the large increase in per-capita intake in Finland during that period. Whether overestimation occurred in the present study could not be examined. However, if there was overestimation due to an increase in overall intake, one would not expect the trends in intake estimates for both populations to be so similar.

The reliability of reports of lifetime drinking behaviour seemed slightly higher for men than for women. A possible reason might be the drinking pattern, which is less frequent and less regular among women (38), increasing the difficulty in remembering their intake. A similar memory effect may be present for reporting alcohol intake during youth because it concerns the distant past and is characterized by an irregular drinking pattern (39). Low test-retest correlations for intake during youth found in the present study were reported earlier for women (40) and veterans (20).

The LDH-q yielded low estimates of lifelong abstention. Only 1.2 percent of men and 6.0 percent of women could be identified as lifelong teetotallers. In earlier Dutch surveys, estimates of nondrinking usually were about 10 percent for men and 25 percent for women $(27,29,41)$, as was also found in the QF-last-year in the present study (13.0 percent for men and 27.6 percent for women). This information could indicate that using non-drinking rates collected during normal drinking inquiries as indicators of lifelong abstention rates causes these rates to be overestimated.

The low correlation for age at onset may have been partly due to problems some people had in understanding the question correctly; some filled in their current age. When this problem occurred, it was corrected by taking the youngest age for the first drinking period. Doing so provided a noticeable increase in the test-retest correlation for men (from 0.21 to 0.60 ) and a small increase for women (from 0.52 to 0.61 ). The revised correlation for women was comparable to reliability estimates for age at onset with a test-retest interval of 5 years in an interview assessing lifetime drink- 
ing history (40). To prevent misunderstandings in the future, one could tie the question about age at onset closer to the drinking periods.

The ICCs for the frequency questions were lower than those for the open-ended quantity questions and the quantity-frequency weekly intakes. Here, a disadvantage of the ICC could have played a role. In general, the ICC tended to be higher the larger the variation was between subjects (34). Restriction of the variation, as was the case for the frequency question, will lower the ICC. However, the ICCs for mean lifetime intake in this study ( 0.75 for men and 0.70 for women) were comparable to results for the LDH interview formats, ranging from 0.70 to 0.93 (19-21).

The finding that correlations decreased with an increase in the interval between self-reports on drinking during two drinking periods and with an increase in the interval between drinking period and current intake indicates reasonable construct validity. However, recall of early drinking periods was comparatively poor in this study, which could have interfered with estimation of construct validity. The high correlations between current intake and reports for the most recent drinking period fell within the range of test-retest figures for normal current intake tests (15). There seemed to be no difference between men and women regarding this validity aspect.

The correlations between the summary measures for the most recent LDH-q drinking period and over the past year were higher than those between the weekly recall method and the LDH-q. Explanations for this difference may be the similar format of the QF methods and the fact that weekly recall is more sensitive to temporal fluctuations. One could argue that the moderately high correlation between current drinking estimates and lifetime intake estimates (between 0.66 and 0.78 ; table 4) would make use of the latter redundant. In an earlier study (25), computer simulations indeed showed that a J-shaped risk curve between a lifetime intake measure and some outcome could not be reproduced if the correlation between this measure and a current intake measure fell below 0.60 . Values of more than 0.60 would not alter the finding reported in many epidemiologic studies of a J-shaped risk curve. However, a correlation of 0.70 , although comparatively high, still leaves much variation unexplained $\left(\mathrm{R}^{2} \leq 0.49\right)$. In addition, one should not ignore the possibility that the value of the correlations between lifetime and current intakes may well vary by drinking habits and over time.

Until the current study, data on lifetime alcohol intake were all collected by means of interviews. In large-scale population studies, interviews are not feasible, and self administration is an alternative. A drawback of using a selfadministrated questionnaire is the lack of control over the response situation, and lack of guidance, should a respondent fail to understand a question or a routing indication. A large number of respondents who did not complete particular sections of the questionnaire could point to high cognitive complexity. However, only six men and seven women did not complete the LDH-q on both occasions.

In conclusion, test-retest reliability of the LDH-q was within the range normally found for self-report measures of drinking. Construct validity checks, such as decreased correlations with increased time lag, seem to indicate that response effects remained within limits. Finally, the LDH-q yielded results comparable to those for interview measures of lifetime drinking. For studies in which the effects of alcohol are cumulative rather than substitutive, assessment of lifetime exposure is necessary. In such cases, the LDH-q seems a suitable measure. 


\section{References}

1. Maclure M. Demonstration of deductive meta-analysis: ethanol intake and risk of myocardial infarction. Epidemiol Rev 1993;15:328-51.

2. Holman CD, English DR, Milne E, Winter MG. Meta-analysis of alcohol and all-cause mortality: a validation of NHMRC recommendations. Med J Aust 1996;164:141-5.

3. Rimm EB, Klatsky A, Grobbee D, Stampfer MJ. Review of moderate alcohol consumption and reduced risk of coronary heart disease: is the effect due to beer, wine, or spirits. Brit Med J 1996;312:731-6.

4. Svärdsudd K. Moderate alcohol consumption and cardiovascular disease: is there evidence for a preventive effect? Alcohol Clin Exp Res 1998;22:307s-14s.

5. Cleophas TJ. Wine, beer and spirits and the risk of myocardial infarction: a systematic review. Biomed Pharmacother 1999;53:417-23.

6. Corrao G, Rubbiati L, Bagnardi V, Zambon A, Poikolainen K. Alcohol and coronary heart disease: a metaanalysis. Addiction 2000;95:1505-23.

7. Berenson GS, Srinivasan SR, Bao W, Newman WP, 3rd, Tracy RE, Wattigney WA. Association between multiple cardiovascular risk factors and atherosclerosis in children and young adults. The Bogalusa Heart Study. New Engl J Med 1998;338:1650-6.

8. Holman RL, McGill HC, Strong JP, Geer JC. The natural history of atherosclerosis. The early aortic lesions as seen in New Orleans in the middle of the 20th century. Am J Pathol 1958;34:209-35.

9. Stary HC, Chandler AB, Glagov S, Guyton JR, Insull W, Jr., Rosenfeld ME, et al. A definition of initial, fatty streak, and intermediate lesions of atherosclerosis. A report from the Committee on Vascular Lesions of the Council on Arteriosclerosis, American Heart Association. Circulation 1994;89:2462-78.

10. Strong JP, McGill HC. The natural history of coronary atherosclerosis. Am J Pathol 1962;40:37-49.

11. Tuzcu EM, Kapadia SR, Tutar E, Ziada KM, Hobbs RE, McCarthy PM, et al. High prevalence of coronary atherosclerosis in asymptomatic teenagers and young adults: evidence from intravascular ultrasound. Circulation 2001;103:2705-10.

12. Booyse FM, Parks DA. Moderate wine and alcohol consumption: beneficial effects on cardiovascular disease. Thromb Haemost 2001;86:517-28.

13. Lemmens PHHM, Drop MJ. Op zoek naar de gezonde drinker. Tijdschr Alcohol Drugs Andere Psychotr Stoffen 1995/96;21:226-34.

14. Babor TF, Steinberg K, Anton R, Del Boca F.Talk is cheap: measuring drinking outcomes in clinical trials. J Stud Alcohol 2000;61:55-63.

15. Feunekes GI, van 't Veer P, van Staveren WA, Kok FJ. Alcohol intake assessment: the sober facts. Am J Epidemiol 1999;150:105-12.

16. Midanik L. The validity of self-reported alcohol consumption and alcohol problems: a literature review. Br J Addict 1982;77:357-82.

17. Van derVaart W. Inquiring into the past: data quality of responses to retrospective questions. Social-Cultural Sciences. Amsterdam:Vrije Universiteit, 1996.

18. Simpura J, Poikolainen K. Accuracy of retrospective measurement of individual alcohol consumption in men; a reinterview after 18 years. J Stud Alcohol 1983;44:911-7.

19. Skinner HA, Sheu WJ. Reliability of alcohol use indices. The Lifetime Drinking History and the MAST. J Stud Alcohol 1982;43:1157-70.

20. Chaikelson JS, Arbuckle TY, Lapidus S, Gold DP. Measurement of lifetime alcohol consumption. J Stud Alcohol 1994;55:133-40.

21. Russell M, Marshall JR, Trevisan M, Freudenheim JL, Chan AW, Markovic N, et al. Test-retest reliability of the cognitive lifetime drinking history. Am J Epidemiol 1997;146:975-81.

22. Kraus L, Augustin R. Measuring alcohol consumption and alcohol-related problems: Comparison of responses from self-administered questionnaires and telephone interviews. Addiction 2001;96:45971.

23. Gronbaek M, Heitmann BL.Validity of self-reported intakes of wine, beer and spirits in population studies. Eur J Clin Nutr 1996;50:487-90.

24. Bongers IM,Van Oers JA. Mode effects on self-reported alcohol use and problem drinking: mail questionnaires and personal interviewing compared. J Stud Alcohol 1998;59:280-5. 
25. Lemmens PH,Volovics L, Haan Yd. Measurement of lifetime exposure to alcohol: data quality of a self-administered questionnaire and impact on risk assessment. Contemp Drug Probl 1997;24:581-600.

26. Skinner HA. Development and validation of a lifetime alcohol consumption assessment procedure. Toronto, 1982.

27. Statistisch Jaarboek 1999.Voorburg/Heerlen: Centraal Bureau voor de Statistiek, 1999.

28. Garretsen HFL, Knibbe RA. Alkohol prevalentie onderzoek Rotterdam/Limburg. Landelijk eindrapport. Rotterdam/Maastricht: Ministerie van Welzijn,Volksgezondheid en Cultuur, 1983.

29. Neve RJ, Diederiks JP, Knibbe RA, Drop MJ. Developments in drinking behavior in The Netherlands from 1958 to 1989, a cohort analysis. Addiction 1993;88:611-21.

30. Metsemakers JF, Hoppener P, Knottnerus JA, Kocken RJ, Limonard CB. Computerized health information in The Netherlands: a registration network of family practices. Br J Gen Pract 1992;42:102-6.

31. Rohan WP. Quantitative dimensions of alcohol use for hospitalized problem drinkers. Dis Nerv Syst 1976;37:154-9.

32. McGraw KO, Wong SP. Forming inferences about some intraclass correlation coefficients. Psychol Methods 1996;1:30-46.

33. Fleiss JL, Cohen J.The equivalence of weighted kappa and the intraclass correlation coefficient as measures of reliability. Educ Psychol Meas 1973;33:613-9.

34. Armitage P, Berry G. Statistical methods in medical research. Oxford: Blackwell Scientific Publications, 1994.

35. Altman DG. Practical statistics for medical research. London: Chapman and Hall, 1991.

36. Jaarverslag Productschap voor Gedestileerde Dranken (PGD) 2000. Schiedam: Productschap voor Gedistilleerde Dranken (PGD), 2000.

37. Bevolking per gemeente naar leeftijd, geslacht en burgerlijk staat. Centraal Bureau voor de Statistiek: http://statline.cbs.nl/StatWeb/ (2002).

38. Ahlstrom S, Bloomfield K, Knibbe R. Gender differences in drinking patterns in nine european countries: descriptive findings. Substance Abuse 2001;22:69-85.

39. Fillmore KM, Hartka E, Johnstone BM, Leino EV, Motoyoshi M,Temple MT. A meta-analysis of life course variation in drinking. Br J Addict 1991;86:1221-67.

40. Harris TR, Wilsnack RW, Klassen AD. Reliability of retrospective self-reports of alcohol consumption among women: data from a U.S. national sample. J Stud Alcohol 1994;55:309-14.

41. Hupkens CL, Knibbe RA, Drop MJ. Alcohol consumption in the European community: uniformity and diversity in drinking patterns. Addiction 1993;88:1391-404. 



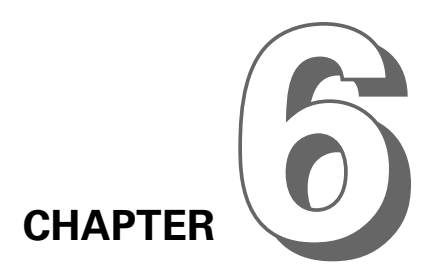

Alcohol intake and cardiovascular disease and mortality:

\section{Current drinking status has more impact than lifetime and past intake}




\begin{abstract}
Current alcohol intake has been associated with cardiovascular morbidity and mortality. In the present study, impact of current, past and lifetime drinking on cardiovascular events and all-cause mortality has been studied. The Lifestyle and Health study is a prospective cohort study in two regions of the Netherlands. Men and women aged 45-70 years registered in 34 general practices were send a baseline questionnaire in June 1996. In the period July 1996-June 2001, 679 men and 397 had a cardiovascular event, and 330 men and 204 women died. Current drinking was associated with lower risks of cardiovascular events (women) and all-cause mortality (men and women) compared to never drinkers. The relationships were strongest for alcohol intake measured with the Weekly Recall. Lifetime alcohol intake and alcohol intake in the distant past did not seem to be related to allcause mortality or cardiovascular events. Adjustments for covariates weakened the relationships. Potential positive effects of drinking seem to be of a transient nature, as lifetime drinking and drinking in the past could not be related to all-cause mortality or cardiovascular events. The alleged benefits of current drinking at baseline diminished with increasing methodological quality and rigor.
\end{abstract}




\section{Introduction}

In the past decades, alcohol intake has been associated with cardiovascular disease, in particular coronary heart disease, and with all-cause mortality (1-3). These relationships are mostly described as Jshaped or U-shaped with higher risk for non-drinkers and heavy drinkers, and lower risk for moderate drinkers. The relationships are often interpreted as causal. Possible biological mechanisms mentioned are inhibition of platelet aggregation, reduction of circulating fibrinogen, and increased level of high-density lipoproteins (4-6).

A methodological critique on the J-curve is that both burden of ill-health and medical treatment increases with age, which could cause a gradual decrease of alcohol intake across all drinking categories (7). Nevertheless, research on the effects of lifetime consumption or moderate drinking in the distant past on cardiovascular disease is scarce (8). In most studies, an average of more than 20 years of drinking have passed at the time of assessment. In those drinking years the pattern has been subject to changes (9-11). The first aim of this article is to assess the impact of assessments of different periods of alcohol intake on the relationship with cardiovascular events and all-cause mortality.

The second aim is to assess the impact of adjustments for confounders and pre-existing diseases on these relationships. A meta-analysis indicated that the quality of a study could influence the results, showing ratios closer to unity in well-conducted studies (12). Three main criteria of high quality were adjustments for the main confounders, separation of former drinkers and never drinkers, and exclusion of subjects with pre-existing diseases. Results of a meta-analysis are based on summarizing various studies, generally with a variety of characteristics. In contrast, with a cohort study the effects of different approaches can be estimated within one group of subjects.

Both aims were investigated using data from the Lifestyle and Health Study (Leefwijze en Gezondheid Onderzoek, LEGO).

\section{Materials and methods}

\section{Population and design}

The Lifestyle and Health Study is a prospective cohort study on alcohol intake and cardiovascular disease. General practitioners were sought through regional health institutes until a sample size of ca. 31,000 men and women aged between 45 and 70 years was reached, which comprised 34 general practices. In the Netherlands, coverage of the general population by patient registration in primary practices is high, as almost all people are registered with a general practitioner due to his central role in health care $(13,14)$. Therefore, the database of a general practice is comparable to a population-based sample. For practical reasons, participation of practices was restricted to two regions in the south-eastern and western part of the Netherlands. These two regions were expected to differ with regard to drinking practices in earlier decades, with the south-eastern region traditionally having a higher average consumption (15).

In June 1996, the baseline questionnaire was send to the selected men and women with a response rate of 51.7 percent. Terminal patients, patients with severe dementia, mentally disabled patients and institutionalised patients were excluded in advance. Informed consent was obtained in a letter presenting the questionnaire. A non-response analysis revealed no differences in demographic variables. However, respondents had slightly more often pre-existing coronary heart disease than non-respondents. No differences were found concerning alcohol-related illness. The respondents received a follow-up questionnaire each year between 1997 and 2000.

The study design, using only coded data, was approved by the review committee of the Registra- 
tion Network Family Practices of the University of Maastricht. For reasons of efficiency, a case-cohort approach was applied, involving a selection of a random sample at baseline. This sample, further referred as subcohort $(n=3,253)$, was used in the analyses as control group.

\section{Baseline measurement}

Baseline measurement consisted of a detailed self-administered questionnaire assessing, among others, the main cardiovascular risk factors. Alcohol consumption was measured as current intake at baseline, and alcohol intake in specified age periods. Lifetime intake was calculated from the alcohol intake in specified age periods. The latter was measured with the Lifetime Drinking History questionnaire (LDH-q). The $\mathrm{LDH}-\mathrm{q}$ is a self-administered questionnaire about alcohol intake since the first glass drunk based on an interview format of the Lifetime Drinking History $(16,17)$. Both reliability and validity of the LDH-q were reasonably high, and were comparable to results obtained with interview formats $(17,18)$. The LDH-q consists of five age periods which are based on transitions in normal human lives, comprising youth (aged 12-18 years), young adulthood (aged 19-27 years), adulthood (aged 28-44 years), middle-age (aged 45-60 years), and old-age (aged $\geq 61$ years). For each period, quantity and frequency of alcohol consumption was assessed. Current intake was assessed using three methods, namely a Weekly Recall, a Quantity-Frequency form about last year's consumption (QF-last-year), and the LDH-q. The Weekly Recall assessed actual intake per day of the last week separately for beer, wine, and spirits. The actual week consumption was calculated by adding up all drinks. The usual consumption in the year prior to baseline was ascertained with the QF-last-year by questions about usual quantity and frequency again separately for beer, wine, and spirits. The beverage-specific week consumptions were added up to a total week consumption. The current drinking period of the LDH-q at baseline was determined by the current age of the respondent. For respondents aged 45 to 60 years their current period was LDH-middle-age and for respondents 61 years or older this was LDH-elderly.

Alcohol intake was distinguished into seven categories: never drinkers; former drinkers; drinkers of $<1$ glass/week; drinkers of 1-6.9 glasses/week; drinkers of 7-14.9 glasses/week; drinkers of 15-28 glasses/week; and drinkers of $>28$ glasses/week. For the Weekly Recall, the category of drinkers of $<1$ glass/week was determined with the QF-last-year. Lifetime drinking pattern has been categorized into eight categories: never drinkers; occasional drinkers; stable drinkers of 1-6.9 glasses/week; stable drinkers of $\geq 15$ glasses/week; drinkers who decreased their drinking during life; drinkers who drank more during young adulthood compared to youth, but decreased their drinking afterwards; drinkers who increased their drinking during life; and a variable drinking pattern.

\section{Endpoints}

All myocardial infarctions, and all deaths occurring in the period from July 1996 up to June 2001 were reported by the general practitioners. Cause of death was reported by the general practitioner using nine main categories: myocardial infarction; other cardiac deaths; stroke; other vascular deaths; cancer; infection or autoimmune diseases; violence or accident; suicide; and other or unknown causes. The death rate in the study was somewhat lower compared to the death rate in the total Dutch population (19), although the distribution over the different causes of death was comparable, with a small overrepresentation of cardiovascular deaths.

Besides these reports, medical information was obtained through the general practitioners who filed all major health problems of the past and during the follow-up period on problem lists (20). Categorization of the health problems was done using ICPC-codes (International Classification of Primary Care) (21). These problem lists were compared to the reports, and discrepancies were communicated with the general practitioners. Non-fatal stroke (K89 or K90), heart failure (K77) 
and coronary heart disease (K74 or K75 or K76) other than (imminent) myocardial infarction were derived from the problem lists only. Reports of myocardial infarction were compared to nationwide admissions into hospitals (22), and endpoints collected from the problem lists were compared to an established registration network, the Registration Network of Family Practices (14). Both comparisons yielded no relevant differences in incidences. Medical records of 81 patients with a myocardial infarction were searched for diagnostic ECGs and lab results at the time of the event. A cardiologist evaluated these records and 79 patients had had a definite myocardial infarction and 2 had had a possible infarction.

Cardiovascular events included all deaths related to cardiovascular causes and all non-fatal events of coronary heart disease, stroke and heart failure. All participants with an endpoint occurring during follow-up were included as cases.

\section{Data analysis}

The total cohort consisted of 16,210 persons. The baseline questionnaires of the subcohort and cases were incorporated for analyses. As a result of one general practitioner failing to report the health problems of his patients, 69 cases and subcohort members had to be excluded. In addition, 80 persons with no data on alcohol intake were excluded. This left a total of 3,135 subcohort members (1,562 men and 1,573 women). Of the total cohort, 679 men and 397 women had had a cardiovascular event of which 601 men and 360 women were diagnosed with non-fatal cardiovascular disease. A total of 330 men and 204 women died during the follow-up.

The Cox regression model was adapted for the case-cohort design by defining the entry time of subjects into the analysis as just before the event, for all cases outside the subcohort. Standard errors of the estimated parameters were estimated using the robust Huber-White sandwich estimator to account for additional variance introduced by sampling from the cohort (23). Men and women were analysed separately. The models assessing the impact of different assessments of alcohol intake were adjusted for age (continuous), region (southeast/west), packyears (non-smokers and categorization of number of packyears in quartiles), body mass index (quintiles), fat intake (quintiles), physical activity (quintiles), education (7 categories), income (5 categories), and medical histories (yes/no) of cardiovascular disease, hypertension, diabetes, and hypercholesterolaemia. The classification into quartiles or quintiles was done using the distribution of the subcohort. The assessment of the impact of confounders and pre-existing diseases was done by comparing the full-adjusted model with several models leaving one or more variables aside. This was done both for alcohol intake in the last year (QF-last-year) and in the last week (Weekly Recall).

The graphic visualization of the shape of the relationship between alcohol intake and the hazard ratios for all-cause mortality was done using spline models (24). A number of join points were chosen and the trend for each line segment was calculated. The curve is modelled by the series of connected line segments.

\section{Results}

\section{Demographic characteristics}

The subcohort was on average five years younger than the cases, for men as well as women. Cases were more often smokers and former smokers, and they had smoked on average more packyears than the subcohort. The subcohort members seemed to have received higher education, and earned more money than the cases. Medical histories of cardiovascular disease, hypertension, diabetes, or hypercholesterolaemia were more prevalent in cases than in subcohort members. Distributions 
within region, body-mass index, fat intake, and physical activity were comparable for cases and subcohort.

\section{Current drinking}

In table 1 and 2, the results of the different measurements and time windows of alcohol intake in relation to all-cause mortality, and cardiovascular events are presented. The results for non-fatal cardiovascular events only were comparable with the overall group of cardiovascular events, and are therefore not presented separately.

Men who abstained in the last week according to the Weekly Recall had higher risk of dying during the five-years period of follow-up compared to male never drinkers. Male and female drinkers had lower hazard ratios for all-cause mortality compared to never drinkers for all measures of current intake at baseline. For men, significance was only reached when measured with the Weekly Recall. For women, significance was not reached using LDH-middle age (for women $\leq 60$ years at baseline). Drinking in the past week was significantly related to cardiovascular events for women only. Other measures of current drinking in women and all current drinking measures in men were not significantly related to cardiovascular events.

A narrow application of the Weekly Recall would imply a compilation of never drinkers, former drinkers and occasional drinkers who abstained in the past week. Expanding the reference group with those occasional drinkers and former drinkers strengthened the effects (table 1 \& 2, WR: reference). This expansion provided significant lower risks for all drinkers in the past week for both allcause mortality and cardiovascular events.

The shape of the association for all-cause mortality is visualized in figure $1 \mathrm{a}$ for men and figure $1 \mathrm{~b}$ for women. Both QF-last-year and Weekly Recall showed J-shaped curves, although the curves for Weekly Recall were more distinct. For cardiovascular events, comparable J-curves were found for men. For women, the curves for cardiovascular events went more towards decreasing linear (graphs not shown).

\section{Past and lifetime drinking}

The hazard ratios for past drinking were, in general, closer to unity compared to current drinking for both all-cause mortality and cardiovascular events (table $1 \& 2$ ). Only consumption of 1 to 15 drinks per week during adulthood for women seemed to be related to lower risk of all-cause mortality, albeit in a smaller degree than current drinking.

Alcohol intake in the different drinking periods in life were combined into four stable drinking patterns and four changing patterns (table 3). An increase of drinking during life led to a significant lower risk of all-cause mortality compared to never drinkers. A stable drinking pattern of 1 to 15 drinks per week for men and less than 1 drink per week for women showed lower hazard ratios for all-cause mortality compared to never drinkers. No significant effects of lifetime alcohol intake were found for cardiovascular events.

The effect of total lifetime number of drinks on all-cause mortality is visualized in figure 2. For men, a slightly significant reduction in all-cause mortality was found when between 11,000 and 22,000 drinks during lifetime were drunk. For women, no significant relationship could be seen. The relationship between total lifetime number of drinks and cardiovascular events was not significant for both men and women (figures not shown).

\section{Covariates and pre-existing disease}

Analyses without adjustments for covariates (table 4) provided stronger relationships between alcohol intake and all-cause mortality, and cardiovascular events, and significance was reached more of- 


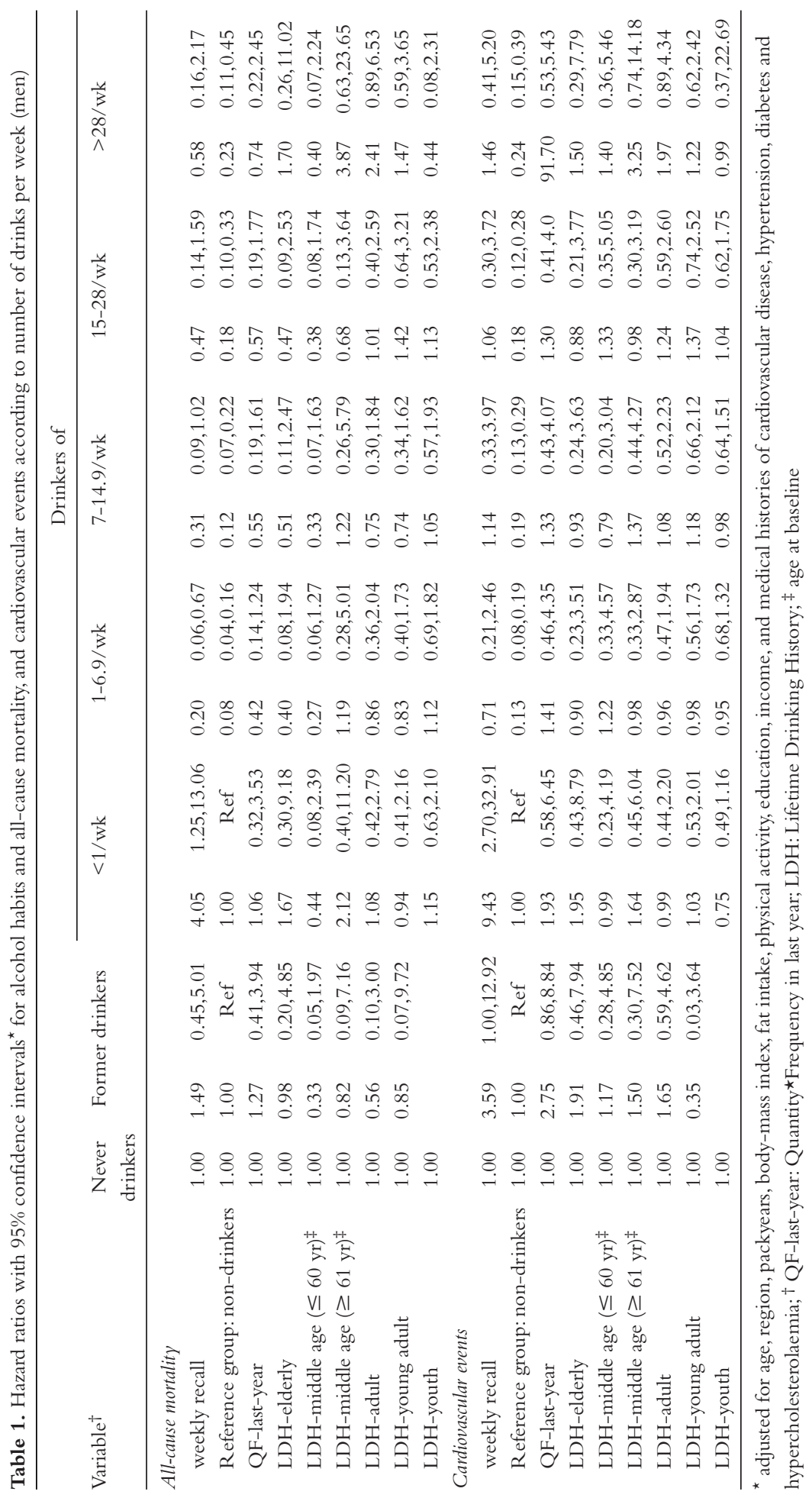




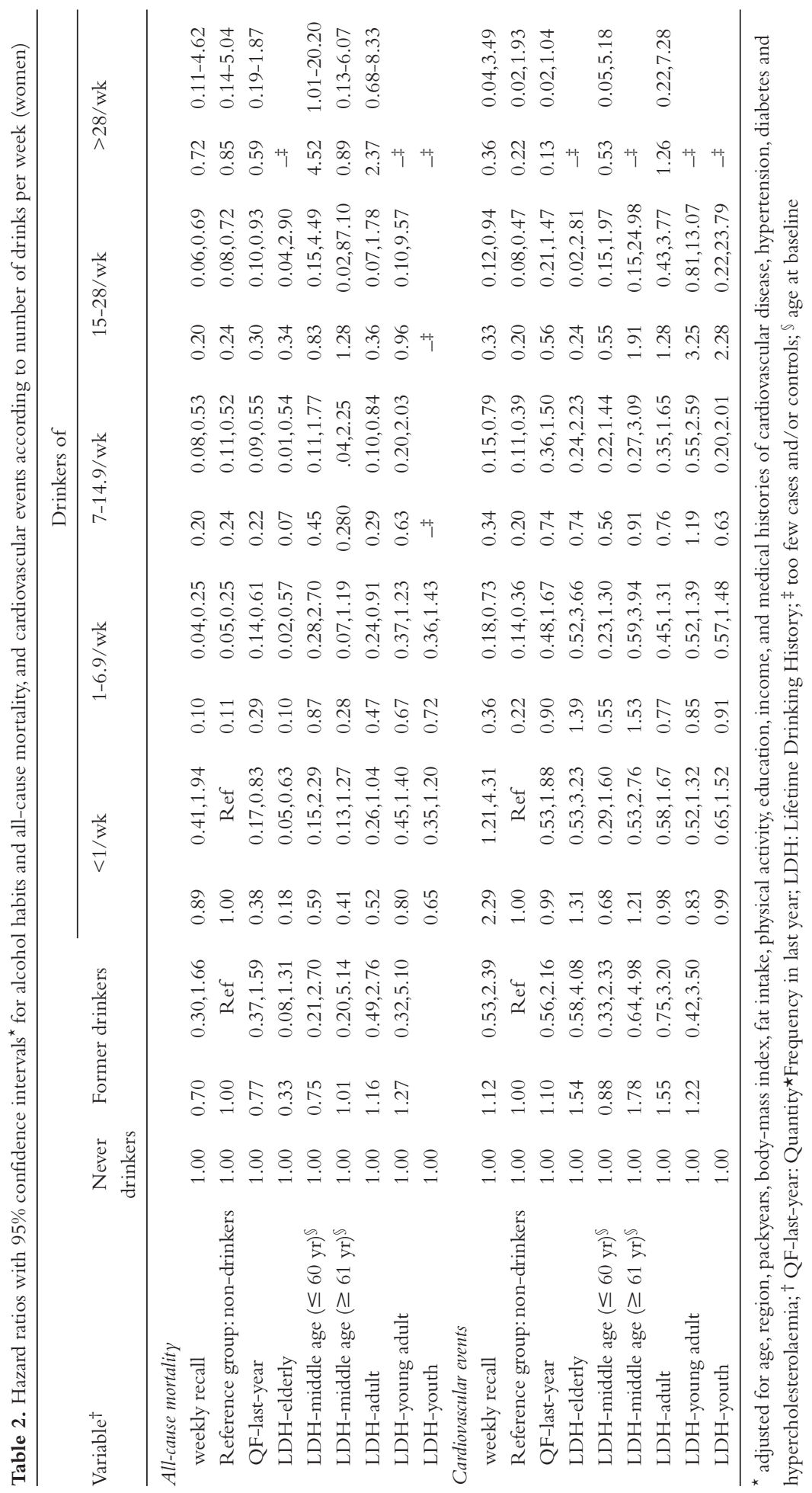


Figure 1a. Hazard ratios for all-cause mortality for current alcohol intake at baseline (men)

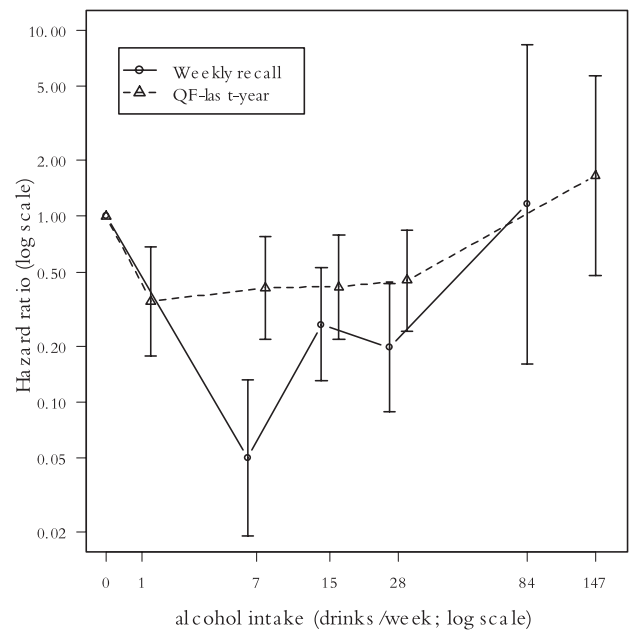

Figure 1b. Hazard ratios for all-cause mortality for current alcohol intake at baseline (women)
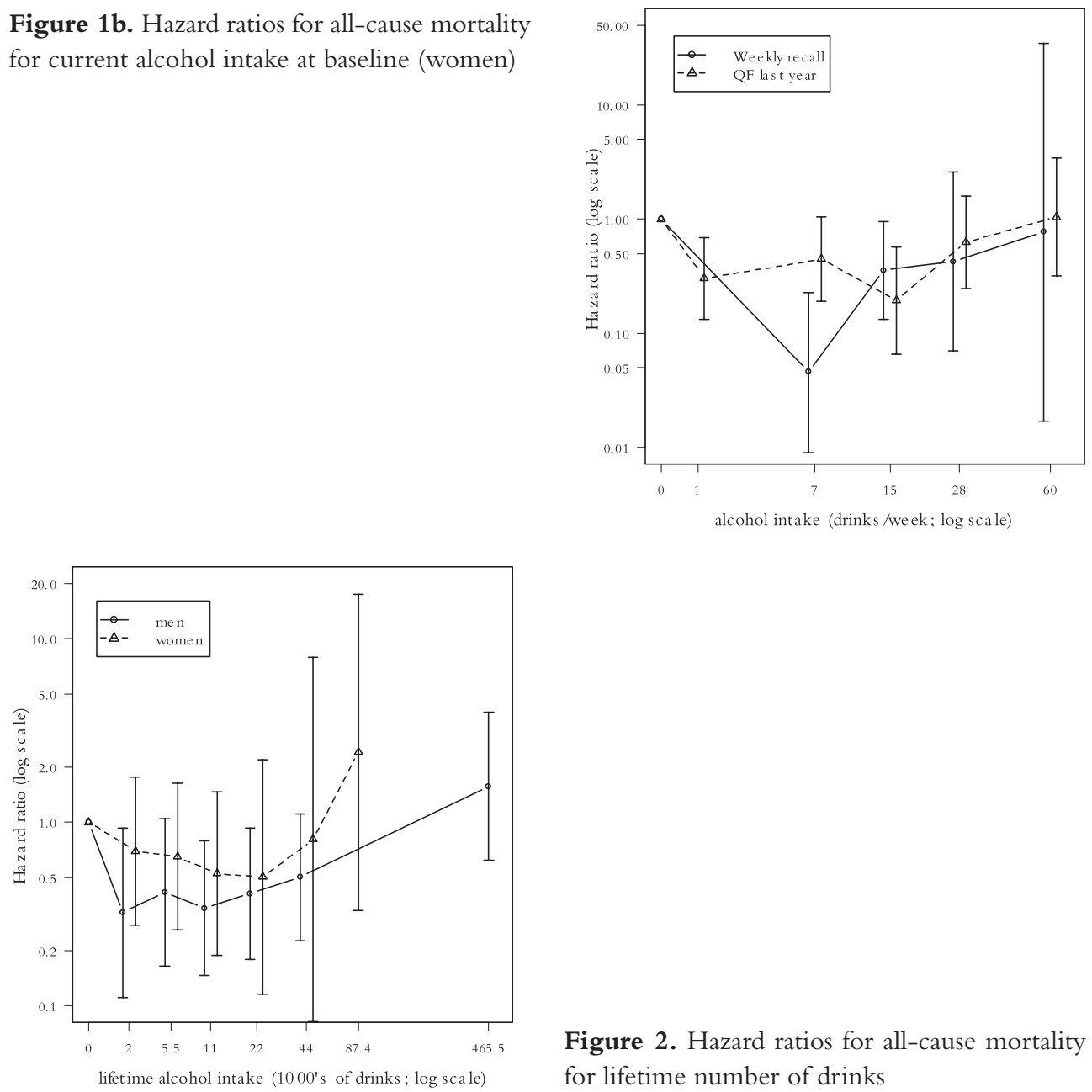

Figure 2. Hazard ratios for all-cause mortality for lifetime number of drinks 


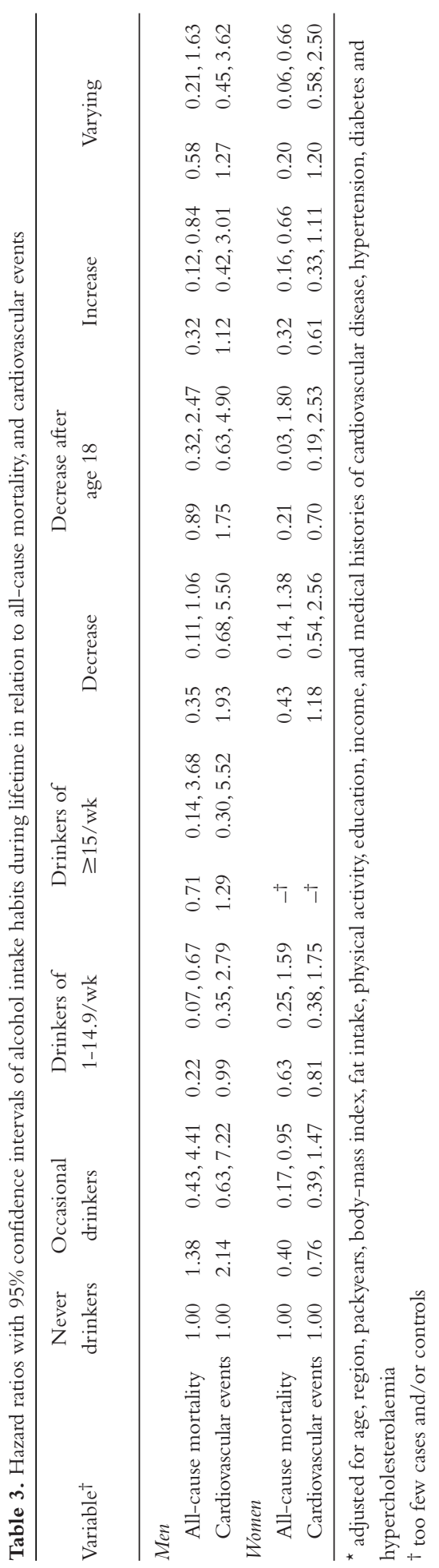


ten than the fully adjusted ratios. The partly adjusted ratios were in between both extremes, and are therefore not included in table 4. Similar trends were seen when using the alcohol intake measured with the Weekly Recall (data not shown).

Exclusion of persons with a medical history of cardiovascular disease lowered the risk of all-cause mortality for male drinkers, especially for those drinking one to seven glasses per week (table 4). However, with the same exclusion, the risk for cardiovascular events increased. A similar increase was seen in risk for cardiovascular events after exclusion of men with pre-existing diabetes. The risk of all-cause mortality was comparable for men without pre-existing diabetes and the total group of men. For women, exclusion of persons with pre-existing cardiovascular disease did not seem to affect the relationship between alcohol intake and all-cause mortality in a specific pattern, and appeared to strengthen the lower risks for drinkers of cardiovascular events. The same trends were seen when women with pre-existing diabetes were excluded.

\section{Discussion}

U-shaped relationships were clearest found for current drinking status at baseline, and especially when measured with the Weekly Recall. Past and lifetime drinking did not appear to be related to risk of all-cause mortality or cardiovascular events in persons over 45 years of age, although there were a few indicators of a small association between drinking in adulthood (only for women) and lifetime drinking, and all-cause mortality. Adjustments for covariates reduce the strength of the relationships, implying that non-adjusted or partly adjusted results overestimate the relationships.

In general, the relationships were stronger for women than for men. Previous studies are inconclusive regarding influence of sex on the relationship between alcohol intake and mortality and morbidity (25-32), although gender affects alcohol intake (33) as well as overall risk of mortality and morbidity $(19,34)$. In the present study, the numbers of male never drinkers were low. This could imply a problem with the power, and could explain the stronger relationships for women. Higher risks for heavy drinkers was not found, which was likely to be the result of low number of heavy drinkers.

Despite high correlations between the different measures of current drinking at baseline (18), the relationships were stronger when using the Weekly Recall compared to the QF-last-year and the LDH-q. This is surprising since this measure assesses recent intake in a specific week of the year. It is especially this measure which will be prone to fluctuations over time, and, hence, a lower reliability and attenuation of associations with endpoints. The fact that more pronounced effects were found with this measure, lends credence to the opinion that the alcohol effects found in epidemiology are to be attributed to current drinking. This would imply that lifelong moderate drinking would not contribute to a decreased mortality or morbidity risk. In the present study, neither lifetime drinking pattern nor total lifetime number of alcoholic drinks were clearly associated with allcause mortality or cardiovascular risks. In addition, drinking habits in the distant past could not be related to all-cause mortality and cardiovascular events. Although several risk factors, such as smoking and obesity, influence atherosclerotic processes already early in life $(35,36)$, alcohol intake appear to be associated with cardiovascular disease only later in life. In case of mortality, the finding of no relationships for alcohol intake in the past may be caused by selective deaths before the age of 45 years, as the cohort consisted of persons aged between 45 and 70 years at baseline. However, this is unlikely, since relationships were not found for past alcohol intake and morbidity.

Several methodological factors seem to influence the relationship between alcohol intake and risk of all-cause mortality or cardiovascular events. First, using a merged group of never drinkers, former drinkers and occasional drinkers as reference group appears to overestimate the possible effects of 


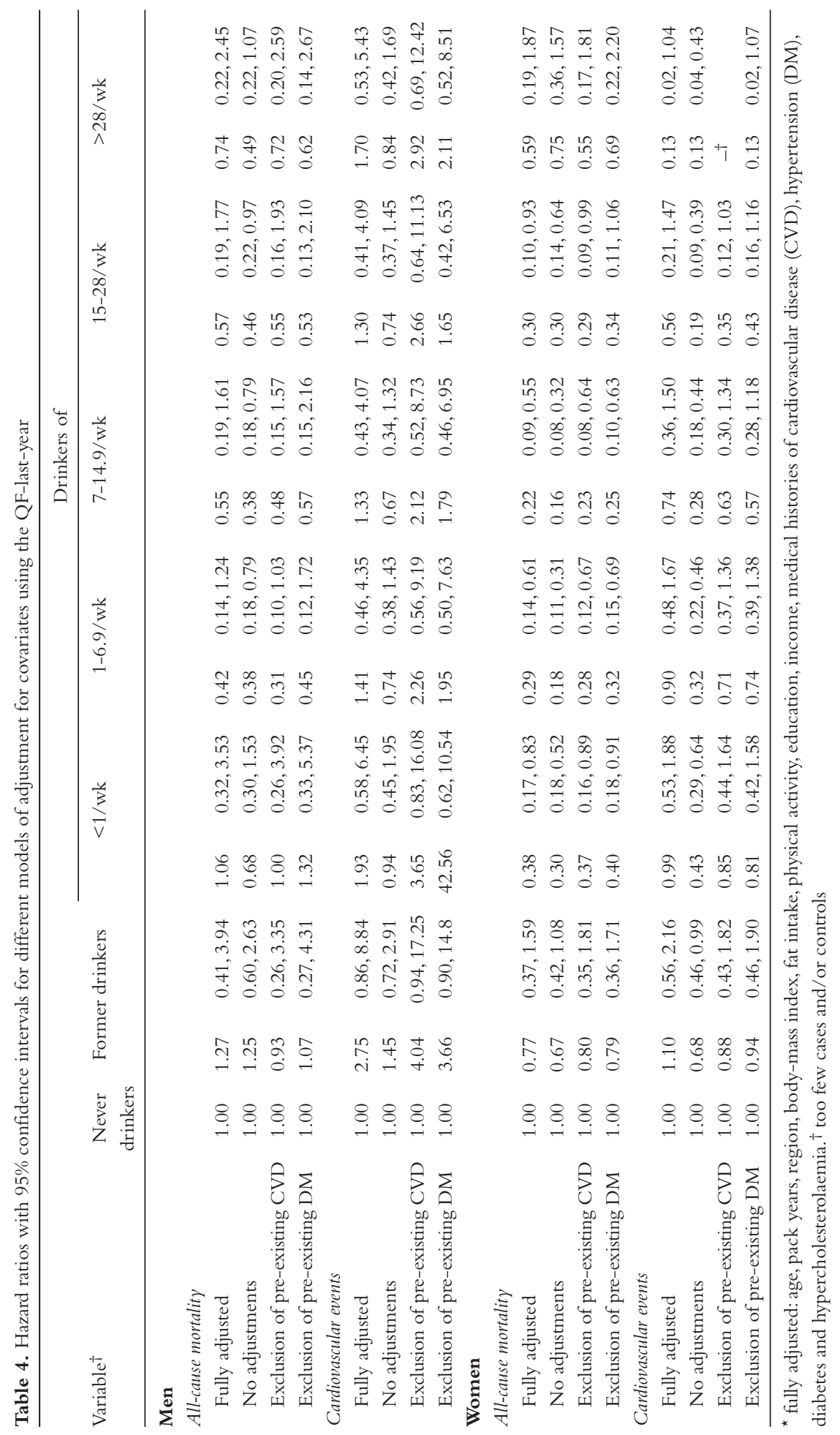


alcohol intake, as already stated by others $(12,37,38)$. Second, the differences in risk between never drinkers and drinkers as regards all-cause mortality and cardiovascular events, are smaller when all measured confounders were included in the model. To what extent one should adjust for hypertension or hypercholesterolaemia is disputable, as both can be intervening factors between alcohol intake and mortality and morbidity, especially in case of cardiovascular events (39). Nevertheless, adjustments for pre-existing hypertension and hypercholesterolaemia did not alter the hazard ratios considerably in the present study.

In conclusion, risk of all-cause mortality and cardiovascular events in a general population aged 4570 years in the Netherlands is primarily based on current drinking at baseline. Drinking in the distant past and lifetime drinking habits do not seem to influence these risks considerably. This would imply that the possible effects of alcohol intake are acute and not long-term. Choice of model specification affects the results. Use of all non-drinkers as reference group, and no or poor adjustment for covariates both appear to overestimate the possible effects of alcohol intake on all-cause mortality and cardiovascular events.

\section{References}

1. Beaglehole R, Jackson R. Alcohol, cardiovascular diseases and all causes of death: a review of the epidemiological evidence. Drug Alcohol Rev 1992;11:275-90.

2. Rehm J, Bondy S. Alcohol and all-cause mortality: an overview. Novartis Found Symp 1998;216:223-32.

3. Andréasson S. Alcohol and J-shaped curves. Alcohol Clin Exp Res 1998;22:359S-64S.

4. Booyse FM, Parks DA. Moderate wine and alcohol consumption: beneficial effects on cardiovascular disease. Thromb Haemost 2001;86:517-28.

5. Fagrell B, De Faire U, Bondy S, Criqui M, Gaziano M, Gronbaek M, et al. The effects of light to moderate drinking on cardiovascular diseases. J Intern Med 1999;246:331-40.

6. Rimm EB, Williams P, Fosher K, Criqui M, Stampfer MJ. Moderate alcohol intake and lower risk of coronary heart disease: meta-analysis of effects on lipids and haemostatic factors. Brit Med J 1999;319:1523-8.

7. Shaper AG, Wannamethee G, Walker M. Alcohol and mortality in British men: explaining the U-shaped curve. Lancet 1988;2:1267-73.

8. Gunzerath L, Faden V, Zakhari S, Warren K. National Institute on Alcohol Abuse and Alcoholism Report on Moderate Drinking. Alcohol Clin Exp Res 2004;28:829-47.

9. Kerr WC, Fillmore KM, Bostrom A. Stability of alcohol consumption over time: evidence from three longitudinal surveys from the United States. J Stud Alcohol 2002;63:325-33.

10. Neve RJ, Diederiks JP, Knibbe RA, Drop MJ. Developments in drinking behavior in The Netherlands from 1958 to 1989 , a cohort analysis. Addiction 1993;88:611-21.

11. Fillmore KM, Hartka E, Johnstone BM, Leino EV, Motoyoshi M,Temple MT. A meta-analysis of life course variation in drinking. Br J Addict 1991;86:1221-67.

12. Corrao G, Rubbiati L, Bagnardi V, Zambon A, Poikolainen K. Alcohol and coronary heart disease: a metaanalysis. Addiction 2000;95:1505-23.

13. Van der Linden MW, Westert GP, De Bakker DH, Schellevis FG. Tweede Nationale Studie naar ziekten en verrichtingen in de huisartspraktijk. Klachten en aandoeningen in de bevolking en in de huisartspraktijk. Utrecht/Bilthoven: NIVEL/RIVM, 2004.

14. Metsemakers JF, Hoppener P, Knottnerus JA, Kocken RJ, Limonard CB. Computerized health information in The Netherlands: a registration network of family practices. Br J Gen Pract 1992;42:102-6.

15. Garretsen HFL, Knibbe RA. Alkohol prevalentie onderzoek Rotterdam/Limburg. Landelijk eindrapport. Rotterdam/Maastricht: Ministerie van Welzijn,Volksgezondheid en Cultuur, 1983.

16. Skinner HA, Sheu WJ. Reliability of alcohol use indices. The Lifetime Drinking History and the MAST.J Stud Alcohol 1982;43:1157-70.

17. Lemmens PH,Volovics L, Haan Yd. Measurement of lifetime exposure to alcohol: data quality of a self-administered questionnaire and impact on risk assessment. Contemp Drug Probl 1997;24:581-600. 
18. Friesema IHM,Veenstra MY, Zwietering PJ, Knottnerus JA, Garretsen HFL, Lemmens PHHM. Measurement of lifetime alcohol intake: Utility of a self-administered questionnaire. Am J Epidemiol 2004;159:809-17.

19. Sterfte naar leeftijd, geslacht en burgerlijk staat. Centraal Bureau voor de Statistiek: http://statline.cbs.nl/ StatWeb/ (2002).

20. Sandlow LJ, Bashook PG. Problem oriented medical records. Self instruction for practitioners. Chicago: Michael Reese Hospital and Medical Center, 1978.

21. Lamberts H, Wood M. ICPC : International Classification of Primary Care. Oxford: Oxford University Press, 1987.

22. Landelijk aantal opnamen, kliniek en dagverpleging, verpleegdagen en gemiddelde verpleegduur per diagnose onderverdeeld naar leeftijd en geslacht. Prismant: http://www.prismant.nl (2004).

23. Lin DY, Wei LJ. The robust inference for the Cox Proportional Hazards Model. J Am Stat Assoc 1989;84:1074-78.

24. Greenland S. Introduction to regression models. In: Rothman KJ, Greenland S, eds. Modern Epidemiology. Philadelphia: Lippincott Williams \& Wilkins, 1998:359-99.

25. Cullen K, Stenhouse NS, Wearne KL. Alcohol and mortality in the Busselton study. Int J Epidemiol 1982;11:67-70.

26. Gordon T, Kannel WB. Drinking habits and cardiovascular disease: the Framingham Study. Am Heart J 1983;105:667-73.

27. Gordon T, Kannel WB. Drinking and mortality. The Framingham Study. Am J Epidemiol 1984;120:97-107.

28. Klatsky AL, Armstrong MA, Friedman GD. Red wine, white wine, liquor, beer, and risk for coronary artery disease hospitalization. Am J Cardiol 1997;80:416-20.

29. Klatsky AL, Friedman GD, Armstrong MA, Kipp H. Wine, liquor, beer, and mortality. Am J Epidemiol 2003;158:585-95.

30. Murray RP, Connett JE, Tyas SL, Bond R, Ekuma O, Silversides CK, et al. Alcohol volume, drinking pattern, and cardiovascular disease morbidity and mortality: is there a U-shaped function? Am J Epidemiol 2002;155:242-8.

31. Rehm JT, Bondy SJ, Sempos CT, Vuong CV. Alcohol consumption and coronary heart disease morbidity and mortality. Am J Epidemiol 1997;146:495-501.

32. Serdula MK, Koong SL, Williamson DF, Anda RF, Madans JH, Kleinman JC, et al. Alcohol intake and subsequent mortality: Findings from the NHANES I follow-up study. J Stud Alcohol 1995;56:233-9.

33. Fillmore KM. Women's drinking across the adult life course as compared to men's. Br J Addict 1987;82:801-11.

34. Statistisch Jaarboek 1999.Voorburg/Heerlen: Centraal Bureau voor de Statistiek, 1999.

35. Ambrose JA, Barua RS. The pathophysiology of cigarette smoking and cardiovascular disease: an update. J Am Coll Cardiol 2004;43:1731-7.

36. McGill HC, Jr., McMahan CA. Starting earlier to prevent heart disease. JAMA 2003;290:2320-2.

37. Shaper AG. Alcohol and mortality: a review of prospective studies. Br J Addict 1990;85:837-47.

38. Tsubono Y,Yamada S, Nishino Y, Tsuji I, Hisamichi S. Choice of comparison group in assessing the health effects of moderate alcohol consumption. JAMA 2001;286:1177-8.

39. Marmot M, Brunner E. Alcohol and cardiovascular disease: the status of the $U$ shaped curve. Brit Med J 1991;303:565-8. 


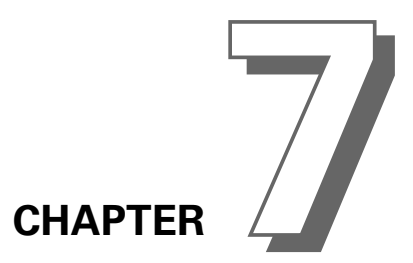

Effects of alcohol intake on cardiovascular disease and mortality in diabetic subjects 


\begin{abstract}
The prevalence of diabetes is rising worldwide. A common complication in diabetes is cardiovascular disease. In general populations, moderate alcohol intake seems to lower risk of cardiovascular disease. First aim was to analyse differences in alcohol intake between diabetic and non-diabetic subjects. Second aim was to assess the association of alcohol intake with risk of cardiovascular morbidity and mortality, and all-cause mortality in diabetic subjects. A prospective cohort study of men and women aged 45-70 years at baseline was set up in 1996. Present analyses are based upon all subjects with diabetes (509 men and 480 women) and a sample of 1,407 men and 1,383 women free of diabetes. Alcohol intake was measured with self-administered questionnaires. Medical information was obtained from general practitioners. Subjects with diabetes at baseline, and those diagnosed with diabetes during the five years of follow-up showed similar drinking patterns. Diabetic men and women drank less often alcohol at baseline compared to non-diabetic subjects. Diabetic men who did not drink or drank occasionally appeared to have higher risk for cardiovascular events and allcause mortality compared to those drinking moderately. For diabetic women, never and occasionally drinking seemed to be associated with higher risks for cardiovascular events compared to moderate drinking. Diabetic subjects differed in alcohol intake compared to non-diabetic subjects. Compared to general population studies, similar associations were found for the relationship between alcohol intake and cardiovascular events, and alcohol intake and all-cause mortality.
\end{abstract}




\section{Introduction}

Diabetes mellitus affects an estimated 171 million persons worldwide, and this number is expected to rise in the next decades (1). In established market economies, numbers are expected to rise with about $50 \%$ in 30 years. Major causes of this rise are the increase of the ageing population and the increasing prevalence of obesity (1). Other factors related to the incidence of diabetes are diet and lifestyle, such as fat consumption, smoking habits, and physical activity $(2,3)$. Alcohol intake has also been related to diabetes, but this association seems to follow a J-shape. Moderate drinkers appear to have lower risks of becoming diabetic than non-drinkers or heavy drinkers (4).

Once diabetic, consumption of alcohol is controversial. Alcohol intake has been related to shortterm risks such as hypoglycaemia and metabolic dysregulation, and long-term effects such as weight gain and hypertension $(5,6)$. Therefore, physicians often advice to reduce or even stop drinking. On the other hand, moderate alcohol intake in diabetes has been associated with increased insulin sensitivity and lower risk of cardiovascular disease, in particular coronary heart disease $(5,7-10)$.

Although the association between alcohol intake and coronary heart disease has been studied before in diabetic populations (7-10), only one study distinguished former drinkers from never drinkers in all analyses (9) and none of the studies assessed alcohol intake other than current intake at baseline. The relationship between alcohol intake and all-cause mortality has been reported by Diem et al (11) who found a reduced risk in a diabetic population for moderate drinkers compared to non-drinkers.

It is known that cardiovascular disease is more prevalent in diabetic populations than in the general population (12). To what extent alcohol intake possibly differs between diabetic and general populations is less known. Therefore, a comparison between diabetic and non-diabetic subjects was made to reveal possible differences in current alcohol intake at baseline and lifetime pattern of drinking. Then, the association between alcohol intake and cardiovascular mortality and morbidity, and between alcohol intake and all-cause mortality were examined for the diabetic population. All analyses were done using data from the Lifestyle and Health Study (Leefwijze en Gezondheid Onderzoek, LEGO).

\section{Materials and methods}

\section{Population}

The LEGO-study is a prospective cohort study on alcohol intake and cardiovascular disease. Subjects were recruited from 34 general practices spread over two regions in the south-eastern and western part of the Netherlands. The reason for using general practices as the sampling frame was the availability of past and future medical information in the patient registration. In the Netherlands, almost everyone is registered with a general practitioner due to his central role in health care $(13,14)$.

The basic cohort was established in June 1996, when all men and women aged 45 to 70 years in the registrations of these practices received a questionnaire. Terminal patients, patients with severe dementia, mentally disabled patients and institutionalised patients were excluded in advance. Of the ca. 31,000 subjects initially selected, $51.7 \%$ responded to the mailed questionnaire. Informed consent was obtained in a letter presenting the questionnaire.

All respondents with diabetes mellitus in the cohort were included in the present study. At baseline, a sample was also drawn among all respondents to be used as control group. 


\begin{abstract}
Alcohol intake
Baseline measurement consisted of a detailed self-administered questionnaire assessing main cardiovascular risk factors. Alcohol consumption was measured as current intake at baseline, and alcohol intake in specified age periods.

Current intake was assessed using a Weekly Recall, and a Quantity-Frequency form about last year's consumption (QF-last-year). The Weekly Recall assessed actual intake per day in the week before baseline separately for beer, wine, and spirits. The actual week consumption was calculated by adding up all drinks. The usual consumption in the year prior to baseline was ascertained with the QF-last-year by questions about usual quantity and frequency, again separately for beer, wine, and spirits. The beverage-specific week consumptions were added up to a total week consumption. Current alcohol intake was distinguished into seven categories: never drinkers; non-drinkers; <1 glass/week; 1-6.9 glasses/week; 7-14.9 glasses/week; 15-28 glasses/week; and >28 glasses/week. In case of the Weekly Recall, the category of drinkers of $<1$ glass/week was determined with the QFlast-year.

Lifetime pattern of alcohol intake was assessed by combining alcohol intake in specified age periods, which was measured with the Lifetime Drinking History questionnaire (LDH-q). The LDH-q is a self-administered questionnaire about alcohol intake since the first glass drunk, based on an interview format of the Lifetime Drinking History (15-17). Eight categories were created: never drinkers; occasional drinkers; stable drinkers of 1-6.9 glasses/week; stable drinkers of $\geq 15$ glasses/ week; drinkers who decreased their drinking during life; drinkers who drank more during young adulthood compared to youth, but decreased their drinking afterwards; drinkers who increased their drinking during life; and a variable drinking pattern.
\end{abstract}

\title{
Medical information
}

Medical information was obtained from the general practitioners who filed all major health problems of the past and during the follow-up period on problem lists (18). Categorization of the health problems was done using ICPC-codes (International Classification of Primary Care) (19).

All subjects with a diagnosis of diabetes mellitus on the problem list (ICPC-code T90) were selected, further referred as the diabetic group. This group of diabetic subjects can be subdivided on date of diagnosis, namely patients with known diabetes at baseline, i.e. date of diagnosis before July 1996; patients unknown with diabetes at baseline, but diagnosed during the five-years period of follow-up; and patients with unknown date of diagnosis. The group with diabetes diagnosed during follow-up was included, because onset of diabetes occurs often several years before it is clinical diagnosed (20). Cardiovascular disease was also derived from the problem list, and was defined as coronary heart disease (ICPC-code K74 or K75 or K76), heart failure (K77), or stroke (K89 or K90). Cardiovascular disease occurring before July 1996 was defined as pre-existing disease. Diagnoses between July 1996 and July 2001 were considered as end points. All myocardial infarctions, including imminent infarctions, and all deaths occurring in the period from July 1996 up to June 2001 were also reported by the general practitioners. Cause of death was reported using nine categories: fatal myocardial infarction; other cardiac deaths; stroke; other vascular deaths; cancer; infection or autoimmune diseases; violence or accident; suicide; and other or unknown causes. The diagnoses on the problem lists were compared to the reports, and discrepancies were communicated and resolved with the general practitioners.

Three groups of endpoints were analysed: non-fatal cardiovascular events, total cardiovascular events, and all-cause mortality. Total cardiovascular events included all non-fatal events of coronary heart disease, stroke and heart failure, and all deaths related to cardiovascular causes. 


\section{Analyses}

The sample of the cohort consisted of 3,253 subjects of which 64 had to be excluded as a result of one general practitioner failing to report the health problems of his patients. No information about alcohol intake was available for 177 subjects. In the present analyses, subjects with diabetes $(n=222)$ were also excluded from the sample to obtain a non-diabetic sample, leaving 1,407 men and 1,383 women. In the total cohort, 1,073 subjects were diagnosed with diabetes of which 84 subjects had to be excluded due to missing alcohol intake data, leaving 509 men and 480 women. Of these subjects, 270 men and 241 women had known diabetes at baseline, 222 men and 218 women were diagnosed with diabetes during follow-up, and for 17 men and 21 women no date of diagnosis was available. All analyses were done separately for men and women.

First, current alcohol intake at baseline and lifetime pattern of drinking were compared between the non-diabetic sample, patients with known diabetes at baseline, and patients who were diagnosed with diabetes during follow-up. Chi-squares were calculated as test for significance.

The associations between alcohol intake and non-fatal cardiovascular events, total cardiovascular events, and all-cause mortality were analysed for the diabetic group only, using Cox regression. All three associations were investigated for both measures of current alcohol intake, and for lifetime pattern of alcohol intake. Initially, never drinkers were planned as reference group. Due to low numbers of this group, moderate drinkers of 7-14.9 glasses per week constituted the reference group. The models were adjusted for age (continuous), region (binar), packyears (non-smokers and categorization of number of packyears in quartiles), body mass index (quintiles), fat intake (quintiles), physical activity (quintiles), education (7 categories), income (5 categories), and medical histories (yes/no) of cardiovascular disease, hypertension, and hypercholesterolaemia.

\section{Results}

\section{Comparison of alcohol intake}

Non-diabetic men were on average younger than diabetic men (55.0 versus 58.7 years). No significant difference in age was found between diabetic men at baseline and men diagnosed with diabetes during follow-up. Non-diabetic women (55.3 years) were younger than women with diabetes at baseline (60.7 years) and women diagnosed with diabetes during follow-up (58.8 years).

Men with known diabetes at baseline and men diagnosed with diabetes during follow-up have similar distributions for alcohol intake according to the Weekly Recall (table 1). Diabetic men were more often non-drinkers and less often drinkers of 1 to 28 glasses per week than non-diabetic men. Less differences were found for alcohol intake according to the QF-last-year. Men with known diabetes at baseline were more often non-drinkers (22.4\%) compared to men diagnosed with diabetes during follow-up (11.9\%) and non-diabetic men (7.9\%). Further, diabetic men at baseline were less often drinkers of 7-14.9 glasses per week compared to both other groups. Differences in lifetime pattern of drinking were only found for decrease of drinking, which was more common among men diagnosed with diabetes during follow-up.

Women diagnosed with diabetes during follow-up were less often never drinkers compared to women with diabetes at baseline and non-diabetic women (table 1). Except never drinking, diabetic women at baseline and women diagnosed with diabetes during follow-up had similar distributions of alcohol intake according to the Weekly Recall. They were both more often non-drinkers and less often drinkers compared to non-diabetic women. Differences between the non-diabetic and both diabetic groups were smaller for alcohol intake in the year before baseline. Women with diabetes at baseline were more often non-drinkers (39.8\%) compared to women diagnosed with di- 
Table 1. Percentages (n) of alcohol intake for non-diabetic sample, diabetes at baseline, and diagnosis of diabetes

\begin{tabular}{|c|c|c|c|c|c|c|}
\hline & \multicolumn{3}{|c|}{ Men } & \multicolumn{3}{|c|}{ Women } \\
\hline & $\begin{array}{c}\text { non- } \\
\text { diabetic }\end{array}$ & $\begin{array}{c}\text { known } \\
\text { diabetes at } \\
\text { baseline }\end{array}$ & $\begin{array}{l}\text { diagnose } \\
\text { during } \\
\text { follow-up }\end{array}$ & $\begin{array}{l}\text { non- } \\
\text { diabetic }\end{array}$ & $\begin{array}{c}\text { known } \\
\text { diabetes at } \\
\text { baseline }\end{array}$ & $\begin{array}{l}\text { diagnose } \\
\text { during } \\
\text { follow-up }\end{array}$ \\
\hline \multicolumn{7}{|l|}{ Weekly Recall } \\
\hline Never drinkers & $2.4(28)$ & $2.5(6)$ & $1.6(3)$ & $12.4(143)$ & $13.2(27)$ & $3.9(7)^{\star \dagger}$ \\
\hline Non-drinkers & $7.4(87)$ & $49.8(118)^{\star}$ & $40.3(77)^{\star}$ & $9.5(110)$ & $60.5(124)^{\star}$ & $61.2(109)^{\star}$ \\
\hline$<1 /$ week & $9.1(108)$ & $8.0(19)$ & $8.9(17)$ & $16.2(187)$ & $9.3(19)^{\star}$ & $12.4(22)$ \\
\hline 1-6.9/week & $23.3(275)$ & $9.7(23)^{\star}$ & $14.1(27)^{\star}$ & $32.8(378)$ & $10.7(22)^{\star}$ & $11.8(21)^{\star}$ \\
\hline 7-14.9/week & $25.5(301)$ & $12.7(30)^{\star}$ & $12.6(24)^{\star}$ & $18.0(207)$ & $4.9(10)^{\star}$ & $5.6(10)^{\star}$ \\
\hline 15-28/week & $20.5(242)$ & $11.4(27)^{\star}$ & $12.6(24)^{\star}$ & $9.4(108)$ & $1.5(3)^{\star}$ & $4.5(8)^{\star}$ \\
\hline$>28$ /week & 11.9 (141) & $5.9(14)^{\star}$ & $9.9(19)$ & $1.6(19)$ & $0(0)$ & $0.6(1)$ \\
\hline \multicolumn{7}{|l|}{ QF-last-year } \\
\hline Never drinkers & $2.0(28)$ & $2.4(6)$ & $1.5(3)$ & $10.7(143)$ & $12.5(27)$ & $3.6(7)^{\star}$ \\
\hline Non-drinkers & $7.9(109)$ & $22.4(55)^{\star}$ & $11.9(24)^{\dagger}$ & $12.1(161)$ & $39.8(86)^{\star}$ & $30.3(59)^{\star \dagger}$ \\
\hline$<1$ /week & $5.8(79)$ & $8.2(20)$ & $7.0(14)$ & 17.9 (239) & $18.1(39)$ & $22.6(44)$ \\
\hline $1-6.9 /$ week & $28.8(395)$ & $26.1(64)$ & $28.9(58)$ & $32.6(434)$ & $20.8(45)^{\star}$ & $29.2(57)^{\dagger}$ \\
\hline 7-14.9/week & $25.8(354)$ & $17.1(42)^{\star}$ & $23.4(47)$ & $16.7(222)$ & $7.4(16)^{\star}$ & $8.2(16)^{\star}$ \\
\hline 15-28/week & $18.8(258)$ & $15.1(37)$ & $16.4(33)$ & $6.8(91)$ & $0.9(2)^{\star}$ & $4.6(9)^{\dagger}$ \\
\hline$>28$ /week & $10.9(150)$ & $8.6(21)$ & $10.9(22)$ & $3.2(43)$ & $0.5(1)^{\star}$ & $1.5(3)$ \\
\hline \multicolumn{7}{|l|}{ Lifetime pattern of drinking } \\
\hline Never drinkers & $2.5(28)$ & $3.0(6)$ & $1.6(3)$ & $13.3(143)$ & $15.3(27)$ & $4.0(7)^{\star \dagger}$ \\
\hline Occasional drinkers & $2.2(25)$ & $3.0(6)$ & $3.3(6)$ & $14.8(159)$ & $11.9(21)$ & $9.2(16)$ \\
\hline 1-14.9/week & $14.0(159)$ & $9.0(18)$ & $9.3(17)$ & $11.7(126)$ & $4.0(7)^{\star}$ & $5.2(9)^{\star}$ \\
\hline$>=15 /$ week & $2.4(27)$ & $1.5(3)$ & $1.1(2)$ & $0.1(1)$ & $0(0)$ & $0(0)$ \\
\hline Decrease & $12.2(139)$ & $11.6(23)$ & $17.6(32)^{\star \star \dagger}$ & $6.3(68)$ & $23.2(41)^{\star}$ & $26.0(45)^{\star}$ \\
\hline $\begin{array}{l}\text { Decrease after age } \\
\text { of } 18\end{array}$ & $12.8(146)$ & $15.1(30)$ & $11.0(20)$ & $3.4(37)$ & $7.9(14)^{\star}$ & $5.8(10)^{\star}$ \\
\hline Increase & $44.0(501)$ & $43.2(86)$ & $41.8(76)$ & $43.0(462)$ & $26.0(46)^{\star}$ & $43.4(75)^{\dagger}$ \\
\hline Variable & $9.9(113)$ & $13.6(27)$ & $14.3(26)$ & $7.3(78)$ & $11.9(21)^{\star}$ & $6.4(11)$ \\
\hline
\end{tabular}

* percentage differs $(\mathrm{p}<.05)$ compared to non-diabetics; ${ }^{\dagger}$ percentage differs $(\mathrm{p}<.05)$ compared to known diabetes at baseline

abetes during follow-up (30.3\%), which were more often non-drinkers compared to non-diabetic women (12.1\%). Non-diabetic women were more often stable moderate drinkers, and less often decreased their intake compared to diabetic women. Women with known diabetes at baseline less often increased their drinking during lifetime than non-diabetic women and women diagnosed with diabetes during follow-up.

\section{Alcohol intake and cardiovascular disease}

Incidence of cardiovascular events during follow-up was about twice as high for diabetic men compared to the male non-diabetic sample, and four times as high for diabetic women compared to the female non-diabetic sample. The hazard ratios for the association between alcohol intake and cardiovascular disease are based upon the total diabetic group, as no significant differences in associations were found between subjects with diabetes at baseline and subjects diagnosed with diabetes during follow-up.

For diabetic men, the hazard ratios for non-fatal, and total cardiovascular events are close. Occasional 


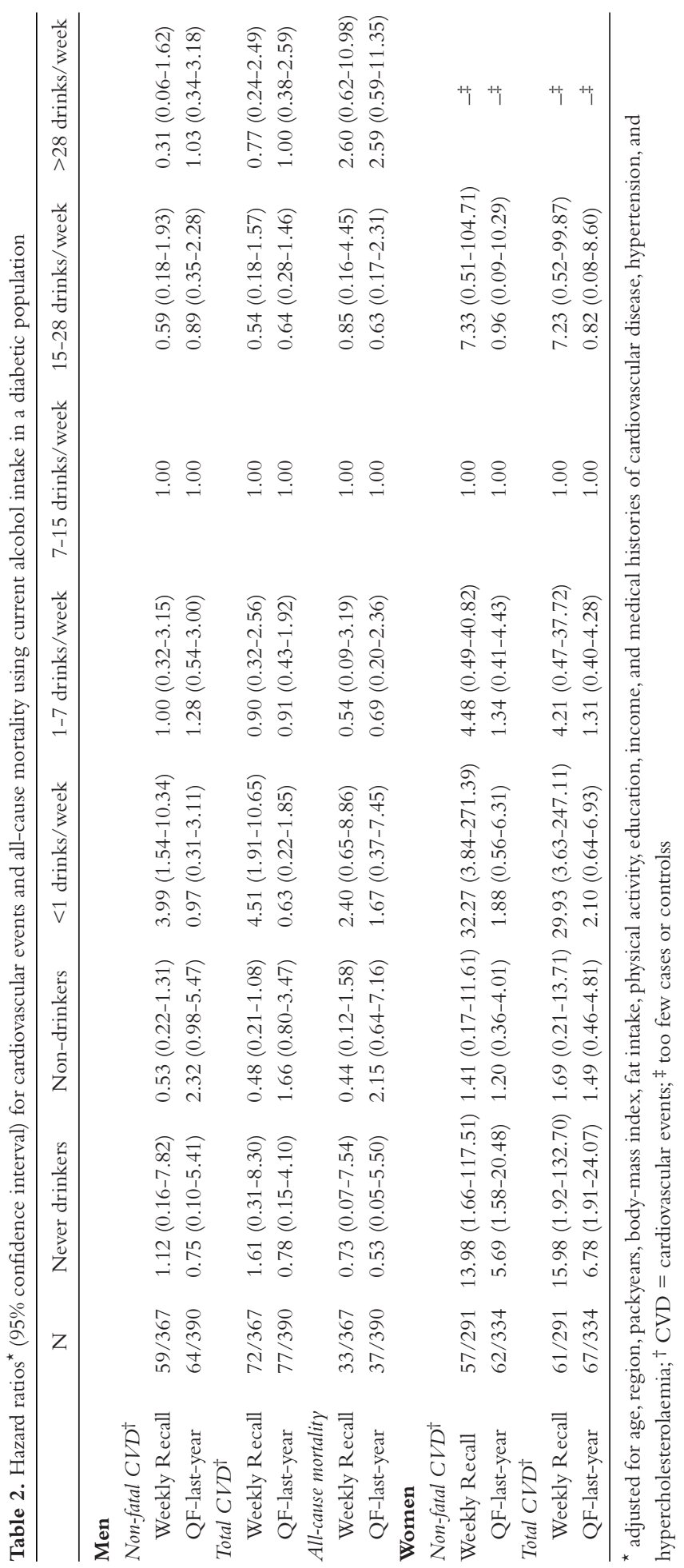




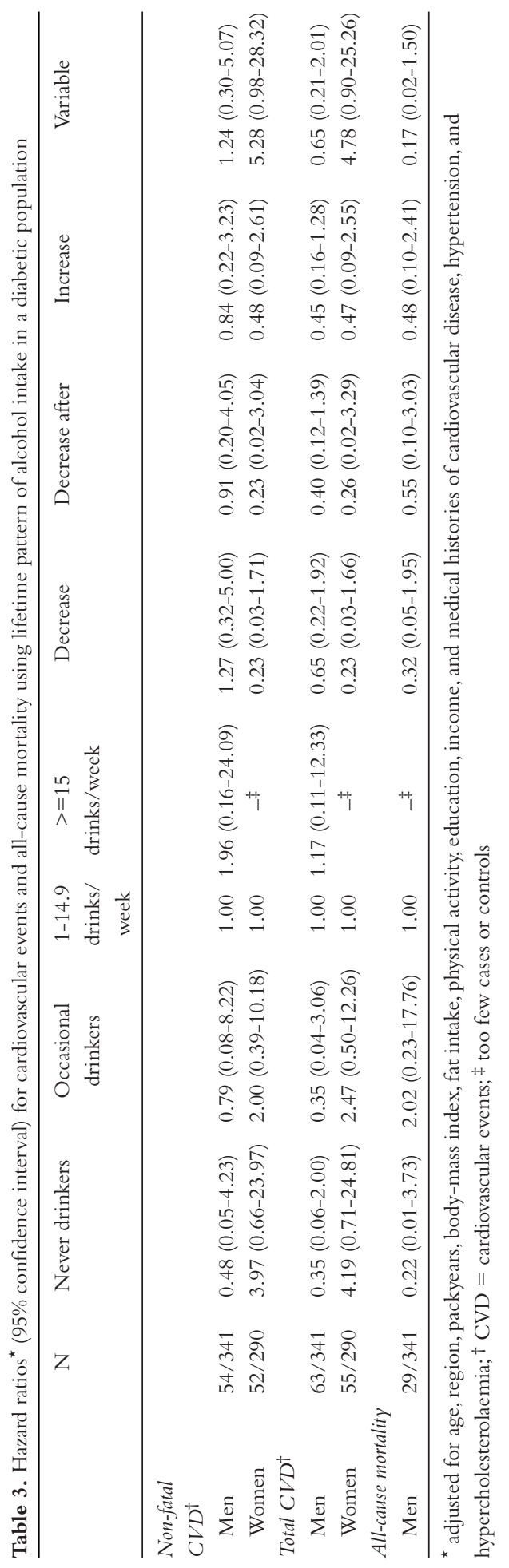


drinkers who did not drink in the past week had higher risks of experiencing an episode of cardiovascular disease than men who drank 7 to 15 glasses according to the Weekly Recall (table 2). Men who did not drink in the year before baseline seemed to have higher risks of non-fatal cardiovascular disease than moderate drinkers $(\mathrm{p}=0.055)$. No associations were found between lifetime drinking pattern and cardiovascular disease (table 3 ).

In diabetic women, no differences in hazard ratios were seen between non-fatal cardiovascular disease and total cardiovascular events (table 2). Never drinkers had higher risks compared to women drinking 7 to 15 glasses per week, just like occasional drinkers who did not drink in the week before baseline. Lifetime abstaining showed a non-significant elevated risk compared to stable moderate drinking (table 3). A variable drinking pattern during life also seemed to increase risk of cardiovascular disease.

\section{Alcohol intake and all-cause mortality}

Risk of dying during follow-up was almost twice as high for both diabetic men and women compared to the non-diabetic sample. Again, the total diabetic group was considered in the analyses.

For diabetic men, occasional and heavy drinkers appeared to have higher risks of dying during follow-up than moderate drinkers (table 2). No significant associations were found between lifetime pattern of alcohol intake and all-cause mortality (table 3).

No analyses could be done for women, due to too few cases. Remarkable was the distribution of the deceased women over the categories of alcohol intake. Only one woman drank between 7 and 15 glasses per week, the remaining deceased women never drank, stopped drinking or drank less than one glass of alcohol per week. These women had almost all been never drinkers or lifetime occasional drinkers.

\section{Discusion}

Comparison of current alcohol intake and lifetime pattern of drinking between diabetic and nondiabetic subjects revealed differences. Diabetic subjects were more often current non-drinkers. Even men and women diagnosed with diabetes during follow-up were more often current non-drinkers compared to the non-diabetic sample. Regarding lifetime pattern, men diagnosed with diabetes during follow-up decreased their intake more often than non-diabetic men and men with known diabetes at baseline. Diabetic women decreased their intake more often than the non-diabetic sample. For diabetic men, non-drinking and occasional drinking seemed to be related with higher risk for cardiovascular events and all-cause mortality compared to moderate drinkers. For diabetic women, never drinking and not drinking in the week before baseline according to the Weekly Recall were associated with higher risks for cardiovascular events compared to moderate drinking.

Diabetic and non-diabetic subjects differ in alcohol intake in that way that diabetic subjects had more often stopped drinking at baseline. It is debatable whether diabetic subjects stop drinking as a result of advices of physicians, as those diagnosed with diabetes during follow-up were already more often non-drinkers than non-diabetic subjects. Onset of diabetes occurs often several years before it is clinical diagnosed (20). Although undiagnosed, subjects could already feel less well and consequently adjust their consumption in the direction of quit drinking. On the other hand, moderate drinking has been associated with lower incidence of diabetes (4). This would mean that those who stop drinking, would run higher risk of developing diabetes. With the present data, the cause of the difference can not be found.

In the present study, no differences in relationship between alcohol intake and cardiovascular disease 
were found for subjects with diabetes at baseline and those diagnosed with diabetes during followup. In the LEGO-cohort, similar analyses were done with subjects free of diabetes at baseline. Comparing the results from those earlier analyses with the current results revealed no large differences in hazard ratios, although both alcohol intake and incidence of cardiovascular events differs between diabetic and non-diabetic subjects. Other studies in diabetic men reported lower risks of total coronary heart disease for drinkers of 0.5 drinks per day or more, and non-significant results for nonfatal coronary heart disease $(8,10)$ compared to non-drinkers. For diabetic women, drinkers of 0.1 grams pure alcohol per day or more appear to have lower risks of total coronary heart disease, and drinkers of 5 grams pure alcohol per day had lower risks of non-fatal coronary heart disease compared to non-drinkers (7). These studies differed on two areas compared to the present study. First, never drinkers were distinguished from non-drinkers within LEGO, which was not done in these studies. Second, in the present study the larger group of cardiovascular disease was used as endpoint compared to coronary heart disease in the other studies. In spite of these differences, diabetic nondrinkers seems to have higher risks on cardiovascular disease or coronary heart disease than diabetic drinkers.

The relationship between alcohol intake and all-cause mortality could only be analysed for men, due to too few deaths among women. No significant association was found in the present study, comparable when analysing the non-diabetic men of the LEGO-cohort. In a cohort of diabetic men and women followed for a period of 12.6 years, subjects drinking 16-30 grams of pure alcohol per day were found to have lower risks of all-cause mortality than non-drinkers (11). So, evidence of a relationship between alcohol intake and all-cause mortality in diabetic populations is not substantive.

In the present study, some limitations have to be named. First, the numbers of diabetic subjects in the analyses were small, especially the number of male never drinkers. Such small groups can cause power problems, in which real differences in risks are not found. Analysing men and women together would have enlarged the numbers. However, men and women differ in alcohol intake (21) and in risk of cardiovascular disease and all-cause mortality (22), therefore, merging was no option. Second, no distinction was made between type 1 and type 2 diabetes. If both groups were distinguished, the number of cases per alcohol strata would have become too small, again causing power problems. Additionally, type of diabetes was not known for all subjects. The subjects diagnosed with diabetes during follow-up will, in general, have had type 2 diabetes, as this type manifest mainly when aging. As no differences in risks were found between subjects with known diabetes at baseline and subjects diagnosed with diabetes during follow-up, and about $85 \%$ of Dutch subjects with diabetes has type 2 (23), results will at least be valid for type 2 diabetes.

Diabetic and non-diabetic subjects differed in alcohol intake. Distribution of alcohol intake in subjects diagnosed with diabetes during follow-up resembled a lot the distribution in subjects with diabetes at baseline. It would be interesting to reveal the cause of this close resemblance. In spite of differences in alcohol intake and incidence of cardiovascular events and mortality between diabetic and non-diabetic subjects, the associations between alcohol intake with cardiovascular disease or allcause mortality seems to be comparable. Further research to the associations between alcohol intake and cardiovascular disease, and all-cause mortality could go in two directions. First, a large cohort study without the limitations of previous studies and this study, namely separate groups of never drinkers and non-drinkers, separate analyses for men and women, and for type 1 and type 2 diabetes could be carried out. Second direction would be a meta-analysis with individual data of the various studies. 


\section{References}

1. Wild S, Roglic G, Green A, Sicree R, King H. Global prevalence of diabetes: estimates for the year 2000 and projections for 2030. Diabetes care 2004;27:1047-53.

2. van Dam RM. The epidemiology of lifestyle and risk for type 2 diabetes. Eur J Epidemiol 2003;18:111525.

3. Choi BC, Shi F. Risk factors for diabetes mellitus by age and sex: results of the National Population Health Survey. Diabetologia 2001;44:1221-31.

4. Howard AA, Arnsten JH, Gourevitch MN. Effect of alcohol consumption on diabetes mellitus: a systematic review. Ann Intern Med 2004;140:211-9.

5. van de Wiel A. Diabetes mellitus and alcohol. Diabetes Metab Res Rev 2004;20:263-7.

6. Sahay BK, Sahay RK. Lifestyle modification in management of diabetes mellitus. J Indian Med Assoc 2002;100:178-80.

7. Solomon CG, Hu FB, Stampfer MJ, Colditz GA, Speizer FE, Rimm EB, et al. Moderate alcohol consumption and risk of coronary heart disease among women with type 2 diabetes mellitus. Circulation 2000;102:494-9.

8. Tanasescu M, Hu FB, Willett WC, Stampfer MJ, Rimm EB. Alcohol consumption and risk of coronary heart disease among men with type 2 diabetes mellitus. J Am Coll Cardiol 2001;38:1836-42.

9. Valmadrid CT, Klein R, Moss SE, Klein BE, Cruickshanks KJ.Alcohol intake and the risk of coronary heart disease mortality in persons with older-onset diabetes mellitus. JAMA 1999;282:239-46.

10. Ajani UA, Gaziano JM, Lotufo PA, Liu S, Hennekens CH, Buring JE, et al. Alcohol consumption and risk of coronary heart disease by diabetes status. Circulation 2000;102:500-5.

11. Diem P, Deplazes M, Fajfr R, Bearth A, Muller B, Christ ER, et al. Effects of alcohol consumption on mortality in patients with Type 2 diabetes mellitus. Diabetologia 2003;46:1581-5.

12. Gale EAM, Anderson JV. Diabetes mellitus and other disorders of metabolism. In: Kumar P, Clark M, eds. Clinical medicine: a textbook for medical students and doctors. London: W. B. Saunders Company Ltd, 1996:829-69.

13. Van der Linden MW, Westert GP, De Bakker DH, Schellevis FG. Tweede Nationale Studie naar ziekten en verrichtingen in de huisartspraktijk. Klachten en aandoeningen in de bevolking en in de huisartspraktijk. Utrecht/Bilthoven: NIVEL/RIVM, 2004.

14. Metsemakers JF, Hoppener P, Knottnerus JA, Kocken RJ, Limonard CB. Computerized health information in The Netherlands: a registration network of family practices. Br J Gen Pract 1992;42:102-6.

15. Skinner HA, Sheu WJ. Reliability of alcohol use indices. The Lifetime Drinking History and the MAST.J Stud Alcohol 1982;43:1157-70.

16. Lemmens PH,Volovics L, Haan Yd. Measurement of lifetime exposure to alcohol: data quality of a self-administered questionnaire and impact on risk assessment. Contemp Drug Probl 1997;24:581-600.

17. Friesema IHM, Veenstra MY, Zwietering PJ, Knottnerus JA, Garretsen HFL, Lemmens PHHM. Measurement of lifetime alcohol intake: Utility of a self-administered questionnaire. Am J Epidemiol 2004;159:80917.

18. Sandlow LJ, Bashook PG. Problem oriented medical records. Self instruction for practitioners. Chicago: Michael Reese Hospital and Medical Center, 1978.

19. Lamberts H, Wood M. ICPC : International Classification of Primary Care. Oxford: Oxford University Press, 1987.

20. Harris MI, Klein R, Welborn TA, Knuiman MW. Onset of NIDDM occurs at least 4-7 yr before clinical diagnosis. Diabetes Care 1992;15:815-9.

21. Fillmore KM. Women's drinking across the adult life course as compared to men's. Br J Addict 1987;82:801-11.

22. Sterfte naar leeftijd, geslacht en burgerlijk staat. Centraal Bureau voor de Statistiek: http://statline.cbs.nl/ StatWeb/ (2002).

23. Gijsen R, Baan C, Feskens E. Hoe vaak komt diabetes mellitus voor en hoeveel mensen sterven eraan? RIVM: http://www.rivm.nl/vtv/object_class/kom_suikerziekte.html (2004). 



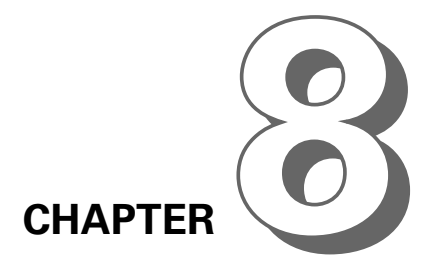

Alcohol intake and cardiovascular disease and mortality: The role of pre-existing disease 


\begin{abstract}
In the past decades numerous studies have demonstrated U-shaped relationships between alcohol intake and cardiovascular disease, and all-cause mortality. Pre-existing conditions have been postulated as possible causes of these relationships. Two research questions have been addressed in the present paper. First question is whether never drinkers and former drinkers differ from moderate drinkers in terms of health, and if so, which health problems contribute to this difference. Second, whether the U-shaped relationship between current alcohol intake and cardiovascular disease or allcause mortality could in part be explained by difference in pre-existing disease burden. These questions were studied within the prospective Lifestyle and Health Study. The cohort consisted of 16,210 respondents aged between 45 and 70 years. Alcohol intake and risk factors were assessed at baseline with a self-administered questionnaire. Medical information was obtained by general practitioners. During a follow-up period of five years, 323 men and 200 women died, and 675 men and 395 women had a cardiovascular event. Never drinkers and former drinkers were less healthy than moderate drinkers. They rated their health more often as poorly, and had more often diseases, such as cardiovascular disease, diabetes, but also alcohol-related diseases. Nevertheless, this difference in disease burden did not change the observed relationship between alcohol intake and cardiovascular events, and only partially the U-shaped relationship between alcohol intake and all-cause mortality. Pre-existing disease appears, therefore, to be only a partial explanation of both observed relationships.
\end{abstract}




\section{Introduction}

Numerous studies have demonstrated a U-shaped or J-shaped association between alcohol intake and cardiovascular disease $(1,2)$ and between alcohol intake and all-cause mortality $(1,3)$. In these studies, both non-drinkers and heavy drinkers appear to have higher morbidity and mortality rates than light and moderate drinkers. In most studies, the group of non-drinkers consists of never drinkers and former drinkers, and in some cases also of occasional drinkers. Despite this heterogeneity, the group of non-drinkers is often used as reference group, which possibly causes overestimation of the potential beneficial effects for moderate drinkers (2). Furthermore, non-drinkers, particularly former drinkers, seem to be less healthy than moderate drinkers (4-6). This difference in health could have an impact on the relationship between alcohol intake and cardiovascular disease, causing an overestimation of this relationship. Subjective health has been related to alcohol intake, in which non-drinkers reported more often poor subjective health than moderate drinkers $(7,8)$. Poor subjective health has also been related to higher risk of all-cause mortality and cardiovascular death (9-12).

Health or health problems are important motives for abstaining (13). Possible reasons behind these motives are medications contradicting the use of alcohol, advice of abstinence or moderation after diagnosed with a specific disease, such as kidney problems, or with alcohol-related diseases, such as liver problems. Furthermore, diseases starting early in life, for example congenital diseases, or chronic diseases could be an individual reason to abstain from alcohol. Shaper and colleagues have examined the influence of pre-existing cardiovascular-related diseases on the relationship between alcohol intake and cardiovascular mortality. They concluded that the observed relationship seemed to be produced by pre-existing disease (14). Most of the studies which intend to avoid the bias due to pre-existing disease do so by excluding individuals with pre-existing cardiovascular disease, diabetes, and/or cancer, or by statistically adjusting for these diseases.

The present study addresses two research questions. First question is whether never drinkers and former drinkers differ from moderate drinkers in terms of health, and if so, which health problems contribute to this difference. Second, whether the U-shaped relationship between current alcohol intake and cardiovascular disease or all-cause mortality can be explained by difference in pre-existing disease burden.

\section{Materials and methods}

\section{Population and design}

The Lifestyle and Health Study (Leefstijl en Gezondheid Onderzoek, LEGO) is a prospective cohort study on alcohol intake and cardiovascular disease. The cohort was established in June 1996 using databases from 34 general practices. In the Netherlands, general practitioners have a central role in health care implying everyone to be registered with a primary practice $(15,16)$. Practices were recruited by Regional Services for Public Health. For practical reasons, participation of practices was restricted to two regions in the south-eastern and western part of the Netherlands.

All men and women aged between 45 and 70 years registered with these 34 practices received a questionnaire. Terminally ill patients, patients with severe dementia, mentally disabled patients and institutionalised patients were excluded in advance. A total of 16,210 subjects (51.7\%) responded to the mailed questionnaire. Informed consent was obtained in a letter presenting the questionnaire. The participants were followed up until June 2001 and received a follow-up questionnaire each year between 1997 and 2000. 
The study design was approved by the review committee of the Registration Network Family Practices of the University of Maastricht. For reasons of efficiency, a case-cohort approach was applied, involving a selection of a random sample at baseline. This sample, further referred as subcohort $(n=3,253)$, was used in the analyses as control group.

\section{Alcohol intake}

Baseline measurement consisted of a detailed self-administered questionnaire assessing, among others, the main cardiovascular risk factors. Current alcohol intake was assessed using a Weekly Recall, and a Quantity-Frequency form about last year's consumption (QF-last-year). The Weekly Recall assessed actual intake per day in the week before baseline separately for beer, wine, and spirits. Actual week consumption was calculated by adding up all drinks. The usual consumption in the year prior to baseline was ascertained with the QF-last-year by questions about usual quantity and frequency, again separately for beer, wine, and spirits. The beverage-specific week consumptions were added up to a total week consumption. Lifetime abstaining was defined as no drinks during lifetime and was derived from the Lifetime Drinking History questionnaire (LDH-q). The LDH-q is a selfadministered questionnaire about alcohol intake since the first glass drunk $(17,18)$, and was also assessed at baseline. Subjects who had drunk during lifetime, but did not drink according to the QF-last-year were defined as former drinkers.

Current alcohol intake was distinguished into seven categories: never drinkers; former drinkers; $<1$ glass/week; 1-6.9 glasses/week; 7-14.9 glasses/week (moderate drinkers); 15-28 glasses/week; and $>28$ glasses/week. For the Weekly Recall, the category of drinkers of $<1$ glass/week was determined with the QF-last-year. In the Netherlands, one glass of alcohol approximates 10 grams of pure alcohol.

\section{Pre-existing disease and subjective health}

Medical information was obtained by general practitioners who filed all major health problems of the past and during the follow-up period of their patients on problem lists (19). Categorization of the health problems was done using ICPC-codes (International Classification of Primary Care) (20). The ICPC-codes are classed under 17 chapters. In different analyses, several groups of diseases were formed. Diseases were only included if date of diagnosis was before the start of the study. First, broad categories of health problems were selected, using the categorization in chapters of the ICPC. In each chapter, ICPC-codes between 70 and 99 represent diagnoses and diseases. Each chapter was analysed using these codes, except chapter W (pregnancy \& family planning) and codes 95, 96, and 97 within chapter General and unspecified diseases (A). The codes between 01 and 29 are assigned to symptoms and complaints. This group of codes was analysed for chapters D (digestive problems), L (musculoskeletal problems), N (neurological problems), and P (psychological problems). Besides the broad categories, more specific categories of diseases were analysed, based upon known risk factors for cardiovascular disease, and possible motives for abstaining (table 1).

Subjective health was derived from the self-administered questionnaire. Respondents were asked whether their health was very good, good, moderate, poor, or very poor. In the analyses, these five options were reduced to two categories comparing (very) good health with moderate and (very) poor health, the latter further referred as poor subjective health.

\section{Endpoints}

Two groups of endpoints were distinguished: cardiovascular events, comprising fatal and non-fatal events, and all-cause mortality. Cardiovascular events occurring in the period from July 1996 up until June 2001 were derived from the problem lists and were reported by the general practitioners. 
Table 1. Summary of included groups of pre-existing disease

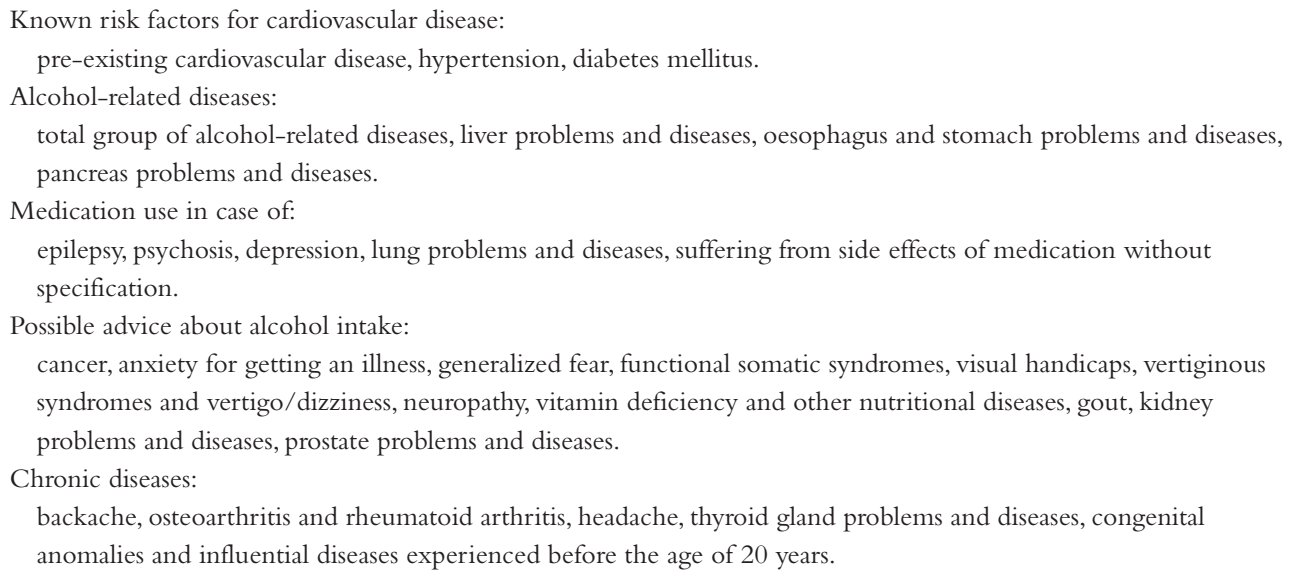

Cardiovascular events on the problem lists were specified as coronary heart disease (K74 or K75 or K76), heart failure (K77), and/or stroke (K89 or K90). All new myocardial infarctions, and all deaths were also reported by the general practitioners to the research team as soon as possible after presentation. Cause of death was reported by the general practitioner using nine main categories: myocardial infarction; other cardiac deaths; stroke; other vascular deaths; cancer; infection or autoimmune diseases; violence or accident; suicide; and other or unknown causes. Fatal myocardial infarctions, other cardiac deaths, fatal stroke, and other vascular deaths were also included in the cardiovascular events. Discrepancies between problem lists and reports were traced and resolved with the general practitioners.

\section{Data analysis}

Current alcohol intake in relationship to pre-existing disease and subjective health was analysed using logistic regression. Moderate drinkers were compared with never drinkers and with former drinkers for each defined group of diseases. Analyses were done separately for men and women. The relationships between current alcohol intake, on the one hand, and cardiovascular events, and all-cause mortality respectively, on the other, were analysed using Cox regression. The Cox regression model was adapted for the case-cohort design by defining the entry time of subjects into the analysis as just before the event for all cases outside the subcohort. Standard errors of the estimated parameters were estimated using the robust Huber-White sandwich estimator to account for additional variance introduced by sampling from the cohort (21). All analyses were done separately for men and women, and for both QF-last-year and Weekly Recall. All models were adjusted for age (continuous), region (southeast/west), packyears (non-smokers and categorization of number of packyears in quartiles), body mass index (quintiles), fat intake (quintiles), physical activity (quintiles), education (7 categories), and income (5 categories). The classification into quartiles or quintiles was done using the distribution in the subcohort.

First, a Cox regression was done with above-mentioned covariates, but without taking pre-existing disease into account. The second analysis was done with exclusion of persons who defined their health as poor (exclusion 1). Finally, the analysis was repeated with healthy subjects only (exclusion 2). Healthy subjects were defined as persons free of the pre-existing disease found to be related to current alcohol intake $(\mathrm{p}<0.05)$ in the logistic regression and who rated their health as (very) good. 
The total cohort consisted of 16,210 persons of whom 330 men and 204 women died, and 679 men and 397 women had a cardiovascular event. These subjects with an endpoint, and the subcohort $(n=3,135)$ were included in the analysis. Cases and subcohort members were excluded in case of missing medical data $(n=229)$ or missing data on alcohol intake $(n=80)$. This left a total of 2,984 subcohort members, 323 men and 200 women who died, and 675 men and 395 women who had a cardiovascular event, with some cases also belonging to the subcohort.

\section{Results}

In the total group of subcohort and cases, 39 men had never drunk alcohol compared to 203 women. The QF-last-year was available for 1,961 men and 1,713 women. Of the men, 472 (24.1\%) drank moderately with 7-14.9 glasses per week. Of the women, 254 (14.8\%) drank 7-14.9 glasses per week. Actual intake in the week before the baseline was available for 1,762 men of whom 365 (20.7\%) were moderate drinkers, and 1,501 women of which $225(15.0 \%)$ drank moderately.

Table 2 (men) and table 3 (women) present the diseases and complaints found to be significantly related to never drinkers and/or former drinkers. Pancreas problems and diseases, and vitamin deficiency and other diseases related to nutritional deficiencies could not be analysed due to too few cases.

In men, never drinkers were more often diagnosed with neuropathy, visually handicaps, diabetes mellitus, oesophagus and stomach problems and diseases, and diseases of the genital system than moderate drinkers. Remarkably, never drinkers also had more often alcohol-related diseases. Both never drinkers and former drinkers rated their health more often as poor than the moderate

Table 2. Odds ratios (95\% confidence interval) for health problems comparing never and former drinkers with moderate drinkers (reference group) (men)

\begin{tabular}{|c|c|c|c|c|}
\hline & \multicolumn{2}{|c|}{ QF-last-year } & \multicolumn{2}{|c|}{ Weekly Recall } \\
\hline & $\begin{array}{l}\text { Never drinkers } \\
\qquad \mathrm{N}=39\end{array}$ & $\begin{array}{l}\text { Former drinkers } \\
\qquad \mathrm{N}=218\end{array}$ & $\begin{array}{l}\text { Never drinkers } \\
\qquad \mathrm{N}=39\end{array}$ & $\begin{array}{l}\text { Former drinkers } \\
\qquad N=184\end{array}$ \\
\hline Poor subjective health & $2.19(1.11-4.34)$ & $3.53(2.46-5.07)$ & $2.16(1.08-4.34)$ & $4.23(2.84-6.31)$ \\
\hline A. General and unspecified diseases & $0.92(0.21-4.12)$ & $2.03(1.11-3.70)$ & $0.74(0.17-3.28)$ & $1.48(0.79-2.79)$ \\
\hline K. Circulatory diseases & $1.49(0.76-2.90)$ & $1.74(1.25-2.44)$ & $1.48(0.75-2.92)$ & $1.91(1.32-2.78)$ \\
\hline N. Neurological diseases & $0.88(0.20-3.90)$ & $2.08(1.15-3.76)$ & $0.89(0.20-4.01)$ & $2.03(1.05-3.93)$ \\
\hline P. Psychological problems & $0.33(0.04-2.51)$ & $1.65(0.96-2.85)$ & $0.40(0.05-3.03)$ & $2.18(1.16-4.10)$ \\
\hline P. Psychological diseases & $1.73(0.57-5.24)$ & $1.86(1.04-3.35)$ & $2.24(0.71-7.06)$ & $2.55(1.28-5.07)$ \\
\hline T. Endocrine and metabolic diseases & $1.60(0.75-3.43)$ & $1.90(1.30-2.78)$ & $1.83(0.84-3.96)$ & $2.04(1.33-3.14)$ \\
\hline Y. Diseases of male genital system & $2.60(1.05-6.46)$ & $1.08(0.58-2.00)$ & $2.65(1.04-6.74)$ & $1.08(0.55-2.13)$ \\
\hline Alcohol-related diseases & $2.09(1.03-4.24)$ & $1.54(1.05-2.24)$ & $2.16(1.05-4.45)$ & $1.72(1.13-2.61)$ \\
\hline $\begin{array}{l}\text { Oesophagus/stomach problems } \\
\text { and diseases }\end{array}$ & $2.85(1.25-6.50)$ & $1.28(0.75-2.19)$ & $3.39(1.43-8.05)$ & $1.59(0.87-2.89)$ \\
\hline Visually handicapped & $7.75(1.33-45.07)$ & $1.06(0.19-5.90)$ & $11.05(1.48-82.44)$ & $1.86(0.26-13.42)$ \\
\hline Cardiovascular disease & $1.38(0.63-3.01)$ & $2.22(1.50-3.26)$ & $1.36(0.61-3.00)$ & $2.51(1.65-3.83)$ \\
\hline Epilepsy & $\star$ & $11.04(1.27-95.82)$ & $\star$ & $5.31(0.55-51.72)$ \\
\hline Neuropathy & $9.96(1.32-75.10)$ & $3.82(0.69-21.17)$ & $\star$ & $\star$ \\
\hline Depression & $2.06(0.44-9.64)$ & $2.13(0.92-4.93)$ & $3.54(0.66-19.07)$ & $3.84(1.26-11.70)$ \\
\hline Diabetes mellitus & $3.29(1.13-9.55)$ & $3.17(1.69-5.95)$ & $3.01(1.03-8.78)$ & $2.91(1.49-5.69)$ \\
\hline
\end{tabular}

$\star$ too few cases 
Table 3. Odds ratios ( $95 \%$ confidence interval) for health problems comparing never and former drinkers with moderate drinkers (reference group) (women)

\begin{tabular}{|c|c|c|c|c|}
\hline & \multicolumn{2}{|c|}{ QF-last-year } & \multicolumn{2}{|c|}{ Weekly Recall } \\
\hline & $\begin{array}{l}\text { Never drinkers } \\
\qquad N=203\end{array}$ & $\begin{array}{l}\text { Former drinkers } \\
\qquad N=270\end{array}$ & $\begin{array}{l}\text { Never drinkers } \\
\qquad \mathrm{N}=203\end{array}$ & $\begin{array}{l}\text { Former drinkers } \\
\qquad N=179\end{array}$ \\
\hline Poor subjective health & $3.42(2.20-5.30)$ & $3.18(2.12-4.76)$ & $3.64(2.31-5.74)$ & $3.77(2.39-5.95)$ \\
\hline D. Digestive problems & $2.71(0.96-7.69)$ & $1.60(0.61-4.21)$ & $4.88(1.14-16.88)$ & $2.50(0.67-9.31)$ \\
\hline D. Digestive diseases & $2.13(1.32-3.43)$ & $1.61(1.03-2.50)$ & $1.83(1.14-2.94)$ & $1.67(1.03-2.72)$ \\
\hline K. Circulatory diseases & $1.49(0.99-2.26)$ & $1.49(1.02-2.17)$ & $1.48(0.97-2.26)$ & $1.60(1.04-2.45)$ \\
\hline N. Neurological problems & $3.78(1.06-13.52)$ & $3.17(1.02-9.90)$ & $2.09(0.68-6.44)$ & $2.33(0.81-6.73)$ \\
\hline N. Neurological diseases & $1.44(0.72-2.87)$ & $1.81(1.00-3.27)$ & $0.97(0.50-1.90)$ & $1.54(0.83-2.88)$ \\
\hline P. Psychological diseases & $2.00(0.99-4.03)$ & $1.57(0.81-3.06)$ & $2.84(1.29-6.26)$ & $3.09(1.41-6.78)$ \\
\hline T. Endocrine and metabolic disease & s1.88 (1.21-2.92) & $1.60(1.07-2.41)$ & $2.48(1.55-3.98)$ & $2.22(1.38-3.58)$ \\
\hline Alcohol-related diseases & $1.67(1.07-2.61)$ & $1.36(0.89-2.07)$ & $1.94(1.22-3.08)$ & $1.78(1.11-2.86)$ \\
\hline Functional somatic syndromes & $2.56(1.14-5.76)$ & $1.64(0.76-3.56)$ & $2.00(0.91-4.40)$ & $1.59(0.70-3.65)$ \\
\hline $\begin{array}{l}\text { Oesophagus/stomach problems } \\
\text { and diseases }\end{array}$ & $3.37(1.35-8.41)$ & $1.36(0.53-3.44)$ & $2.11(0.92-4.85)$ & $1.37(0.56-3.38)$ \\
\hline Cardiovascular disease & $1.96(1.03-3.72)$ & $2.40(1.32-4.39)$ & $2.19(1.13-4.27)$ & $2.72(1.41-5.26)$ \\
\hline Hypertension & $1.70(1.04-2.78)$ & $1.68(1.05-2.69)$ & $1.95(1.16-3.28)$ & $2.07(1.22-3.53)$ \\
\hline Depression & $2.06(0.82-5.17)$ & $2.08(0.88-4.88)$ & $3.49(1.10-11.09)$ & $5.03(1.64-15.46)$ \\
\hline Thyroid gland problems and diseases & $0.86(0.40-1.83)$ & $1.27(0.67-2.40)$ & $1.52(0.65-3.57)$ & $2.21(1.01-4.83)$ \\
\hline Diabetes mellitus & $6.92(2.32-20.64)$ & $7.05(2.43-20.50)$ & $6.85(2.29-20.44)$ & $6.74(2.25-20.18)$ \\
\hline
\end{tabular}

drinkers. Former drinkers suffered more often from circulatory diseases, especially cardiovascular disease, endocrine and metabolic diseases, especially diabetes mellitus, and alcohol-related diseases than moderate drinkers. Neurological diseases, and psychological problems and diseases, such as depression, were also more common among former drinkers compared to moderate drinkers. Differences in results between QF-last-year and Weekly Recall were overall small. Differences in significance were only found for former drinkers, namely for general and unspecified diseases, psychological problems, depression, and epilepsy. The other groups of pre-existing disease were not significantly related to alcohol intake.

In women, the largest differences for both never drinkers and former drinkers compared to moderate drinkers were found for subjective health and diabetes mellitus. Never drinkers also had more often digestive diseases, cardiovascular disease, hypertension, and, similar to the men, alcohol-related diseases. Less pronounced differences were found for digestive problems, psychological diseases, functional somatic syndromes, and oesophagus and stomach problems and diseases. Former drinkers were more often diagnosed with circulatory, especially cardiovascular disease, and digestive diseases than moderate drinkers. Neurological problems were found to be significantly more common among never drinkers and former drinkers when using the QF-last-year, but not when using the Weekly Recall. The opposite was found for depression for both never and former drinkers, and alcohol-related diseases, and thyroid gland problems and diseases for former drinkers only.

Table 4 and 5 give the results for the relationships between alcohol intake and all-cause mortality, and alcohol intake and cardiovascular events with and without exclusion of non-healthy subjects for respectively men and women. The results for alcohol intake measured with the QF-last-year are also visualised in figures 1 and 2 . Without exclusions of non-healthy subjects, both male and female drinkers appear to have lower risks of all-cause mortality and cardiovascular events than never drinkers. Excluding men with poor subjective health did not appear to reveal differences in point 
Figure 1a

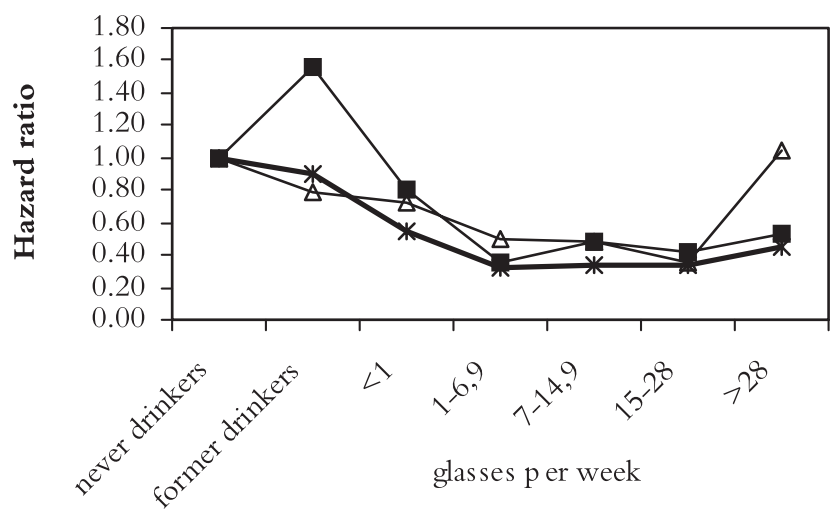

Figure $1 b$
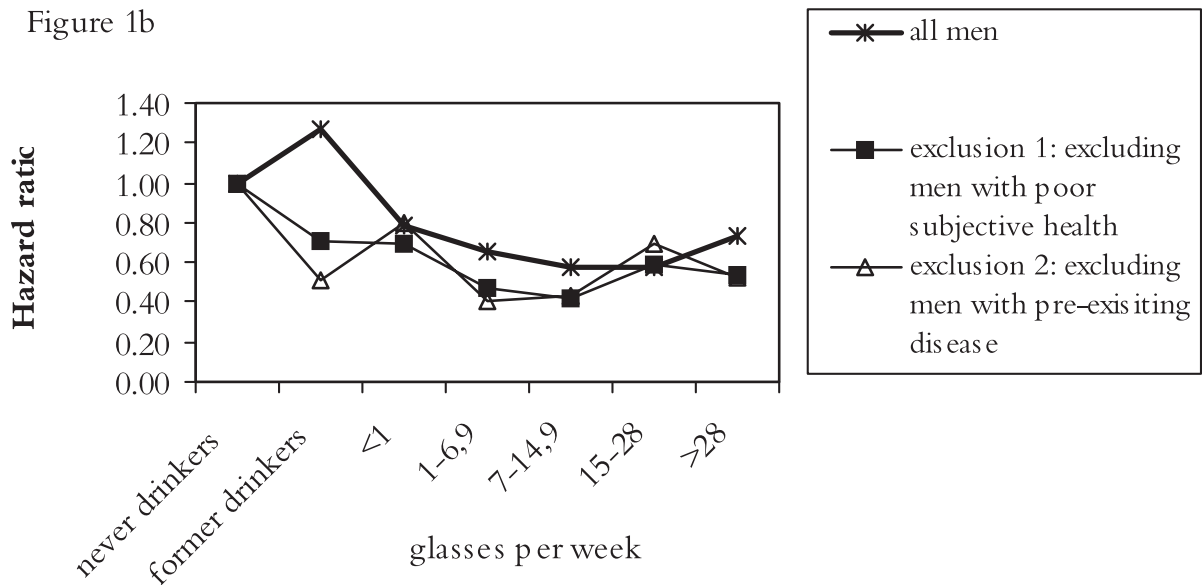

Figure 1. Relationships between alcohol intake and all-cause mortality (figure 1a), and between alcohol intake and cardiovascular disease (figure 1b) without and with exclusion of non-healthy men, with alcohol intake measured with the QF-last-year.

estimates for drinkers, as excluding all men with one or more found pre-existing disease seemed to reduce the difference in all-cause mortality between drinking and abstaining compared to the total group of men. Healthy male former and occasional drinkers seemed to have higher risk of all-cause mortality compared to never drinkers than in the total group of men, when using the Weekly Recall. Exclusion of men reporting poor health did not seem to have much effect on the relationship between alcohol intake and cardiovascular disease. The relationship of alcohol intake and cardiovascular events seemed to become smaller when excluding non-healthy men (exclusion 2). Excluding women with poor subjective health led to lower point estimates for all-cause mortality for former drinkers compared to the total group. Exclusion of non-healthy women (exclusion 2) appeared to moderate the risk of all-cause mortality for drinkers. The relationship between alcohol intake and cardiovascular events for women was linear instead of U-shaped. Healthy female former drinkers appear to have lower risk of cardiovascular events compared to never drinkers, which was less seen in the total group of women. Both exclusions did not seem to affect the point estimates for drinkers. 


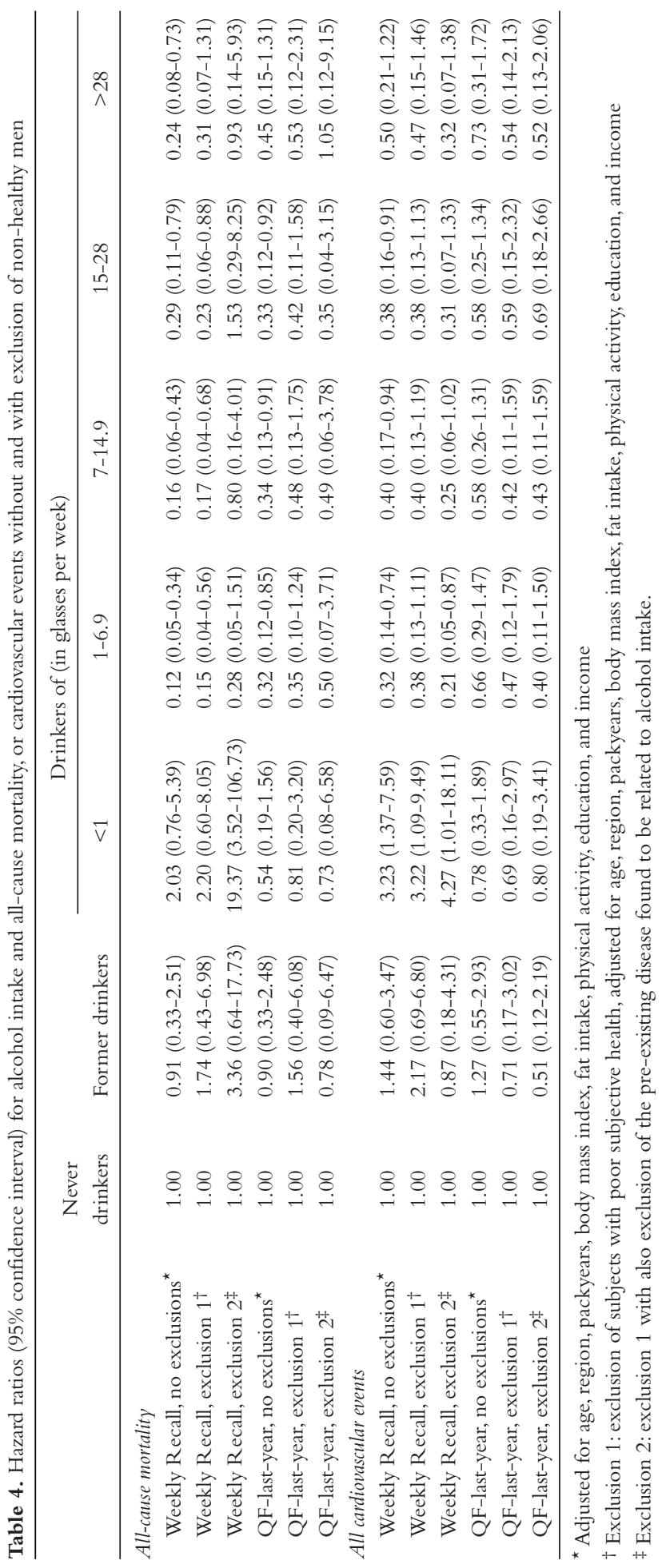


Figure 2a

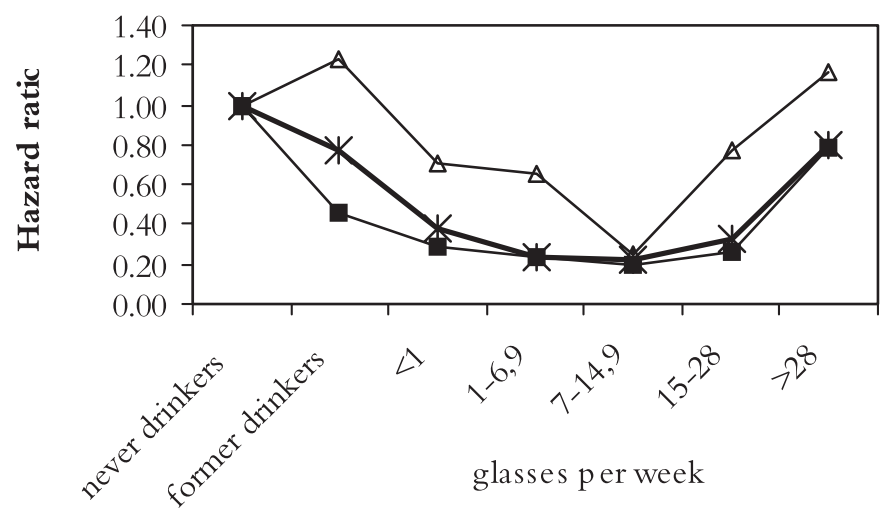

Figure $2 b$
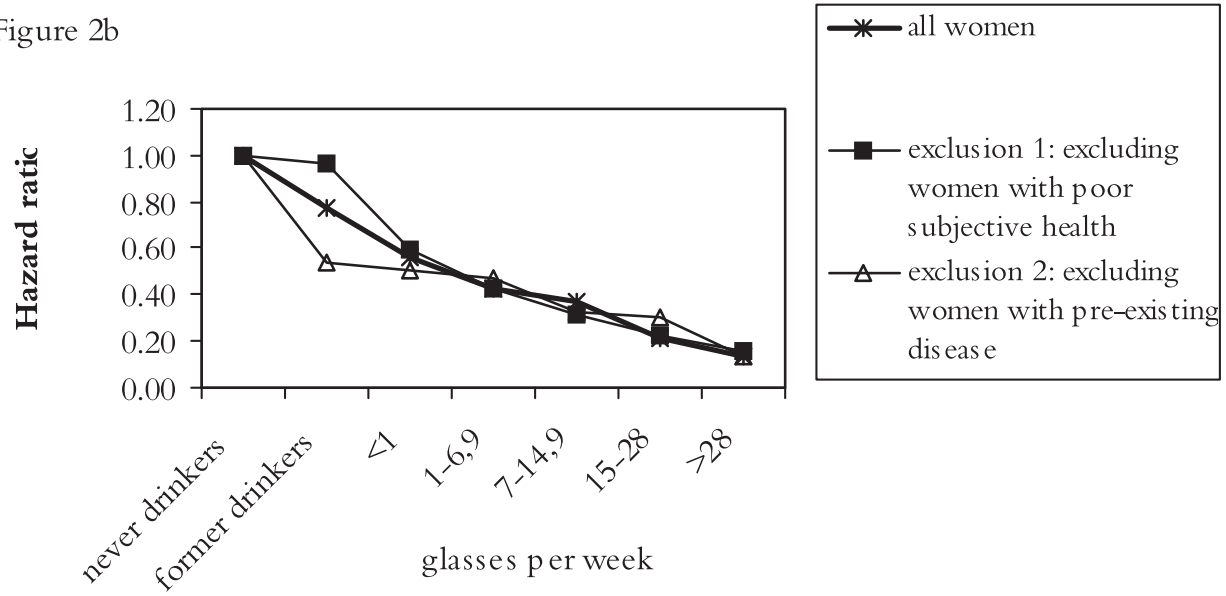

Figure 2. Relationships between alcohol intake and all-cause mortality (figure 2a), and between alcohol intake and cardiovascular disease (figure $2 \mathrm{~b}$ ) without and with exclusion of non-healthy women, with alcohol intake measured with the QF-last-year. 


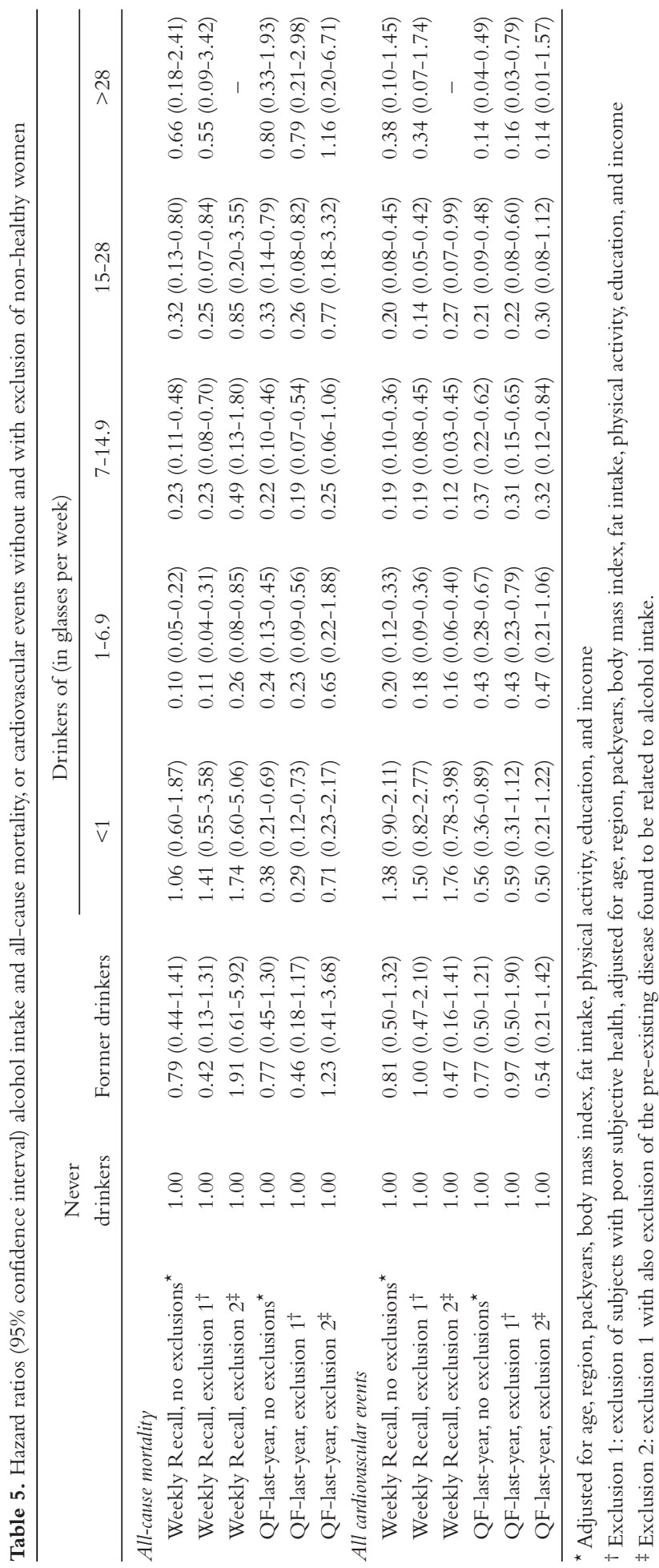




\section{Discussion}

The present study showed that both male and female never drinkers and former drinkers were less healthy and rated their subjective health more often as poor than moderate drinkers. Exclusion of subjects with one or more of these health problems related to alcohol intake, seemed to lead to a smaller difference in risk of all-cause mortality between never drinkers and moderate drinkers. For cardiovascular events, the differences between healthy subjects and the total group were less clear.

Subjective health is an indicator of the health status of the respondent. In the present study, never drinkers and former drinkers reported more often poor subjective health than moderate drinkers. Previous studies have also observed non-drinkers to have more often poor subjective health than drinkers, which pattern can be described as J-shaped $(7,8,22)$. Furthermore, poor subjective health has been related to a higher risk of all-cause mortality and cardiovascular death (9-12). In the present study, the effects of exclusion of subjects with poor subjective health from the analyses were minimal on the relationships between alcohol intake and cardiovascular events, and all-cause mortality. The U-shaped curve between alcohol intake and all-cause mortality, or cardiovascular events seems, therefore, could not be explained by subjective health.

The relationship between alcohol intake and health problems has been studied before (e.g. (4-6)). The type and definition of the health problems between the studies differ and no clear associations could be seen. Nevertheless, digestive problems, cardiovascular problems, and diabetes are often reported to occur more among non-drinkers than drinkers. Although these relationships were found in this study and in other studies, it is unclear what came first. The health problems could have led subjects to stop drinking or even stay a never drinker. In the present study, no relationship between congenital diseases and diseases diagnosed before the age of 20 years and alcohol intake was found. It could indicate that health problems do not influence reasons for being a never drinker. Another possibility is selection bias with respect to chronically ill persons not participating in the study. On the other hand, abstaining could also have led to health problems, which would confirm the beneficial effect of alcohol intake. This has, for example, been stated for cardiovascular disease and diabetes. Finally, heavy drinking can cause serious health problems, for example liver diseases, with subjects consequently becoming non-drinkers. However, prospective observational studies can only indicate a certain direction, but cannot demonstrate causality.

When comparing the three different models specified in this study, one has to conclude that preexisting disease does affect the risk estimates regarding the relationship between alcohol intake and all-cause mortality, but not regarding the relationship between alcohol intake and cardiovascular events. The effect of pre-existing disease on the relationship between alcohol intake and all-cause mortality is, however, not strong enough to explain the U-shaped curve of this relationship. This contradicts the findings of Shaper and colleagues (14) who suggested that relationships between alcohol intake and mortality could be produced by pre-existing disease. However, some differences in model specification could have caused this difference in findings. First the British Regional Heart Study could not separate non-drinkers into never drinkers and former drinkers, which has been done in the present study. Second, the results were adjusted for age, social class, and smoking. In the present study, the models included also body mass index, fat intake, and physical activity. Finally, Shaper and colleagues included cardiovascular-related diseases only, whereas a broader range of preexisting disease were included in the present study.

In conclusion, non-drinkers, among them both never drinkers and former drinkers, rate their health more often as poorly and suffer more often from several health problems, such as cardiovascular disease, diabetes, and alcohol-related diseases. However, these differences in health do not seem to ex- 
plain the observed U-shaped curve between alcohol intake and cardiovascular events and only partially the U-shaped curve between alcohol intake and all-cause mortality.

\section{References}

1. Beaglehole R, Jackson R. Alcohol, cardiovascular diseases and all causes of death: a review of the epidemiological evidence. Drug Alcohol Rev 1992;11:275-290.

2. Corrao G, Rubbiati L, Bagnardi V, Zambon A, Poikolainen K. Alcohol and coronary heart disease: a metaanalysis. Addiction 2000;95:1505-1523.

3. Poikolainen K.Alcohol and mortality: a review. J Clin Epidemiol 1995;48:455-65.

4. Cederfjäll J, Lidfeldt J, Nerbrand C, Samsioe G, Öjehagen A. Alcohol consumption among middle-aged women: A population-based study of Swedish women:The Women's Health in Lund Area (WHILA) study. Eur Addict Res 2004;10:15-21.

5. Green CA, Polen MR. The health and health behaviors of people who do not drink alcohol. Am J Prev Med 2001;21:298-305.

6. Tracy JI, Gorman DM, Leventhal EA. Reports of physical symptoms and alcohol use: findings from a primary health care sample. Alcohol Alcohol 1992;27:481-91.

7. Guallar Castillón P, Rodríguez Artalejo F, Díez Gañán LD, Banegas Banegas JR, Lafuente Urdinguio PL, Herruzo Cabrera RH. Consumption of alcoholic beverages and subjective health in Spain. J Epidemiol Community Health 2001;55:648-52.

8. Poikolainen K, Vartiainen E, Korhonen HJ. Alcohol intake and subjective health. Am J Epidemiol 1996;144:346-50.

9. Appels A, Bosma H, Grabauskas V, Gostautas A, Sturmans F. Self-rated health and mortality in a Lithuanian and a Dutch population. Soc Sci Med 1996;42:681-9.

10. Kaplan GA, Goldberg DE, Everson SA, et al. Perceived health status and morbidity and mortality: evidence from the Kuopio ischaemic heart disease risk factor study. Int J Epidemiol 1996;25:259-65.

11. Pijls LT, Feskens EJ, Kromhout D. Self-rated health, mortality, and chronic diseases in elderly men. The Zutphen Study, 1985-1990. Am J Epidemiol 1993;138:840-8.

12. Wannamethee G, Shaper AG. Self-assessment of health status and mortality in middle-aged British men. Int J Epidemiol 1991;20:239-45.

13. Graham K. Alcohol abstention among older adults: reasons for abstaining and characteristics of abstainers. Addiction Research 1998;6:473-487.

14. Shaper AG, Wannamethee G, Walker M. Alcohol and mortality in British men: explaining the U-shaped curve. Lancet 1988;2:1267-73.

15. Van der Linden MW, Westert GP, De Bakker DH, Schellevis FG. Tweede Nationale Studie naar ziekten en verrichtingen in de huisartspraktijk. Klachten en aandoeningen in de bevolking en in de huisartspraktijk. Utrecht/Bilthoven: NIVEL/RIVM, 2004.

16. Metsemakers JF, Hoppener P, Knottnerus JA, Kocken RJ, Limonard CB. Computerized health information in The Netherlands: a registration network of family practices. Br J Gen Pract 1992;42:102-6.

17. Lemmens PH,Volovics L, Haan Yd. Measurement of lifetime exposure to alcohol: data quality of a self-administered questionnaire and impact on risk assessment. Contemp Drug Probl 1997;24:581-600.

18. Friesema IHM,Veenstra MY, Zwietering PJ, Knottnerus JA, Garretsen HFL, Lemmens PHHM. Measurement of lifetime alcohol intake: Utility of a self-administered questionnaire. Am J Epidemiol 2004;159:809817.

19. Sandlow LJ, Bashook PG. Problem oriented medical records. Self instruction for practitioners. Chicago: Michael Reese Hospital and Medical Center, 1978.

20. Lamberts H, Wood M. ICPC : International Classification of Primary Care. Oxford: Oxford University Press, 1987.

21. Lin DY, Wei LJ. The robust inference for the Cox Proportional Hazards Model. J Am Stat Assoc 1989;84:1074-78.

22. Gronbaek M, Mortensen EL, Mygind K, et al. Beer, wine, spirits and subjective health. J Epidemiol Community Health 1999;53:721-4. 



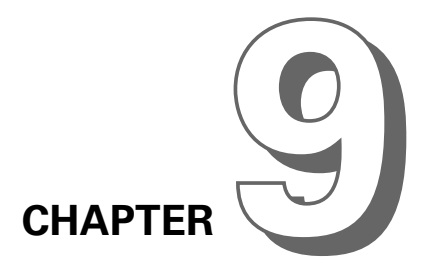

Discussion 



\section{General discussion}

\section{Introduction}

In the past decades, moderate alcohol intake increasingly has become associated with lower risks of cardiovascular events and all-cause mortality. The relationships between alcohol intake and cardiovascular disease, and between alcohol intake and all-cause mortality are often described as J-shaped or U-shaped. Biologically, alcohol has been found to affect, among others, platelet aggregation, quantity of circulating fibrinogen and lipoproteins (1-3)s. On the other hand, other factors also influence the observed relationship directly or through the design of the study. In case the mechanism behind the relationship is a biological one, everyone should be advised to drink one or two glasses of alcohol every day. However, the benefits of moderately drinking will probably not counterbalance the risks if other mechanisms, especially methodological mechanisms, are responsible for the found relationship.

In the present study, several non-biological factors which could explain the observed U-shape were examined. Explanations which were investigated, were sought in the direction of pre-existing disease, type of alcohol questionnaire and reference period of alcohol intake, and other model specifications. The results are based upon data of the Lifestyle and Health Study (Leefwijze en Gezondheid Onderzoek, LEGO). The LEGO-study was a prospective cohort study in which men and women aged 45-70 years at baseline were followed for five years (1996-2001). In this chapter, the findings presented in the preceding chapters are merged and discussed.

\section{Main Findings}

First, a systematic review summarized previous cohort studies on the relationship between alcohol intake and cardiovascular disease. None of the studies included in the review examined the influence of past and lifetime alcohol intake on cardiovascular disease. Furthermore, a majority of the studies did not distinguish never drinkers from former drinkers, and most studies only accounted for a few covariates in the analyses. Each of these disregards could impact the relationship between alcohol intake and cardiovascular disease.

The LEGO-study was set up to investigate methodological and psychosocial explanations for the found U-shape of the relationships between alcohol intake and cardiovascular disease, and between alcohol intake and all-cause mortality. A total of 31,349 men and women aged 45-70 years were approached of whom $51.7 \%$ responded. Data were collected both via general practitioners and by questionnaires. The general practitioners registered current and past health problems of respondents and non-contacts. For refusals, a summary of past health problems was available. Respondents filled in a baseline questionnaire and a maximum of four follow-up questionnaires. Non-response analyses revealed some small differences in cardiovascular risk factors, cardiovascular disease and death rates between respondents, non-contacts, and refusals. These differences may have led to attenuation of the observed relationships. Nevertheless, all analyses were adjusted for cardiovascular risk factors, and pre-existing cardiovascular disease.

Measurement of alcohol intake is difficult as it often fluctuates and changes over time. Nevertheless, past and lifetime alcohol intake can be measured with a self-administered questionnaire as was shown with the Lifetime Drinking History-questionnaire (LDH-q). Reliability and validity were examined in a subsample of the LEGO-study which was drawn at baseline, and both appeared to be reasonably high.

Analyses within LEGO-study were done using the data of the subcohort, and the data of all cases with an endpoint, namely cardiovascular event or death, respectively. First, impact of different periods of alcohol intake and type of questionnaire was assessed. Past and lifetime alcohol intake was not 
related to cardiovascular disease or all-cause mortality, whereas current alcohol intake, especially when measured as actual alcohol intake in the week before baseline, overall showed a U-shaped curve. Second, model specification influenced the relationships, as the alleged benefits of current drinking at baseline diminished with increasing methodological quality and rigor. Third, subjective health, and several health problems, for example psychological diseases, oesophagus and stomach diseases, and diabetes mellitus, were found to be related to alcohol intake. Nevertheless, the relationship between alcohol intake and cardiovascular disease was hardly influenced by pre-existing disease or subjective health. The relationship between alcohol intake and all-cause mortality appeared to be partially produced by pre-existing disease.

Diabetics form a specific group, as they have different alcohol intake habits and higher risks of cardiovascular disease and mortality than non-diabetics. Comparison of subjects with known diabetes at baseline with subjects diagnosed with diabetes during the five-years period of follow-up and non-diabetics revealed that the habits of subjects diagnosed with diabetes during follow-up showed a large similarity with that of the diabetics at baseline. Despite the above-mentioned differences between diabetics and non-diabetics, comparable relationships between alcohol intake and cardiovascular events, and alcohol intake and all-cause mortality were found.

\section{Strengths and limitations}

The LEGO-study was a large prospective cohort study consisting of both men and women aged 45 to 70 years. The cohort comprised a total of 16,210 respondents over two regions of the Netherlands, reflecting the Dutch general population. A case-cohort approach was chosen for financial and efficiency reasons (4-6). Such a case-cohort approach comprises an a-select subsample drawn at baseline. Although the subsample consisted of $20 \%$ of all respondents, the number of, especially male, never drinkers was low. This could have led to power problems in some analyses, meaning that real associations possibly were missed and effects of some mechanisms were underestimated. A casecohort approach also implied the need of a more complex analysis (6-7).

Databases of general practitioners were used to establish the study population. In the Netherlands, these databases are suitable as sampling frame. First, nearly everyone is registered with a general practitioner, irrespective of type of insurance $(8,9)$. Second, referrals to other specialists take place, as a rule, via general practitioners. The foregoing implies complete data on health problems of patients. In practice, general practitioners had most medical information still on paper at the start of the study. Health problems of the cohort members were derived from the computerized medical databases of the general practitioners only. At the end of the follow-up period, it turned out that obtaining problem lists of all cohort members was not realistic. Nevertheless, problem lists were available for almost all cases and subcohort members included in the analyses. All available problem lists were checked for irrelevant items and incompleteness, although it can not be ruled out that some health problems were missed. Nevertheless, no indications were found for differences in chance of missed health problems between cases and controls.

Research on the relationship between alcohol intake and cardiovascular disease is difficult. First, alcohol intake is subject to fluctuations and changes over time (10-12), causing difficulties in measuring a person's intake. An attendant problem with self-reports is the tendency of subjects to underreport their intake (13). Nevertheless, self-reports of alcohol intake are the simplest method and do not seem to be less valid than more objective techniques (14-16). Furthermore, alcohol intake was measured extensively in the present study, and the utility of the LDH-q was tested with reasonable results. On the other hand, a possible selective non-response of heavy drinkers can not be excluded.The number of heavy drinkers in the analyses was low, which may attenuate the results for this group of drinkers, but will have had little effect on the results for the other groups. 
Second, cardiovascular disease can already be present in youth or young adulthood expressed as atherosclerotic lesions (17-21), and cardiovascular disease can be latent for many years. In the present study, no attempts were made to find latent cardiovascular disease. The results are, therefore, based upon clinical cases and cases who came across.

Third, a number of factors influences alcohol intake, other factors influence the risk of cardiovascular disease, and there are factors influencing the association between both. In other, large, cohort studies, adjustment for these factors is often minimal, as could be seen in chapter 2. In the present study, a clear effect was shown for adjustment for covariates. Adjustment for important covariates reduced differences in risk between never drinkers and moderate drinkers compared to less extensive adjustments. However, one group of covariates were left out, namely psychosocial factors. A possible important factor of this group is stress. Stress has been related to both alcohol intake and cardiovascular disease, which makes it complex to study. In the LEGO-study, this part has been examined by Marja Veenstra.

\section{Discussion}

In the past decades, numerous studies have reported J-shaped or U-shaped curves as description of the relationship between alcohol intake and cardiovascular events, and between alcohol intake and all-cause mortality (22-27). The underlying mechanism of the observed lower risk of cardiovascular events for moderate drinkers compared to non-drinkers is less clear, although several explanations have been proposed.

First, clinical studies suggest that the cardio protective effects of alcohol intake may be generated by decreased platelet function, increased fibrinolysis, and certain lipoproteins, such as cholesterol (3). The first two mechanisms both reduce the risk of formation of thrombi, the last mechanism reduces the risk of formation of plaque. Atherosclerotic lesions, the first expression of cardiovascular disease can already be present in youth or young adulthood (17-21). The above-mentioned mechanisms all advertise a biological effect of alcohol intake. One would expect the effects to be throughout life. However, in the present study, only current alcohol intake measured at baseline, but not lifetime drinking or drinking habits in the past, was related to cardiovascular disease. This implies a shortterm, rather than a long-term effect of alcohol intake. Also with short-term effects, one would expect lifetime moderate drinking to be beneficial, as the effect is than constantly prolonged. Thus, according to this study, the alleged biological effects are only visible in or valid for subjects older than 45 years of age, which is the group with the highest risk of cardiovascular events, or the relationship between alcohol intake and cardiovascular events is not (completely) the result of a direct biological effect of alcohol intake.

In experimental trials, circumstances are created in which only one factor affecting the outcome varies. However, the relationship between alcohol intake and cardiovascular events has been examined using epidemiological studies, because of ethical and practical difficulties. This implies careful examination of influencing factors. A meta-analysis (28), and also the present thesis showed a clear effect of model specification. The relationship between alcohol intake and cardiovascular events was less present when extensively corrected for important covariates compared to results obtained with minimal correction. The selection of reference group also appeared to influence the results. One reference group composed of the heterogeneous groups of never drinkers, former drinkers, and sometimes even occasional drinkers, led to an overestimation of the relationship between alcohol intake and cardiovascular events. Although these model specifications could not explain the relationship on its own, the effects should not be ignored in further research.

Measurement of alcohol intake could impact the relationships between alcohol intake and cardiovascular disease, and between alcohol intake and all-cause mortality. Although self-reports are one of 
the best available methods for measuring alcohol intake, recall bias can never be ruled out. This is especially the case when measuring alcohol intake in the distant past. Nevertheless, the reliability for alcohol intake in the distant past was measured in the present study with a one-year interval. Only the reliability of the measurement of alcohol intake in youth (before the age of 18 years) was somewhat low, the other life periods showed reasonable reliability. Besides recall bias, the type of measurement also seems to matter. A measurement of short-term actual intake was stronger associated with cardiovascular events than a summary measurement, although the high correlation in alcohol intake between both measures. This could be a methodological issue with actual intake at baseline being stronger related to cardiovascular events than a summary measurement of a years intake. On the other hand, this difference could be an adaptation of drinking habits anticipating on oncoming disease which is measured with the Weekly Recall, but not or less with the QF-last-year.The results of the relationship between alcohol intake and diabetes appeared suggestive of such adaptation. Drinking habits at baseline of subjects who developed diabetes during follow-up resembled the habits of diabetics at baseline, especially when measured with the Weekly Recall. However, epidemiological studies cannot distinguish cause and consequence. Thus, decreasing alcohol intake or abstaining could also be the cause of the following disease. Concluding, type of questionnaire influences the relationship between alcohol intake and cardiovascular disease, but the cause of this difference remains unclear.

Pre-existing diseases could be an explanation for, particularly, alcohol intake habits, but consequently also for the stated relationship between alcohol intake and cardiovascular events. Shaper et al (29) reported pre-existing disease being an important explanation for the J-shaped curve. Or, in other words, non-drinkers have more often pre-existing diseases. In the present thesis, occurrence of several diseases was more common among former and/or never drinkers, and these groups rated their health worse than moderate drinkers. However, exclusion of subjects with these pre-existing diseases and subjects rating their health as poor did not affect the found relationship between alcohol intake and cardiovascular events. These results contradict with the results reported by Shaper et al (29). Three differences can be pointed out between the British Regional Heart Study and the present study. First, former drinkers could not be separated from the never drinkers in the British Regional Heart Study. Second, the results were less adjusted for covariates than the results of the present study. Finally, pre-existing diseases was defined differently. The British Regional Heart Study included cardiovascular disease only, whereas a broader range of diseases was included in the present study. Therefore, the role of pre-existing disease in the relationship between alcohol intake and cardiovascular disease seems to be minor.

Although several mechanisms seems to influence the observed relationship between alcohol intake and cardiovascular events, none of them appears to explain the J-shaped or U-shaped curve on its own. This can be explained in two directions. First, there is still another explanation not found yet. Second, several mechanisms together produce this specific relationship between alcohol intake and cardiovascular events. This second option is possibly the most logical explanation, as both alcohol intake and cardiovascular disease are complex matter with a lot of influencing factors and continuing a whole life long. This complexity also introduces another possible mechanism, the methodological explanation. Thus, the observed relationship between alcohol intake and cardiovascular disease could partially be caused by biological mechanisms, but probably also by surrounding factors influencing alcohol intake, cardiovascular events, or both, and methodological factors in the design of a study.

Besides reservations about a biological cause of the relationship between alcohol intake and cardiovascular disease, this relationship should also be placed in a broader view. First, heavy alcohol intake and binge drinking can cause serious health problems. Second, subjects can become addicted to al- 
cohol. The point at which it becomes hazardous for someone depends from person to person. Furthermore, moderate alcohol intake can already be hazardous, for example in traffic, but has also found to be related to diseases such as several forms of cancer $(31,31)$. As an U-shaped curve was found in the analyses between alcohol intake and all-cause mortality, one could conclude that the benefits of moderate alcohol intake exceed the risks, at least for mortality. However, a large part of this relationship can be explained by the proportion of cardiovascular deaths, as this is one of the leading causes of mortality in developed countries. Furthermore, if surrounding, non-biological, factors influencing alcohol intake could affect the relationship with cardiovascular events, it also could affect a broader group of mortality. As long as these positive effects are related to causes of death occurring more often than deaths caused by alcohol intake, moderate alcohol intake will overall be related to lower risk of all-cause mortality.

\section{Conclusions and recommendations}

Several explanations have been tested for their role in the observed relationships between alcohol intake and cardiovascular disease, and alcohol intake and all-cause mortality. None of these explanations could extinguish the relationships, although some factors did influence these relationships, especially type of questionnaire and model specification. Lower risks of cardiovascular disease and all-cause mortality for moderate drinkers were found only for current drinking, in a population aged $45-70$ years.

The relationship between lifetime and past alcohol intake, and cardiovascular events has not been studied before. Therefore, the present study could be repeated in another large cohort study, which considers influencing factors, such as model specification, including pre-existing disease, and choice of alcohol questionnaire. If possible, latent cardiovascular disease should be included through active health control of the participants at baseline and during follow-up.

Concluding, moderate drinking before the age of 45 years could not be clearly related to lower risk of cardiovascular disease after the age of 45 years, and before this age the risk of cardiovascular events is already low. Moderate drinking after the age of 45 years has been related to lower risks of cardiovascular events. A biological mechanism could not be ruled out, but at least model specification and type of questionnaire influenced the observed relationship. The search for clarification of the underlying mechanism in the relationship between alcohol intake and cardiovascular disease should continue. Besides research to the relative short-term biological effects of alcohol intake, long-term biological effects of alcohol intake should be investigated, as epidemiologically no lifetime effect of moderate drinking was found in the present study. Till the underlying mechanism or mechanisms are more profound, one should be careful with promoting moderate alcohol intake as being healthy.

\section{References}

1. Fagrell B, De Faire U, Bondy S, Criqui M, Gaziano M, Gronbaek M, et al. The effects of light to moderate drinking on cardiovascular diseases. J Intern Med 1999;246:331-40.

2. Rimm EB, Williams P, Fosher K, Criqui M, Stampfer MJ. Moderate alcohol intake and lower risk of coronary heart disease: meta-analysis of effects on lipids and haemostatic factors. Brit Med J 1999;319:1523-8.

3. Booyse FM, Parks DA. Moderate wine and alcohol consumption: beneficial effects on cardiovascular disease. Thromb Haemost 2001;86:517-28.

4. ErnsterVL. Nested case-control studies. Prev Med 1994;23:587-90.

5. Wacholder S, Silverman DT, McLaughlin JK, Mandel JS. Selection of controls in case-control studies. III. Design options. Am J Epidemiol 1992;135:1042-50. 
6. Langholz B, Thomas DC. Nested case-control and case-cohort methods of sampling from a cohort: a critical comparison. Am J Epidemiol 1990;131:169-76.

7. Prentice RL. A case-cohort design for epidemiologic cohort studies and disease prevention trials. Biometrika 1986;73:1-11.

8. Van der Linden MW, Westert GP, De Bakker DH, Schellevis FG. Tweede Nationale Studie naar ziekten en verrichtingen in de huisartspraktijk. Klachten en aandoeningen in de bevolking en in de huisartspraktijk. Utrecht/Bilthoven: NIVEL/RIVM, 2004.

9. Metsemakers JF, Hoppener P, Knottnerus JA, Kocken RJ, Limonard CB. Computerized health information in The Netherlands: a registration network of family practices. Br J Gen Pract 1992;42:102-6.

10. Kerr WC, Fillmore KM, Bostrom A. Stability of alcohol consumption over time: evidence from three longitudinal surveys from the United States. J Stud Alcohol 2002;63:325-33.

11. Neve RJ, Diederiks JP, Knibbe RA, Drop MJ. Developments in drinking behavior in The Netherlands from 1958 to 1989, a cohort analysis. Addiction 1993;88:611-21.

12. Fillmore KM, Hartka E, Johnstone BM, Leino EV, Motoyoshi M,Temple MT.A meta-analysis of life course variation in drinking. Br J Addict 1991;86:1221-67.

13. Lemmens P, Tan ES, Knibbe RA. Measuring quantity and frequency of drinking in a general population survey: a comparison of five indices. J Stud Alcohol 1992;53:476-86.

14. Babor TF, Steinberg K, Anton R, Del Boca F.Talk is cheap: measuring drinking outcomes in clinical trials. J Stud Alcohol 2000;61:55-63.

15. Feunekes GI, van 't Veer P, van Staveren WA, Kok FJ. Alcohol intake assessment: the sober facts. Am J Epidemiol 1999;150:105-12.

16. Midanik L. The validity of self-reported alcohol consumption and alcohol problems: a literature review. $\mathrm{Br}$ J Addict 1982;77:357-82.

17. Berenson GS, Srinivasan SR, Bao W, Newman WP, 3rd, Tracy RE, Wattigney WA. Association between multiple cardiovascular risk factors and atherosclerosis in children and young adults. The Bogalusa Heart Study. New Engl J Med 1998;338:1650-6.

18. Holman RL, McGill HC, Strong JP, Geer JC. The natural history of atherosclerosis. The early aortic lesions as seen in New Orleans in the middle of the 20th century. Am J Pathol 1958;34:209-35.

19. Stary HC, Chandler AB, Glagov S, Guyton JR, Insull W, Jr., Rosenfeld ME, et al. A definition of initial, fatty streak, and intermediate lesions of atherosclerosis. A report from the Committee on Vascular Lesions of the Council on Arteriosclerosis, American Heart Association. Circulation 1994;89:2462-78.

20. Strong JP, McGill HC. The natural history of coronary atherosclerosis. Am J Pathol 1962;40:37-49.

21. Tuzcu EM, Kapadia SR, Tutar E, Ziada KM, Hobbs RE, McCarthy PM, et al. High prevalence of coronary atherosclerosis in asymptomatic teenagers and young adults: evidence from intravascular ultrasound. Circulation 2001;103:2705-10.

22. Kannel WB, Ellison RC.Alcohol and coronary heart disease: the evidence for a protective effect. Clin Chim Acta 1996;246:59-76.

23. Klatsky AL. Alcohol, coronary disease, and hypertension. Annu Rev Med 1996;47:149-60.

24. Cleophas TJ. Wine, beer and spirits and the risk of myocardial infarction: a systematic review. Biomed Pharmacother 1999;53:417-23.

25. Poikolainen K. Alcohol and mortality: a review. J Clin Epidemiol 1995;48:455-65.

26. White IR. The level of alcohol consumption at which all-cause mortality is least. J Clin Epidemiol 1999;52:967-75.

27. Rehm J, Bondy S. Alcohol and all-cause mortality: an overview. Novartis Found Symp 1998;216:223-32.

28. Corrao G, Rubbiati L, Bagnardi V, Zambon A, Poikolainen K. Alcohol and coronary heart disease: a metaanalysis. Addiction 2000;95:1505-23.

29. Shaper AG, Wannamethee G, Walker M. Alcohol and mortality in British men: explaining the U-shaped curve. Lancet 1988;2:1267-73.

30. Hamdy RC, Aukerman MM. Alcohol on trial: the evidence. South Med J 2005;98:34-68.

31. Eckardt MJ, Harford TC, Kaelber CT, Parker ES, Rosenthal LS, Ryback RS, et al. Health hazards associated with alcohol consumption. JAMA 1981;246:648-66. 
Summary \& Samenvatting 



\section{Summary}

Chapter 1 outlines the background and aims of this thesis. In the past decades, a lot of attention has been paid to the relationship between alcohol consumption and cardiovascular disease. In most of the epidemiological studies, a J- or U-shaped curve was found with an elevated risk for nondrinkers and heavy drinkers and a reduced risk for moderate drinkers. A clear explanation for this relationship has not been found yet. Biologically, alcohol appears to have positive effects on several mechanisms, but other, non-biological, explanations could also be relevant. The aim of this thesis was to investigate some of these non-biological explanations.

First, can the observed relationships between alcohol intake and cardiovascular disease, and between alcohol intake and all-cause mortality be explained by the use of different periods of alcohol intake or different types of questionnaires? Second, do several model specifications change these relationships? Third, what is the impact of pre-existing diseases on these observed relationships between alcohol intake and cardiovascular disease, and between alcohol intake and all-cause mortality? Furthermore, both relationships has also been analysed using a diabetic population.

Data from the Leefwijze En Gezondheid Onderzoek (LEGO, Lifestyle and Health Study) were used to investigate these explanations of the found relationships.

Chapter 2 presents the systematic review of cohort studies on the relationship between alcohol intake and cardiovascular disease, coronary heart disease, myocardial infarction, angina pectoris, sudden cardiac death, or non-sudden cardiac death published between 1966 and 2002. Special attention has been given to the way alcohol intake was measured, correction for covariates and pre-existing diseases, and length of follow-up.

All 58 studies measured current alcohol intake, of which 71\% did not define the reference period of the alcohol intake. Of the studies, $74 \%$ did not distinguish different groups of non-drinkers. Definition of reference period, definition of the non-drinkers group, length of follow-up, and pre-existing diseases and covariates each seemed to affect some endpoints, but not all.

Although many studies have investigated the relationship between alcohol intake and cardiovascular disease, studies to the effect of lifetime alcohol intake, and alcohol intake in the distant past have not been done. There is also a need for more information about the impact of definition of nondrinkers group, pre-existing diseases, and adjustment for covariates on the relationship between alcohol intake and cardiovascular disease.

Chapter 3 describes design and methods of the Leefwijze En Gezondheid Onderzoek (LEGO, Lifestyle and Health Study). Data from this prospective case-cohort study were used to investigate explanations for the relationships between alcohol intake and cardiovascular disease, and between alcohol intake and all-cause mortality.

The study started in 1996 by sending 31,349 men and women a self-administered baseline questionnaire. Registration systems of 34 general practices were used as sampling frame. Everyone aged between 45 and 70 years was selected. Terminally ill patients with life expectancies of less than three months, patients with severe dementia, mentally handicapped persons and institutionalised persons were excluded from the cohort. The response rate was $51.7 \%(\mathrm{n}=16,210), 18.8 \%(\mathrm{n}=5,882)$ actively refused, and $29.5 \%(\mathrm{n}=9,257)$ did not respond.

Main issues of the baseline questionnaire were demographic variables, behavioural factors, including alcohol intake, health and attitude towards health, and social environment. Three types of selfreports of alcohol intake were used, namely a 7-day recall or Weekly Recall (WR), a Quantity- 
Frequency questionnaire about alcohol intake in the last year (QF-last-year), and the Lifetime Drinking History questionnaire (LDH-q).

General practitioners (GPs) registered past and present health problems of their patients in problem lists. These problem lists were extracted from the registration system of the GPs. GPs also reported all myocardial infarctions and all deaths occurring during the follow-up period of five years, directly to the research group.

Analyses were done applying a case-cohort approach, meaning that data of the subcohort and of all incident cases in the total cohort were used.

In chapter 4 the relationship between response behaviour and health status at baseline, and survival in a 5 years follow-up period was assessed. Additionally, the relationship between reasons for nonresponse and health status at baseline was assessed. Problem lists with retrospective and prospective health information was available for respondents and non-contacts. For refusals, retrospective information about cardiovascular disease (i.e. angina pectoris, acute myocardial infarction, chronic ischemic heart disease, heart failure, non-fatal stroke, and other arterial obstructive / peripheral vascular disease), and hypertension with involvement of target organs, diabetes mellitus, and hypercholesterolaemia was available.

Results showed that among respondents coronary heart disease was more prevalent. Compared with respondents, non-contacts had a higher mortality risk during follow-up. Refusals had more often hypercholesterolaemia, and less often coronary heart disease, or diabetes mellitus, compared to noncontacts.

The results are paradoxically with respondents being less healthy at baseline, but prospectively having a lower mortality risk. This may point at a selection effect indicating that the 'worried ill' are more inclined to participate. This effect could imply that observed relationships between risk factors or behaviours and outcomes in cohort studies may be attenuated.

In chapter 5 the utility of a new self-administered alcohol questionnaire is tested. The Lifetime Drinking History questionnaire (LDH-q) was developed within LEGO, as only interview schedules existed for measuring lifetime alcohol intake. In large cohort studies, such as the LEGO-study, interviewing all participants is often not possible.

The data of the subcohort, consisting of 3,255 men and women was used to determine the reliability and validity of the LDH-q. Test-retest reliability was assessed by means of the intraclass correlation coefficient and kappa scores. Correlations between lifetime and current intake scores were used to assess discriminant and convergent validity.

Both reliability and validity appeared to be reasonably high compared with results obtained by using interview formats to measure lifetime alcohol intake. Reliability of the LDH-q was higher for men than for women, probably because of the more frequent and regular drinking of men. Indices of validity were similar for men (0.75) and women (0.70). Results show that the LDH-q can be a useful instrument in large-scale cohort studies.

In chapter 6, the impact of current, past and lifetime drinking on cardiovascular events and all-cause mortality has been studied. Additionally, impact of methodological factors on these relationships has been assessed. In the period July 1996-June 2001, 679 men and 397 women had a cardiovascular event, and 330 men and 204 women died.

Current drinking was associated with lower risks of cardiovascular events (women) and all-cause mortality (men and women) compared to never drinkers. The relationships were strongest for alcohol intake measured with the Weekly Recall. Lifetime alcohol intake and alcohol intake in the dis- 
tant past did not seem to be related to all-cause mortality or cardiovascular events. Adjustments for covariates weakened the relationships.

Potential positive effects of drinking seem to be of a transient nature, as lifetime drinking and drinking in the past could not be related to all-cause mortality or cardiovascular events. Furthermore, the alleged benefits of current drinking at baseline diminished with increasing methodological quality and rigor.

Chapter 7 reports results of analyses done within the group of diabetics. The prevalence of diabetes is rising worldwide, and a common complication in diabetes is cardiovascular disease. First aim was to analyse differences in alcohol intake between diabetic and non-diabetic subjects. Second aim was to assess the relationships between alcohol intake and cardiovascular disease, and between alcohol intake and all-cause mortality in diabetic subjects. In the LEGO-study, 509 men and 480 women were diagnosed with diabetes. The subcohort, with exclusion of those with diabetes, was used as sample for non-diabetics.

Subjects with diabetes at baseline, and those diagnosed with diabetes during the five years of followup showed similar drinking patterns. Diabetic men and women drank less often alcohol at baseline compared to non-diabetic subjects. Diabetic men who did not drink or drank occasionally appeared to have higher risk for cardiovascular events and all-cause mortality compared to those drinking moderately. For diabetic women, never and occasionally drinking seemed to be associated with higher risks for cardiovascular events compared to moderate drinking. Compared to general population studies, similar associations were found for the relationship between alcohol intake and cardiovascular events, and alcohol intake and all-cause mortality in diabetics.

Chapter 8 outlines the relationship between alcohol intake and pre-existing diseases, and the impact of pre-existing diseases on the relationships between alcohol intake and cardiovascular disease, and all-cause mortality.

Never drinkers and former drinkers were less healthy than moderate drinkers. They were more often diagnosed with diabetes mellitus, cardiovascular disease, digestive problems, and alcohol-related diseases than moderate drinkers. They also rated their health more often as poorly than moderate drinkers. This difference in disease burden did not change the observed relationship between alcohol intake and cardiovascular events, and only partially the U-shaped relationship between alcohol intake and all-cause mortality. The role of pre-existing diseases appears, therefore, to be minimal in both relationships.

Chapter 9 summarizes and discusses the findings of the present thesis. Additionally, strengths and limitations of the study were addressed. The main aim of the study was to investigate several alternative, non-biological, explanations for the stated relationship between alcohol intake and cardiovascular disease. Although none of the possible mechanisms could explain the observed relationship, practising correct model specifications reduced the difference in risk between never drinkers and moderate drinkers. A lifetime effect of moderate alcohol drinking was not found, which one would expect to exist if the relationship between alcohol intake and cardiovascular disease would be biologically. Thus, till the underlying mechanism or mechanisms are more profound, one should be careful with promoting moderate alcohol intake as being healthy. 



\section{Samenvatting}

Hoofdstuk 1 schetst de achtergrond en de doelen van dit proefschrift. In de afgelopen jaren is er veel aandacht geweest voor de relatie tussen alcoholconsumptie en cardiovasculaire ziekte. In de meeste epidemiologische studies werd een J- of U-vormig verband gevonden met een verhoogd risico op cardiovasculaire ziekte voor niet-drinkers en zware drinkers en een verlaagd risico voor matige drinkers. Een duidelijke verklaring voor deze relatie is nog niet gevonden. Alcohol lijkt een positief effect te hebben op een aantal biologische mechanismen, maar andere, niet-biologische, verklaringen zouden ook relevant kunnen zijn.

In dit proefschrift zijn een aantal van deze mogelijke verklaringen onderzocht. Ten eerste kan de gevonden relatie tussen alcoholconsumptie en cardiovasculaire ziekte en tussen alcoholconsumptie en totale sterfte verklaard worden door het gebruik van verschillende levensperiodes waarin alcohol genuttigd is of het gebruik van verschillende alcoholvragenlijsten? Ten tweede, verandert de keuze van modelspecificatie deze relaties? Ten derde, wat is de impact van andere, al bij de start van het onderzoek aanwezige, ziekten op de relatie tussen alcoholconsumptie en cardiovasculaire ziekte en tussen alcoholconsumptie en totale sterfte? Verder zijn beide relaties geanalyseerd binnen de diabetische populatie.

Deze mogelijke verklaringen voor de gevonden relaties zijn onderzocht met gebruikmaking van de gegevens uit het Leefwijze en Gezondheid Onderzoek (LEGO).

In hoofdstuk 2 wordt een overzicht gegeven van de cohortstudies naar de relatie tussen alcoholconsumptie en cardiovasculaire ziekte, coronaire hartziekte, hartinfarct, angina pectoris, plotselinge en niet-plotselinge cardiale sterfte gepubliceerd tussen 1966 en 2002. In deze systematische review wordt aandacht besteed aan de manier waarop alcoholconsumptie in de studies is gemeten, voor welke covariaten en onderliggend lijden bij de start van de studie gecorrigeerd is en tenslotte is bekeken of de lengte van follow-up van invloed is op de relatie.

In alle 58 studies werd het huidige alcoholgebruik gemeten, waarbij in $71 \%$ van de studies de referentieperiode niet was gedefinieerd. Daarnaast maakte $74 \%$ van de studies geen onderscheid naar nooit drinkers en ex-drinkers. Definitie van de referentieperiode, definitie van de groep niet-drinkers, duur van follow-up en correctie voor covariaten en onderliggend lijden leken ieder effect te hebben op de gevonden relaties bij een aantal eindpunten, maar niet voor alle eindpunten.

Hoewel er al veel studies zijn gedaan naar de relatie tussen alcoholconsumptie en cardiovasculaire ziekte, zijn de effecten van levenslange alcoholconsumptie en alcoholconsumptie in het verleden op cardiovasculaire ziekte nog niet onderzocht. Daarnaast zou er meer onderzoek gedaan moeten worden naar de effecten van definitie van de groep niet-drinkers en correctie voor covariaten en onderliggend lijden op de relatie tussen alcoholconsumptie en cardiovasculaire ziekte.

Hoofdstuk 3 beschrijft de design en de methoden van de LEGO-studie. De gegevens uit deze prospectieve case-cohort studie zijn gebruikt om verklaringen voor de relatie tussen alcoholconsumptie en cardiovasculaire ziekte en tussen alcoholconsumptie en totale sterfte te kunnen onderzoeken. De studie startte in 1996, waarbij 31,349 mannen en vrouwen de baseline vragenlijst toegestuurd kregen. Als steekproefkader is het registratiesysteem van 34 huisartspraktijken gebruikt in Limburg en Rotterdam en omstreken. Iedereen in de leeftijd van 45 tot en met 70 jaar werd uit deze registratiesystemen gefilterd. Patiënten met een terminale ziekte waarvan de levensverwachting korter dan drie maanden was, als ook patiënten met ernstige dementie, geestelijk gehandicapten en personen die in een instelling woonden werden uitgesloten. De response op de baseline vragenlijst was $51,7 \%(n=16.210), 18,8 \%(n=5.882)$ weigerde medewerking en $29,5 \%(n=9.257)$ stuurde geen vragenlijst terug. 
Onderwerpen van de baseline vragenlijst waren demografische variabelen, gedragsfactoren, waaronder alcoholconsumptie, gezondheid en gezondheidsgedrag en sociale omgeving van de respondent. De baseline vragenlijst bevatte drie verschillende vragenlijsten over alcoholconsumptie, namelijk een Weekly Recall (WR) met vragen over de alcoholconsumptie in de week voor het invullen van de vragenlijst, een Quantity-Frequency vragenlijst met vragen over de gemiddelde consumptie in het voorafgaande jaar (QF-last-year) en de Lifetime Drinking History vragenlijst (LDH-q) met vragen over de gemiddelde consumptie in verschillende perioden gedurende iemands leven.

De deelnemende huisartsen registreerden alle voormalige en huidige gezondheidsproblemen van hun patiënten op de zogenaamde probleemlijsten. Deze probleemlijsten konden vervolgens uit het registratiesysteem van de huisarts geëxtraheerd worden voor het onderzoek. Tijdens de follow-up periode meldden de huisartsen daarnaast alle hartinfarcten en alle sterfgevallen direct aan de onderzoeksgroep.

De analyses werden gedaan volgens het case-cohort principe, wat betekent dat gegevens van een subcohort en van alle incidente cases binnen het totale cohort werden gebruikt.

De relatie tussen response en gezondheidsstatus ten tijde van de baseline en tussen response en overleving tijdens de follow-up periode van vijf jaar wordt beschreven in hoofdstuk 4. Daarnaast wordt de relatie tussen reden van non-response en gezondheidsstatus ten tijde van de baseline bekeken. Voor respondenten en non-contacts waren probleemlijsten beschikbaar met retrospectieve en prospectieve gezondheidsgegevens. Voor de weigeraars was alleen retrospectieve informatie over cardiovasculaire ziekte (te weten angina pectoris, acuut myocard infarct, chronische ischemische hartziekte, hartfalen, niet-fatale beroerte en andere arteriële obstructieve of perifere vaatziekte), hypertensie met orgaanbeschadiging, diabetes mellitus en hypercholesterolemie beschikbaar.

De resultaten lieten zien dat coronaire hartziekte vaker voorkwam bij respondenten. Non-contacts hadden een hoger risico op sterfte tijdens de follow-up periode dan respondenten. Vergeleken met non-contacts hadden weigeraars vaker hypercholesterolemie en minder vaak coronaire hartziekte of diabetes mellitus.

De resultaten zijn paradoxaal, aangezien de respondenten minder gezond zijn ten tijde van de baseline, maar vervolgens een lager risico op sterfte hebben. Dit zou kunnen duiden op een selectie-effect, waarbij de "worried ill" sneller geneigd zijn deel te nemen. Dit effect zou kunnen betekenen dat de gevonden relaties tussen risicofactoren of gedragingen en resultaten van cohortstudies afgezwakt kunnen zijn.

In hoofdstuk 5 worden de resultaten wat betreft de bruikbaarheid van een nieuwe alcoholvragenlijst weergegeven. De Lifetime Drinking History questionnaire (LDH-q) is voor LEGO ontwikkeld, aangezien er alleen interview-vragenlijsten bestonden voor het meten van alcoholconsumptie gedurende het leven. In grote cohortstudies, zoals de LEGO-studie, is het vaak niet mogelijk om alle deelnemers te interviewen.

De gegevens van het subcohort, bestaande uit 3,255 mannen en vrouwen, is gebruikt om de betrouwbaarheid en de validiteit van de $\mathrm{LDH}-\mathrm{q}$ te bepalen. De test-retest betrouwbaarheid is geschat met behulp van de intraclass correlatiecoëfficiënt en kappa scores. Correlaties tussen levenslange en huidige consumptie zijn gebruikt om discriminante en convergente validiteit te bepalen.

Zowel betrouwbaarheid als validiteit leek redelijk hoog te zijn vergeleken met resultaten uit vergelijkbare studies voor de interview-vragenlijsten naar alcoholconsumptie gedurende het leven. De betrouwbaarheid van de LDH-q was hoger voor mannen dan voor vrouwen, wat mogelijk veroorzaakt wordt door een frequenter en regelmatiger consumptiepatroon van mannen. Resultaten van 
indicatoren voor validiteit waren vergelijkbaar voor mannen (0.75) en vrouwen (0.70). Uit deze resultaten blijkt dat de LDH-q een bruikbaar instrument kan zijn in grote cohortstudies.

In hoofdstuk 6 is het effect van huidig, vroeger en levenslange alcoholconsumptie op cardiovasculaire eindpunten en totale sterfte bestudeerd. Daarnaast is gekeken naar de invloed van methodologische factoren op de relaties tussen alcoholconsumptie en cardiovasculaire eindpunten en tussen alcoholconsumptie en totale sterfte. Tussen juli 1996 tot en met juni 2001 hadden 679 mannen en 397 vrouwen een of meer episodes van cardiovasculaire ziekte en 330 mannen en 204 vrouwen stierven gedurende deze follow-up periode.

Huidig alcoholconsumptie was gerelateerd aan lagere risico's op cardiovasculaire ziekte (vrouwen) en totale sterfte (mannen en vrouwen) vergeleken met nooit drinkers. Deze relaties waren het sterkste wanneer alcoholconsumptie was gemeten met de Weekly Recall. Levenslange alcoholconsumptie en alcoholconsumptie in het verleden leken niet gerelateerd te zijn aan cardiovasculaire ziekte of totale sterfte. Correctie van de resultaten voor covariaten zwakte de gevonden relaties af.

De mogelijk positieve effecten van alcoholconsumptie lijken van voorbijgaande aard te zijn, aangezien levenslange consumptie en vroegere consumptie niet aan cardiovasculaire ziekte en totale sterfte gerelateerd konden worden. Bovendien namen deze mogelijke voordelen van huidige consumptie af bij toenemende methodologische kwaliteit en striktheid.

In hoofdstuk 7 staan de resultaten van de analyses binnen de groep van diabetici centraal. Wereldwijd stijgt de prevalentie van diabetes mellitus en een veel voorkomende complicatie bij diabetes is cardiovasculaire ziekte. Het eerste doel was om verschillen in alcoholconsumptie tussen niet-diabetici en diabetici te analyseren. Het tweede doel was het bekijken van de relaties tussen alcoholconsumptie en cardiovasculaire ziekte en tussen alcoholconsumptie en totale sterfte binnen de groep van diabetici. In de LEGO-studie hadden 509 mannen en 480 vrouwen de diagnose diabetes mellitus. Alle niet-diabetici in het subcohort zijn in de analyses meegenomen als representatie van de niet-diabetici.

Personen met diabetes bij de start van het onderzoek en personen die gediagnosticeerd werden met diabetes tijdens de follow-up periode hadden een vergelijkbare alcoholconsumptie. Diabetici dronken minder vaak alcohol ten tijde van de baseline ten opzichte van niet-diabetici. Diabetische mannen die niet of af en toe dronken schenen een hoger risico op cardiovasculaire ziekte en totale sterfte te hebben dan de diabetische mannen die matig dronken. Bij diabetische vrouwen werd voor nooit en af en toe drinkers een hoger risico op cardiovasculaire ziekte gevonden ten opzichte van de matige drinkers. Vergeleken met studies in de algemene populaties werden vergelijkbare associaties gevonden voor de relaties tussen alcoholconsumptie en cardiovasculaire ziekte en tussen alcoholconsumptie en totale sterfte in de diabetische populatie.

In hoofdstuk 8 wordt de relatie tussen alcoholconsumptie en onderliggend lijden ten tijde van de start van de studie en het effect van deze ziekten op de relaties tussen alcoholconsumptie en cardiovasculaire ziekte en tussen alcoholconsumptie en totale sterfte beschreven.

Nooit en ex-drinkers waren minder gezond dan matige drinkers. Zij hadden vaker een diagnose van diabetes mellitus, cardiovasculaire ziekte, digestieve problemen en alcoholgerelateerde aandoeningen dan matige drinkers. Ze beoordeelden hun eigen gezondheid tevens vaker als slecht dan matige drinkers. Dit verschil in ziektelast veranderde niet de gevonden relatie tussen alcoholconsumptie en cardiovasculaire ziekte en slechts gedeeltelijk de U-vormige relatie tussen alcoholconsumptie en totale sterfte. De rol van reeds anwezige aandoeningen in beide relaties lijkt daarom minimaal te zijn. 
In hoofdstuk 9 worden de resultaten van dit proefschrift samengevat en bediscussieerd. Daarnaast worden de sterke en zwakke punten van de studie benoemd. Het hoofddoel van de studie was de bestudering van een aantal alternatieve, niet-biologische, verklaringen voor de gevonden relatie tussen alcoholconsumptie en cardiovasculaire ziekte. Hoewel geen van de onderzochte mechanismen de gevonden relatie konden verklaren, reduceerde correcte modelspecificaties het verschil in risico tussen nooit en matige drinkers. Een levenslang effect van matig alcoholconsumptie werd niet gevonden, wat men wel zou verwachten als de relatie tussen alcoholconsumptie en cardiovasculaire ziekte een biologische verklaring heeft. Totdat er meer duidelijkheid is over het onderliggende mechanisme of de onderliggende mechanismen, is het raadzaam om voorzichtig te zijn met het promoten van matig alcoholconsumptie als zijnde gezond. 


\section{Dankwoord}



En dan tenslotte nog het dankwoord, want ook dit proefschrift was niet tot stand gekomen zonder de hulp en steun van velen. Ik begin met de mensen die op inhoudelijk vlak veel hebben gedaan. Allereerst Riet. Marja en ik zouden je laatste AIO's zijn. Dit is helaas wel erg letterlijk geworden. Hoewel ik maar twee jaar van je kennis en begeleiding gebruik heb mogen maken, was je zo nauw verbonden met LEGO dat jouw aanwezigheid nooit is verdwenen. André, bedankt dat je zonder een moment te twijfelen bereid was om voor zover mogelijk en nodig de rol van eerste promotor over te nemen. Je kennis, kalmte en diplomatie heb ik zeer gewaardeerd. PaulZ, voor een buitenstaander zagen onze overleggen er misschien niet altijd even effectief uit. Eerst het Limburgs (of was het een academisch) kwartiertje, dan moest er meestal eerst nog even een sigaretje gerookt worden, gevolgd door een kop koffie. Maar de overleggen verliepen altijd in een prettige sfeer en ik heb ze dan ook zeer gewaardeerd. Je huisartsenervaring zorgde voor interessante discussies over het onderzoek en de resultaten. PaulL, ik weet dat alcoholonderzoek jouw terrein is, maar je onuitputtelijke kennis over alcohol heeft me vaak verbaasd. Je was daarnaast altijd bereid mee te denken, zelfs als je eigenlijk geen tijd had. Henk, officieel was je alleen de promotor van Marja. Toch heb je ook altijd alle stukken van mij gelezen en van commentaar voorzien. En dat dan nog in recordtempo's, soms zelfs binnen 24 uur. Marja, we hebben de afgelopen jaren heel wat lief en leed gedeeld. Je luisterende oor heeft me regelmatig geholpen, vaak was een half woord genoeg. Ik heb met veel plezier met je samengewerkt. Naast deze directe collega's waren er nog vele anderen zonder wie het onderzoek niet uitgevoerd had kunnen worden. Met name TruusC, TruusU en Vonca bedankt voor de ondersteuning. Arnold, bedankt voor de statistische hulp. Maar ook de huisartsen, respondenten, interviewers, cardiologen en vroegere projectteamleden, zonder jullie inzet had dit proefschrift er niet kunnen komen.

Naast de collego's (goed bedacht, PaulL!) waren er natuurlijk ook nog 'gewone' collega's. In de bijna vijf jaar dat ik bij Medische Sociologie heb gezeten, is daar veel veranderd. In het eerste jaar waren we met vier AIO's, toen ik weg ging waren er ongeveer vijftien. Naast de gezelligheid leverde dit ook een aantal goede initiatieven op. Ga vooral door met de AIO-soepen en de junioren-avonden, zoals de sinterklaasavond. Twee junioren wil ik nog even bij naam noemen. Jade, je was een fijne kamergenote en ik kan dankzij jou nu meer met internet. Godelief, ik mis het gezellige theeleuten met je. Ik kon bij jou altijd terecht als ik even wilde kletsen. Helaas is dit 'live' wat moeilijker geworden door de 200 kilometers die ons tegenwoordig scheiden, maar gelukkig is er telefoon en e-mail. Bedankt dat je mijn paranimf wil(de) zijn en veel succes met je eigen proefschrift.

MedSoc bestond natuurlijk niet alleen uit junioren. De ondersteuning van een secretariaat maakt een en ander altijd een stuk makkellijker. Marjoke, Sylvia en Lilian: bedankt. Arnold, niemand die met een computer werkt, kan zonder een (goede) systeembeheerder. Je hebt me regelmatig uit de brand geholpen, zelfs toen ik officieel niet meer bij MedSoc werkte. Het heeft me heel wat ellende bespaard. Tenslotte voor alle MedSoccers, ik denk met plezier terug aan mijn tijd op de vierde verdieping van UNS40-west.

Mijn nieuwe collega's bij het CIE wil ik bedanken voor de fijne ontvangst. Ondanks de grote van de afdeling (bijna 100 mensen) is het een gezellige en gemoedelijke groep. Ook met het projectgroepje heb ik het zeer getroffen. Het was een 'grote' verhuizing van Maastricht naar Utrecht, maar ik voel me hier dankzij jullie ondertussen helemaal thuis. Tenslotte heeft jullie belangstelling voor mijn proefschrift en de voortgang mij zeer gesteund.

Peter, bedankt dat je ondanks de geboorte van je tweede zoontje toch bereid was om de kaft van dit boekje te maken. 
Naast de steun van oude en nieuwe collega's, wil ik ook vrienden, kennissen en familie bedanken voor hun interesse in mijn onderzoek en de voortgang van mijn promotie. Onmisbaar waren natuurlijk pap en mam. Bedankt voor alles, zonder jullie was het nooit gelukt. Jullie hebben me altijd gesteund zonder eisen te stellen en waren er voor me als ik mijn verhaal even kwijt moest. Dit boekje is dan ook aan jullie opgedragen, maar ik zal niet van jullie vragen het van voor tot achter te lezen. Tenslotte, Edith en André. Jullie zijn dan misschien de laatste in mijn opsomming, maar lest best, niet waar? Jullie hebben dit promotie-proces allebei al eens doorgemaakt en weten wat er allemaal bij komt kijken. Dank voor jullie steun, onder andere in de vorm van jullie laptop. Het was de bedoeling dat ik de laptop de maand dat ik op een camping net buiten Utrecht bivakkeerde, zou lenen om toch door te kunnen werken. Door onder andere een crash van mijn eigen computer is het uiteindelijk een heel jaar geworden. En Edith, dankzij jou heb ik een promotie al eens van dichtbij mogen meemaken als paranimf. Ik ben dan ook heel blij dat je hebt toegezegd bij mijn promotie paranimf te willen zijn. 
Curriculum vitae 



\section{Curriculum vitae}

Ingrid Friesema werd geboren op 4 februari 1976 in Zwolle en groeide op in het nabij gelegen Hattem. Na het behalen van het gymnasium-B diploma aan het Thomas à Kempiscollege in Zwolle (1994), studeerde ze Milieugezondheidkunde en Epidemiologie aan de Universiteit Maastricht. Ze studeerde in de zomer van 1999 af.

Van november 1999 tot augustus 2000 werkte ze als epidemioloog bij de GGD Zuid-Kennemerland, Haarlem, waar zij zich bezig hield met de implementatie van een nationaal patiënt-controle onderzoek naar risicofactoren van veteranenziekte.

Op 1 september 2000 begon ze als AIO (assistent in opleiding) bij Medische Sociologie aan de Universiteit Maastricht. Haar promotieonderzoek makte deel uit van een groot prospectief cohortstudie, het Leefstijl en Gezondheid Onderzoek (LEGO). De resultaten van dit onderzoek vormen dit proefschrift. Naast het uitvoeren van het promotieonderzoek heeft ze onderwijstaken binnen de faculteit Gezondheidswetenschappen vervuld. Tenslotte was ze ruim vier jaar promovendus-lid van de opleidingscommissie van de onderzoeksschool CaRe.

Sinds 1 april 2005 is ze werkzaam als epidemioloog op de afdeling Centrum voor Infectieziekten Epidemiologie (CIE) van het Rijksinstituut voor Volksgezondheid en Milieu (RIVM). De nadruk van haar werkzaamheden ligt op onderzoek naar maag-darm infecties oftewel gastro-enteritis. 

Appendix A \& B 


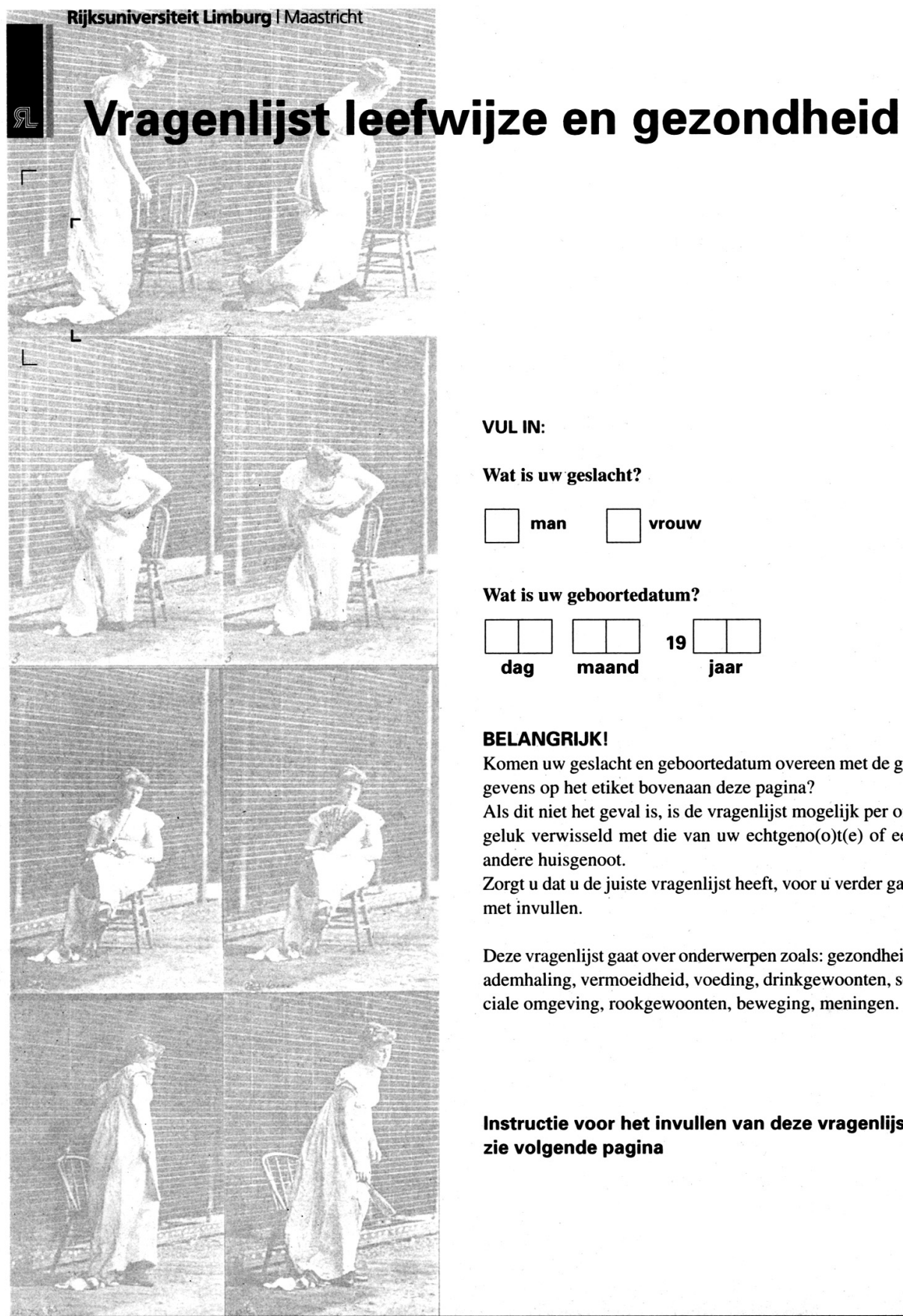

VUL IN:

Wat is uw geslacht?

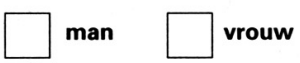

Wat is uw geboortedatum?

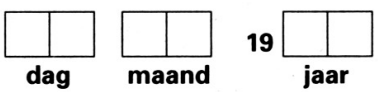

\section{BELANGRIJK!}

Komen uw geslacht en geboortedatum overeen met de gegevens op het etiket bovenaan deze pagina?

Als dit niet het geval is, is de vragenlijst mogelijk per ongeluk verwisseld met die van uw echtgeno(o)t(e) of een andere huisgenoot.

Zorgt $\mathbf{u}$ dat $\mathbf{u}$ de juiste vragenlijst heeft, voor u verder gaat met invullen.

Deze vragenlijst gaat over onderwerpen zoals: gezondheid, ademhaling, vermoeidheid, voeding, drinkgewoonten, sociale omgeving, rookgewoonten, beweging, meningen.

Instructie voor het invullen van deze vragenlijst: zie volgende pagina

Dit onderzoek is mede mogelijk gemaakt door de Nederlandse Hart Stichting 


\section{INSTRUCTIE}

Sommige vragen gaan over gezondheidsklachten. Het is mogelijk dat u niet alles precies meer weet. U hoeft in dat geval niet uw huisarts te bellen. Wat u zelf nog weet is voor ons voldoende.

Probeert u wel alle vragen volledig te beantwoorden. Als u de lijst erg lang vindt, kunt u deze ook in twee keer invullen. Er zijn geen 'goede' of 'foute' antwoorden.. Elk antwoord is belangrijk voor dit onderzoek als het voor u van toepassing is.

Deze vragenlijst is voor UZELF bedoeld. Het is belangrijk dat $\mathbf{u}$ de lijst invult en niet iemand anders. Leest $\mathbf{u}$ voor $u$ verder gaat, eerst rustig de aanwijzingen.

Als u per ongeluk het verkeerde hokje aankruist, maakt u het dan helemaal dicht en kruis dan het juiste hokje aan.

fout

\oed

Soms zijn één of meer vragen voor u niet van toepassing. Dit wordt zo aangegeven:

nee $\Rightarrow$ ga verder met vraag 6

U kunt dan alle vragen tot het genoemde nummer overslaan. 


\section{ALGEMENE GEZONDHEID}

1 Hoe is over het algemeen uw gezondheid?

2 Heeft u een of meer chronische aandoeningen of langdurige ziekten?

3 In welke mate is deze aandoening of ziekte van invloed op uw dagelijks leven?

4 Heeft u ooit ernstige lichamelijke klachten gehad of heeft u ze nog, en wel op het vlak van:

Meer dan één antwoord mogelijk.

$$
\begin{array}{r}
\text { hart of bloedsomloop } \\
\text { klachten in rug of ledematen } \\
\text { longen } \\
\text { andere lichamelijke klachten } \\
\text { ongeluk of val }
\end{array}
$$

5 Heeft u ooit ernstige psychische klachten gehad of heeft u ze nog, en wel op het vlak van:

Meer dan één antwoord mogelijk.

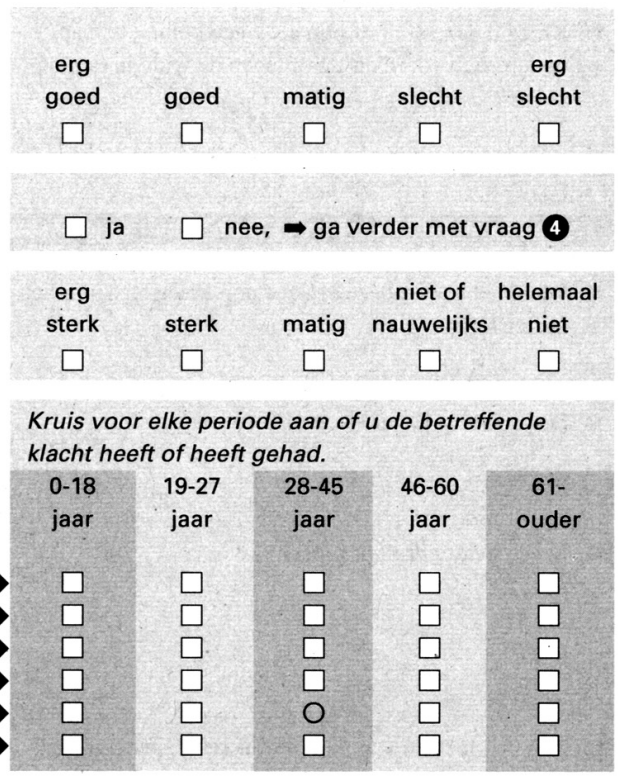

Kruis voor elke periode aan of $u$ de betreffende klacht heeft of heeft gehad.

$\begin{array}{llll}0-18 & 19-27 & 28-45 & 46-60\end{array} 61$.

$\begin{array}{rccccc} & \text { jaar } & \text { jaar } & \text { jaar } & \text { jaar } & \text { ouder } \\ \text { moeheid } & \square & \square & \square & \square & \square \\ \text { depressie } & \square & \square & \square & \square & \square \\ \text { nerveus } & \square & \square & \square & \square & \square \\ \text { angst } & \square & \square & \square & \square & \square \\ \text { slapeloosheid } & \square & \square & \square & \square & \square \\ \text { verwardheid } & \square & \square & \square & \square & \square \\ \text { andere psychische klachten } & \square & \square & \square & \square & \square\end{array}$

6 Wat is uw lengte (zonder schoenen)?

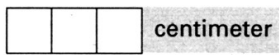

7 Wat is uw gewicht (zonder kleren)? kilo

\section{BORSTKLACHTEN:}

IN DE AFGELOPEN 6 MAANDEN

Als $\mathrm{u}$ het niet zeker weet, kruis dan het vraagteken aan

8 Heeft u pijn of een onaangenaam gevoel in de borst gehad? (verkoudheid niet meetellen)
$\square$ ja
$\square$ ? $\square$ nee

9 Heeft u een drukkend of zwaar gevoel op de borst gehad? (verkoudheid niet meetellen)

10 Heeft u aanvallen van beklemmende pijn in de borst gehad?

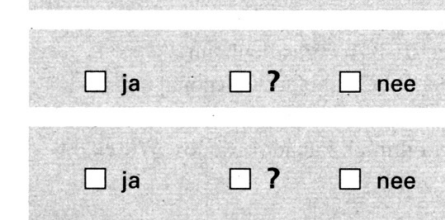


11 Kreeg u deze druk of pijn als $u$ een helling of trap opliep, zich voorthaastte of tegen de wind in liep of fietste?

$\square$ ja

12 Kreeg u deze druk of pijn als u gewoon op straat liep?

$\square$ ja
ja
$\square ?$
$\square$ nee

\section{Als u de vragen 11 en 12 met "nee" heeft beantwoord, kunt u doorgaan met vraag}

13 Wat deed $u$ als u deze druk of pijn kreeg terwijl u liep of fietste?

14 De druk of pijn verdween dan...

15 Kreeg u deze druk of pijn...

16 Zijn de klachten van pijn of drukkend gevoel in de borst pas de laatste drie maanden opgetreden?

17 Kwamen de klachten van pijn of drukkend gevoel in de borst pas de laatste drie maanden veel vaker voor?

18 Werden deze klachten steeds erger?

19 Heeft $u$ ooit een aanval gehad van ernstige pijn voor op de borst, die een half uur of langer duurde? $\square$ gewoon doarlopen of doorfietsen

$\square$ langzamer lopen of fietsen, of stilstaan

$\square$ tablet onder de tong nemen

$\square$ binnen tien minuten

$\square$ na langer dan tien minuten

$\square$ helemaal niet

$\square$ als u van de warmte in de kou kwam

$\square$ als u van de kou in de warmte kwam

$\square$ als u opgewonden of overstuur was

$\square$ binnen tien minuten na de maaltijd

$\square$ anders, $\mathrm{nl}$.

\section{Als u vraag 19 met "nee" heeft beantwoord, kunt u doorgaan met vraag}

20 Heeft u meer dan eens zo'n langdurige pijn gehad?

21 Hoe lang geleden had $\mathrm{u}$ de laatste aanval van pijn? ja

korter dan een jaar geleden

langer dan een jaar geleden

\section{MEDICIJNGEBRUIK:}

22 Gebruikte u de afgelopen 12 maanden minstens één keer per week pijnstillers?

Kruis op elke regel één hokje aan.

- Aspirine, Acetosal, Acetylsalicylzuur: Aspro, Alka-Seltzer, APC, Chefarine, Rhonal e.d.

- Paracetamol: Finimal, Panadol, Hedex, Witte Kruis e.d.

- Overige pijnstillers bijv. ibuprofen e.d.

\section{IN DE AFGELOPEN 12 MAANDEN}

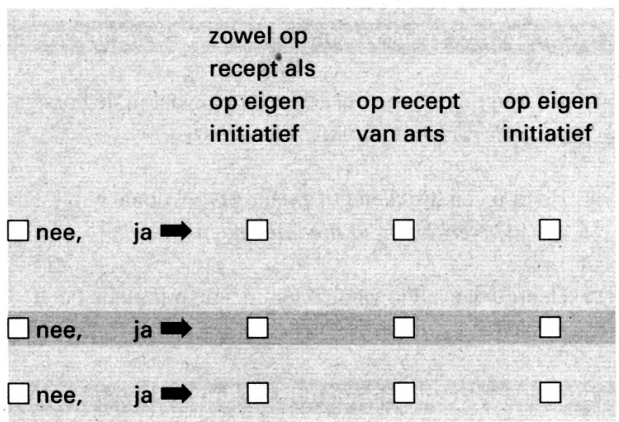


23 Gebruikte u de afgelopen 12 maanden minstens één keer per week de volgende medicijnen?

Kruis op elke regel één hokje aan. zowel op

recept als

op eigen

initiatief op recept op eigen van arts initiatief

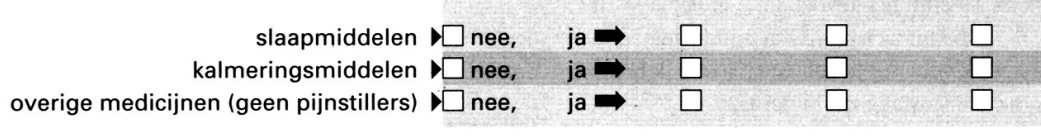

24 Heeft u de afgelopen 12 maanden vitaminepillen,

nee

ja, nl. de volgende merken: -druppels of andere preparaten geslikt?

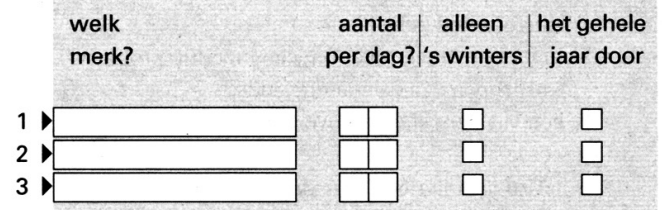

25 Bent $u$ buiten adem wanneer $u$ een heuveltje oploopt of wanneer u zich moet haasten, lopend op vlak terrein?

26 Raakt u sneller buiten adem dan andere mensen van uw leeftijd als u op vlak terrein loopt?

27 Moet $\mathbf{u}$ af en toe stoppen om op adem te komen als $\mathbf{u}$ in uw eigen tempo loopt op vlak terrein?

28 Raakt $\mathrm{u}$ buiten adem wanneer $\mathrm{u}$ zich wast of aankleedt?

29 Hoe vaak snurkt u?

30 Wordt het snurken onderbroken door adempauzes?

$\square$ ja $\quad \square$ nee $\square$ weet ik niet
$\square$ alleen $\square$ met iemand samen

1 Slaapt u doorgaans alleen of met iemand samen op één kamer?

IN DE AFGELOPEN 3 MAANDEN

\section{VERMOEIDHEID:}

Kruis op elke regel één hokje aan.

32 - Voelt u zich vaak moe?

- Heeft u vaak moeite om in te slapen?

- Wordt u 's nachts vaak wakker?

- Ik doe 's nachts vaak geen oog dicht

- Voelt u zich vaak slap?

- Heeft u het gevoel dat u de laatste tijd weinig presteert?

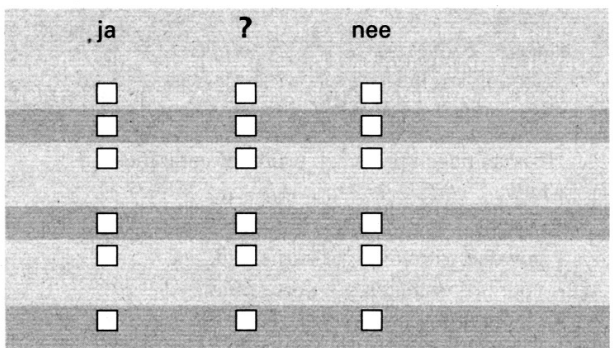


Kruis op elke regel één hokje aan.

- Heeft $\mathrm{u}$ weleens het gevoel dat het $\mathrm{u}$ allemaal wat te veel wordt?

- Heeft u het gevoel dat $\mathrm{u}$ in het slop zit?

- Voelt u zich de laatste tijd lustelozer dan vroeger?

- Ik voel mij 's ochtends, nadat ik ben opgestaan, meestal goed uitgerust

- Is uw plezier in het seksuele verminderd?

- Heeft u de laatste tijd weleens een gevoel van hopeloosheid gehad?

- Doet u er nu langer over om een moeilijk probleem te begrijpen dan een jaar geleden?

- Ik ben vaak erg slaperig overdag

- Is het zo dat allerlei kleine dingen u meer ergeren dan vroeger?

- Heeft u de laatste tijd weleens het verlangen voelen opkomen om het bijltje erbij neer te gooien?

- Ik voel me prima

- Heeft u weleens het gevoel dat uw lichaam een batterij is, waarvan de kracht of het vermogen aan het opraken is?

- Overdag val ik soms in slaap ook al wil ik dat niet

- Zou u soms weleens dood willen zijn?

- Heeft u de laatste tijd het gevoel dat u niet meer zoveel waard bent als vroeger?

- Voelt u zich moedeloos?

- Heeft u weleens huilbuien?

- Ik word overdag vaak overmand door slaap

- Wordt u wel eens wakker met een gevoel van uitputting en vermoeidheid?

- Is het moeilijk voor u geworden om u lang op één ding te concentreren?

- Kunt u de laatste tijd door kleine dingen soms erg geprikkeld raken?

- Ik kan de laatste tijd soms erg opvliegend zijn

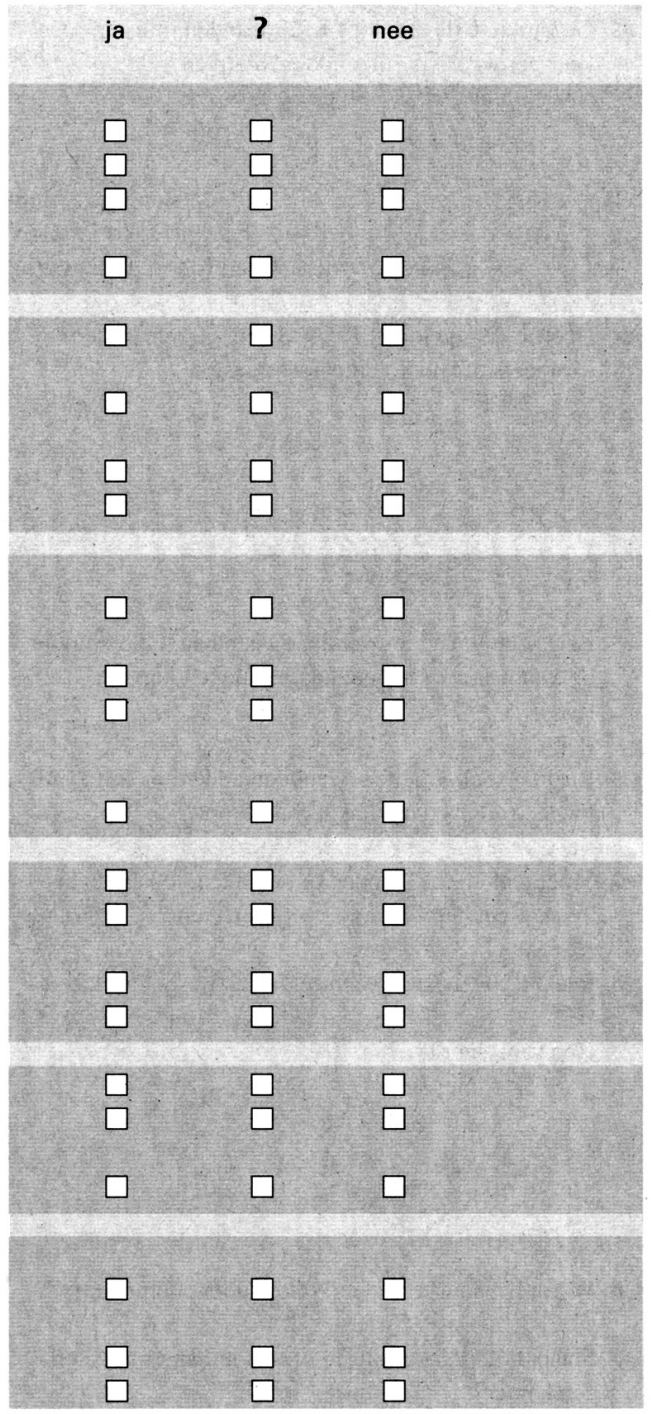

IN DE AFGELOPEN 3 MAANDEN

\section{VOEDING:}

aalde voedingsmiddelen eet. Wat u eventueel voor De volgende vragen gaan over hoe

Denkt $u$ hierbij aan wat $u$ de afgelopen DRIE MAANDEN gewoonlijk heeft gegeten. Laat een eventueel dieet buiten beschouwing als het korter duurde dan drie weken.

1 Hoeveel dagen per week drinkt of eet u meestal... Kruis op elke regel één hokje aan.

nooit of minder dan 1 keer per week

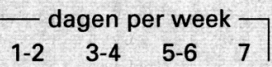

- gewone witte melk of karnemelk?

- yoghurt, vruchten yoghurt of biogarde?

- vla, pudding of pap?

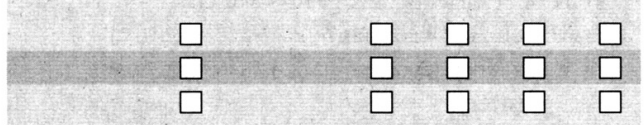


2 Hoeveel glazen of schaaltjes drinkt of eet u gewoonlijk op zo'n dag?

Kruis op elke regel één hokje aan.

- glazen melk of karnemelk?

- schaaltjes yoghurt?

- schaaltjes vla, pudding of pap?

3 Wat voor soort melk gebruikt u meestal?

4 Wat voor soort yoghurt, vruchtenyoghurt of biogarde gebruikt u meestal?

5 Kruis op elke regel één hokje aan.

- Hoeveel sneetjes brood, broodjes, crackers of beschuiten eet u meestal per dag?

- Hoeveel daarvan belegt u meestal met kaas?

- Hoeveel daarvan belegt u meestal met vleeswaren?

6 Kunt u drie soorten vleeswaren opschrijven die u gewoonlijk op uw brood eet?

7 Wat voor soort boter smeert u MEESTAL op uw brood?

8 Hoe vaak eet u vleessoorten zoals rookworst, verse worst, of saucijsjes bij de warme maaltijd?

9 Hoe vaak eet u half-om-half gehakt?

10 Hoe vaak eet u speklappen of doorregen varkenslappen?

11 Hoeveel dagen per week gebruikt u jus bij de warme maaltijd?

12 Hoeveel lepels jus gebruikt $\mathrm{u}$ dan gewoonlijk per maaltijd?

13 Over wat voor soort lepel heeft $u$ het dan?
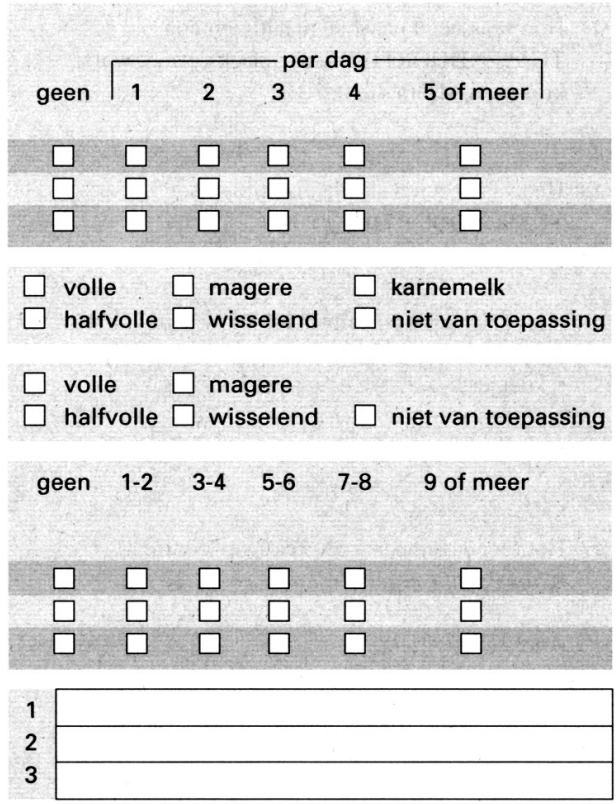

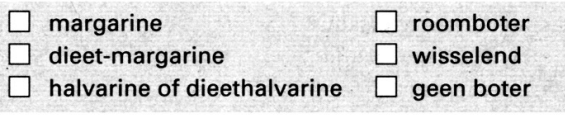

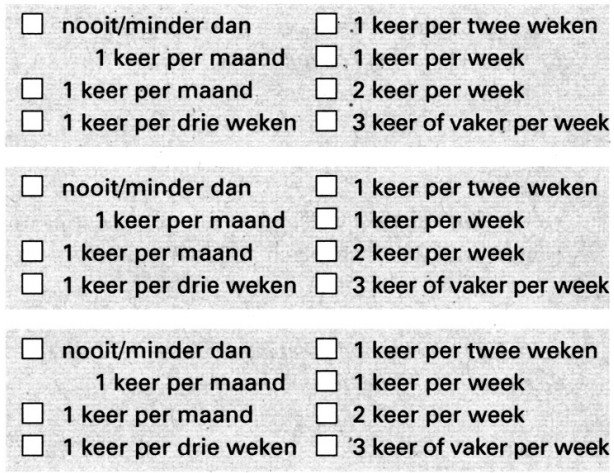

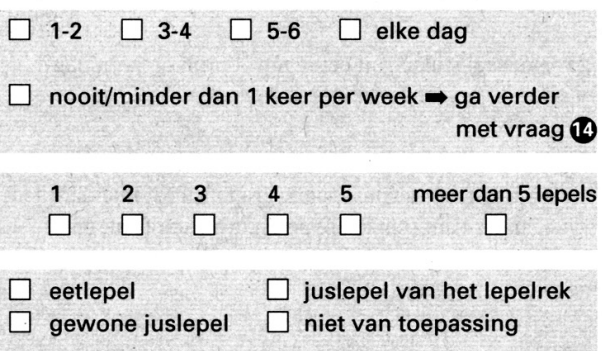


14 Hoe vaak eet u naast de maaltijden nog TUSSENDOORTJES zoals snacks, patat, worst, kroketten, slaatjes, enz.?

15 Hoe vaak eet u naast de maaltijden nog TUSSENDOORTJES zoals:

Kruis op elke regel één hokje aan.

- pinda's, nootjes, chips, blokjes kaas of worst?

- gebak, cake, grote koeken en chocolade?

- koekjes?

Hoeveel koekjes eet u dan gemiddeld op zo'n dag?

17 Hoeveel dagen per week eet u gewoonlijk...

Kruis op elke regel één hokje aan.

- gekookte groente?

- sla of andere rauwkost?

18 Eet u gewoonlijk groente of sla?

Kruis op elke regel één hokje aan.

- bij de warme maaltijd

- bij de broodmaaltijd

- tussendoor

19 Hoeveel dagen per week eet u gewoonlijk... Kruis op elke regel één hokje aan

- uien

- knoflook (teentje)

- appels

- citrusfruit (sinaasappels, grapefruit of mandarijnen)

- ander fruit (bananen, peren, tropisch fruit, enz.)

20 Hoeveel uien of teentjes knoflook eet $\mathrm{u}$ dan ZELF op zo'n dag? (deel zonodig het aantal uien of teentjes in de maaltijd door het aantal personen)

- uien

- teentjes knoflook

21 Hoeveel stuks fruit eet u gewoonlijk op zo'n dag? Kruis op elke regel één hokje aan.

- appels

- citrusfruit (sinaasappels, grapefruit of mandarijnen)

- ander fruit (bananen, peren, tropisch fruit, enz.)

Bent u vegetariër?

23 Volgt u momenteel een dieet?

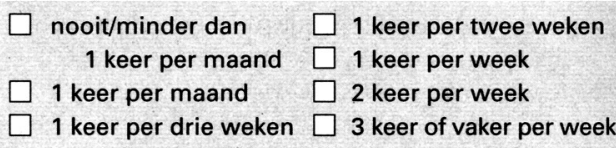

t vaker per week
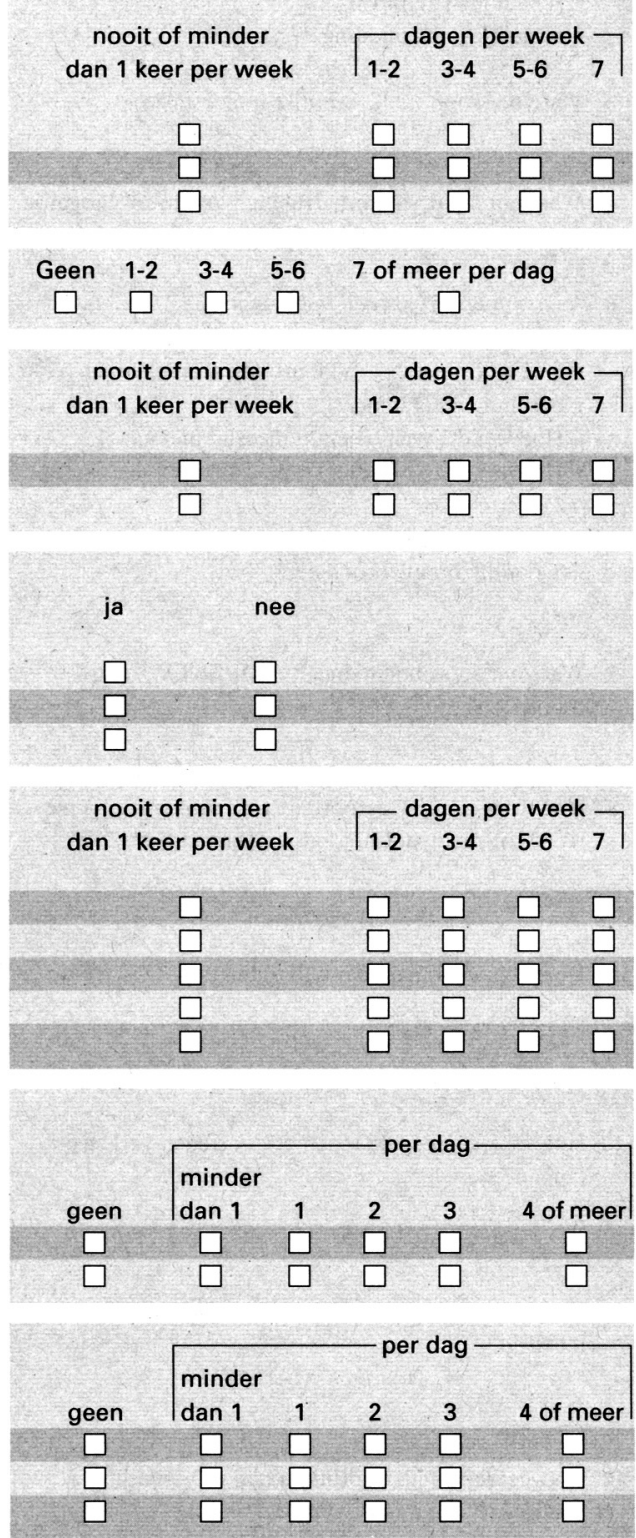

$\begin{array}{ll}\square \text { ja } & \square \text { nee } \\ \square \text { ja } & \square \text { nee }\end{array}$




\section{KOFFIE EN THEE:}

24 Hoe vaak drinkt u koffie?

25 Hoeveel koppen zijn dat dan op zo'n dag?

26 Gebruikt u cafeïne-vrije koffie?

27 Hoe vaak per week drinkt $\mathrm{u}$ thee?

28 Hoeveel koppen zijn dat dan op zo'n dag?

\section{IN DE AFGELOPEN 12 MAANDEN}

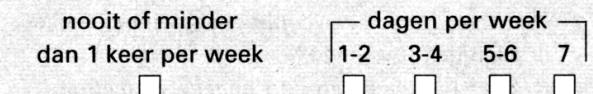

koppen

altijd meestal af en toe zelden nooit

nooit of minder

dan 1 keer per week

$\left[\begin{array}{llll}\text { dagen per week } & \\ 1-2 & 3-4 & 5-6 & 7\end{array} \mid\right.$

koppen

\section{GEBRUIK VAN BIER, WIJN, STERKE DRANK}

Het doel van deze vragen is om een indruk te krijgen van uw gebruik van bier, wijn en sterke drank vanaf uw jeugd tot nu.

We onderscheiden drie soorten drank, nl. bier, wijn en sterke drank (gedistilleerd).

We verstaan onder:

BIER: alle biersoorten, behalve alcoholvrij bier

WIJN: $\quad$ alle wijnsoorten, sherry, Martini, port en vruchtenwijnen

STERKE DRANK: alle gedistilleerde dranken (jenever, whisky, cognac), mixen, cocktails en likeur (met een alcohol percentage hoger dan $20 \%$ ).

1 Op welke leeftijd heeft u voor het eerst bier, wijn of sterke drank gedronken?

We bedoelen een heel glas en niet alleen proeven aan een glaasje van iemand anders.
Vul hier de leeftijd in:

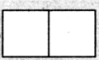

Ligt deze leeftijd tussen:

Kruis de juiste periode aan
12-18 jaar?
$\Rightarrow$ ga verder met vraag
JEUGD op pagina 10
19-27 jaar?
- ga verder met vraag
JONGE VOLWASSENHEID op pagina 11
28-44 jaar?
- ga verder met vraag
VOLWASSENHEID op pagina 12
45-60 jaar?
$\Rightarrow$ ga verder met vraag
MIDDELBARE LEEFTIJD op pagina 13
61 jaar of ouder?
$\Rightarrow$ ga verder met vraag
OUDERE LEEFTIJD op pagina 14

Ik heb nog nooit bier, wijn of sterke drank gedronken $\Rightarrow$ ga verder met EFFECTEN op pagina 18 


\section{A JEUGD}

2 Hoe vaak dronk u gewoonlijk bier, wijn of sterke drank tijdens uw jeugd?

Reken vanaf de bij vraag 1 opgegeven leeftijd.

\section{$U$ was toen tussen de 12 en 18 jaar}

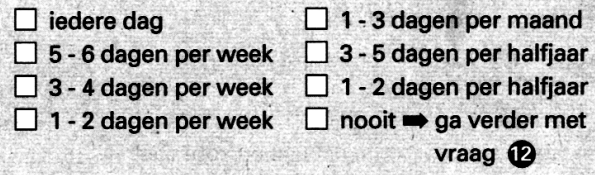

3 Hoeveel glazen dronk u doorgaans op zo'n dag?

4 Dronk u meestal bier, wijn of sterke drank? Kruis op elke regel één hokje aan. sterke drank

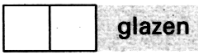

\section{altijd meestal af en toe zelden nooit}

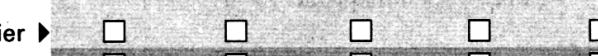
$\square$ mijn $\square \quad \square$ 十

5 Waar dronk u tijdens uw jeugd?

Kruis op elke regel één hokje aan.

altijd meestal af en toe zelden nooit

thuis of bij anderen thuis buitenshuis, zoals café, dancing, restaurant

Dronk u meestal alleen?

7 Hoe vaak dronk u tijdens uw jeugd 6 of meer glazen bier, wijn of sterke drank op één dag?

8 Bent u ooit bewust gestopt met het drinken van alcohol in deze periode?

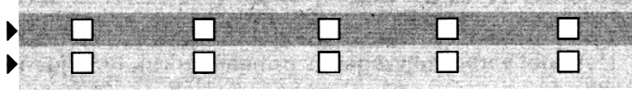

\section{Indien gestopt tijdens uw jeugd, bent u toen voorgoed} of tijdelijk gestopt?
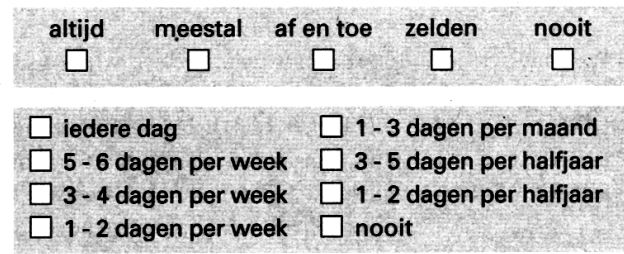

$\square$ ja $\quad \square$ nee $\Rightarrow$ ga verder met vraag 12

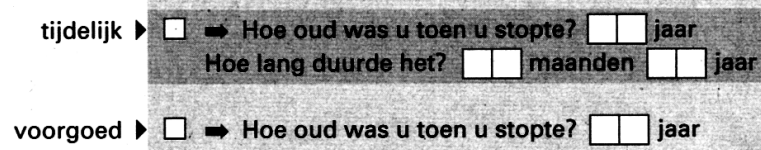

10 Bent $\mathrm{u}$ toen gestopt...

Meer dan één antwoord mogelijk.

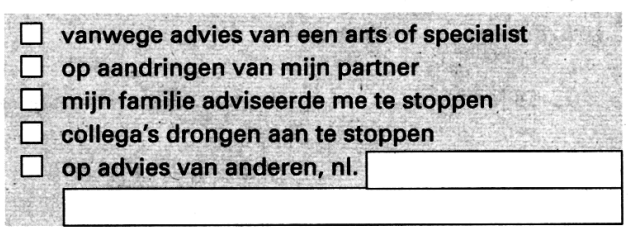

11. Om welke reden bent $\mathrm{u}$ toen gestopt... Meer dan één antwoord mogelijk. 
12 Heeft u na uw 18e levensjaar nog bier, wijn of sterke drank gedronken?

ja $\quad \Rightarrow$ ga verder met vraag 13

nee $\Rightarrow$ ga verder met "EFFECTEN" op pag. 18

\section{B JONGE VOLWASSENHEID}

13 Hoe vaak dronk u gewoonlijk bier, wijn of sterke drank tussen uw $19 \mathrm{e}$ en $27 \mathrm{e}$ jaar?

14 Hoeveel glazen dronk u doorgaans op zo'n dag?

15 Dronk u meestal bier, wijn of sterke drank?

Kruis op elke regel één hokje aan.

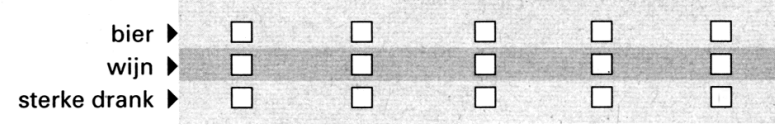

16 Waar dronk u tijdens uw jonge volwassenheid

(19-27 jaar)? Kruis op elke regel één hokje aan. thuis of bij anderen thuis buitenshuis, zoals café, dancing, restaurant

17 Dronk u meestal alleen?

18 Hoe vaak dronk u 6 of meer glazen bier, wijn of sterke drank op één dag tussen uw $19 \mathrm{e}$ en $27 \mathrm{e}$ jaar?

19 Bent u ooit bewust gestopt met het drinken van alcohol in deze periode?

20 Indien gestopt tussen uw $19 \mathrm{e}$ en $27 \mathrm{e}$ jaar, bent $\mathrm{u}$ toen voorgoed of tijdelijk gestopt?

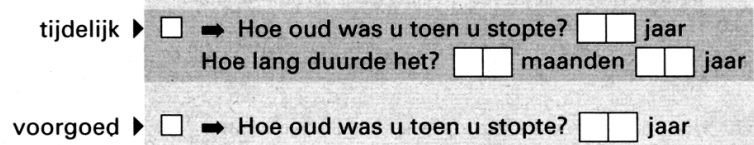

21 Bent $\mathbf{u}$ toen gestopt...

Meer dan één antwoord mogelijk. altijd meestal af en toe zelden nooit

\section{U was toen tussen de 19 en 27 jaar}

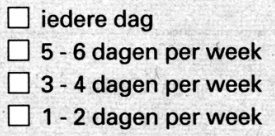

1 - 3 dagen per maand

3 - 5 dagen per halfjaar

1 - 2 dagen per halfjaar

nooit $\Rightarrow$ ga verder met vraag 23
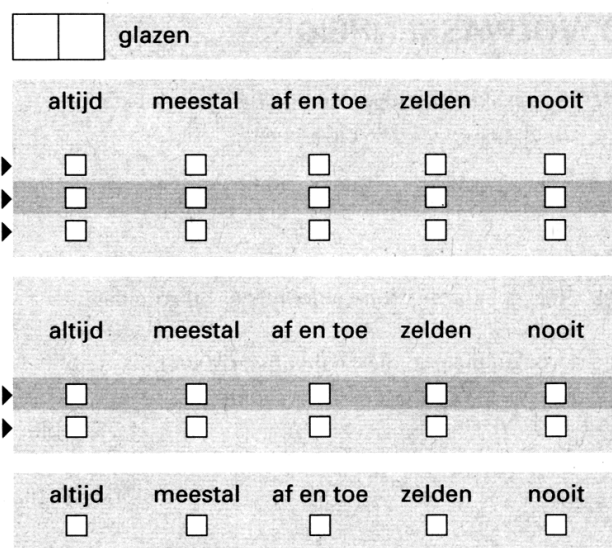

iedere dag

1 - 3 dagen per maand

5 - 6 dagen per week $\square 3$ - 5 dagen per halfjaar

3-4 dagen per week $\square 1$ - 2 dagen per halfjaar

1 - 2 dagen per week $\square$ nooit

$\square$ ja $\quad \square$ nee $\Rightarrow$ ga verder met vraag 23 
$22 \mathrm{Om}$ welke reden bent $\mathrm{u}$ toen gestopt.. Meer dan één antwoord mogelijk. vanwege uw gezondheid

$\square$ vanwege te grote afhankelijkheid van de drank

$\square$ omdat het te duur was

$\square$ vanwege uw werk

$\square$ omdat u moeilijkheden kreeg met anderen

andere reden, $\mathrm{nl}$.

23 Heeft u na uw 27ste levensjaar nog bier, wijn of sterke drank gedronken?

$\square$ ja $\quad \Rightarrow$ ga verder met vraag 24

nee $\Rightarrow$ ga verder met "EFFECTEN" op pag. 18

\section{VOLWASSENHEID}

\section{$\mathrm{U}$ was toen tussen de 28 en 44 jaar}

24 Hoe vaak dronk u gewoonlijk bier, wijn of sterke drank tussen uw $28 \mathrm{e}$ en $44 \mathrm{e}$ jaar?

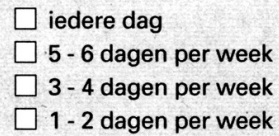

$\square 1$ - 2 dagen per week

25 Hoeveel glazen dronk u doorgaans op zo'n dag?

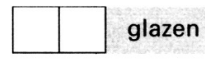

26 Dronk u meestal bier, wijn of sterke drank?

Kruis op elke regel één hokje aan.

bier sterke drank

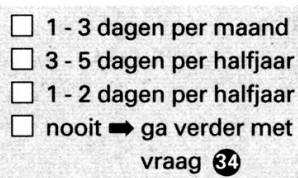
vraag 34

27 Waar dronk u tijdens uw volwassenheid (28-44 jaar)? Kruis op elke regel één hokje aan.

altijd meestal af en toe zelden nooit

\begin{abstract}
thuis of bij anderen thuis buitenshuis, zoals café, dancing, restaurant
\end{abstract}

28 Dronk u meestal alleen?

29 Hoe vaak dronk u 6 of meer glazen bier, wijn of sterke drank op één dag tussen uw $28 \mathrm{e}$ en $44 \mathrm{e}$ jaar?

30 Bent $\mathrm{u}$ ooit bewust gestopt met het drinken van alcohol in deze periode?

31 Indien gestopt tussen uw $28 \mathrm{e}$ en $44 \mathrm{e}$ jaar, bent u toen voorgoed of tijdelijk gestopt?

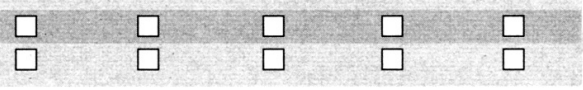

altijd meestal af en toe zelden nooit<smiles>[TeH]</smiles>

iedere dag

1 - 3 dagen per maand

5 - 6 dagen per week $\square 3-5$ dagen per halfjaar

3-4 dagen per week $\square 1-2$ dagen per halfjaar

1 - 2 dagen per week $\square$ nooit

\begin{tabular}{|c|c|c|c|c|}
\hline \multirow{2}{*}{ tijdelijk $\square$} & $\square \Rightarrow$ Hoe ot & topte? & ] jaar & \\
\hline & Hoe lang duurde het? & maanden & & jaar \\
\hline
\end{tabular}


32 Bent u toen gestopt...

Meer dan één antwoord mogelijk.

33 Om welke reden bent $\mathrm{u}$ toen gestopt... Meer dan één antwoord mogelijk. vanwege advies van een arts of specialist

op aandringen van mijn partner

mijn familie adviseerde me te stoppen

collega's drongen aan te stoppen

op advies van anderen, $\mathrm{nl}$.

vanwege uw gezondheid

vanwege tè grote afhankelijkheid van de drank

omdat het te duur was

vanwege uw werk

omdat u moeilijkheden kreeg met anderen

andere reden, $\mathrm{nl}$.

34 Heeft u na uw 44ste levensjaar nog bier, wijn of sterke drank gedronken?

ja $\quad \Rightarrow$ ga verder met vraag 35

nee $\Rightarrow$ ga verder met "EFFECTEN" op pag. 18

\section{MIDDELBARE LEEFTIJD}

35 Hoe vaak dronk u gewoonlijk bier, wijn of sterke drank tussen $45 \mathrm{e}$ en $60 \mathrm{e}$ jaar?

36 Hoeveel glazen dronk u doorgaans op zo'n dag?

37 Dronk u meestal bier, wijn of sterke drank?

Kruis op elke regel één hokje aan.

\section{$\mathrm{U}$ was toen tussen de $\mathbf{4 5}$ tot $\mathbf{6 0}$ jaar}

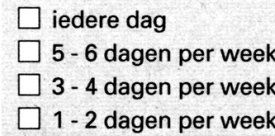

$\square 1$ - 3 dagen per maand

$\square 3$ - 5 dagen per halfjaar

$\square 1$ - 2 dagen per halfjaar

$\square$ nooit $\Rightarrow$ ga verder met vraag 45

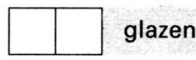

altijd meestal af en toe zelden nooit

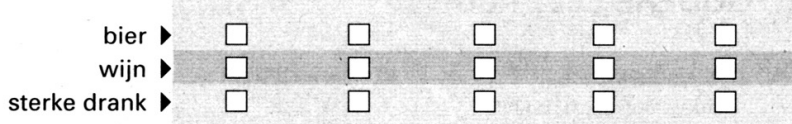

38 Waar dronk u tijdens uw middelbare periode

(45-60 jaar)? Kruis op elke regel één hokje aan.

altijd meestal af en toe zelden nooit

thuis of bij anderen thuis buitenshuis, zoals café, dancing, restaurant

Dronk u meestal alleen?

Hoe vaak dronk u 6 of meer glazen bier, wijn of sterke drank op één dag tussen uw 45 e en 60 e jaar?

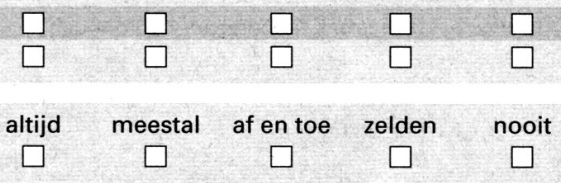
$\square 5$ - 6 dagen per week
1 - 3 dagen per maand
3 - 4 dagen per week
1 - 2 dagen per week
3 - 5 dagen per halfjaar
$\square 1$ - 2 dagen per halfjaar
$\square$ nooit

41 Bent u ooit bewust gestopt met het drinken van alcohol in deze periode?
ja
nee $\Rightarrow$ ga verder met vraag 45 
42 Indien gestopt tussen uw $45 \mathrm{e}$ en $60 \mathrm{e}$ jaar, bent $\mathrm{u}$ toen

voorgoed of tijdelijk gestopt?

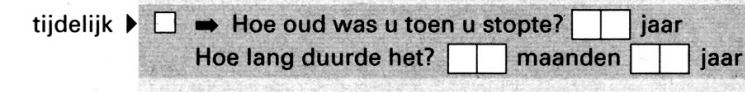

voorgoed $\square \Rightarrow$ Hoe oud was u toen u stopte? $\square \square$ jaar

43 Bent u toen gestopt...

Meer dan één antwoord mogelijk.

44 Om welke reden bent $\mathrm{u}$ toen gestopt...

Meer dan één antwoord mogelijk.

45 Bent u ouder dan 60 jaar? $\square$ vanwege advies van een arts of specialist

$\square$ op aandringen van mijn partner

$\square$ mijn familie adviseerde me te stoppen

$\square$ collega's drongen aan te stoppen

$\square$ op advies van anderen, $\mathrm{nl}$.

$\square$ vanwege uw gezondheid

$\square$ vanwege tè grote afhankelijkheid van de drank

$\square$ omdat het te duur was

$\square$ vanwege uw werk

omdat u moeilijkheden kreeg met anderen

andere reden, $\mathrm{nl}$.
46 Heeft u na uw 60ste levensjaar nog bier, wijn of sterke drank gedronken? $\square$ ja $\quad \Rightarrow$ ga verder met vraag 47

nee $\Rightarrow$ ga verder met "EFFECTEN" op pag. 18

\section{E OUDERE LEEFTIJD}

47 Hoe vaak dronk u gewoonlijk bier, wijn of sterke drank vanä uw 61e jaar?

48 Hoeveel glazen dronk u doorgaans op zo'n dag?

49 Dronk u meestal bier, wijn of sterke drank? Kruis op elke regel één hokje aan.

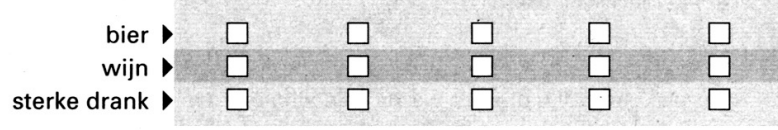

50 Waar dronk u vanaf uw 61e jaar?

Kruis op elke regel één hokje aan.

thuis of bij anderen thuis buitenshuis, zoals café, dancing, restaurant

51 Dronk u meestal alleen?

\section{$\mathbf{U}$ bent 61 jaar of ouder}

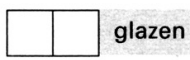

altijd meestal af en toe zelden nooit
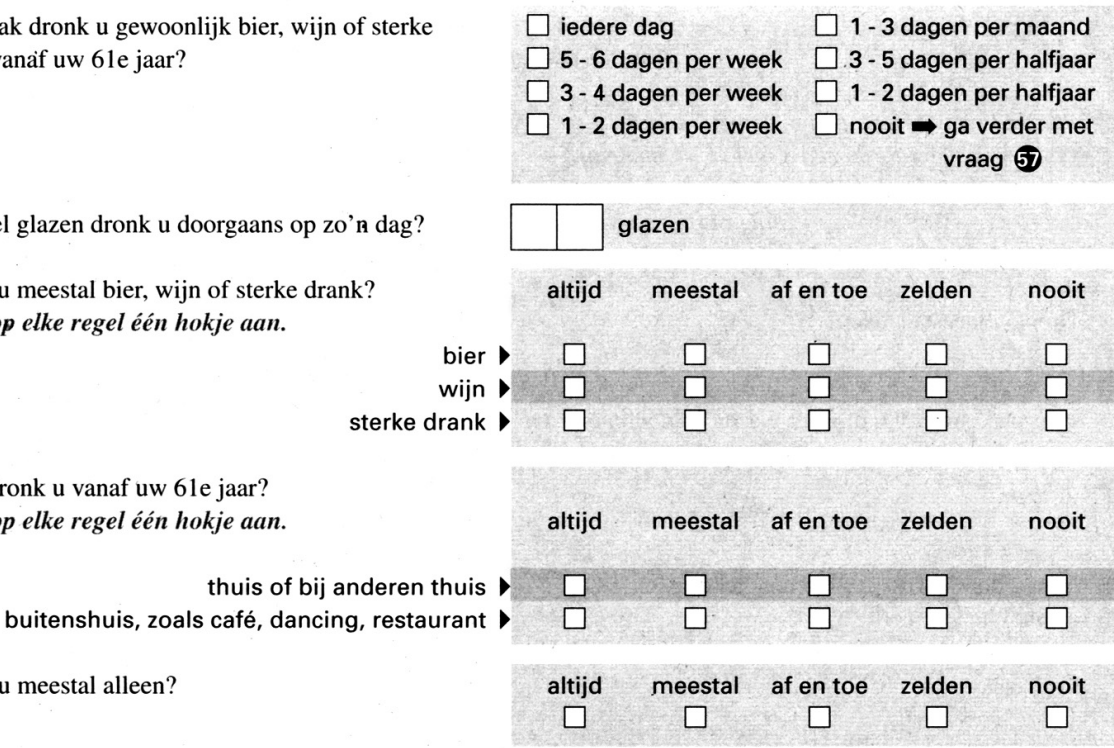
52 Hoe vaak dronk u vanaf uw 61 e jaar 6 of meer glazen bier, wijn of sterke drank op één dag?

53 Bent u ooit bewust gestopt met het drinken van alcohol in deze periode?

54 Indien gestopt vanaf uw 61e jaar, bent u toen voorgoed of tijdelijk gestopt?

Meer dan één antwoord mogelijk.

56 Om welke reden bent $\mathbf{u}$ toen gestopt... Meer dan één antwoord mogelijk. ja $\quad \square$ nee $\Rightarrow$ ga verder met vraag 57

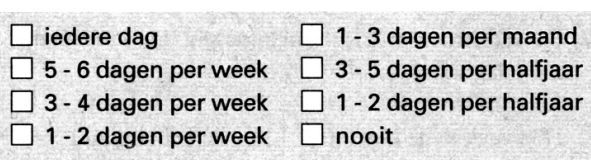

$\square$ ja

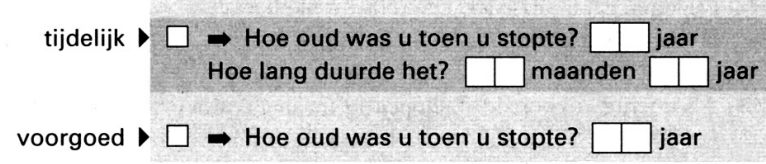

vanwege advies van een arts of specialist

$\square$ op aandringen van mijn partner

$\square$ mijn familie adviseerde me te stoppen

$\square$ collega's drongen aan te stoppen

$\square$ op advies van anderen, $\mathrm{nl}$.

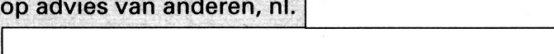

$\square$ vanwege uw gezondheid

$\square$ vanwege tè grote afhankelijkheid van de drank

$\square$ omdat het te duur was

$\square$ vanwege uw werk

$\square$ omdat u moeilijkheden kreeg met anderen

$\square$ andere reden, $\mathrm{nl}$.

57 Heeft u de afgelopen 12 maanden nog bier, wijn of sterke drank gedronken?

$\square$ ja $\quad \Rightarrow$ ga verder met vraag 58

$\square$ nee $\Rightarrow$ ga verder met "EFFECTEN" op pag. 18

\section{F IN DE AFGELOPEN 12 MAANDEN}

58 Hoe vaak in de afgelopen 12 maanden heeft u WIJN (ook sherry, port, Martini e.d.) gedronken?

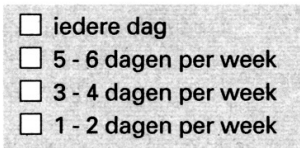

$\square 3$ - 4 dagen per week

$\square 1$ - 2 dagen per week

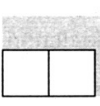

$\square$ vooral rood
$\square$ vooral wit
$\square$ ongeveer evenveel

61 Hoe vaak in de afgelopen 12 maanden heeft u BIER gedronken?

\section{glazen.}

60 Drinkt u vooral rode of vooral witte wijn?

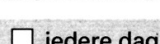

1 - 3 dagen per maand

3 - 5 dagen per halfjaar

1 - 2 dagen per halfjaar

nooit $\Rightarrow$ ga verder met vraag 61

$$
\text { zo'n dag? }
$$

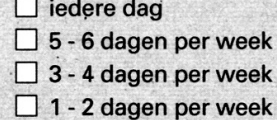

1 - 3 dagen per maand

$\square$ - 5 dagen per halfjaar

$\square 1$ - 2 dagen per halfjaar

$\square$ nooit $\Rightarrow$ ga verder met vraag 63 
62 De keren dat u BIER dronk, hoeveel dronk u dan op zo'n dag?

63 Hoe vaak in de afgelopen 12 maanden heeft u STERKE DRANK gedronken?

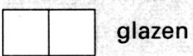

$\square$ iedere dag

5 - 6 dagen per week

3 - 4 dagen per week

1 - 2 dagen per week

1 - 3 dagen per maand

$\square 3$ - 5 dagen per halfjaar

1 - 2 dagen per halfjaar

$\square$ nooit $\Rightarrow$ ga verder met vraag 65

64 De keren dat u STERKE DRANK dronk, hoeveel dronk $u$ dan op zo'n dag?

65 Als u terug kijkt op de afgelopen 12 maanden, wat is het GROOTSTE aantal glazen bier, wijn of sterke drank dat u op één dag gedronken heeft?

66 Drinkt u weleens wijn, bier of sterke drank vlak voor het naar bed gaan?

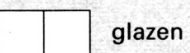

$\square$ meer dan 12 glazen

$\square 9$ à 12 glazen

$\square 6$ à 8 glazen

4 of 5 glazen
3 glazen

1 of 2 glazen

weet ik niet

\section{G IN DE AFGELOPEN WEEK}

67 Kruis aan: welke dag het is vandaag?

\section{$\mathrm{Ma} \mathrm{Di}$ Wo Do Vrij Za Zon}

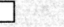

68 Geef in het schema aan hoeveel glazen bier, wijn en/of sterke drank u op elk van de afgelopen 7 dagen heeft gedronken. Begin bij gisteren.

Bier

Wijn
Sterke drank

Gisteren

2 dagen geleden

3 dagen geleden

4 dagen geleden

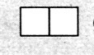

glazen

5 dagen geleden

$\square$ glazen

प

6 dagen geleden

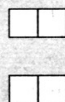

glazen

glazen
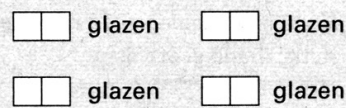

glazen

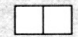

glazen

$\square$ glazen

$\square$ glazen

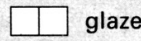

$\square$ glazen

glazen

glazen

7 dagen geleden

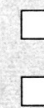

glazen

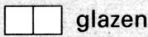

glazen 


\section{H REDENEN}

Hieronder staan redenen waarom mensen weleens bier, wijn of sterke drank drinken. Geef aan hoe in hoeverre deze redenen voor $u$ een rol spelen.

Kruis op elke regel één hokje aan.

12 Ik drink bier, wijn of sterke drank...

- om speciale gebeurtenissen te vieren

- omdat het de druk van mijn dagelijkse problemen verlicht

- omdat het contact met anderen dan makkelijker gaat

- omdat dit mijn eetlust verhoogt

- omdat ik dan meer geniet van het contact met anderen

- tegen de stress en spanningen

- omdat anderen die ik ontmoet ook drinken

- omdat ik het lekker vind

- omdat ik niet durf te weigeren

- om mezelf op te beuren

- omdat het goed is voor mijn gezondheid

- omdat het lekker smaakt

- omdat ik me er lichamelijk beter bij voel

- omdat ik daarmee beter de dagelijkse beslommeringen van me af kan zetten

- omdat het een positief effect heeft op mijn hart en bloedvaten

- omdat ik het nodig heb als ik gespannen en nerveus ben

- omdat het mij meer energie geeft

- omdat me dat helpt mijn zorgen te vergeten

- omdat de arts het mij adviseerde

- omdat het me minder nerveus maakt

- omdat ik me dan beter kan concentreren

- om te ontspannen

- omdat ik er aan verslaafd ben

- omdat ik me verveel
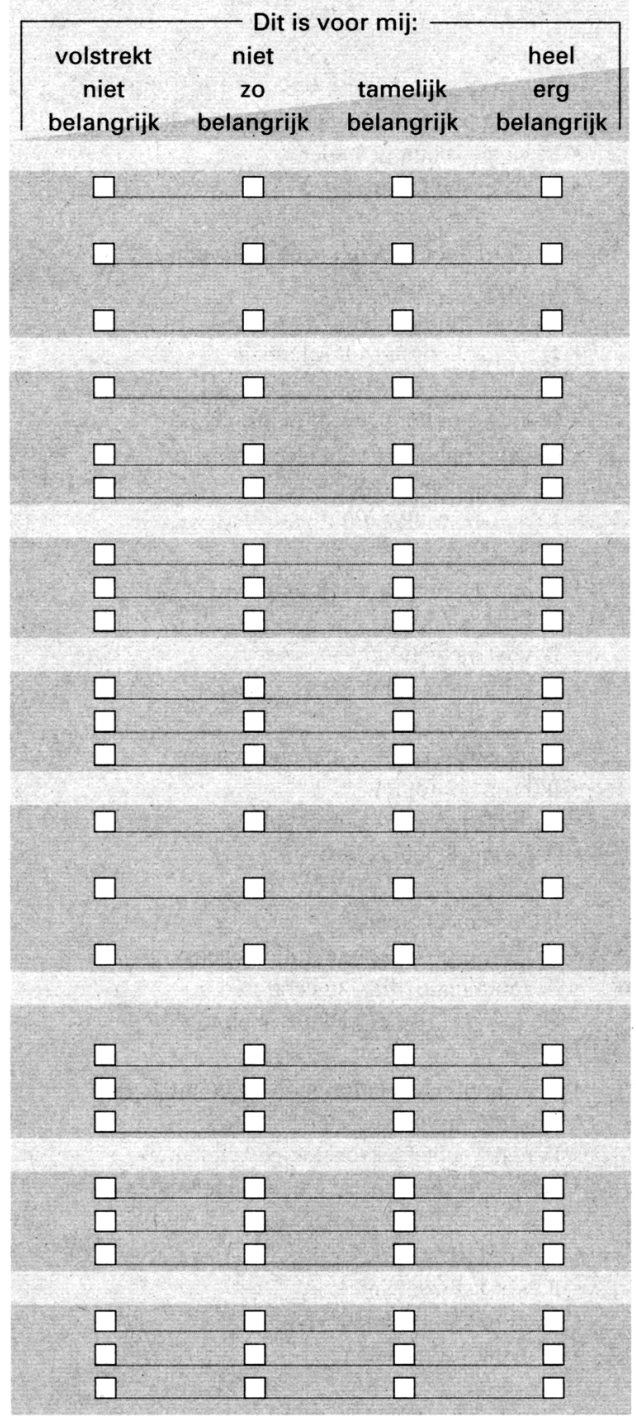


\section{EFFECTEN}

Bier, wijn en sterke drank hebben verschillende effecten. Kruis voor elk effect aan of $U$ denkt dat dit bij $u$ al dan niet zal optreden als u drinkt of zou gaan drinken.

1. Ik amuseer me beter

- Ik krijg problemen met het rijden in het verkeer

- Ik ga me schuldig voelen

- Ik slaap sneller in

- Ik word door anderen beter geaccepteerd

- Ik word agressief

- Ik word minder alert

- Ik ga me voor mezelf schamen

- Ik krijg een licht gevoel in mijn hoofd

- Ik word onhandig en ongecoördineerd

- Ik ga me beter voelen

- Ik raak betrokken bij ruzies

- Ik kan me niet concentreren

- Ik krijg een kater

- Ik voel me gelukkiger

- Ik krijg meer zin in seks

- Ik ga gemakkelijker met anderen om

- Ik krijg hoofdpijn

- Ik durf meer op seksueel gebied

- Alles wordt leuker

- Ik ga gemeen doen

- Ik krijg problemen met mijn geheugen

- Ik kan me moeilijk concentreren

- De lichamelijke effecten zijn prettig

- Ik krijg minder schroom om er op uit te gaan

- Mijn stemming verbetert

- Ik raak sneller seksueel opgewonden

- Ik voel me beter in de omgang met anderen

- Ik word triest

- Ik word spraakzamer

- Ik word seksueel actiever

- Ik ga me ziek voelen

- Ik voel me minder gespannen

- Ik word vriendelijker

- De lichamelijke effecten zijn vervelend

- Ik ben in staat om aan iets anders dan mijn problemen te denken

- Ik ga me kalmer voelen

- Ik word slaperig
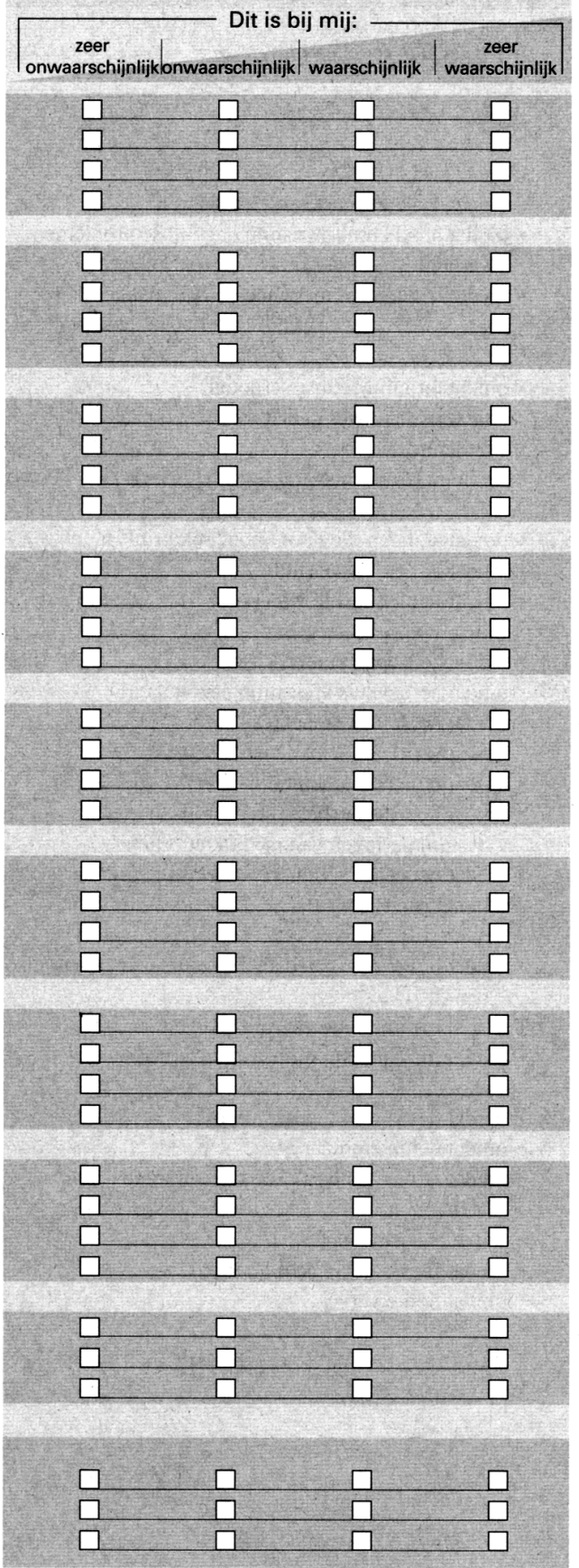


\section{PERSOONSKENMERKEN}

1 In welk land bent u geboren?

2 Welke nationaliteit heeft u? Als u een dubbele nationaliteit heeft, beide aankruisen en invullen. $\square$ Nederland

anders, $\mathrm{nl}$.

Nederlandse

anders, $\mathrm{nl}$.

3 Wat is uw burgerlijke staat?

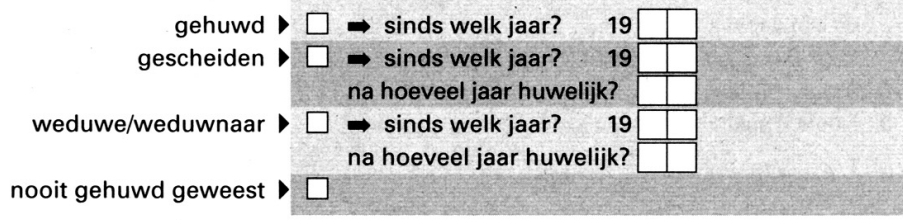

4 Woont u samen met een vaste partner?

ja

Hieronder verstaan we ook uw huwelijkspartner.

nee

5 Rekent u zichzelf tot een kerkgenootschap, een godsdienstige gemeente of een andere levensbeschouwelijke groepering?

ja

$\square$ nee $\Rightarrow$ ga verder met vraag "ROKEN" op deze pag.

6 Tot welke kerk of levensbeschouwelijke groepering rekent u zich in de eerste plaats?

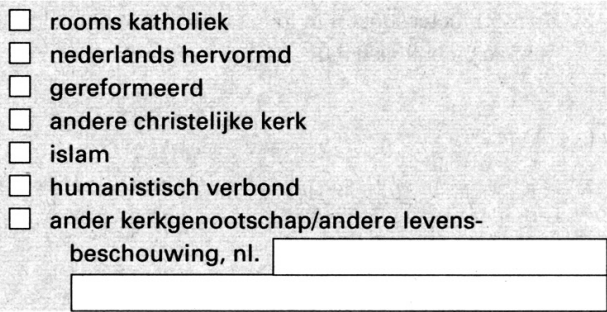

7 Hoe vaak gaat $u$ in het algemeen naar de kerk of bezoekt u bijeenkomsten?

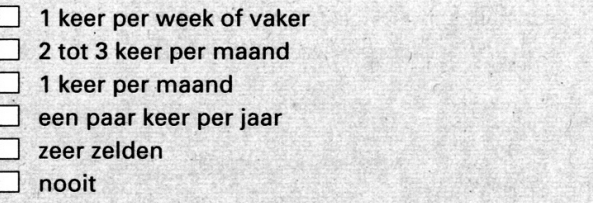

8 Hoe zou u zichzelf willen omschrijven wat betreft uw godsdienstige overtuiging?
sterk overtuigd overtuigd
$\square$ enigszins overtuigd
$\square$ weinig overtuigd
helemaal niet overtuigd

\section{ROKEN}

1 Rookt u sigaretten en/of shag?

2 Heeft $\mathrm{u}$ in uw leven ten minste 100 sigaretten en/of shagjes gerookt?

3 Heeft u ooit dagelijks gerookt?

\section{ja $\Rightarrow$ ga verder met vraag 5}

ja

nee $\Rightarrow$ ga verder met "BEWEGEN" op pag. 20
ja
nee 
4 Op welke leeftijd bent u voorgoed gestopt met het roken van sigaretten of shag?

5 Rookt u elke dag sigaretten of shag?

6 Op welke leeftijd bent u voor het eerst dagelijks sigaretten en/of shag gaan roken?

7 Hoeveel sigaretten en/of shagjes rookt u gemiddeld op een dag dat u rookt?

(ex-rokers: vóór u de laatste keer stopte)

8 Rookt u sigaren, cigarillo's en/of pijp?

9 Heeft u vroeger sigaren, cigarillo's of pijp gerookt?

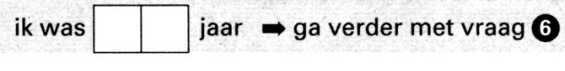

$\square$ ja $\quad \square$ nee
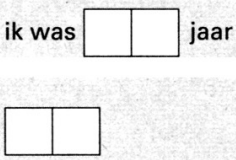

$\square$ ja $\Rightarrow$ hoeveel gemiddeld per dag?

nee

ja $\square$ nee

\section{BEWEGEN}

1 Hoeveel trappen loopt u per dag? (één trap is ongeveer 12 treden; op en neer is 2 trappen)

2 Hoeveel meter loopt $\mathrm{u}$ in totaal op een doorsnee dag? (binnen én buitenshuis)

3 Doet u regelmatig aan sport of aan een lichamelijke activiteit in uw vrije tijd?

4 Hoeveel tijd heeft $\mathrm{u}$ in de afgelopen 12 maanden gemiddeld besteed aan een zware sport?

(zie de lijst met voorbeelden hieronder)

\section{Voorbeelden van zware sporten: \\ voetbal en andere balsporten \\ hardlopen, trimmen \\ aerobics, joggen}

\section{IN DE AFGELOPEN 12 MAANDEN}

$\begin{array}{lll}\square 0 & \square 11-30 & \square 51-80 \\ \square 1-10 & \square 31-50 & \square \text { meer dan } 80\end{array}$

$\square 0$

$\square \quad 1-500$ meter 1000-2500 meter $\square$ meer dan 10.000 meter

5 Hoeveel tijd heeft $\mathrm{u}$ in het laatste jaar besteed aan een lichtere sport? (zie de lijst met voorbeelden hieronder)

\section{zwemmen \\ wielrennen tennis, badminton, squash}

schaatsen

en andere zware sporten

\section{Voorbeelden van lichte sporten:}

\section{fietsen}

wandelen

bowlen, kegelen

zeilen
$\square$ o uur
$\square 1$ uur per week
$\square 2$ uur per week
3 uur per week

(volks)dansen

gymnastiek

golf

yoga

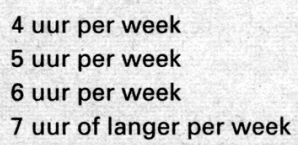

tuinieren

bijjarten

en andere lichte sporten 


\section{SOCIALE CONTACTEN 1:}

\section{IN DE AFGELOPEN 12 MAANDEN}

\section{Het gaat bij deze vragen over contacten met mensen die u geregeld ziet.}

Kruis op elke regel één hokje aan.

- Ik praat vertrouwelijk met anderen

- Anderen komen bij mij voor steun of advies

- Vrienden en/of familie bezoeken mij

- Als ik me gespannen voel of onder druk sta, dan is er iemand die mij helpt

- Als ik iets leuks meemaak, dan is er iemand met wie ik dat kan delen

- Als ik pijn heb, dan is er iemand die me steunt

- Ik bespreek mijn persoonlijke problemen met anderen

- Ik bezoek familie en/of vrienden

- Anderen komen bij mij met hun persoonlijke problemen

- Als ik verdrietig ben, dan is er iemand met wie ik dat kan delen

- Als ik hulp nodig heb bij karweitjes die ik niet alleen kan uitvoeren, dan is er iemand die me daarbij helpt

- Als anderen iets leuks meemaken, sta ik er voor open om dat met ze te delen

- Als ik ziek ben, is er iemand die mij helpt

- Als anderen verdriet hebben, dan kunnen ze bij mij terecht

- Ik help anderen als ze hulp nodig hebben bij karweitjes die ze niet alleen af kunnen

- Ik steun anderen als ze pijn hebben

- Anderen praten vertrouwelijk met mij

- Ik help anderen als ze ziek zijn

- Ik ga naar anderen voor steun en advies

- Ik help anderen als ze zich gespannen voelen of onder druk staan.

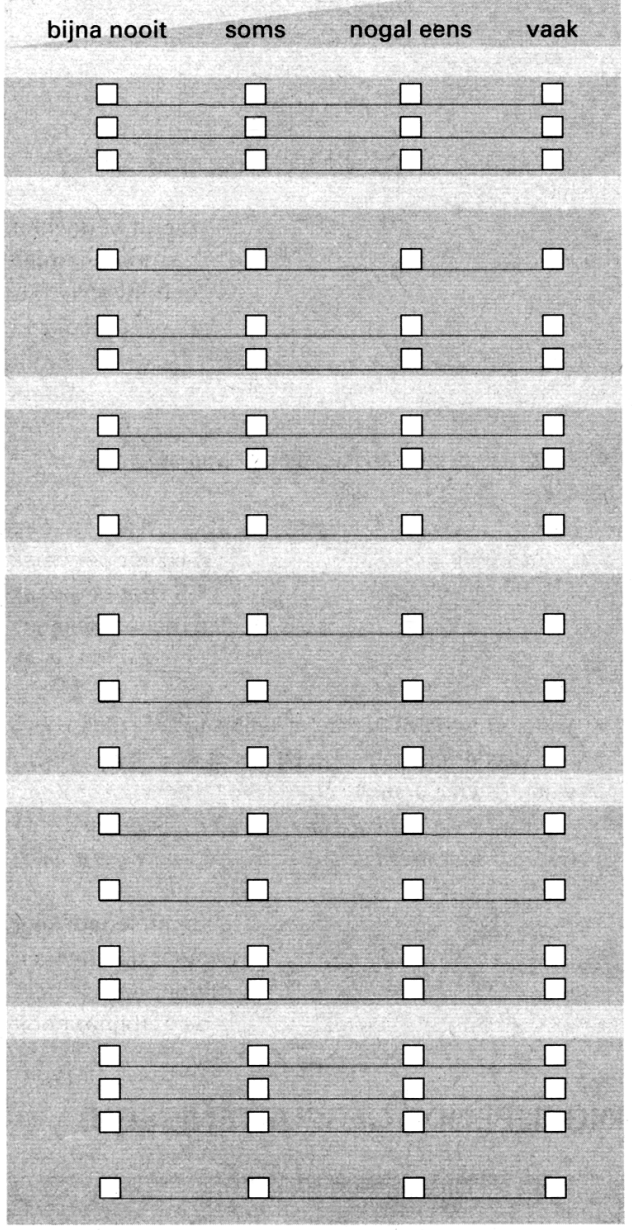


SOCIALE CONTACTEN 2:

NIET UW PARTNER, NIET UW HUISGENOTEN

Schrijft $u$ in onderstaande hokjes de voornamen van de mensen met wie u het vaakst contact heeft. Schrijf maximaal vijf namen op, anderen dan partner of huisgenoot.

3 In wat voor soort relatie staan deze mensen tot $u$ ?

$$
\begin{array}{r}
\text { zoon of dochter } \\
\text { andere familie } \\
\text { vriend(in) of kennis } \\
\text { collega } \\
\text { buur } \\
\text { anders }
\end{array}
$$

4 Hoe vaak heeft u contact met elk van deze mensen?

iedere dag
$4-6$ keer per week
$1-3$ keer per week
elke maand weleens
minder vaak

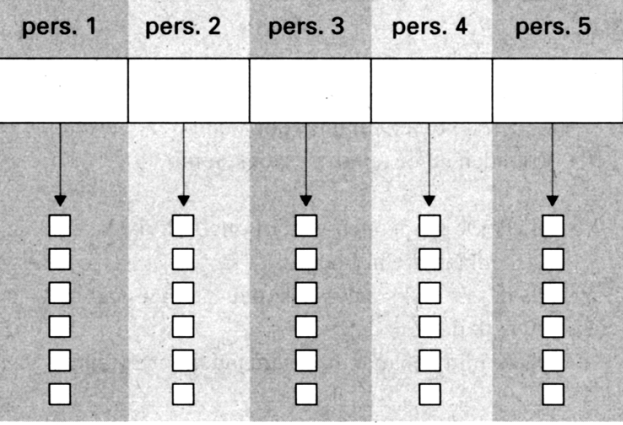
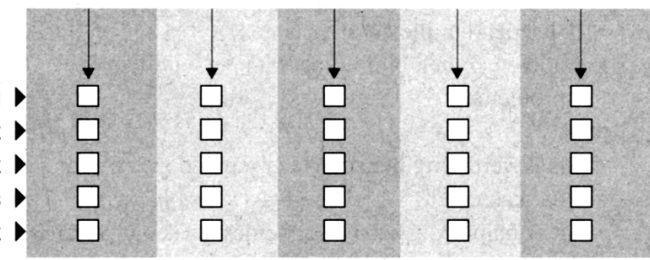

5 Wanneer u SAMEN bent met elk van deze mensen, hoe vaak drinkt $u$ dan samen een of meer glazen bier, wijn of sterke drank?

Als $u$ zelf geen alcohol gebruikt, vult $u$ dan in hoe vaak u contact heeft gehad waarbij de ander wel dronk.

(bijna) iedere keer meer dan de helft minder dan de helft

(bijna) nooit
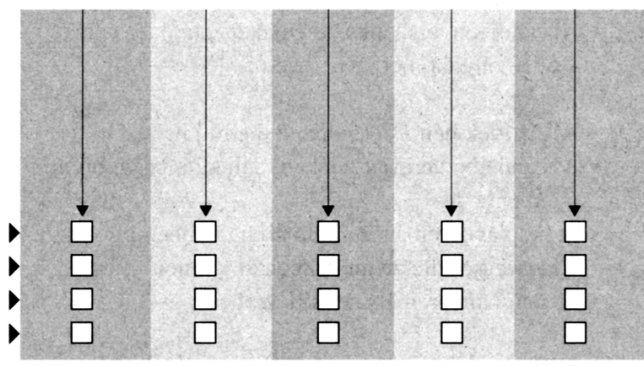

INGRIJPENDE GEBEURTENISSEN:

IN DE AFGELOPEN 2 JAAR

Ga na of u zelf sinds april 1994 een van de volgende gebeurtenissen is overkomen.

Indien u een vraag met "ja" beantwoordt, geef dan aan hoe erg u de gebeurtenis vond of nog steeds vindt.

Kruis op elke regel één hokje aan.

- een ernstige ziekte of zwaar ongeval van uzelf

- een ernstige ziekte of zwaar ongeval in de familie

- dood van uw echtgeno(o)t(e), levenspartner, eigen kind, ouder, broer of zus

- dood van een goede vriend of nauw verwant familielid

- scheiding door huwelijksmoeilijkheden (van uzelf)

- einde van een langdurige liefdesrelatie (van uzelf) erg niet erg positief

$\begin{array}{lllll}\square \text { nee } & \text { ja } \Rightarrow & \square & \square & \square \\ \square \text { nee } & \text { ja } \Rightarrow & \square & \square & \square \\ \square \text { nee } & \text { ja } \Rightarrow & \square & \square & \square \\ & & & & \\ \square \text { nee } & \text { ja } \Rightarrow & \square & \square & \square \\ \square \text { nee } & \text { ja } \Rightarrow & \square & \square & \square \\ \square \text { nee } & \text { ja } \Rightarrow & \square & \square & \square\end{array}$


Kruis op elke regel één hokje aan.

- serieuze ruzie met een vriend, buur of familielid

- werkloos of werkzoekend voor langer dan 1 maand van $u$ of uw partner

- verlies van baan van u of uw partner

- serieuze financiële moeilijkheden

- als verdachte in contact met politie of justitie (bijv. arrestatie, veroordeling)

- verlies of diefstal van waardevol bezitting(en)

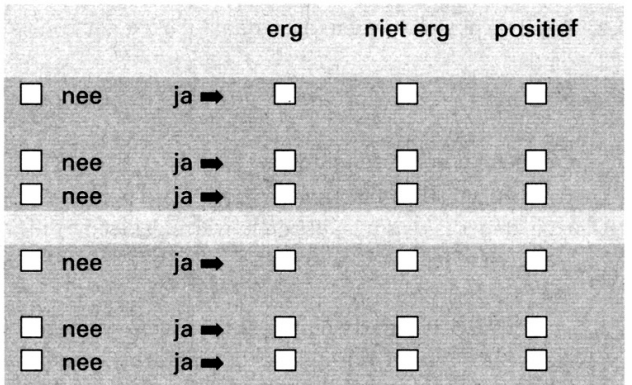

\section{STEMMING}

Het gaat hier om hoe u zich de afgelopen week, met vandaag erbij, voelde.

Kruis op elke regel één hokje aan.

- Verstrikt zijn of je gevangen voelen

- Te veel over de dingen piekeren

- Het gevoel in de put te zitten

- De gedachte, dat je voor je zonden gestraft zou moeten worden

- Huilbuien

- Je eenzaam voelen

- Denken om er maar een eind aan te maken

- Een gevoel van leegte

- Denken aan dood of sterven

- Jezelf van allerlei dingen de schuld geven

- Nare gedachten of ideeën niet kwijt kunnen raken

- Je gauw gekwetst voelen

- Gevoelens dat je niets waard bent

- Je alleen voelen, zelfs bij andere mensen

$\begin{array}{cccc}\begin{array}{c}\text { helemaal } \\ \text { niet }\end{array} & \text { tamelijk } & \text { heel } \\ \text { beetje nogal veel } & \text { erg }\end{array}$
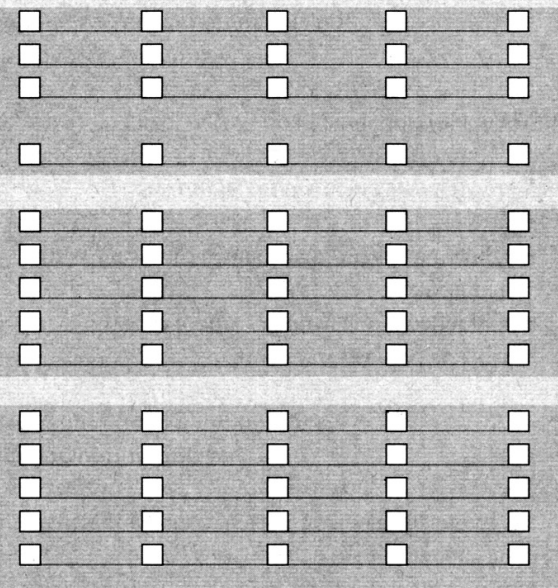

\section{LICHAMELIJKE ERVARINGEN:}

\section{IN DE AFGELOPEN 3 MAANDEN}

De volgende vragen gaan over gebeurtenissen en omstandigheden die mensen soms meemaken.

Per ervaring worden vier vragen gesteld.

1 Als ik voortdurend hoofdpijn zou hebben en houden, dan zou ik denken dat komt omdat:

Kruis op elke regel één hokje aan.

- ik ben emotioneel van slag

- er is iets mis met mijn spieren, zenuwen of hersenen

- een harde knal, fel licht, of iets anders heeft me geïrriteerd
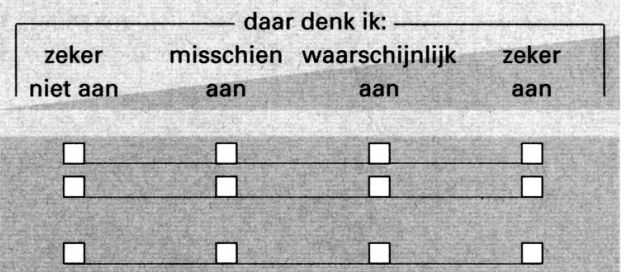

Heeft $\mathrm{u}$ in de laatste 3 maanden aanhoudende hoofdpijn gehad?

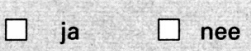


2 Als ik flink zou zweten, dan zou ik denken dat komt omdat:

Kruis op elke regel één hokje aan.

- ik heb koorts of een infectie

- ik ben angstig en nerveus

- de kamer te warm is, ik ben te warm gekleed of $\mathrm{ik}$ werk te hard

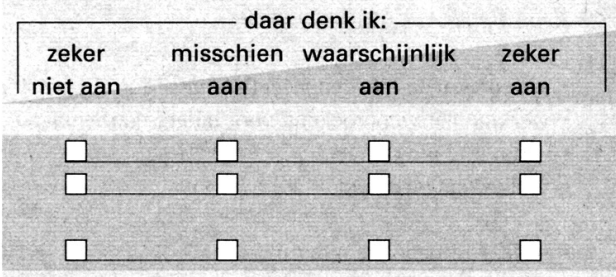

$$
\begin{array}{r}
\text { Heeft } u \text { in de laatste } 3 \text { maanden gemerkt } \\
\text { dat u sterk zweette? }
\end{array}
$$

3 Als ik plotseling duizelig zou worden, dan zou ik denken dat het komt omdat:

Kruis op elke regel één hokje aan.

- er is iets mis met mijn hart

- ik heb niet gegeten of ik ben te snel opgestaan

- ik sta er onder druk en stress

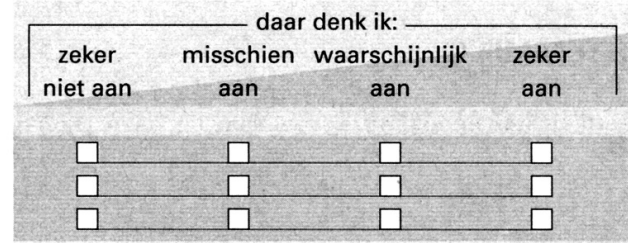

Heeft u zich in de laatste 3 maanden duizelig gevoeld?

4 Als ik hartkloppingen zou voelen, dan zou ik denken dat komt omdat:

Kruis op elke regel één hokje aan.

- ik heb me te zeer ingespannen of te veel koffie gedronken

- ik moet echt opgewonden zijn of angstig

- er is iets mis met mijn hart

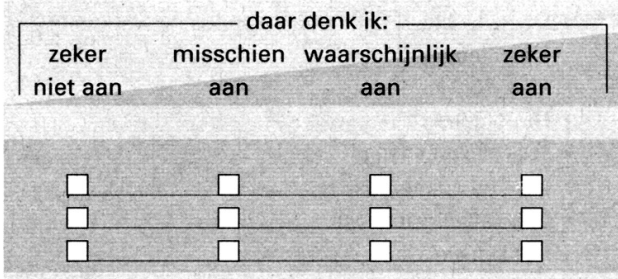

Heeft $u$ in de laatste 3 maanden hartkloppingen gehad?

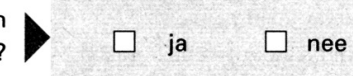

5 Als ik me erg moe zou voelen, dan zou ik denken dat komt omdat:

Kruis op elke regel één hokje aan.

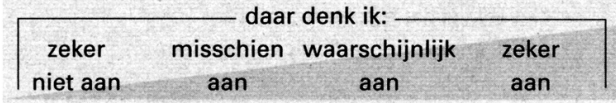

- ik ben emotioneel op of futloos

- ik heb me te zeer ingespannen of ik heb niet genoeg gesport

- ik heb bloedarmoede of mijn bloed is niet in orde

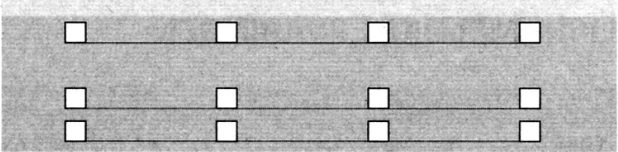

Heeft u zich in de laatste 3 maanden moe gevoeld?

ja $\square$ nee


6 Als ik mijn eetlust zou verliezen, dan zou ik denken dat komt omdat:

Kruis op elke regel één hokje aan.

\begin{tabular}{|cccc|}
\hline $\begin{array}{c}\text { zeker } \\
\text { niet aan }\end{array}$ & misschien & waarschijnlijk & zeker \\
aan & aan & aan
\end{tabular}

- ik heb te veel gegeten de laatste tijd, of ik heb minder eten nodig

- ik heb me zoveel zorgen gemaakt dat het eten me niet smaakt

- ik heb een maag of darmprobleem

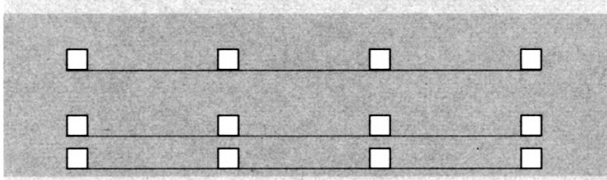

Heeft $u$ in de laatste 3 maanden uw eetlust verloren?

7 Als ik sneller dan anders buiten adem zou raken, dan zou ik denken dat komt omdat:

Kruis op elke regel één hokje aan.

- mijn longen zitten dicht door een infectie, irritatie of een probleem met mijn hart

- de kamer is te benauwd of de lucht is erg verontreinigd

- ik ben te zeer opgewonden of angstig

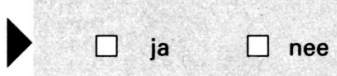

\section{Bent $\mathrm{u}$ in de laatste 3 maanden} snel buiten adem geraakt?
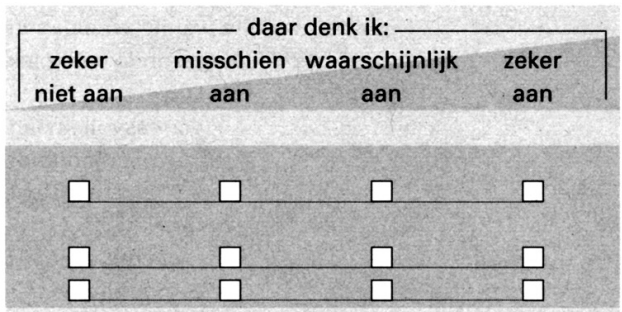

\section{OPVATTINGEN}

Kruis op elke regel één hokje aan.

- Als ik goed voor mijzelf zorg, kan ik ziektes voorkomen

- Ik heb mijn gezondheid in eigen hand

- Als ik iets wil doen om mijn gezondheid te verbeteren, dan lukt het me ook om dat te bereiken

- Als ik ziek ben ligt het aan mijzelf hoe snel ik beter word

- Ik heb het idee dat dingen die ik doe om mijn gezondheid te verbeteren geen effect hebben.

- Mijn gezondheid wordt in de eerste plaats bepaald door wat ik zelf doe

- Wat ik er ook voor doe, mijn gezondheid wordt niet zoals ik zou willen.

- Als ik ziek word, is dat mijn eigen schuld

- Ik ben even goed als anderen in staat om dingen te doen die goed zijn voor mijn gezondheid.

- Het ligt vooral aan mijzelf hoe snel ik van een ziekte kan genezen

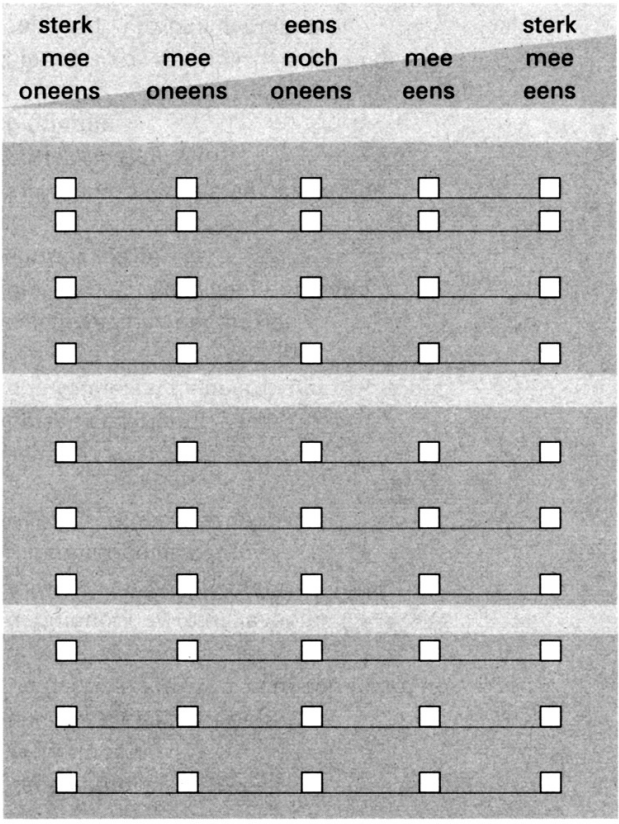




\section{OORZAKEN HARTAANVAL}

\section{Geef aan hoe belangrijk u elk van deze zaken vindt bij het ontstaan van een hartaanval}

Kruis op elke regel één hokje aan.

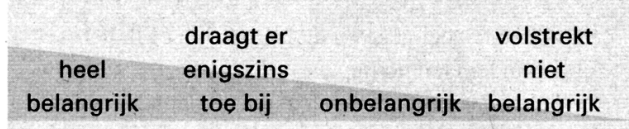

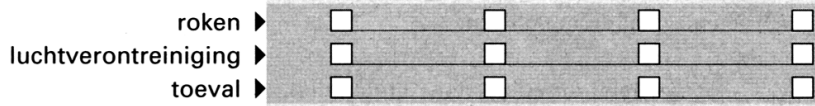

giftige stoffen in de voeding te veel werk, te weinig vrije dagen ongezonde werkplek

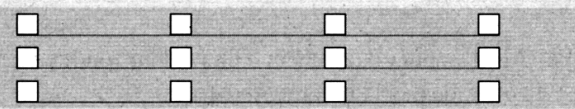
stressvolle baan noodlot God's wil slechte voeding nervositeit

gebrek aan lichamelijke weerstand

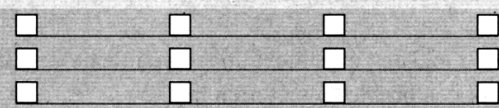

te hoge eisen aan jezelf stellen erfelijkheid, constitutie

verlies van een geliefd persoon

andere, eerdere ziektes spanningen in gezin of relaties een pessimistische kijk op de wereld

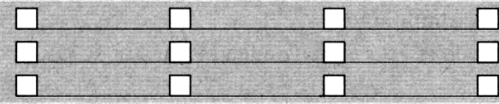

$$
\text { moeilijke kindertijd }
$$
gebrek aan erkenning op het werk
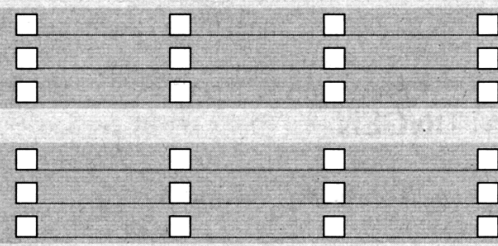

$$
\begin{array}{r}
\text { drankgebruik } \\
\text { onvoldoende lichaamsbeweging } \\
\text { verdringen van gevoelens }
\end{array}
$$

aardstralen en waterstromen innerlijke angsten infecties

onvoldoende weerbaarheid in contacten met anderen straf voor een verkeerde leefwijze ongevallen of verwondingen

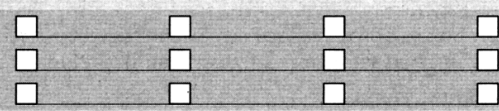

onvoldoende macht om spanningen en crises de baas te kunnen soort werk medicijnen
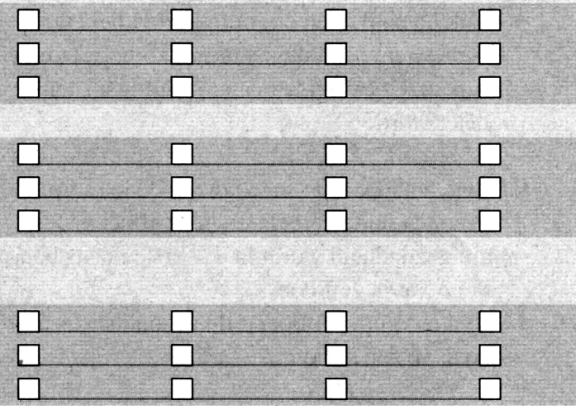

soort werk
medicijnen

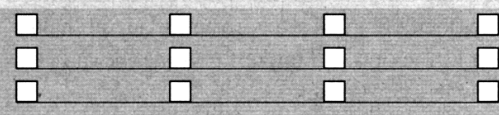


Kruis op elke regel één hokje aan.

\begin{tabular}{|ccc|}
\hline heel & $\begin{array}{c}\text { draagt er } \\
\text { enigszins } \\
\text { toe bij }\end{array}$ & onbelangrijk \\
belangrijk & $\begin{array}{c}\text { volstrekt } \\
\text { belangrijk }\end{array}$ \\
\hline
\end{tabular}

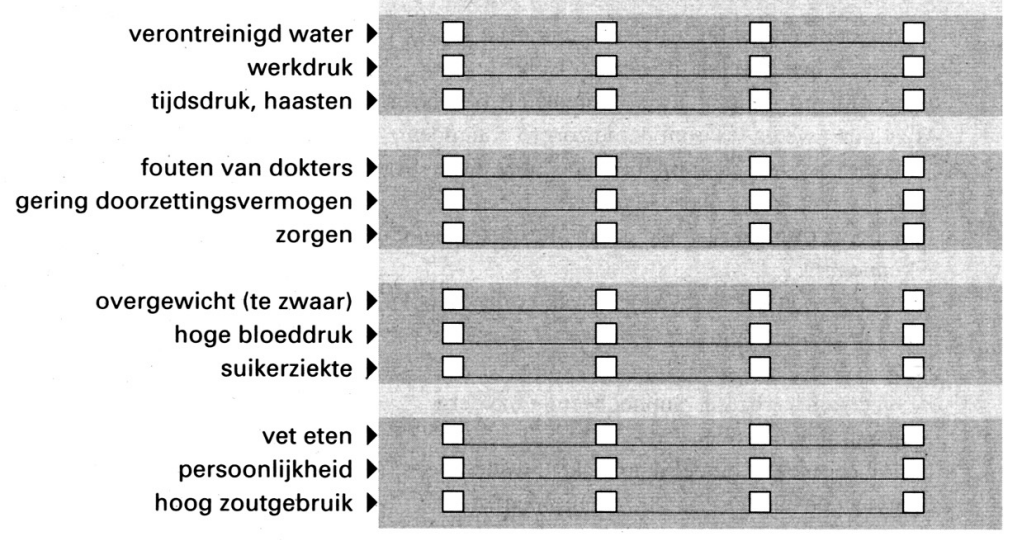

\section{OMGAAN MET PROBLEMEN}

Als u iets overkomt (bijv. ziekte, scheiding, verlies van werk, e.d.), hoe gaat u daar dan mee om.

Kruis op elke regel één hokje aan.

- Ik vraag me af waarom zoiets juist mij moest overkomen

- Lichaamsoefeningen ter ontspanning helpen mij goed door de moeilijke periode heen

- Ik stort me op het werk (of mijn hobby); dat leidt me af van de moeilijkheden

- Zoiets maakt me vaak woedend op anderen

- Het is belangrijk voor me, mezelf te beheersen, me niet te laten gaan

- Als ik de zaak met humor bekijk, kan ik zelfs om mezelf lachen

- Ik denk, dat ik de ongemakken kan accepteren en ze met gelatenheid draag

- Ter oplossing van mijn problemen stel ik mij zo bereidwillig mogelijk op

- Ik raak het gevoel niet kwijt, dat ik zelf schuld heb aan de crisis

- Mijn gedachten draaien steeds weer rond de problemen, zonder dat het resultaat oplevert

- Ik makk meer tijd vrij om iets opbouwends te doen

- Me om anderen bekommeren helpt me ook mijn problemen de baas te worden

- Er zijn dingen die belangrijker voor me zijn en die me helpen, me af te leiden van mijn problemen
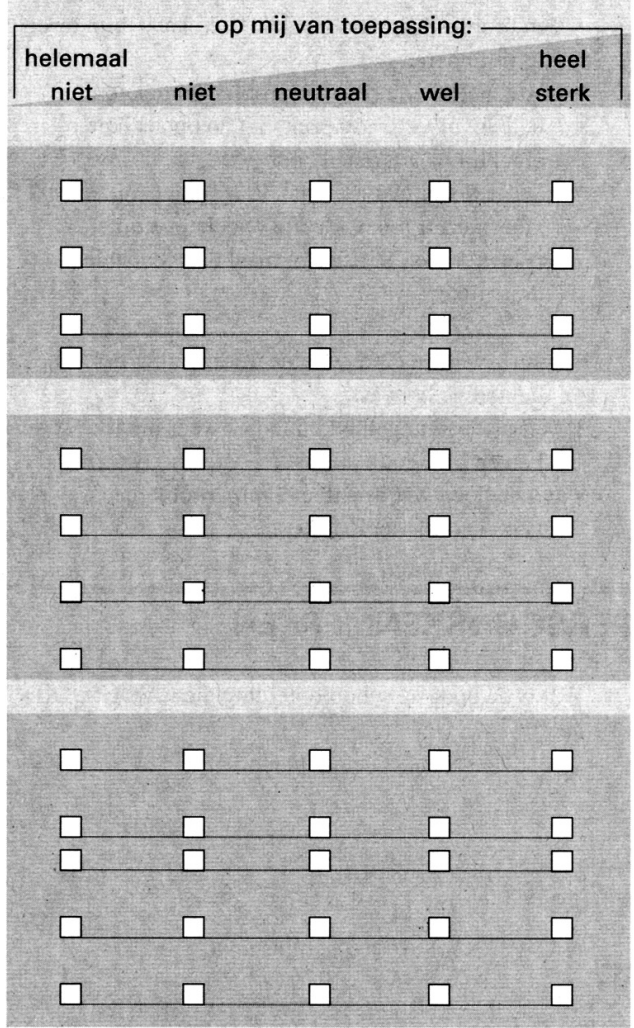
Kruis op elke regel één hokje aan.

- Over een moeilijke levensfase kom ik net zo goed heen als over iets dat minder erg is; het lukt me eigenlijk goed om nieuwe problemen te beheersen

- Ik zou niet weten waarom ik me zorgen zou moeten maken, het gaat eigenlijk best goed met me en het is lang niet zo erg als ze denken

- Ik heb meer tijd en rust nodig, om alles beter aan te kunnen

- Het komt voor, dat een woedeaanval, huilen of ook wel lachen me oplucht

- Ik sta er zelf verbaasd van, hoe weinig me dergelijke problemen doen

- Ik probeer mezelf duidelijk te maken, wat er met mij aan de hand is en wat deze problemen betekenen

- Ik zoek steun en een goed gesprek bij mensen die dichtbij me staan

- Als ik aan de mensen denk, die het nog moeilijker hebben, gaat het relatief goed met mij

- Een probleemsituatie zie ik als een kans mijn leven te veranderen

- Ik stel het uit me bij mijn problemen te laten helpen, of volg adviezen niet zo op als ik het eigenlijk zou moeten doen

- Als het slecht met mij gaat, koop ik iets bijzonders voor mezelf (eten, kleding, boeken, etc.).

- Iets eten, roken of drinken maakt een en ander draaglijker

- Mijn geloof in God en in de Voorziening geeft me de nodige houvast.

- Met een beetje geluk komt alles weer in orde. Ik ben en blijf een optimist

- Ik kan doen wat ik wil: aan mijn problemen verandert dat toch niets

\section{PERSOONSKENMERKEN}

1 Wat is de hoogste schoolopleiding die u VOLTOOID heeft?
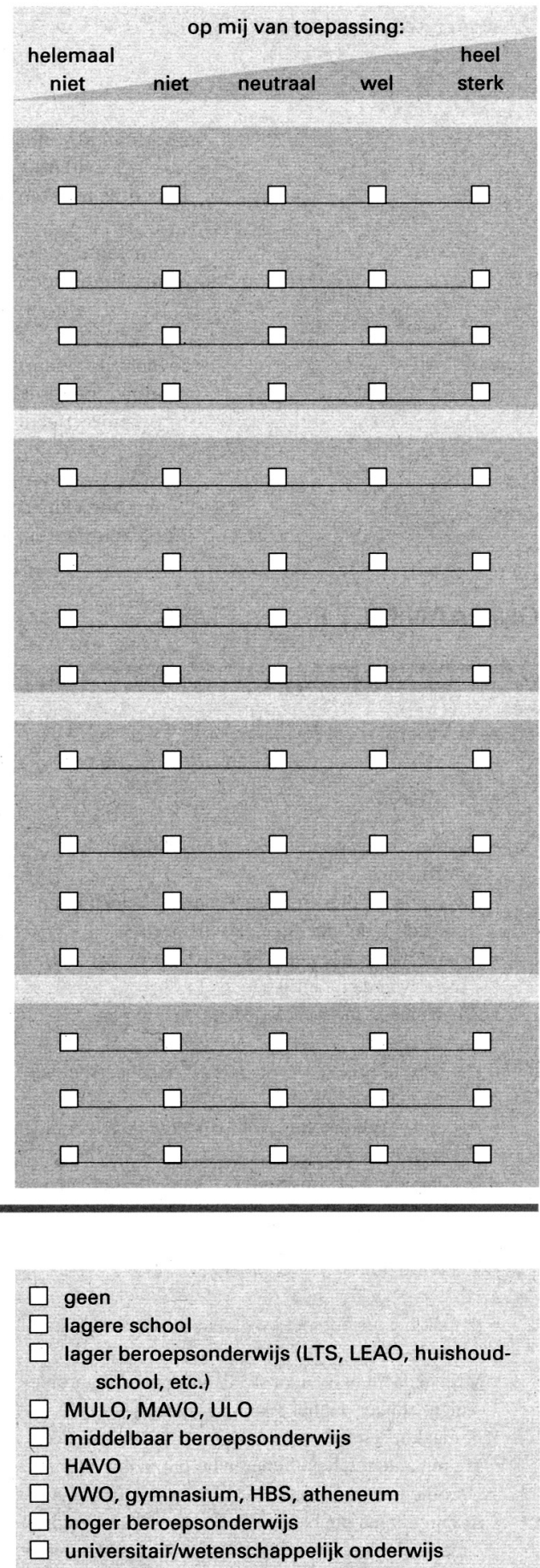
2 Heeft $\mathrm{u}$ betaald werk of heeft $\mathrm{u}$ eerder betaald werk gehad? Hieronder verstaan we ook een baan (of werk als zelfstandige) van maar enkele uren per week.

\section{heb nu betaald werk vroeger betaald werk gehad nooit betaald werk gehad \\ $\Rightarrow$ sinds wanneer niet meer: 19 \\ $\Rightarrow$ ga verder met vraag 9}

3 Er zijn verschillende mogelijkheden met betrekking tot betaald werk. Kunt $\mathrm{u}$ aangeven welke van toepassing zijn op uw (vroegere) werk?

Meer dan één antwoord mogelijk.

4 Hoeveel uur werkt (of werkte) u doorgaans per week?

5 Welk beroep oefent $\mathrm{u}$ op dit moment uit of oefende $\mathrm{u}$ het laatste uit?

Het gaat om de precieze werkzaamheden. "Docent”, "bouwvakker" etc. is niet voldoende; dat moet zijn:

“lerares wiskunde aan de MAVO”, “betonvlechter", e.d.

6 Geeft $\mathrm{u}$ (of gaf $\mathrm{u}$ ), direct of via anderen, leiding aan personeel?

7 Wie beslist(e) er over de indeling van uw werktijd, u zelf of anderen?

8 Bent u tevreden over uw situatie wat betreft werk?

9 Tot welke van de volgende groepen rekent u zichzelf op dit moment?

Kruis op elke regel één hokje aan.

- Ik doe het huishouden

- Ik ben (gedeeltelijk) arbeidsongeschikt

- Ik ben gepensioneerd (VUT, AOW e.d.)

- Ik heb een betaalde werkkring

- Ik ben werkloos/werkzoekend

- Ik doe onbetaald werk met behoud van uitkering

- Ik doe vrijwilligerswerk (onbetaald werk dat ten goede komt aan bepaalde personen, groepen of de gemeenschap)

- Ik volg een opleiding

- Anders, nl. ik werk tegen loon of salaris (óók uitzendwerk)

ik werk voor eigen rekening, als zelfstandige in eigen bedrijf of praktijk

ik werk op free-lance basis (géén uitzendwerk)

ik werk mee in gezins- of familie bedrijf, maar sta NIET op de loonlijst.

16 uur of minder

32 tot 40 uur

16 tot 32 uur

meer dan 40 uur

geen leidinggevende functie

1-9 personen

10-49 personen

meer dan 50 personen

ik beslis(te) zelf

ik beslis(te) gedeeltelijk zelf

anderen beslissen (-sten)

heel tevreden

tamelijk tevreden

niet zo tevreden

tamelijk tevreden

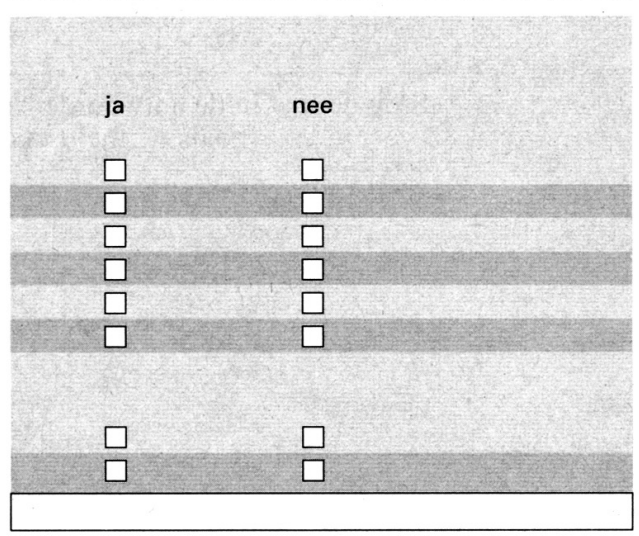


10 Kunt u hiernaast aankruisen tot welke categorie het inkomen VAN UW HUISHOUDEN behoort? Bedoeld wordt NETTO PER MAAND, zonder vakantiegeld, 13de maand e.d.

11 Wat is de hoogste schoolopleiding die uw partner VOLTOOID heeft?

12 Heeft uw partner op dit moment een betaalde baan van minimaal 15 uur?

13 Welk beroep oefent uw partner op dit moment uit of oefende hij/zij het laatste uit?

Het gaat om de precieze werkzaamheden. 'Docent', 'bouwvakker'etc. is niet voldoende; dat moet zijn: 'lerares wiskunde aan de MAVO', 'betonvlechter', e.d. minder dan 2000 gld.

$2000-3200$ gld.

meer dan 4600 gld.

$3200-4600$ gld.

kan ik niet zeggen

geen

$\square$ lagere school

$\square$ lager beroepsonderwijs (LTS, LEAO, huishoudschool, etc.)

$\square$ MULO, MAVO, ULO

$\square$ middelbaar beroepsonderwijs

$\square$ HAVO

$\square$ VWO, gymnasium, HBS, atheneum

$\square$ hoger beroepsonderwijs

universitair/wetenschappelijk onderwijs

\section{ja}

nee

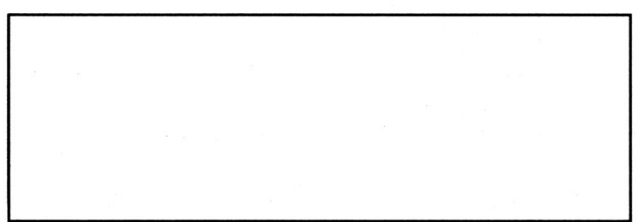

Dit is het einde van de vragenlijst.

Hartelijk dank voor het invullen.

Stop de lijst in de antwoordenvelop en volg verder de instructies zoals vermeld in de bijgesloten brief. 


\section{GEBRUIK VAN BIER, WIJN, STERKE DRANK}

Het doel van deze vragen is om een indruk te krijgen van uw gebruik van bier, wijn en sterke drank vanaf uw jeugd tot nu.

We onderscheiden drie soorten drank, nl. bier, wijn en sterke drank (gedistilleerd):

BIER: alle biersoorten, behalve alcoholvrij bier

WIJN: $\quad$ alle wijnsoorten, sherry, Martini, port en vruchtenwijnen

STERKE DRANK: alle gedistilleerde dranken (jenever, whisky, cognac), mixen, cocktails en likeur (met een alcohol percentage hoger dan 20\%)

1 Op welke leeftijd heeft u voor het eerst bier, wijn of sterke drank gedronken? We bedoelen een heel glas en niet alleen proeven aan een glaasje van

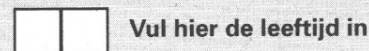

iemand anders.
Ik heb nog nooit bier, wijn of sterke drank gedronken $\Rightarrow$ ga verder met KOFFIE en THEE op pagina 11

2 Dronk u wel eens bier, wijn of sterke drank tussen uw 12e en $18 \mathrm{e}$ jaar?

JA

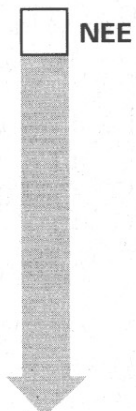

- Hoe vaak dronk u gewoonlijk bier, wijn of sterke drank tussen uw 12 e en $18 e$ jaar?

$\square$ iedere dag $\quad \square$ 1-2 dagen per week $\square$ 1-2 dagen per halfjaar
$\square$-6 dagen per week $\square$ 1-3 dagen per maand $\square$ NOOIT $\Rightarrow$ ga verder met
vraag 3
3-4 dagen per week $\square 3$-5 dagen per halfjaar
- Hoeveel glazen dronk u doorgaans op zo'n dag? $\square \square$ glazen
- Heeft u na uw 18e levensjaar bier, wijn of sterke drank gedronken?
$\square$ ja $\Rightarrow$ ga verder met vraag $3 \square$ nee - ga verder met KOFFIE en THEE
op pagina 11

3 Dronk u wel eens bier, wijn of sterke drank tussen uw 19e en $27 \mathrm{e}$ jaar?

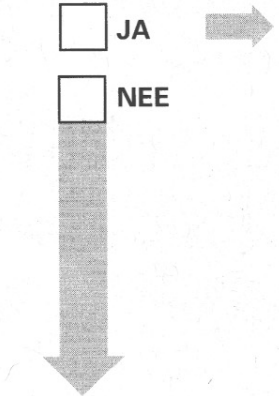

GA DOOR MET VRAAG 4 OP DE VOLGENDE PAGINA
- Hoe vaak dronk u gewoonlijk bier, wijn of sterke drank tussen uw 19e en 27e jaar?

$\square$ iedere dag $\square$ 1-2 dagen per week $\square 1$ - 2 dagen per halfjaar

$\square$ - 6 dagen per week $\square 1$-3 dagen per maand

3-4 dagen per week $\square 3$ - 5 dagen per halfjaar

$\square$ NOOIT $\Rightarrow$ ga verder met vraag 4

- Hoeveel glazen dronk u doorgaans op zo'n dag? $\square \quad \square$ glazen

- Heeft u na uw 27e levensjaar bier, wijn of sterke drank gedronken?

$\square$ ja $\Rightarrow$ ga verder met vraag $4 \square$ nee $\Rightarrow$ ga verder met KOFFIE en THEE op pagina 11 
4 Dronk u wel eens bier, wijn of sterke drank tussen uw $28 \mathrm{e}$ en $44 \mathrm{e}$ jaar?

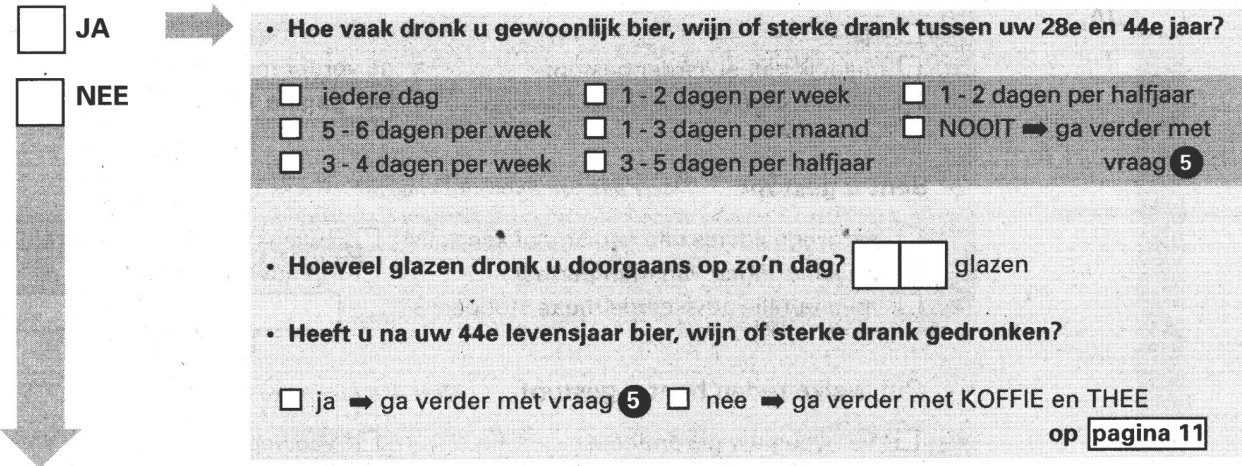

5 Dronk u wel eens bier, wijn of sterke drank tussen uw $45 \mathrm{e}$ en $60 \mathrm{e}$ jaar?

JA

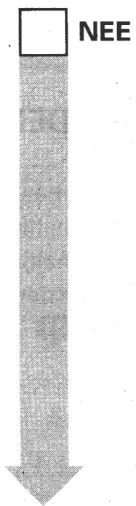

- Hoe vaak dronk u gewoonlijk bier, wijn of sterke drank tussen uw 45 e en 60 e jaar?
iedere dag
1- 2 dagen per week
$\square 1$ - 3 dagen per maand
1 - 2 dagen per halfjaar
NOOIT $=$ ga verder met
dagen per week
3 - 5 dagen per halfjaar
vraag 6

- Hoeveel glazen dronk u doorgaans op zo'n dag?

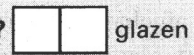

- Bent u ouder dan 60 jaar?

$\square$ ja

nee $\Rightarrow$ ga verder met vraag 7 op pagina 10

- Heeft u na uw $60 \mathrm{e}$ levensjaar nog bier, wijn of sterke drank gedronken?

$\square$ ja $\Rightarrow$ ga verder met vraag $6 \square$ nee $\Rightarrow$ ga verder met vraag 7 op pagina 10

6 Dronk u wel eens bier, wijn of sterke drank na uw 60e jaar?

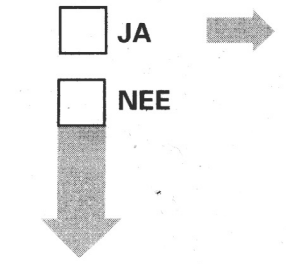

GA DOOR

Hoe vaak dronk u gewoonlijk bier, wijn of sterke drank vanaf uw 61e jaar?

OP DE VOLGENDE PAGINA
iedere dag
$\square 1$ - 2 dagen per week
$\square 1$ - 3 dagen per maand
$\square$ 3-5 dagen per halfjaar
$\square 1$ - 2 dagen per halfjaar
$\square$ NOOIT $\Rightarrow$ ga verder met vraag 7

- Hoeveel glazen dronk u doorgaans op zo'n dag? $\square$ glazen 
7 Heeft u de afgelopen 12 maanden bier, wijn of sterke drank gedronken?

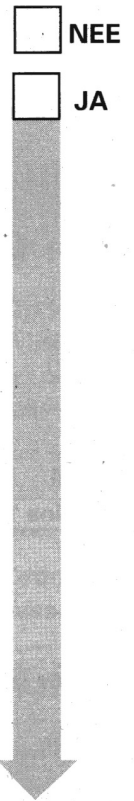

- Bent u de afgelopen 12 maanden bewust gestopt met het drinken van bier, wijn of sterke drank?

$\square$ ja
$\square$ nee, ik ben al eerder gestopt
$\square$ nee, ik dronk sowieso heel weinig $\Rightarrow\} \begin{aligned} & \text { ga verder met KOFFIE en THEE } \\ & \text { op pagina 11 }\end{aligned}$
Bent u gestopt... Meer dan één antwoord mogelijk.
$\square$ vahwege advies van een arts of specialist $\square$ collega's drongen aan te stoppen
$\square$ op aandringen van mijn partner
$\square$ mijn familie adviseerde me te stoppen

- Om welke reden bent u gestopt... Meer dan één antwoord mogelijk.

$\begin{array}{ll}\square \text { vanwege uw gezondheid } & \square \text { vanwege uw werk } \\ \square \text { vanwege tè grote afhankelijkheid } & \square \text { omdat u moeilijkheden kreeg } \\ \text { van de drank } & \text { met anderen } \\ \square \text { omdat het te duur was } & \square \text { andere reden, nl. } \\ \end{array}$

GA VERDER MET KOFFIE EN THEE OP PAGINA 11

\section{GEBRUIK VAN BIER, WIJN, STERKE DRANK IN DE AFGELOPEN 12 MAANDEN}

8 Hoe vaak in de afgelopen 12 maanden heeft u WIJN (ook sherry, port, Martini e.d.) gedronken?

9 De keren dat u WIJN dronk, hoeveel dronk u dan op zo'n dag?

10 Drinkt u vooral rode of vooral witte wijn?

11 Hoe vaak in de afgelopen 12 maanden heeft u BIER gedronken?

12

De keren dat u BIER dronk, hoeveel dronk u dan op zo'n dag?

13 Hoe vaak in de afgelopen 12 maanden heeft $u$ STERKE DRANK gedronken?

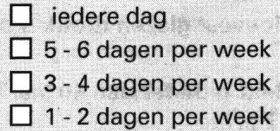

1 - 3 dagen per maand

$\square 3$ - 5 dagen per halfjaar

$\square 1$ - 2 dagen per halfjaar

NOOIT $\Rightarrow$ ga verder met vraag 11
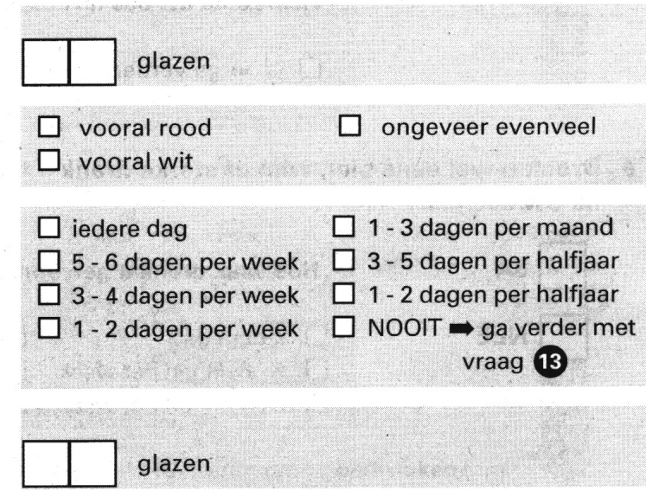

glazen

$\square$ iedere dag

$\square 5$ - 6 dagen per week

3 - 4 dagen per week

1 - 2 dagen per week
1 - 3 dagen per maand

3 - 5 dagen per halfjaar

1 - 2 dagen per halfjaar

NOOIT $\Rightarrow$ ga verder met vraag 15 
